\title{
Hanford Medium/Low Curie Waste Pretreatment Alternatives Project - Fractional Crystallization Pilot Scale Testing Final Report
}

\author{
E. A. Nelson, D. J. Geniesse, and J. J. Zimmer
}

AREVA

Richland, WA 99352

U.S. Department of Energy Contract DE-AC27-99RL14047

$\begin{array}{lll}\text { EDT/ECN: } & \text { DRF } & \text { UC: } \\ \text { Cost Center: } & 74 \mathrm{~A} 10 & \text { Charge Code: } \\ \text { B\&R Code: } & & \text { Total Pages: } 169\end{array}$

Key Words: fractional, crystallization, laboratory, tests, planning, pilot, simulated, tank, crystals, SRNL, waste, HLW, LAW, treatment, disposal, WTP, dissolved, saltcake, solids, pretreatment, design, construction, analyses, lessons learned, benchmark, baseline, hardware, centrifuge, pumps, heaters, instrumentation, configuration, controls, reboiler, steam supply,vacuum, solids, single-shell tank

Abstract: The Fractional Crystallization Pilot Plant was designed and constructed to demonstrate that fractional crystallization is a viable way to separate the high-level and low-activity radioactive waste streams from retrieved Hanford single-shell tank saltcake. The focus of this report is to review the design, construction, and testing details of the fractional crystallization pilot plant not previously disseminated.

TRADEMARK DISCLAIMER. Reference herein to any specific commercial product, process, or service by trade name, trademark, manufacturer, or otherwise, does not necessarily constitute or imply its endorsement, recommendation, or favoring by the United States Government or any agency thereof or its contractors or subcontractors.

Printed in the United States of America. To obtain copies of this document, contact: Document Control Services, P.O. Box 950, Mailstop H6-08, Richland WA 99352, Phone (509) 372-2420; Fax (509) 376-4989.
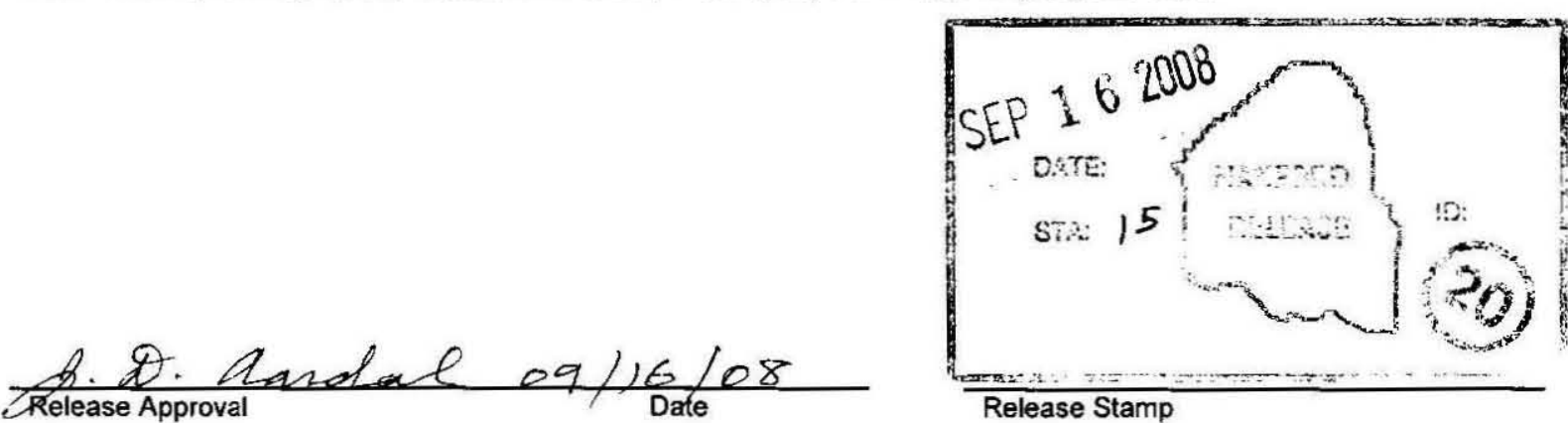

Approved For Public Release 


\section{Hanford Medium/Low Curie Waste Pretreatment Alternatives Project - Fractional Crystallization Pilot Scale Testing Final Report}

\section{CH2MHILL \\ Hanford Group, Inc.}

Prepared for the U.S. Department of Energy

Office of River Protection

Contract No. DE-AC27-99RL14047 


\section{AREVA}

\section{Hanford Medium/Low Curie Waste Pretreatment Alternatives Project - Fractional Crystallization Pilot Scale Testing Final Report}

Prepared for:

U.S. Department of Energy

Richland, Washington USA

Contract No. 25464

Project No. 01922.01.A501.02.11834

Prepared by:

AREVA Federal Services LLC

Richland Office

2425 Stevens Center Place $-2^{\text {nd }}$ floor

Richland, WA 99354

Author:

EA Nelson, PE

DJ Geniesse

JJ Zimmer

Date Published:

August 2008 


\section{AREVA}

Hanford Medium/Low Curie Waste Pretreatment Alternatives Project - Fractional Crystallization Pilot Scale Testing Final Report

Author:

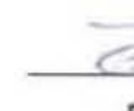

\section{EA Nelson, PE}

AREVA Federal Services LLC

Author:

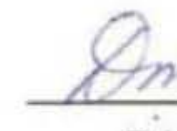

DJ Geniesse

AREVA Federal Services LLC

Approved:
Date: $8 / 28 / 08$

Date: $8 / 28 / 08$

Date: $8 / 28 / 08$
JJ Zimmer

AREVA Federal Services LLC 


\section{TABLE OF CONTENTS}

LIST OF ACRONYMS

viii

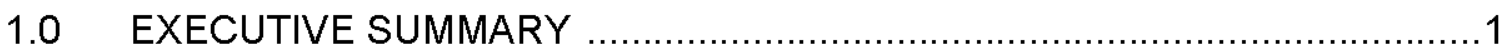

$2.0 \quad$ INTRODUCTION

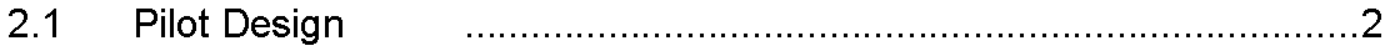

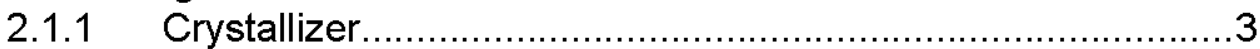

2.1.1.1 Recirculation Pump .......................................... 4

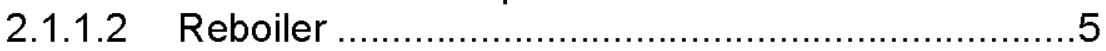

2.1.1.3 Condenser and Steam Jet Vacuum Pumps ............5

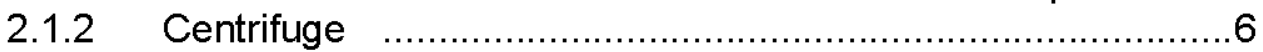

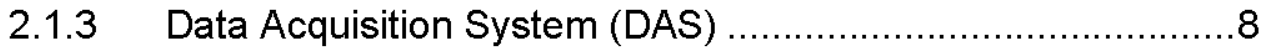

2.1.4 Piping, Instrumentation, and Miscellaneous Components ......8

$2.2 \quad$ Pilot Plant Construction ...............................................................11

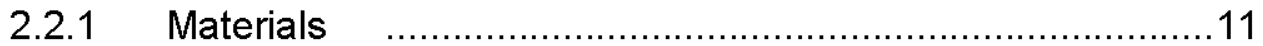

2.2.2 Installation and Testing .............................................. 11

2.2.3 Manufacturer's Instructions .................................................12

2.2.4 Readiness Certification .................................................12

3.0 TEST PLANNING

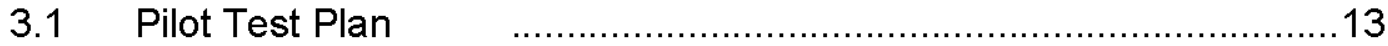

3.2 SRNL Analytical Test Plan .....................................................14

3.2.1 Sampling Frequency ....................................................14

3.2.2 Sample Types and Analyses Performed ...........................16

3.2.2.1 Density ............................................................19

3.2.2.2 Total Solids, Undissolved Solids (TS, UDS) .........19

3.2.2.3 Quick Weight Percent (WT\%) Undissolved ...........21 Solids (Q-UDS)

3.2.2.4 Trailing Edge Apparent Settling Volume/..............21 Density (TEASV or ASV/Density)

3.2.2.5 Crystal Size Distribution ....................................21

3.2.2.6 Polarized Light Microscopy (PLM) ......................22

3.2.2.7 Aluminum by Turbidity ......................................22

3.2.3 Analyses Performed by Savannah River Ecology ...............23 Laboratory (SREL)

3.2.3.1 Standard and Sample Preparation ........................23

3.2.3.2 Free Hydroxide and Other Base ...........................23

Excluding Carbonate

3.2.3.3 Carbonate by Total Inorganic Carbon (TIC) .........24 Measurement

3.2.3.4 Inductively Coupled Plasma-Mass ........................24 Spectrometry (ICPMS)

3.2.3.5 Inductively Coupled Plasma-Optical......................25

Emission Spectroscopy (ICPOES)

3.2.3.6 Ion Chromatography, Anions (ICA) ………...........26

3.2.4 Samples Requiring Immediate Dilution ...............................26 


\section{TABLE OF CONTENTS (contd)}

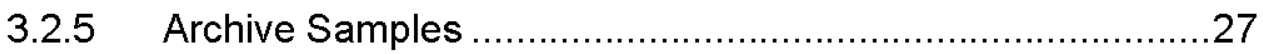

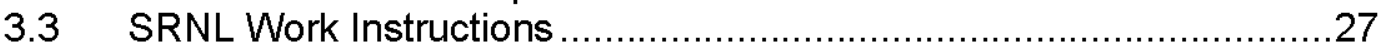

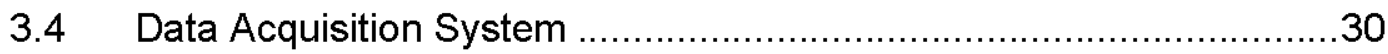

3.4.1 DAS Hardware …….....................................................

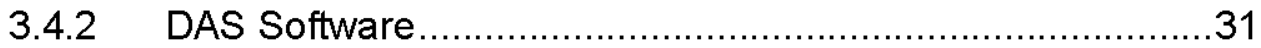

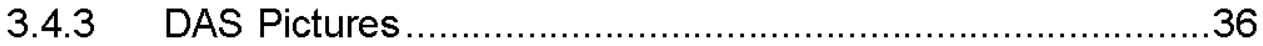

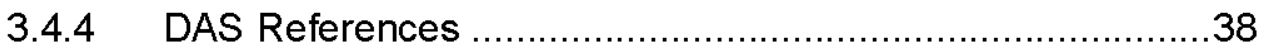

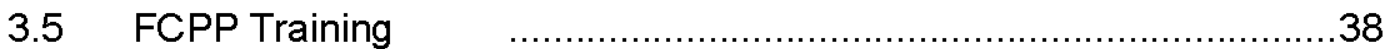

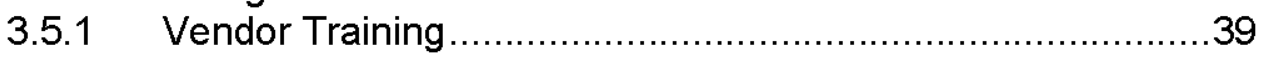

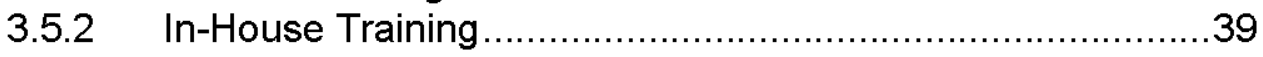

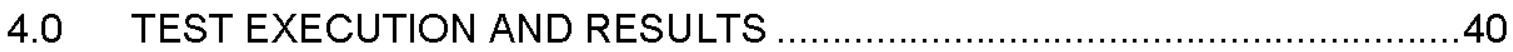

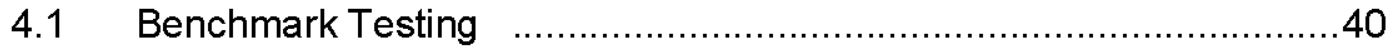

4.1.1 Crystallizer Loop .................................................... 41

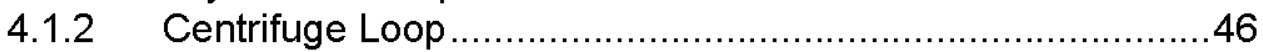

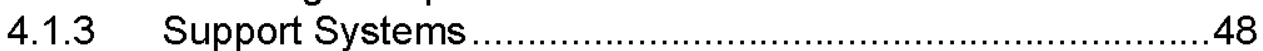

4.1.4 Sample Drawing and Analysis .......................................48

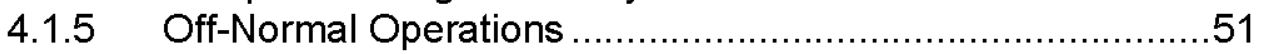

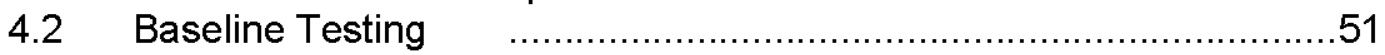

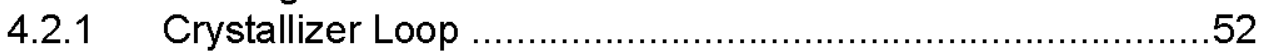

4.2.2 Centrifuge Loop ........................................................55

4.2.3 Support Systems ....................................................58

4.2.4 Sample Drawing and Analysis ........................................58

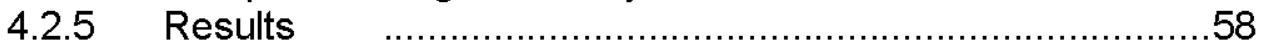

4.2.5.1 PLM Results ............................................... 72

4.2.6 Sodium Aluminosilicate (NAS) Gel in Simulant....................75

4.2.7 Sodium Yield Calculations and Comparison to .....................78 Flowsheet Yield

5.0 LESSONS LEARNED

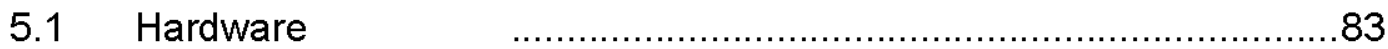

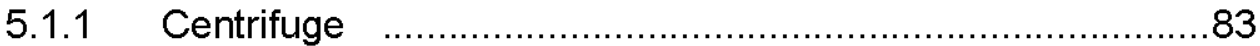

5.1.1.1 Centrifuge Capacity ......................................... 83

5.1.1.2 Product Chute Pluggage ...................................83

5.1.1.3 Centrifuge Cleaning ........................................ 84

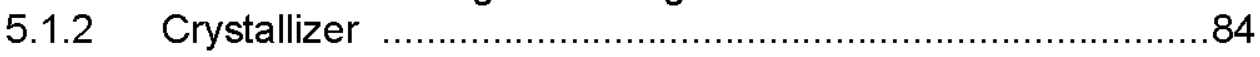

5.1.2.1 Crystallizer Control ..................................................

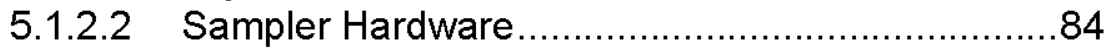

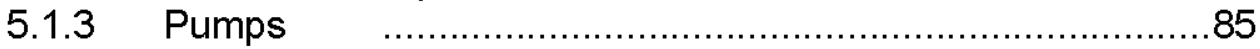

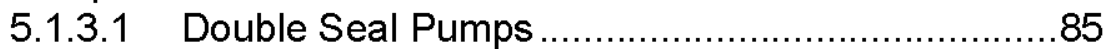

5.1.3.2 Double Diaphragm Pump .....................................

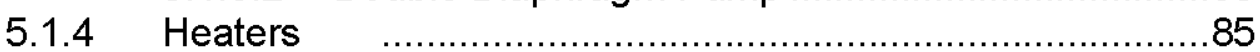

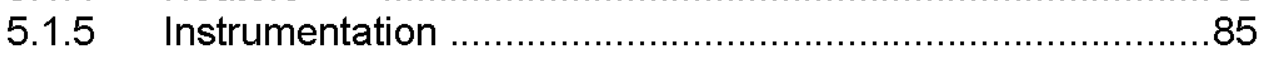

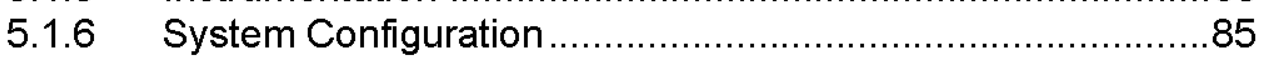

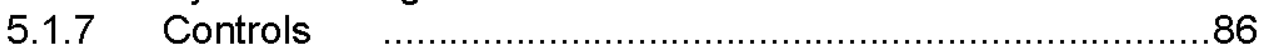

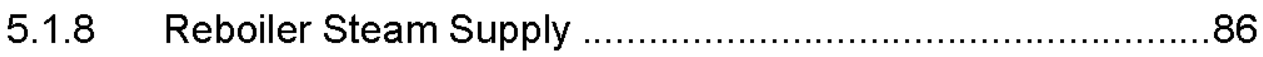




\section{TABLE OF CONTENTS (contd)}

5.1.9 Rapid Isolation fom Vacuum System ................................86

5.2 Operations

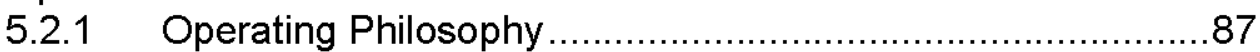

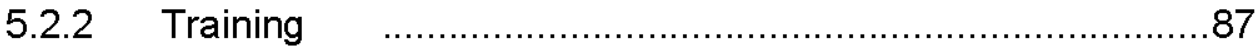

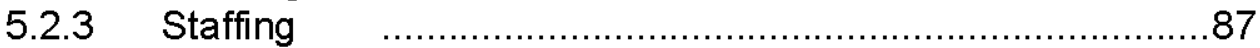

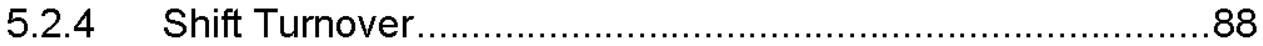

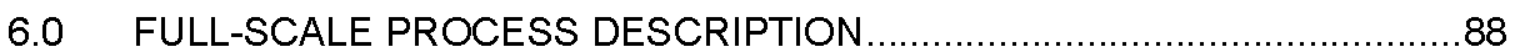

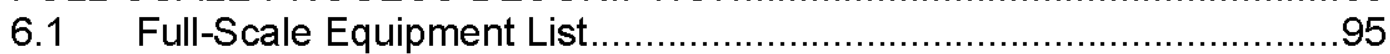

7.0 CONCLUSIONS

7.1 ITDP Enabling Assumptions..................................................109

7.1.1 Modeling - Enabling Assumption ....................................109

7.1.2 Simulant Performance - Enabling Assumption..................109

7.1.3 Scalability - Enabling Assumption ..................................109

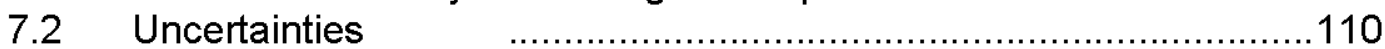

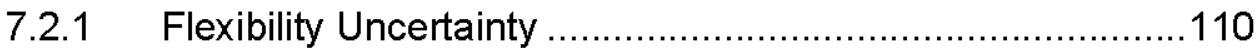

7.2.2 Efficiency Uncertainty.....................................................110

7.2.3 Crystal Growth Uncertainty .........................................110

7.2.4 Complexity of Control System Uncertainty .......................111

7.2.5 Robustness Uncertainty ..............................................111

7.3 Summary

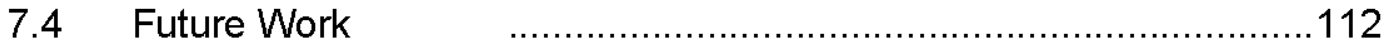

8.0 APPENDICES

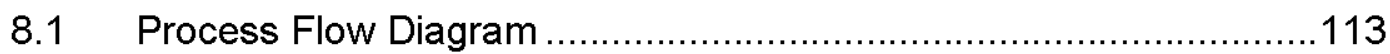

8.2 Process and Instrumentation Diagram ......................................115

8.3 Northwest Copper Crystallizer Drawing ....................................117

8.4 Northwest Copper Reboiler Drawing ..........................................119

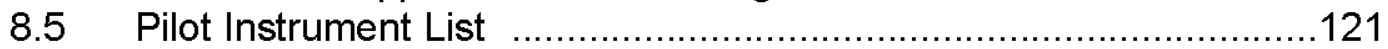

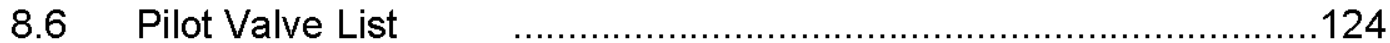

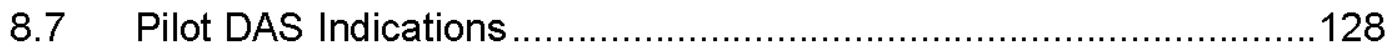

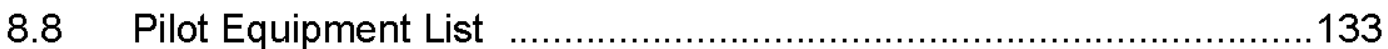

8.9 Readiness Certification Document ………………….................... 137

8.10 Final Benchmark Test Run Plan................................................... 148

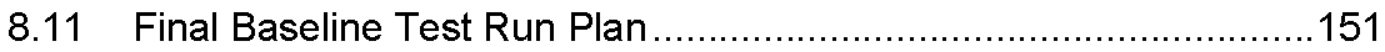

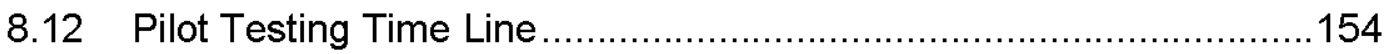


RPP-39091, Rev. 0

\section{LIST OF TABLES}

Table 1. Sampling Locations and Frequencies Planned …........................................... 15

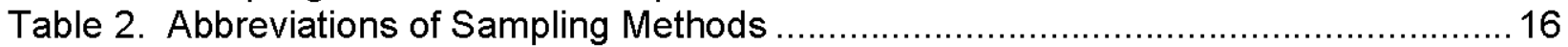

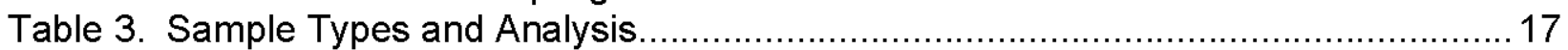

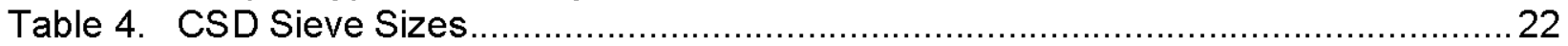

Table 5. DAS Input Channel Allocation List for FC Instruments .....................................32

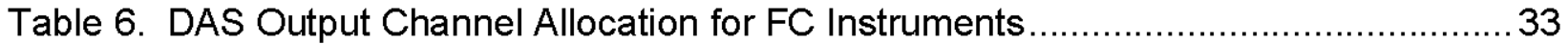

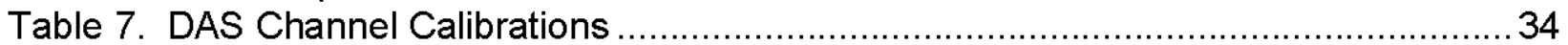

Table 8. Transfer Functions Developed for Each Channel on DAS .................................. 35

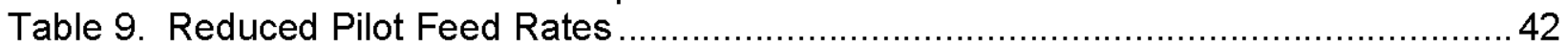

Table 10. Test Plan Initial Key Operating Conditions/Parameters .................................43

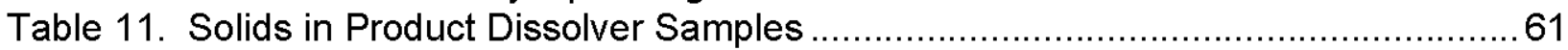

Table 12. Fractional Crystallization Equipment List.................................................... 96

\section{LIST OF FIGURES}

Figure 1. FCPP Crystallizer, Reboiler and Recirculation Pump.................................... 4

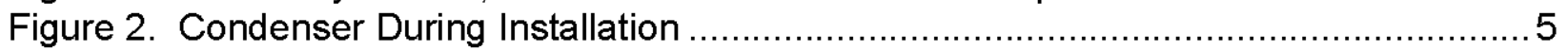

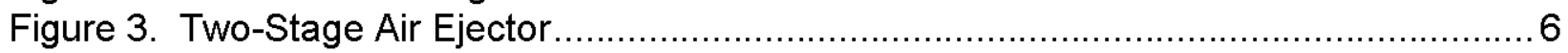

Figure 4. Centrifuge Before Piping Installation ..................................................... 7

Figure 5. Product Dissolver Below Centrifuge Platform......................................... 8

Figure 6. Centrifuge Tanks and Miscellaneous Controls ............................................ 10

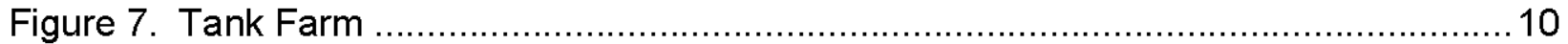

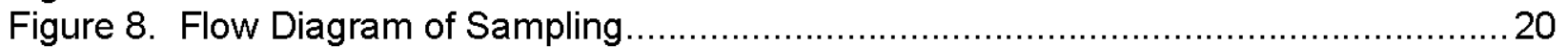

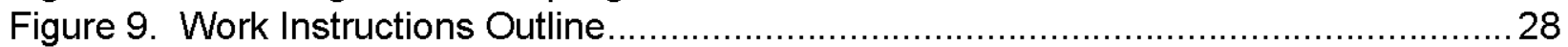

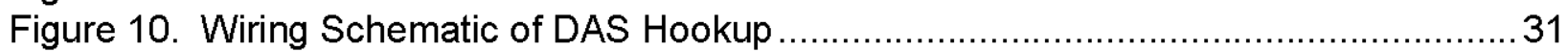

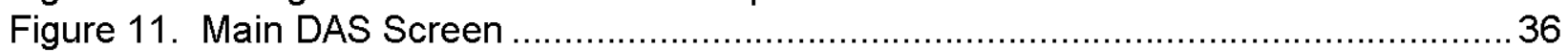

Figure 12. Trend Chart Screen on Additional Monitor for the FC Test Rig DAS ................37

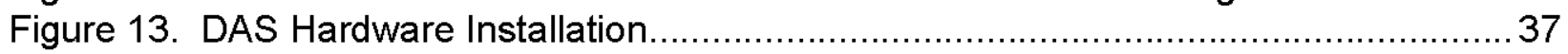

Figure 14. Graph of Crystallizer Temperature and Pressure ........................................ 44

Figure 15. Graph of Reboiler Steam Temperature, Delta T and Pressure ........................44

Figure 16. Graph of Crystallizer Level and Slurry Density ........................................... 45

Figure 17. Graph of Crystallizer Circulation Pump Flowrate and Speed ...........................46 46

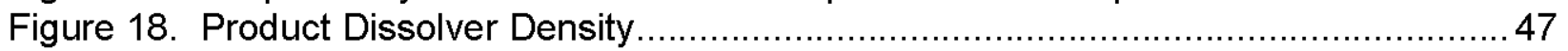

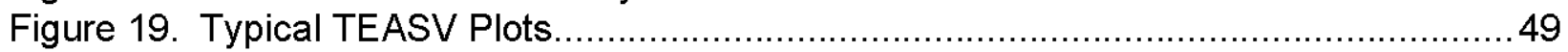

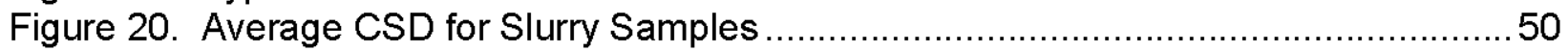

Figure 21. Graph of Crystallizer Temperature and Pressure ........................................53

Figure 22. Graph of Reboiler Temperature, Pressure, and Delta T ................................54

Figure 23. Graph of Crystallizer Level and Slurry Density ............................................5

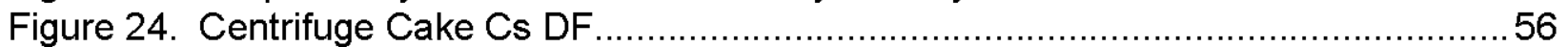

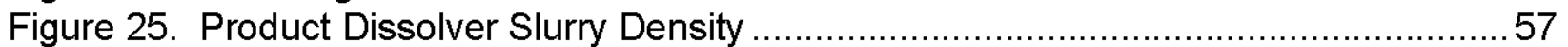

Figure 26. Product Dissolver Cs DF .......................................................................... 58

Figure 27. Total Solids and Undissolved Solids in Slurry Recirculation Samples ...............59

Figure 28. Total and Supernate Solids in Slurry Recirculation Samples ...........................60

Figure 29. Slurry Recirculation UDS and Quick UDS Values .......................................60

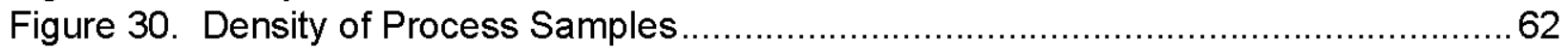




\section{LIST OF FIGURES (contd.)}

Figure 31. Density and Total Solids of Feed Samples

Figure 32. Elemental Analyses of Centrifuge Cake Samples .........................................6 65

Figure 33. Elemental Analyses of Slurry Recirculation Samples ...................................6 66

Figure 34. Elemental Analyses of Product Dissolver Samples .....................................67

Figure 35. Elemental Analyses of Spent Wash Samples ............................................68

Figure 36. Elemental analyses of Recycle Wash Samples ...........................................69

Figure 37. Elemental Analyses of Feed and Product Samples .................................... 70

Figure 38. Anion Chromatography Analyses of Feed and Product Samples ......................71

Figure 39. Reference PLM of Sodium Nitrate Crystal................................................ 72

Figure 40. Undissolved Salts in Feed Sample ...................................................... 72

Figure 41. Large Sodium Nitrate Crystals in Crystallizer Slurry ..................................... 73

Figure 42. Crystal Matrix with Poor Morphology ................................................... 73

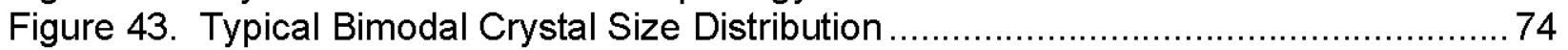

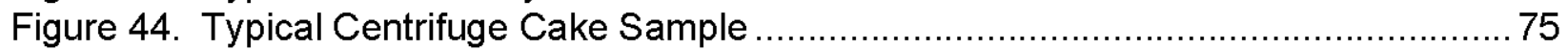

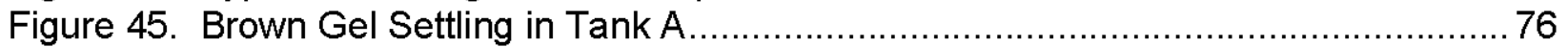

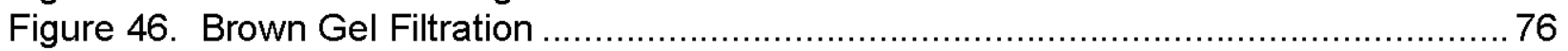

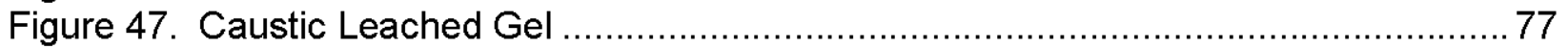

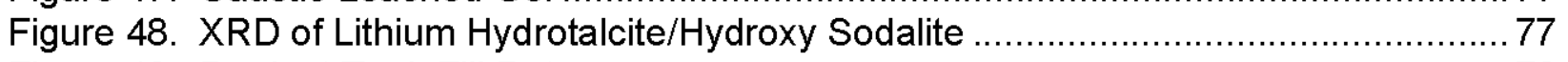

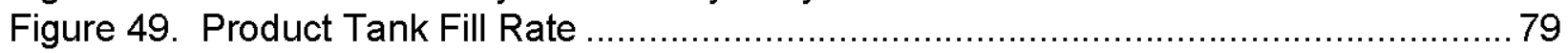

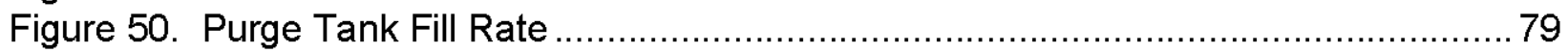

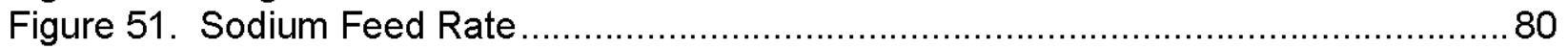

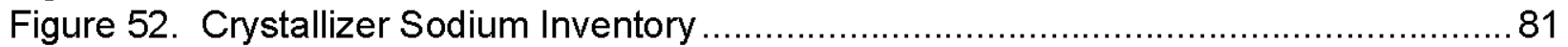

Figure 53. Correlation of Crystallizer Vapor Pressure to Sodium Yield at $131^{\circ} \mathrm{F} \ldots \ldots \ldots \ldots \ldots . . . .82$

Figure 54. Two Stage Crystallization Process Flow Diagram ........................................ 89

Figure 55. Two Stage Crystallization Block Flow diagram............................................90

Figure 56. Two Stage Crystallization Mass Balance ……............................................. 91

Figure 57. Full-Scale Equipment Layout............................................................. 107

Figure 58. Full-Scale Equipment Elevation View.................................................... 108 
RPP-39091, Rev. 0

RPT-3000755 Rev. 000

\section{LIST OF ACRONYMS AND ABBREVIATIONS}

\begin{tabular}{ll} 
ASV & Apparent Settling Velocity \\
CK & Centrifuge Cake \\
CPVC & Chlorinated Polyvinyl Chloride \\
CSD & Crystal Size Distribution \\
DAS & Data Acquisition System \\
DF & Decontamination Factor \\
DO & Draw-Off \\
DST & Double-Shell Tank \\
DTE & Draft Tube Entry \\
EDL & Engineering Development Laboratory \\
FA & Feed Tank A \\
FC & Fractional Crystallization \\
FCPP & Fractional Crystallization Pilot Plant \\
Free OH & Free Hydroxide \\
GTAW & Gas Tungsten Arc Welding \\
HLW & High Level Waste \\
HP & Horsepower \\
gpm & gallons per minute \\
ICA & lon Chromatography for Anions \\
ICPMS & Inductively Coupled Plasma - Mass Spectroscopy \\
ICPOES & Inductively Coupled Plasma - Optical Emission Spectroscopy \\
IPS & Interim Pretreatment System \\
ITDP & Integrated Test and Demonstration Plan \\
LAN & Local Area Network \\
LAW & Low Activity Waste \\
mADC & milliamp direct current \\
NAS & Sodium (Na) Aluminosilicate \\
NPSHA & Net Positive Suction Head Available \\
P\&ID & Piping and Instrumentation Diagram \\
PFD & Process Flow Diagram \\
PLC & Programmable Logic Controller \\
PD & Product Dissolver \\
PEDL & Process Engineering Development Lab \\
PLM & Polarized Light Microscopy \\
PTP & Pilot Test Plan \\
PSAL & Process Science Analytical Laboratory \\
PSE & Process Science and Engineering \\
QC & Quality Control \\
QEW & Qualified Electrical Worker \\
Q-UDS & Quick Undissolved Solids \\
rpm & revolutions per minute \\
RWT & Recycle Wash Tank \\
SR & Slurry Recirculation \\
SS & Stainless Steel \\
& \\
& \\
\hline
\end{tabular}


RPP-39091, Rev. 0

RPT-3000755 Rev. 000

LIST OF ACRONYMS AND ABBREVIATIONS (continued)

SRNL Savannah River National Laboratory

SREL Savannah River Ecology Laboratory

SST Single-Shell Tank

SWT Spent Wash Tank

TIC Total Inorganic Carbon

TEASV Trailing Edge Apparent Settling Volume

TRP

TS

Test Run Plan

UDS Undissolved Solids

VFD Variable Frequency Drive 
RPP-39091, Rev. 0

RPT-3000755 Rev. 000

\title{
HANFORD MEDIUM/LOW CURIE WASTE PRETREATMENT ALTERNATIVES PROJECT
}

\author{
FRACTIONAL CRYSTALLIZATION PILOT SCALE TESTING \\ FINAL REPORT
}

\subsection{EXECUTIVE SUMMARY}

Fractional crystallization (FC) has been studied as a potential Hanford tank waste pretreatment process since January 2005. FC uses an evaporation and crystallization process to separate radioactive isotopes from the nitrate and nitrite salts that make up a large fraction of the waste in Hanford's tanks. As the liquid in the waste evaporates, salt crystals are left behind. These salt crystals form a matrix that generally excludes most radioactive isotopes, including cesium, technetium, and iodine. The overall testing program was developed to provide insights into how FC a process similar to that used to purify table salt - could be used to separate the radioactive waste in the underground tanks at the U.S. Department of Energy's (DOE) Hanford Site into High-Level Waste (HLW) and Low-Activity Waste (LAW) streams. The LAW stream would be used to feed the Hanford Waste Treatment and Immobilization Plant LAW vitrification plant, reducing the volume of waste that must be treated as HLW.

Process modeling and flowsheet development was completed, followed by successful bench-scale testing using clean and real-waste simulants at the Georgia Institute of Technology (Georgia Tech) and actual tank waste at Hanford. The Engineering Development Laboratory (EDL) of the Savannah River National Laboratory (SRNL) assembled a Pilot Test Facility to achieve test conditions specified in the Process Flow Diagram (PFD) developed by AREVA Federal Services LLC (AREVA). Major components such as Crystallizer Vessel, Reboiler, Circulation Pump and Centrifuge were provided by Swenson Technology Inc. (Swenson). EDL designed and fabricated the balance of the system based on these documents and fundamental knowledge and experiences established in previous related experimentation.

Following construction activities, the EDL facility initiated a series of system checks and functional tests commensurate with the design of the facility and requirements for the safety inspection requirements for the facility and equipment. After completing all primary functional testing, the system was declared ready for chemical operations in April 2008.

In this large-scale (1/5th scale) pilot test, using non-radioactive simulants (including cesium) of the Hanford waste, SRNL successfully demonstrated FC's effectiveness. The EDL completed the seven-week pilot test of the FC technology as part of overall project testing and demonstration program described in the Hanford Medium/Low Curie Waste Pretreatment Alternatives Project Integrated Test and Demonstration 
RPP-39091, Rev. 0

Plan. The pilot scale tests demonstrated that FC effectively separates nonradioactive sodium salts from cesium such that all cesium decontamination and sodium product yield goals were met. Specifically, the pilot:

- Achieved an Average Filter Cake Cesium Decontamination Factor of 130, compared to a goal of at least 50 .

- Achieved a Sodium Product Yield (percentage of sodium isolated to send to LAW vitrification) of $52 \%$, compared to a goal of $50 \%$.

As with most Research and Development (R\&D) activities, many challenges were faced during the pilot testing and the combined team of AREVA, Swenson and SRNL EDL overcame the obstacles to complete the required testing on time, within budget, and with results that met or exceeded the desired goals of the program.

\section{$2.0 \quad$ INTRODUCTION}

The Fractional Crystallization Pilot Plant (FCPP) was designed and constructed to demonstrate that FC is a viable way to separate the high-level and low-activity radioactive waste streams from retrieved Hanford single-shell tank (SST) saltcake. Details of the preliminary laboratory testing program that led up to the pilot testing phase are contained in documents referenced by the Fractional Crystallization Pilot Scale Testing Preliminary Report, RPT-3000559, Rev 000, and will not be repeated herein. The focus of this report is to review the design, construction, and testing details of the FCPP not previously disseminated.

\subsection{Pilot Design}

Design and fabrication responsibilities for the FCPP were divided between a team consisting of AREVA, Swenson, and the SRNL EDL group. The AREVA/Swenson team was responsible for delivering the crystallizer, reboiler, centrifuge and the main recirculation pump while the EDL group was responsible for installing these components along with required instrumentation and support systems in the SRNL $786 \mathrm{~A}$ Building. The overall crystallization process is depicted in AREVA drawing C-01118-008, Revision 1, Pilot Plant Crystallization System Process Flow Diagram. For the purposes of this report, the FCPP, as shown in SRNL drawing EES-23164M6-001, Fractional Crystallization Pilot Scale Facility P\&ID, Revision "D", will be divided into four major subsystem groupings:

1. Crystallizer - The crystallizer subsystem consisted of the crystallizer vessel, recirculation pump, reboiler, condenser, steam jet vacuum pumps, and the interconnecting piping.

2. Centrifuge - The centrifuge subsystem consisted of the centrifuge, its programmable logic controller (PLC), and the 11/2" slurry draw-off line that supplied the crystal slurry from and returned it to the 6 " main crystallizer recirculation pipe. 
RPP-39091, Rev. 0

3. Data Acquisition System (DAS) - The DAS consisted of the instruments and the LabVIEW ${ }^{\mathrm{T} M}{ }^{1}$ software configured to monitor and control various process functions.

4. Balance-of-Plant (BOP) Systems - The BOP systems consisted of utilities, e.g. steam and electrical power, components, and piping systems necessary to interconnect all the FCPP process functions.

\subsubsection{Crystallizer}

The purpose of the crystallizer is to evaporate water from the incoming slurry (from the reboiler) until the dissolved salts reach a supersaturated condition. At this point, nucleation of solid salt crystals occurs and as long as proper conditions, i.e. time, temperature, and super-saturation prevail, the crystals will grow until they are of proper size for separation from the circulating slurry. The crystallizer operating temperature is fixed at a predetermined value established by a thermodynamic model of the system and is controlled by the head space pressure which is modulated by the vacuum system through an atmospheric bleed valve. The crystallizer boiling rate is fixed by the steam flow rate to the reboiler. This boiling rate is predetermined to create a vapor flow rate at the operating pressure that will effectively load the demisters. As evaporation and draw-off to the centrifuge lower the crystallizer liquid level, fresh feed is introduced to the recirculation loop upstream of the reboiler to maintain the liquid level. The feed rate should be nearly constant at steady state. A stable liquid level is required to maintain constant back-pressure on the draft tube to assure that boiling occurs in the crystallizer vessel and not in the recirculation loop or reboiler.

The slurry flows into the crystallizer through an internal draft tube with a conical outlet. The conical outlet promotes even radial distribution of the slurry to the boiling surface of the existing liquor volume within the vessel. This flow distribution ensures a uniform vapor release velocity, which is necessary to prevent splashing or slugging of liquid vertically into the entrainment separator and limits carryover of dissolved solids into the vapor stream. For experimental purposes, the draft tube may consist of three interlocking sections (one flared section and two, 1' straight extensions) which allow slurry volume changes for residence time adjustment. For the FCPP testing only the flared section was utilized, i.e. the operating volume provided the minimum crystal residence time.

The crystallizer is a stainless steel (SS) vessel 23' high with a major diameter of 5'-0" at its cylindrical mid-shell section and conical transition sections at both the top and bottom (see Northwest Copper Drawing D-7007, Appendix 8.3). A vortex breaker at the outlet nozzle prevents rotation of the fluid in the recirculation pipe leading to the recirculation pump. The crystallizer is supported by structural steel (pipe) columns to provide a minimum net positive suction head available (NPSHA) at the recirculation pump suction centerline.

\footnotetext{
${ }^{1}$ LabVIEW is a registered trademark for National Instruments, Austin, TX
} 
Figure 1. FCPP Crystallizer, Reboiler and Recirculation Pump

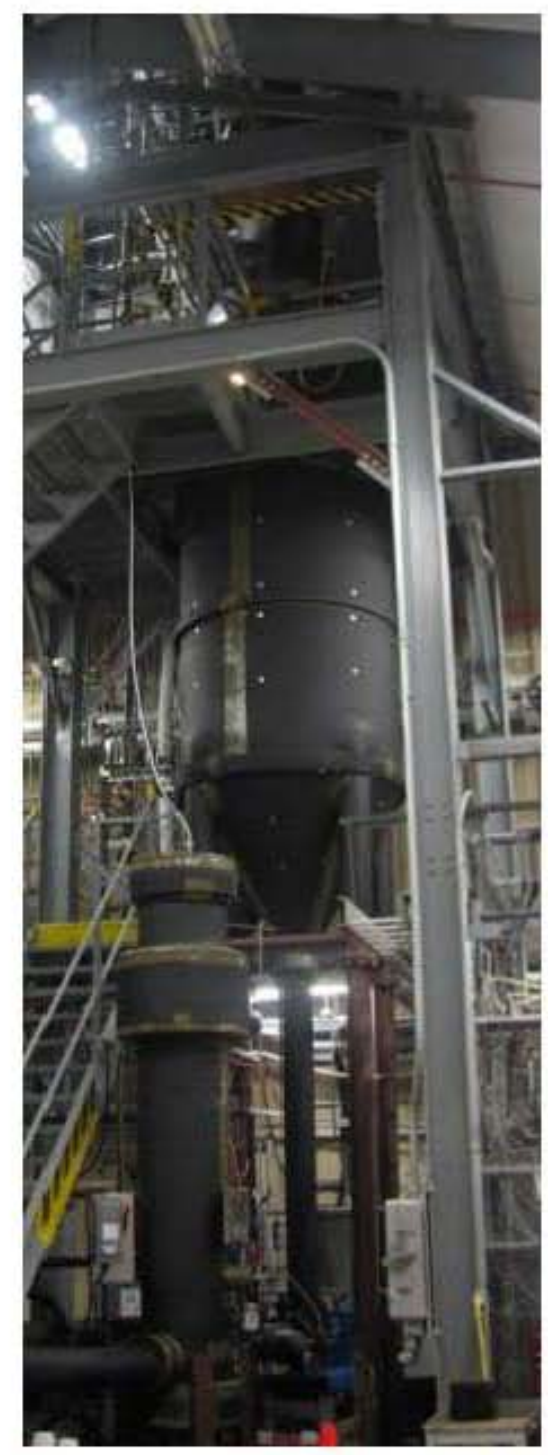

\subsubsection{Recirculation Pump}

Slurry flow from the crystallizer through the reboiler and back to the crystallizer was provided by an axial flow recirculation pump. The axial flow pump was chosen to minimize damage to the crystals in the slurry. The operating flowrate (fixed at $\sim 600 \mathrm{gpm}$ ) was established to minimize slurry temperature rise across the reboiler (less than or equal to $3^{\circ} \mathrm{F}$ for tube fouling considerations) while maintaining solids in suspension (velocity at $\sim 6.5 \mathrm{fps}$ ) to prevent reboiler tube blockage. The recirculation pump was equipped with a variable frequency drive (VFD) that provided slumy flow rate, pump speed, and pump current readings to the DAS. 
RPP-39091, Rev. 0

RPT-3000755 Rev. 000

\subsubsection{Reboiler}

The SS reboiler was supplied with low pressure ( $\sim 3 \mathrm{psia})$ saturated steam through a measuring orifice and a flow control valve. Since the steam becomes superheated as it is throttled to the reboiler shell pressure, condensate is sprayed through a desuperheater nozzle to remove the superheat and provide saturated steam to the reboiler. The low temperature rise and large heat transfer surface $\left(\sim 112 \mathrm{ft}^{2}\right)$ prevent film boiling in the reboiler tubes.

\subsubsection{Condenser and Steam Jet Vacuum Pumps}

To meet the condensing capacity required for the design crystallizer vapor flow, a new SS condenser (Figure 2) was procured by SRNL for the FCPP from Hoffman Process, Inc. The unit was sized to condense $900 \mathrm{lbs} / \mathrm{hr}$ of vapor $\left(\right.$ at $131^{\circ} \mathrm{F}$ ) while the expected crystallizer design flow was $684 \mathrm{lbs} / \mathrm{hr}$. The condenser used SRNL Site process water for cooling (design flow $75,000 \mathrm{lb} / \mathrm{hr} @ 70^{\circ} \mathrm{F}$ inlet temperature) and was equipped with a pressure relief device attached to the vapor inlet piping.

Figure 2. Condenser During Installation.

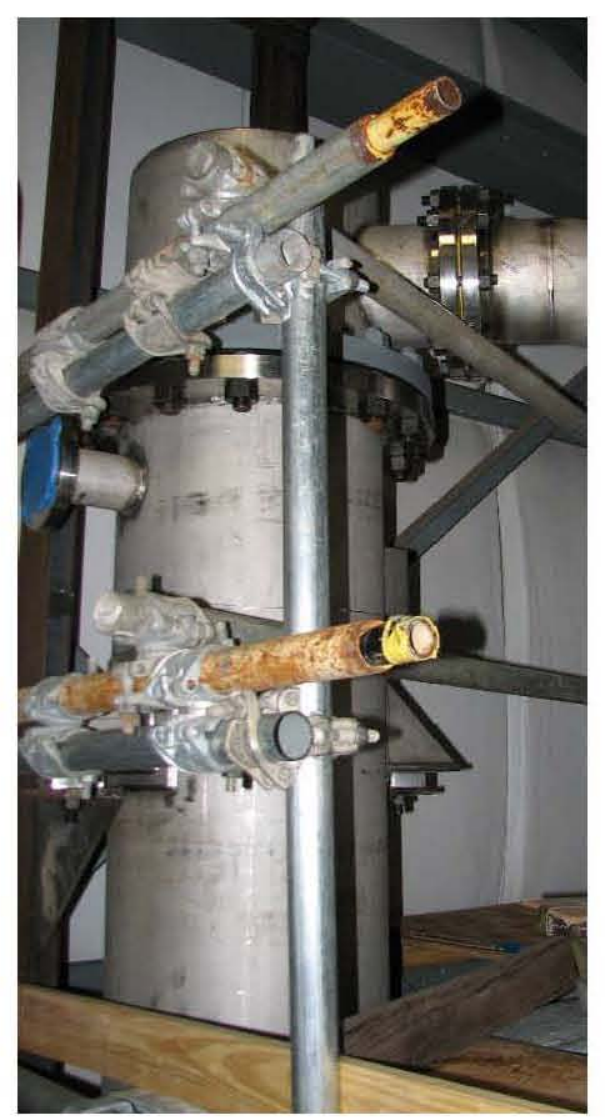

The steam jet vacuum pump (Figure 3 ) used to remove non-condensable gases from the condenser and reboiler was a two-stage Schutte \& Koerting Type AHTR steam jet ejector system. The air ejectors were capable of removing $25 \mathrm{lb} / \mathrm{hr}$ of air 
and $3 \mathrm{lb} / \mathrm{hr}$ of water vapor at 2 " $\mathrm{Hg}$ absolute when supplied with a total of $42 \mathrm{lb} / \mathrm{hr}$ of steam at 100 psig and $4 \mathrm{gpm}$ of process cooling water at $85^{\circ} \mathrm{F}$.

Figure 3. Two-Stage Air Ejector

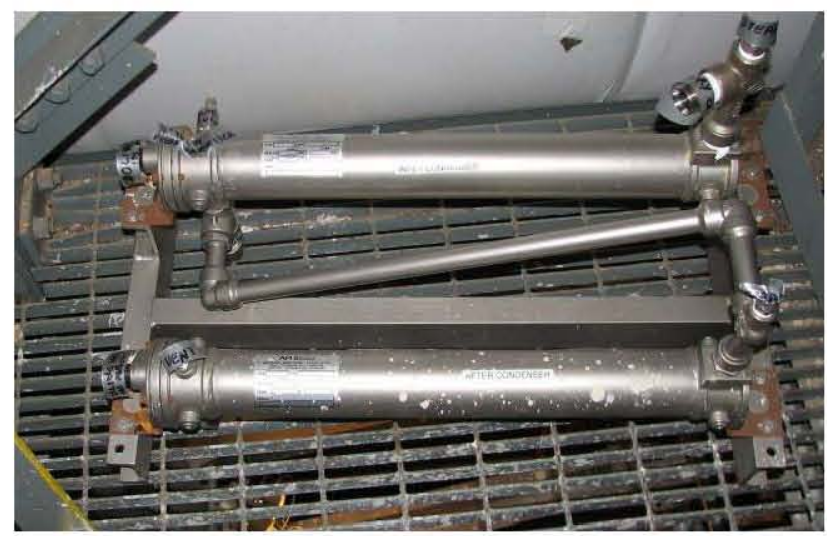

\subsubsection{Centrifuge}

The Krauss-Maffei HZ - $40 \mathrm{Si}$ centrifuge (Figure 4) was the solid/liquid separation device for removing product crystals from the draw-off loop (recirculating slurry sidestream). Due to a long lead time and cost for a new unit a factory reconditioned unit was purchased. The reconditioned unit was guaranteed to perform as well as a new unit however automatic basket speed control was not provided, i.e. speed was controlled by manually adjusting hydraulic pressure. The loop flow rate was determined by the minimum velocity $(\sim 6.5 \mathrm{ft} / \mathrm{sec}$.) required to maintain the crystals in suspension in the 11/2" draw-off pipeline while at the same time providing sufficient head to overcome the elevation difference between the location of the pump and the centrifuge slurry feed valve.

The draw-off flow from the crystallizer to the centrifuge was provided by a Flowserve $2 \mathrm{~K} 2 \times 2 \mathrm{R}$ pump rated for $40 \mathrm{gpm}$ at $36 \mathrm{ft}$. total developed head (TDH). A 2" pinch valve was installed at the slurry return to the main 6 " crystallizer recirculation loop to control the draw-off loop flowrate and ensure positive pressure at the draw-off point. A VFD controller was installed on the pump to maintain line velocity and reduce pipeline pressure.

During the separation process, slurry was fed to a rotating basket where the crystals were retained on a screen (screen mesh size determines the minimum retained particle size) and the liquid (mother liquor) passed through the screen and was collected in a tank before recycling to the crystallizer or purging from the system. Therefore the draw-off rate was controlled by the centrifuge's capacity to process the incoming slurry. 
Figure 4. Centrifuge Before Piping Installation

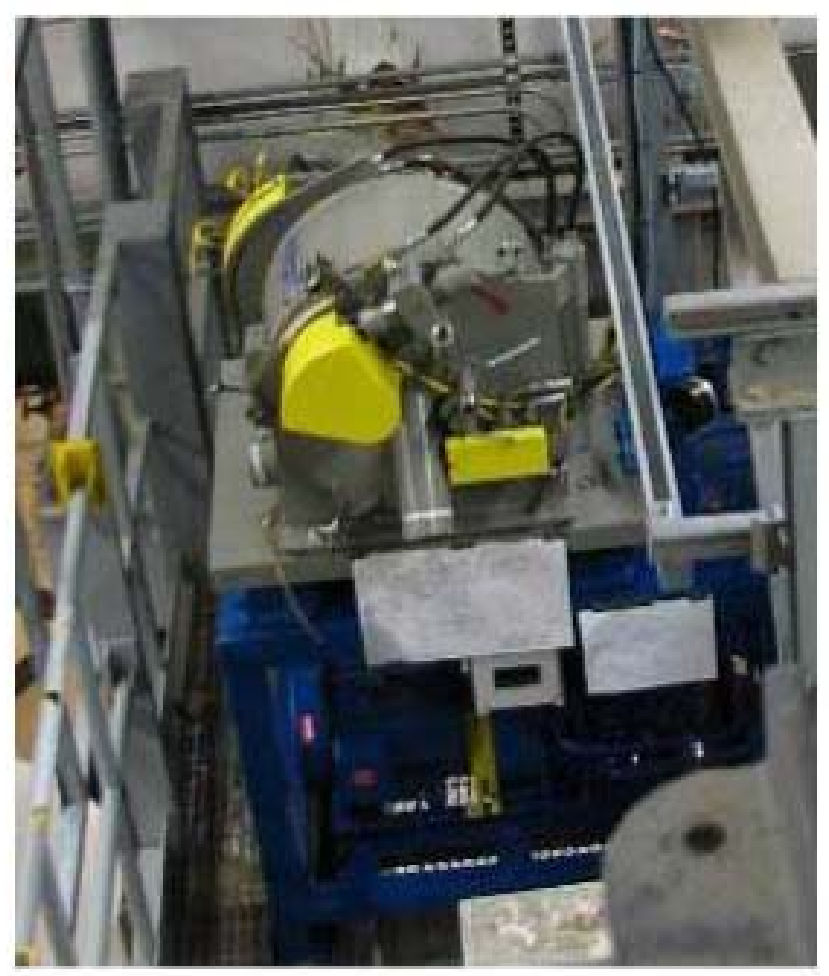

Factors affecting liquid flow through the cake include crystal size distribution (CSD), cake thickness, cake porosity, and centrifuge rotational speed. Excess fines (small crystals) in the slurry can clog cake interstitial spaces (pores) and impede liquid flow and therefore limit centrifuge processing capability. The centrifuge operational cycle (feed, wash, and cake peel) are controlled by the vendor-supplied PLC. During the peel step a small residual cake (heel) was left as a "bed" for the next slurry batch. Over a period of time the heel becomes packed or clogged by fines and must be removed to restore capacity. To prevent contamination of the product discharge chute, only condensate was used to dissolve the heel.

Product cake was discharged to the insulated Product Dissolver Tank (Figure 5) through a 4" vertical pipe and dissolved in condensate. Because crystal dissolution is an endothermic reaction, an electrically operated heater was employed to maintain process temperature at $131^{\circ} \mathrm{F}$ for the optimum dissolution rate.

Since the dissolver solution was used for washing the centrifuge cake, it had to be maintained near sodium nitrate saturation ( 10M Na) to prevent centrifuge cake dissolution. At this concentration, sodium carbonate and sulfate are oversaturated. To remove these solids from the centrifuge wash solution, a cross-flow filter was installed on the product dissolver. Concentration of the dissolver solution was monitored by specific gravity of the solution and condensate was added to control the concentration at the near saturated condition. 
Figure 5. Product Dissolver Below Centrifuge Platform

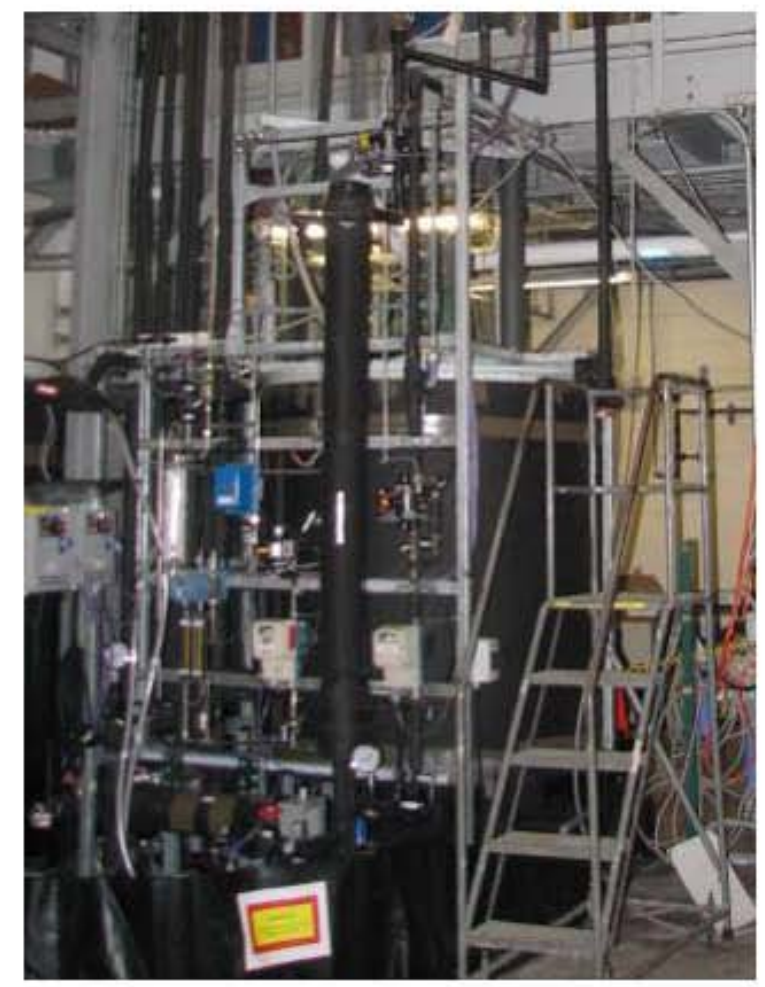

\subsubsection{Data Acquisition System (DAS)}

The Data Acquisition (and Control) System for the FCPP was composed of National Instruments(R) (NI) Signal Processing and Acquisition hardware and NI Labview(R) DAS software coupled with a Dell Workstation computer. Specifics of the DAS are included in Section 3.4.

The DAS was used for data acquisition and process alarms only. Process controllers were not installed in the DAS software. Therefore, process flowrates, temperatures, pressures, densities, vessel levels, and other control points had to be adjusted by operators by throttling manual valves.

\subsubsection{Piping, Instrumentation, and Miscellaneous Components}

AREVASwenson provided the PFD and sized the piping for the crystallizer recirculation loop. The detailed design for the FCPP piping was performed by SRNL and installed in accordance with guidelines provided by AREVASwenson and with the configuration depicted on the SRNL P\&ID. 
RPP-39091, Rev. 0

Process piping consisted of small diameter ( $1 / 4$ to $1 / 2$ ") SS tubing and Swagelok fittings, $1 / 2$ " to 2" CPVC pipe and solvent welded fittings, and welded 6" and 8" schedule 10 SS pipe. Steam supply pipes were 1.5 " schedule 40 threaded SS pipe with SS tubing branches. Threaded and solvent welded piping were selected to facilitate field fitting using existing supports wherever possible. The process piping was sized to provide reasonable pressure drops while maintaining line velocities to maintain solids in suspension. Numerous sample ports were provided as well as connections for flushing out lines with condensate to prevent and remove plugs when the systems had to be shutdown. No allowance was made for corrosion since the test would be short term.

Instruments used included flowmeters, thermocouples, tank level indicators, pressure and vacuum gauges and transmitters. Existing EDL instruments were used wherever possible. New instruments were specified and purchased when unavailable from the existing EDL stocks. Instrument data that was needed for process analysis was connected to the DAS and recorded electronically. Instruments that were expected to be useful only for troubleshooting or primary instrument backup provided local readout only.

Miscellaneous components such as small pumps, tanks, equipment supports, etc. were either selected from SRNL stock, or purchased new when suitable equipment was not available. Most of the pumps were simple centrifugal pumps with single mechanical seals. The draw-off pump was designed with double mechanical seals and a pressurized seal water supply. A special centrifugal pump with a flow inducer was provided to pump condensate from the reboiler while preventing cavitation at low pressure.

To ensure an adequate steam supply to meet the expected demand from the reboiler and the air ejectors, a new Electro-Steam $250 \mathrm{KW}$ package electric steam boiler was installed in parallel with the existing $150 \mathrm{KW}$ unit. Both boilers were connected to a common 11/2" header and cycled on-and-off in response to header pressure. Each unit had their own integral, independent control system and an installed relief valve for over-pressure protection. Process condensate was supplied to the boilers for feed water make-up.

Polypropylene tanks were used for in-process tanks. The heated and insulated centrifuge product and wash solution tanks, along with typical heater controls, automatic valves, instruments, and pump, etc. are shown Figure 6. 
Figure 6. Centrifuge Tanks and Miscellaneous Controls

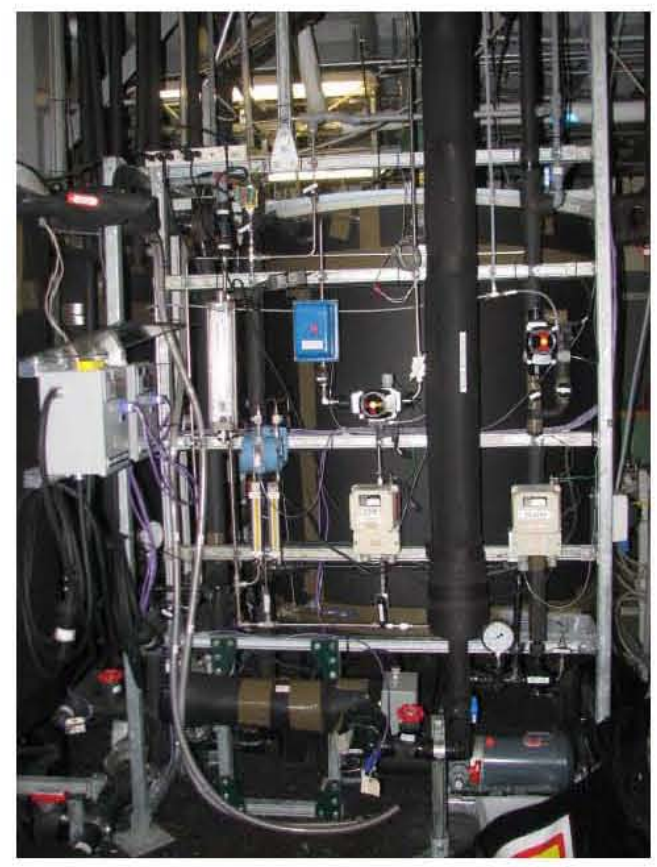

Large polypropylene tanks were used to store the feed and recycled simulant solution. The feed tanks are depicted in the P\&ID and shown in the "tank farm" picture (Figure 7). The tanks were wrapped in plastic film as a precaution against a spray rupture event. The tanks were installed in a 1-foot high flexible secondary containment around the tanks to guard against a spill release to the environment.

Figure 7. Tank Farm

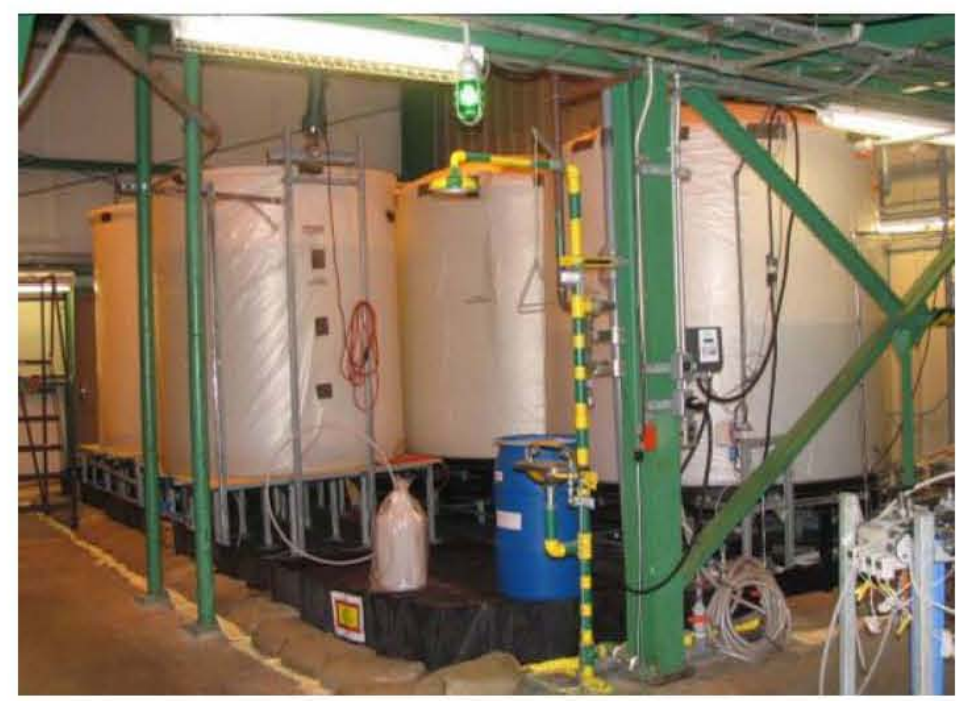


RPP-39091, Rev. 0

Excess condensate from the process was stored in covered, plastic tanks outside the EDL. During Construction Acceptance Testing all tanks were "calibrated" by pumping in known volumes of water then measuring level rise. Where applicable, the calibrated levels were compared to indicated levels from ultrasonic level detectors. All tanks were equipped with high level alarms that alarmed at the Shift Engineer's desk.

\subsection{Pilot Plant Construction}

Pilot plant construction was performed by EDL staff and SRNL Site construction craftsmen. Prior to installing the FCPP systems and equipment, some modifications were required for the 786A Building including the removal of materials from previous testing programs and strengthening support structures. Construction activities, including Construction Acceptance Testing, commenced in July, 2007 and completed in April, 2008.

\subsubsection{Materials}

The major equipment (crystallizer, reboiler, axial flow pump, and primary condenser) were constructed using 304-L SS. For the other equipment and piping, CPVC and polypropylene were selected for their ease of installation, the flexibility to rework if necessary, and adequate chemical and thermal resistance for use with the process chemicals. Pumps were generally SS both for better durability and because of their availability from the existing EDL equipment stocks. Graphite filled flexitallic gaskets were used between SS flanges; $1 / 8$ " thick viton rubber gaskets were used any time a CPVC flange was bolted to either a SS or another CPVC flange. Small diameter polyethylene tubing was used to pipe condensate streams because it was easy to route and adequate for the expected process temperatures and pressures. $316 \mathrm{SS}$ tubing was generally used for process lines less than $1 / 2$ " in diameter.

\subsubsection{Installation and Testing}

The 786-A building was high enough to enclose the crystallizer and reboiler. However, minor structural modifications were required to accommodate the new components weighing 3 tons and 1 ton (dry weight), respectively.

Major equipment was placed in the building according to a preliminary assembly drawing prepared by the EDL staff. Large SS piping was detailed on drawings and shop fabricated in sections, with the final fit and welding in the field. Minor equipment, instruments, and piping less than 6" was field installed to meet the requirements shown on the P\&ID. Standard Unistrut was used to support instrumentation and piping. Existing building steel was used, where available, to minimize the need for customized supports.

Major equipment and tanks were surrounded by 12"-18" high flexible secondary containers sized to hold the entire contents of the largest single source of chemical spills or leaks. 
Electrical connections were utilized from existing EDL $120 \mathrm{~V}$ single phase and $208 \mathrm{~V}$ three phase receptacles. Three $480 \mathrm{~V}$ three phase disconnect/receptacles were installed to power the $15 \mathrm{HP}$ axial flow recirculation pump, the $10 \mathrm{HP}$ draw-off loop pump, and the $7.5 \mathrm{HP}$ centrifuge.

Piping was installed and tested in accordance with the ASME B31.3 process piping code. For testing purposes, the process chemical piping was judged to be "category normal" while steam, condensate, and air were categorized as B31.3 "category D." Welding of SS pipe was performed by machine shop staff formally trained and qualified on the GTAW process. The EDL technicians were formally trained and qualified for solvent welding of CPVC piping. An independent inspector visually inspected over $5 \%$ of the GTAW welds and witnessed over $5 \%$ of the solvent welds on the process chemical piping. The process pipes were hydrostatically tested according to specific written work instructions as specified in the code. Wherever possible, the non-code piping was included in the hydro test of the code piping. However, sections that could not be pressurized (such as piping between open top tanks and the first valve) were leak checked during initial system shakedown with water.

Many of the instruments were bench calibrated before installation. Some that were provided simply for troubleshooting were not calibrated while a few of the instruments had to be calibrated in situ. The master instrument list identified in Appendix 8.5 identifies which instruments were calibrated.

\subsubsection{Manufacturer's Instructions}

Manufacturer's Instructions covering installation, operation, and maintenance of certain FCPP equipment were provided to SRNL for inclusion in Work Instructions. These instructions included:

- Crystallizer Operating Instructions (Swenson)

- Gould's Model AF (6x6-6") MXR Pump (Goulds Pumps)

- KMPT HZ 40 Si Peeler Centrifuge (KMPT)

- Centrifuge Functional Design Specification (KMPT)

- Pump Smart PS 200 drive (ITT)

\subsubsection{Readiness Certification}

In preparation for the chemical operations of the FC system, a management review was initiated to ensure proper documentation, training, and concurrence had been completed to ensure the facility was in the required readiness to operate safely and effectively. A Readiness Certification document was generated to establish the state of readiness to perform the R\&D activities for the pilot-scale facility and is included as Appendix 8.9. The purpose of the readiness report was to establish a documentation record for the readiness of the facility for chemical operations based on the following criteria: Work Construction, Safety Compliance Documentation and Controls, Compliance with Conduct of Research and Development, Work Documentation Completion and Readiness, Training Status for Personnel, 
Compliance with Expectations from Customer, Satisfying Internal Management Requirements, Satisfying DOE Oversight. A thorough review was completed and documented in the report and approved by the EDL management, the Manager of Research Programs and the Manager of Safety Programs within the SRNL.

\subsection{TEST PLANNING}

Testing of the FCPP was the last event in the Hanford Medium/Low Curie Waste Pretreatment Alternatives Project Integrated Test and Demonstration Plan (ITDP) RPP-PLAN-34134, Rev. 0. While the Fractional Crystallization Test Plan, RPPPLAN-34135, Rev. 0 (Pilot Test Plan) contained specific test requirements at the pilot plant operations level, the ITDP incorporated requirements at a higher, program level. Specifically, these requirements involved validating or resolving certain enabling assumptions and uncertainties. In addition, contractual process performance requirements would have to be met and these would be validated by analyzing the process and product streams detailed in a laboratory Analytical Test Plan.

Significant enabling assumptions in the ITDP included:

- Modeling can be used to predict FC process performance with Hanford waste.

- Simulant can be used to investigate FC performance with actual Hanford waste.

- The FC process is scalable, i.e. the full-scale process performance can be predicted from laboratory, engineering and pilot scale operations.

ITDP uncertainties included:

- FC ability to handle feed variability.

- FC efficiency of separating salt crystals from the mother liquor containing cesium (Cs), technetium (Tc), and iodine (I).

- Crystallizer vessel retention time adequate for crystal growth.

- Complexity of the required FC control system necessary to provide ease of operation.

- FC system's ability to recover from process upsets.

Process performance requirements included removing at least $50 \%$ of the incoming feed stream sodium content and attaining a product DF of at least 50 .

\subsection{Pilot Test Plan}

The Pilot Test Plan (PTP) incorporated the above assumptions and uncertainties to be addressed with the exception of modeling and use of simulants. Both the ability to effectively model the process and the comparison of simulant to actual waste 
RPP-39091, Rev. 0

performance had been demonstrated in earlier project reports so they were considered "verified" in regard to further exploration during pilot plant operation. The PTP was structured to sequentially address the remaining assumptions and uncertainties in a series of five tests:

- Test 1 - Benchmark Testing

- Test 2 - Baseline Testing

- Test 3 - Process Parameter Variation Testing

- Test 4 - Feed Variability Testing

- Test 5 - Casualty Testing

Each test would be governed by a "Test Run Plan" (TRP) document that provided the operators with instructions on how to conduct the test, parameters to observe and data to be collected. As noted in the Fractional Crystallization Pilot Scale Testing Preliminary Report, RPT-3000559, the testing period was curtailed so that results could be utilized to select the technology for conceptual design of the Interim Pretreatment System (IPS). As a result of the accelerated testing schedule and a lack of additional funding, only Test 1 and Test 2 were completed. However in performing these test runs, some elements of the planned subsequent tests were also successfully demonstrated. Copies of the final Test 1 and Test 2 TRPs as implemented are contained in Appendices 8.10 and 8.11.

\subsection{SRNL Analytical Test Plan}

The final analytical plan was issued as document SRNL-PSE-2008-0046, Rev. 0 on April 16, 2008. This document outlined the analytical techniques to be performed and the expected sampling and analysis frequencies.

\subsubsection{Sampling Frequency}

The samples that were planned to be taken and the times at which these would be taken are shown in Table 1. The sample analysis techniques abbreviated in Table 1 are described in Table 2 . The sampling described in Table 1 was roughly followed throughout both the Benchmark and Baseline phases of operation.

Initially, the destination tanks for the HLW and LAW fractions were misidentified (including in the issued Analytical Plan). A corrected flow diagram of sample locations was produced on May 8, 2008 and is shown in Figure 8. The "Purge Liquor" identified in Table 1 was meant to be the HLW product sent to HLW Receipt Tank $E$, but was incorrectly assumed to be the Liquor sample taken from the line from the centrifuge to the SWT during the dewatering step. However, the intended samples were actually taken periodically during the tests; these samples were identified as sample PR or PR(E). 
Table 1. Sampling Locations and Frequencies Planned

\begin{tabular}{|c|c|c|c|c|c|c|c|c|c|c|c|c|c|c|c|c|}
\hline Stream & $\begin{array}{c}\text { Process Stage } \\
\text { Or Time }\end{array}$ & Notes & $\begin{array}{l}\text { Total } \\
\text { Solids }\end{array}$ & $\begin{array}{l}\text { Total Solids, } \\
\text { Undissolved } \\
\text { Solids (wt \%) }\end{array}$ & $\begin{array}{l}\text { Quick } \\
\text { UDS } \\
\text { (wt \%) }\end{array}$ & Density & CSD & PLM & \begin{tabular}{|c|} 
Apparent \\
Settling \\
Volumel \\
Density \\
\end{tabular} & $\begin{array}{c}\text { Aluminum by } \\
\text { Turbidity }\end{array}$ & $\begin{array}{l}\text { Sample } \\
\text { Prep }\end{array}$ & $\begin{array}{c}\text { Free } \\
\text { Hydroxide, } \\
\text { Total Base } \\
\end{array}$ & $\begin{array}{c}\text { ICPMS } \\
\text { Cs }\end{array}$ & $\begin{array}{l}\text { ICP. } \\
\text { OES }\end{array}$ & $\begin{array}{c}\mathrm{IC} \\
\text { Anions }\end{array}$ & $\begin{array}{l}\text { TICl } \\
\text { TOC }\end{array}$ \\
\hline Feed Tank & before start of run & $\begin{array}{l}\text { reconstituted feed: } \\
\text { archive only unless } \\
\text { specific reason to } \\
\text { analyze }\end{array}$ & $x$ & $x$ & & $x$ & & & & & & $x$ & $x$ & $x$ & $x$ & $x$ \\
\hline \multirow[t]{5}{*}{ Slurry Recirc } & Prior to nucleation & & & & & $\begin{array}{l}\text { Every } \\
8 \mathrm{hr}\end{array}$ & & & & & & & & & & \\
\hline & $\begin{array}{c}\text { Nucleation to } 10 \\
\text { wt } \% \text { UDS }\end{array}$ & & & & every $8 \mathrm{hr}$ & & & & every $8 \mathrm{hr}$ & & & & & & & \\
\hline & $\begin{array}{c}10 \text { to } 20 w t \% \\
\text { UDS }\end{array}$ & & & & every $2 \mathrm{hr}$ & & & & every $2 \mathrm{hr}$ & & & & & & & \\
\hline & $\begin{array}{c}20 \text { wt } \% \text { UDS to } \\
\text { Steady State }(\sim 30 \\
\text { wt } \% \text { UDS })\end{array}$ & & & every $2 \mathrm{hr}$ & every $1 \mathrm{hr}$ & & & & every $1 \mathrm{hr}$ & & & & & & & \\
\hline & Steady State & & & & & & $\begin{array}{c}\text { every } 8 \\
\mathrm{hr}\end{array}$ & $\begin{array}{l}\text { every } \\
8 \mathrm{hr}\end{array}$ & Every $4 \mathrm{hr}$ & & & & & & & \\
\hline $\begin{array}{l}\text { Slurry Draw- } \\
\text { Off }\end{array}$ & Steady State & & 1 per Test & & & & $\begin{array}{c}\text { as } \\
\text { needed }\end{array}$ & $\begin{array}{c}\text { as } \\
\text { needed }\end{array}$ & & & & & & & & \\
\hline Purge Liquor & $\begin{array}{l}1 \text { at start and } 1 \text { at } \\
\text { end of steady } \\
\text { state portion of } \\
\text { each Test }\end{array}$ & & 2 per Test & & & & & & & & $\begin{array}{l}\text { immediate } \\
\text { dilution }\end{array}$ & $x$ & $x$ & $x$ & $x$ & $x$ \\
\hline $\begin{array}{l}\text { Spent Wash } \\
\text { Tank }\end{array}$ & 1 per Test & & $x$ & & & & & & & & $\begin{array}{l}\text { immediate } \\
\text { dilution }\end{array}$ & & $x$ & $x$ & $x$ & $x$ \\
\hline Cake 3 & 1 per Test $(1,2)$ & & & & & & $\begin{array}{c}\text { as } \\
\text { needed }\end{array}$ & $\mathrm{x}$ & & $\begin{array}{c}\text { as needed } \\
\text { during } \\
\text { centrifuge tests }\end{array}$ & dilution & & $x$ & $x$ & & \\
\hline $\begin{array}{l}\text { LAW Product } \\
\text { Tank }\end{array}$ & $\begin{array}{l}1 \text { per day or per } \\
\text { "batch" (c) }\end{array}$ & $\begin{array}{c}\text { analyze } 1 \text { sample } \\
\text { only per Test }\end{array}$ & $x$ & $x$ & & $x$ & & & & & & & $x$ & $x$ & $x$ & $x$ \\
\hline Condensate & once per day & $\begin{array}{l}\text { archive; analyze } \\
\text { only if warranted }\end{array}$ & & & & & & & & & & & $\mathrm{x}$ & $x$ & & \\
\hline
\end{tabular}


RPP-39091, Rev. 0

RPT-3000755 Rev. 000

Table 2. Abbreviations of Sampling Methods

Method

Abbreviation

\begin{tabular}{|lc|}
\hline Inductively Coupled Plasma - Optical Emission & ICPOES \\
Spectroscopy for elemental analysis & \\
\hline Inductively Coupled Plasma - Mass Spectrometry for Cs & ICPMS \\
\hline lon Chromatography for Anions & ICA \\
\hline Total Solids & TS \\
\hline Undissolved Solids & UDS \\
\hline Polarized Light Microscopy & PLM \\
\hline Crystal Size Distribution & CSD \\
\hline Free Hydroxide & Free OH \\
\hline Trailing Edge- Apparent Settling Volume & TEASV \\
\hline Apparent Settling Volume & ASV \\
\hline Aluminum by Turbidity & - \\
\hline
\end{tabular}

To facilitate recombining LAW and HLW to reconstitute the feed, the LAW product could be sent to any of the feed/product tanks (A, B, C, D). These product samples were identified as $\mathrm{FA}, \mathrm{FB}, \mathrm{FC}$, or FD as were feed samples from the same tank.

Samples were taken during the Baseline test from the Recycle Wash Tank and the Product Dissolver for various analyses. Samples from the centrifuge discharge lines to the SWT and RWT were also taken during the Baseline test. None of these samples were originally in the Analytical Plan.

\subsubsection{Sample Types and Analyses Performed}

The types of samples taken and the analyses typically performed on each type of sample are shown in Table 3. There are differences between these actual sample analyses performed and those that had been originally planned. Both the originally planned analyses and the actual analyses performed are discussed herein.

Occasionally, additional analyses other than those shown in Table 3 were performed. Numerous samples were analyzed for only density or density, total solids, and undissolved solids. The analysis method abbreviations are shown in Table 2 . No samples were taken from the Draw-Off tap on the slurry feed to the centrifuge.

All samples were submitted for one of each analysis. Replicate samples were not submitted except in cases where the validity of results was in question. However additional samples were archived in case repeat or additional analyses were needed. Duplicate analyses at the laboratories were performed and the average concentrations determined were reported. 
Table 3. Sample Types and Analysis

\begin{tabular}{|c|c|c|c|c|}
\hline Sample Description & Sample Location & Abbreviation & $\begin{array}{l}\text { Sam ple Preparation } \\
\text { Method (1) }\end{array}$ & Sample Analyses \\
\hline \multirow[t]{2}{*}{ Feed } & \multirow{2}{*}{$\begin{array}{l}\text { feed tank A or B } \\
\text { bottom drain or dip } \\
\text { sample }\end{array}$} & \multirow{2}{*}{ FA, FB } & none & density \\
\hline & & & none & $\begin{array}{c}\text { density, ICPOES, ICPMS, ICA } \\
\text { (+ initial \& final samples: TS, Free } \\
\mathrm{OH} \text {, Carbonate) }\end{array}$ \\
\hline \multirow[t]{5}{*}{ Crystallizer slurry (Slurry Recirc) } & \multirow[t]{5}{*}{ slurry recirculation line } & \multirow[t]{5}{*}{ SR } & none & density, TS \\
\hline & & & hot filtration - solids & PLM \\
\hline & & & $\begin{array}{l}\text { acetone wash of solids } \\
\text { and drying }\end{array}$ & CSD \\
\hline & & & hot filtration - liquid & density, TS (to give UDS) \\
\hline & & & none & TEASV or ASV \\
\hline Crystallizer salt slurry@ @raw-off line & draw-off line drain & DO & no samples taken & \\
\hline Crystallizer condenser condensate (Condensate) & primary condensate line & $\mathrm{CO}$ & none & density, ICPOES, ICA, pH \\
\hline \multirow[t]{2}{*}{$\begin{array}{l}\text { Centrifuge liquor composite from peels } 1-4 \text { (taken } 5 / 30 \\
@ \sim 13: 00 \text { ) }\end{array}$} & \multirow[t]{2}{*}{$\begin{array}{l}\text { line from centrifuge to } \\
\text { SWT }\end{array}$} & \multirow[t]{2}{*}{$\begin{array}{l}\text { LQ-0530- } \\
1300-B\end{array}$} & none & density \\
\hline & & & $\begin{array}{l}\text { dilution; equal vol. } \\
\text { each peel combined }\end{array}$ & ICPOES, ICPMS \\
\hline \multirow[t]{2}{*}{$\begin{array}{l}\text { Centrifuge liquor composite from peels } 5-8 \text { (taken } 5 / 30 \\
@ \sim 13: 00 \text { ) }\end{array}$} & & \multirow[t]{2}{*}{$\begin{array}{l}\text { LQ-0530- } \\
1300-E\end{array}$} & none & density \\
\hline & & & $\begin{array}{l}\text { dilution; equal vol. } \\
\text { each peel combined }\end{array}$ & ICPOES, ICPMS \\
\hline \multirow[t]{2}{*}{ Spent Wash Tank liquid } & SWT tank dip sample & SW & none & density \\
\hline & & & none & $\begin{array}{c}\text { density, ICPOES, ICPMS } \\
\text { (+ final sample only: TS, ICA, Free } \\
\text { OH, Carbonate) }\end{array}$ \\
\hline \multirow[t]{2}{*}{$\begin{array}{l}\text { Spent Wash Tank washes 1-4 composite sample from } \\
\text { Centrifuge (taken } 5 / 30 @ \sim 16: 00 \text { ) }\end{array}$} & \multirow[t]{2}{*}{$\begin{array}{l}\text { line from centrifuge to } \\
\text { SWT }\end{array}$} & \multirow[t]{2}{*}{$\begin{array}{c}\text { SW-0530- } \\
1300-(C 1-C 4)\end{array}$} & none & density \\
\hline & & & $\begin{array}{l}\text { dilution; equal vol. } \\
\text { each wash combined }\end{array}$ & ICPOES, ICPMS \\
\hline \multirow[t]{2}{*}{$\begin{array}{l}\text { Spent Wash Tank washes } 5-8 \text { composite sample from } \\
\text { Centrifuge (taken } 5 / 30 @ \sim 16: 00 \text { ) }\end{array}$} & & \multirow[t]{2}{*}{$\begin{array}{l}\text { SW-0530- } \\
1300-(C 5-C 8)\end{array}$} & none & density \\
\hline & & & $\begin{array}{l}\text { dilution; equal vol. } \\
\text { each wash combined }\end{array}$ & ICPOES, ICPMS \\
\hline \multirow[t]{2}{*}{ Recycle Wash Tank liquid (slurry) } & \multirow[t]{2}{*}{ RWT tank dip sample } & \multirow[t]{2}{*}{ RW } & none & density \\
\hline & & & dilution & $\begin{array}{c}\text { ICPOES, ICPMS } \\
\text { (+ final sample only: TS, ICA, Free } \\
\text { OH, Carbonate) }\end{array}$ \\
\hline $\begin{array}{l}\text { Recycle Wash Tank washes 1, 2, } 4 \text { composite sample } \\
\text { from Centrifuge (taken } 5 / 30 @ \sim 16: 00 \text { ) }\end{array}$ & $\begin{array}{l}\text { line from centrifuge to } \\
\text { RWT }\end{array}$ & $\begin{array}{l}\text { RW-0530- } \\
1300-C 124\end{array}$ & none & density \\
\hline
\end{tabular}


RPP-39091, Rev. 0

RPT-3000755 Rev. 000

\begin{tabular}{|c|c|c|c|c|}
\hline Sample Description & Sample Location & Abbreviation & $\begin{array}{c}\text { Sam ple Preparation } \\
\text { Method (1) }\end{array}$ & Sample Analyses \\
\hline (wash 3 was missed) & & & $\begin{array}{l}\text { dilution; equal vol. } \\
\text { each wash combined }\end{array}$ & ICPOES, ICPMS \\
\hline \multirow[t]{2}{*}{$\begin{array}{l}\text { Recycle Wash Tank washes } 5-8 \text { composite sample from } \\
\text { Centrifuge (taken } 5 / 30 @ \sim 16: 00 \text { ) }\end{array}$} & $\begin{array}{l}\text { line from centrifuge to } \\
\text { RWT }\end{array}$ & $\begin{array}{l}\text { RW-0530- } \\
1300-(C 5-C 8)\end{array}$ & none & density \\
\hline & & & $\begin{array}{l}\text { dilution; equal vol. } \\
\text { each wash combined }\end{array}$ & ICPOES, ICPMS \\
\hline \multirow[t]{4}{*}{ Product Dissolver Tank slurry } & PD tank dip sample & PD & none & density \\
\hline & & & dilution & $\begin{array}{c}\text { ICPOES, ICPMS } \\
\text { (+ final sample only: TS, ICA, Free } \\
\text { OH, Carbonate) }\end{array}$ \\
\hline & & $\mathrm{PD}(\mathrm{F})$ & $\begin{array}{l}\text { hot filtered - filtrate; } \\
\text { diluted }\end{array}$ & ICPOES, ICPMS, ICA \\
\hline & & $\mathrm{PD}(\mathrm{S})$ & $\begin{array}{l}\text { hot filtered - solids; } \\
\text { diluted }\end{array}$ & ICPOES, ICPMS, ICA \\
\hline \multirow[t]{2}{*}{ Centrifuge Cake (product to PD) } & chute to PD & CK & dilution & ICPOES, ICPMS \\
\hline & & & none & PLM \\
\hline \multirow[t]{2}{*}{ HLW Product (from SWT) } & HLW Tank E (2) & PR or $P R(E)$ & none & density \\
\hline & $\begin{array}{l}\text { bottom drain or dip } \\
\text { sample }\end{array}$ & & none & $\begin{array}{c}\text { density, ICPOES, ICPMS, ICA } \\
\text { (+ final sample: TS, Free OH, } \\
\text { Carbonate) }\end{array}$ \\
\hline \multirow[t]{2}{*}{ LAW Product (from PD) } & Tank C & FC & none & density \\
\hline & $\begin{array}{l}\text { bottom drain or dip } \\
\text { sample }\end{array}$ & & none & $\begin{array}{l}\text { density, ICPOES, ICPMS, ICA } \\
\text { (+ final sample: TS, Free OH, } \\
\text { Carbonate) }\end{array}$ \\
\hline
\end{tabular}

(1) Sample preparation method does not include additional dilution or acidification done by analytical laboratories prior to analyses.

(2) HLW Tank E was incorrectly called the Product Receipt Tank in "Analytical Plan for the Fractional Crystallization Pilot Plant", so the designation was $\mathrm{PR}$ or $\mathrm{PR}(\mathrm{E})$ to emphasize which tank was to be sampled 
RPP-39091, Rev. 0

RPT-3000755 Rev. 000

\subsubsection{Density}

Density measurements were performed on both clear (no undissolved solids) aqueous and slurry samples. Samples from every tank were analyzed. Initially, the density of clear samples was measured using an Anton Paar DMA 4500 density analyzer per ITS-WI-0029 or by weighing a known volume of sample in a precision volumetric flask. During testing operations, it was determined that there was insufficient time to complete all clear liquid densities with the Anton Paar analyzer, so all density measurements were switched to the volumetric flask method.

The Anton Paar analyzer was calibration-checked with deionized water at $25^{\circ} \mathrm{C}$ or $55^{\circ} \mathrm{C}$. The mark on the volumetric flask was based on a fixed temperature of $20^{\circ} \mathrm{C}$. All density measurements by volumetric flask were made with the sample starting at the process temperature; no attempts were made to control temperature during density measurement. A small error $(<0.05 \%)$ in density for samples above $20^{\circ} \mathrm{C}$ was unavoidable but not significant. All density measurements were conducted by PSE staff at EDL.

\subsubsection{Total Solids, Undissolved Solids (TS, UDS)}

Total Solids is the weight percent of the total amount of solids, both dissolved and undissolved, that remains after the sample has been dried at approximately $150^{\circ} \mathrm{C}$. Volatile components of the sample are not accounted for by this method. This analysis was performed using an AND MX-50 Halogen Lamp Moisture Analyzer per ITS-WI-0029. The analyzer was periodically checked by measuring the solids content of a standard $\mathrm{NaCl}$ solution. All solids analyses were conducted by PSE staff at EDL.

Undissolved Solids is the weight percent of the solids that are not dissolved at the conditions at which the sample is filtered. The UDS was measured on slurry samples using the following steps. First, the Total Solids content of the original sample was measured. Another sample, taken at the same time, was kept at the process temperature and hot filtered (in the same way the crystals are prepared for the CSD and PLM measurements). The filtrate was then analyzed for its total solids content, which was called the Supernate Solids, or SS. This filtrate did not need to be kept at the process temperature because the total solids content was independent of temperature. (There will be precipitation of undissolved solids, but this has no effect on the total solids measurement.)

The UDS was then calculated from TS and SS:

$$
\mathrm{UDS}=100 \frac{\mathrm{TS}-\mathrm{SS}}{100-\mathrm{SS}}
$$


Figure 8. Flow Diagram of Sampling

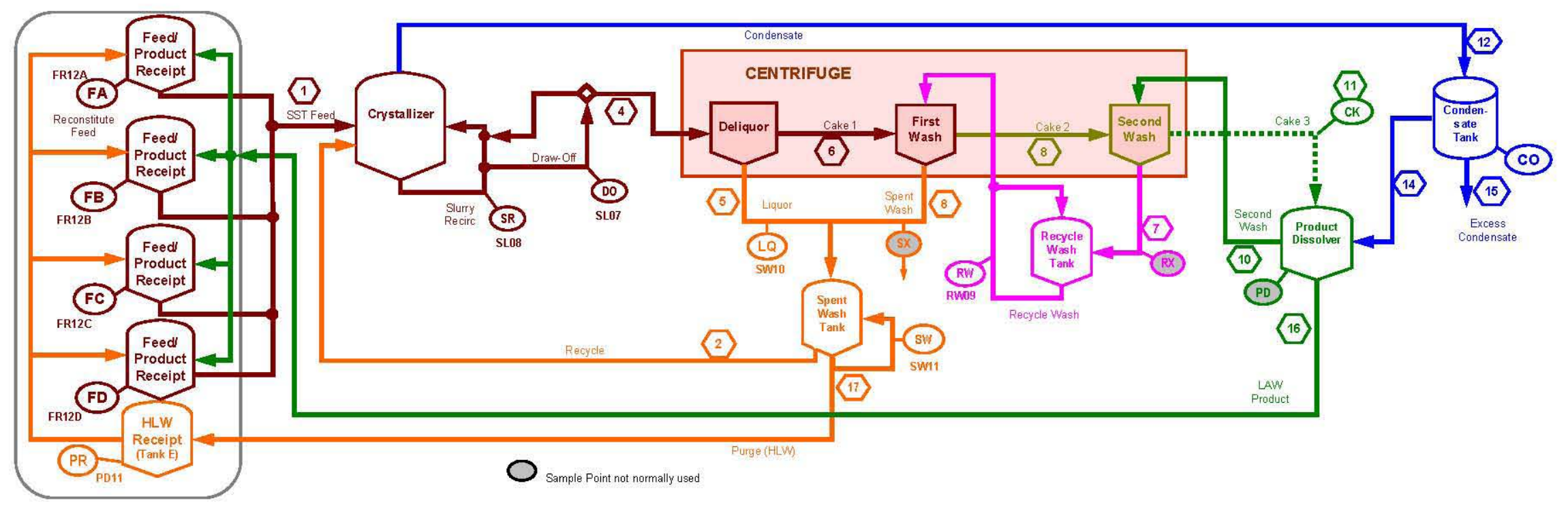


RPP-39091, Rev. 0

RPT-3000755 Rev. 000

\subsubsection{Quick Weight Percent (Wt\%) Undissolved Solids (Q-UDS)}

A quick estimate of the UDS was performed on some Slurry Recirculation samples by filtration of the hot slurry. The sample was taken into an insulated container and then quickly filtered using a 350-mL medium glass frit Buchner filter (Chemglass CG-1402-23). The weights of the filtrate and cake collected were then determined from the final and initial weights of the filter and the filter flask. This method is known to be biased high due to the residual moisture in the filter cake. This process is described in ITS-WI-0026. These measurements were performed by PSE personnel at EDL.

Quick Wt $\%$ UDS $=\frac{(\text { Total Mass of Slurry }- \text { Mass of Filtrate })}{\text { Total Mass of Slurry }}=\frac{\text { Mass of Filter Cake }}{\text { Total Mass of Slurry }}$

\subsubsection{Trailing Edge Apparent Settling Volume / Density (TEASV or ASV/Density)}

The Trailing Edge Apparent Settling Volume (TEASV) and Density were measured by placing a known amount of a Slurry Recirculation sample into a graduated cylinder with volumetric markings. This graduated cylinder was externally heated to maintain the process temperature of nominally $55^{\circ} \mathrm{C}$. These measurements were performed per ITS-WI-0023.

A camera was used to photograph the graduated cylinder at 10 minute intervals for up to four hours. The volume of the settled solids and the total sample volume as a function of time were then determined by manually reviewing the recorded photos. The accuracy of reading the volume in the photos was about $\pm 20 \mathrm{~mL}$; the total volume was typically $180-240 \mathrm{~mL}$ and the final settled volume ranged from $130-$ $210 \mathrm{~mL}$. It was often difficult to determine the location of the actual interfaces between the air and sample and between the settled solids and the clearer liquid. For many samples, there was a foam layer on top of the liquid that was up to $60 \mathrm{~mL}$ volume. The settled solids interface was difficult to determine because this interface was often very indistinct.

The data recorded were entered into spreadsheets to produce plots of settled volume / total volume versus time. After about two weeks of operation, it was obvious that the TEASV curves were linear over the range measured, so only the last data point was plotted for many samples. These measurements were performed by PSE personnel at EDL.

\subsubsection{Crystal Size Distribution}

CSD was measured by separating the dried crystals into size ranges using sieves and a sieve shaker. The sieve shaker used was a Fritsch Analysette Pro 3. The sieves used were Newark stainless steel 3" sieves. The sieve sizes are shown in Table 4. 
RPP-39091, Rev. 0

RPT-3000755 Rev. 000

Table 4. CSD Sieve Sizes.

\begin{tabular}{|c|c|}
\hline Sieve Number & $\begin{array}{c}\text { Nominal Sieve } \\
\text { Opening }(\boldsymbol{\mu m})\end{array}$ \\
\hline 20 & 850 \\
\hline 30 & 600 \\
\hline 40 & 425 \\
\hline 50 & 300 \\
\hline 70 & 212 \\
\hline 100 & 150 \\
\hline 140 & 106 \\
\hline 200 & 75 \\
\hline 270 & 53 \\
\hline 400 & 38 \\
\hline
\end{tabular}

The samples were prepared by hot filtering the Slurry Recirculation sample, followed by washing of the filter cake with acetone. The amount of acetone used was about four times the volume of the filter cake. The acetone washed cake was then vacuum dried for 12-24 hours at about $28 \mathrm{in}$. Hg vacuum. The vacuum drying was followed by oven drying at $110^{\circ} \mathrm{C}$ for several hours. The dried crystals were then gently separated and sieved through an $850 \mu \mathrm{m}$ screen to remove the larger agglomerated particles. The resulting sample was then split evenly into eight fractions using a riffler device. Several sample fractions were then combined to give about $15 \mathrm{~g}$ total sample. This sample was then sieved in the shaker. The sieving process is described in detail in ITS-WI-0025. The amounts of sample collected on each sieve were then used to produce a crystal size distribution plot. This method was performed by PSE staff at EDL.

\subsubsection{Polarized Light Microscopy (PLM)}

PLM was conducted per methods developed at Hanford (HNF-11585, Rev. 0). The microscope used was an Olympus SZX Research Stereomicroscope System outfitted with polarizers, a Red I compensator, and a Pax-It camera and analysis software. Numerous photos of various process samples were taken throughout the tests. PSE and Materials Science \&Technology staff performed all PLM work.

\subsubsection{Aluminum by Turbidity}

The Aluminum by Turbidity method for determining the amount of aluminum in centrifuge cake samples was used for 11 cake samples and also for four feed tank samples. This method was not used after $5 / 17 / 08$ because it appeared to be too insensitive to changes in $\mathrm{Al}$ concentration and the amount of $\mathrm{Al}$ in the cake wash solution from the Product Dissolver was higher than it would be after the process reached steady state with respect to Al. 
RPP-39091, Rev. 0

RPT-3000755 Rev. 000

\subsubsection{Analyses Performed by Savannah River Ecology Laboratory (SREL)}

\subsubsection{Standard and Sample Preparation}

Calibration and Quality Control (QC) solutions were prepared daily from certified stock solutions of single elements and/or custom multi-element blends (Inorganic Ventures, Fisher, Spex CertiPrep, Ultra Scientific and SCP Science). An internal control verification (ICV) created from a different certified stock solution and/or lot as well as blanks were included in daily routine analysis. The calibration and QC solutions were diluted with $>18 \mathrm{~m} \Omega / \mathrm{cm}^{3}$ water (Barnstead NANOpure Diamond Water Purification System) and stabilized in $1 \% \mathrm{v} / \mathrm{v}$ ultra high purity $\mathrm{HNO}_{3}$ (Fisher Scientific Optima Grade) when necessary. Samples diluted for lon Chromatography analysis did not include $\mathrm{HNO}_{3}$ as it interfered with the analysis. QC protocols were followed with different and same dilution replicates, blind standard checks, and spikes at 10 to $20 \%$ the original number of samples.

\subsubsection{Free Hydroxide and Other Base Excluding Carbonate}

\subsection{Instrumentation}

A Radiometer Analytical TitraLab 870 titration workstation was used with a Radiometer combined $\mathrm{pH}$ electrode.

\subsection{Method}

The Free hydroxide and other bases excluding carbonate determination were adopted from Manual L16.1 Procedure ADS-1206 revision 4.

$100 \mu \mathrm{L}$ of sample was transferred into a centrifuge tube containing $2 \mathrm{~mL}$ of $\mathrm{H}_{2} \mathrm{O}$. Approximately $2 \mathrm{~mL}$ of $0.5 \mathrm{M} \mathrm{BaCl}_{2} \cdot 2 \mathrm{H}_{2} \mathrm{O}$ was added and sample was allowed to mix on a Vortex mixer for approximately 30 seconds. The sample was then centrifuged for approximately 2 minutes at $1 / 2$ maximum speed to separate the precipitate. The supernate was then transferred quantitatively into $25 \mathrm{~mL}$ deionized water in a titration sample cup. These prepared samples were then titrated to $\mathrm{pH} 4.0$ against a $0.100 \mathrm{~N} \mathrm{HCl}$ at a $0.1 \mathrm{~mL} / \mathrm{min}$ or $0.01 \mathrm{~mL} / \mathrm{min}$ in a dynamic IP mode, which controls the volume of titrant so that the increment size is inversely proportional to the slope of the titration curve.

Two inflection points were recorded: the first between $\mathrm{pH} 11$ and 8 was equated to the free hydroxide normality; the second inflection point closest to 7.0 was considered to be the normality of the free hydroxide plus the other base excluding carbonate. 
RPP-39091, Rev. 0

RPT-3000755 Rev. 000

\subsubsection{Carbonate by Total Inorganic Carbon (TIC) Measurement}

\subsection{Instrumentation}

A Vacuum filtration apparatus and a vacuum extraction line for carbonate digestions were used for carbonate analysis.

\subsection{Method}

Fifty grams of saturated $\mathrm{BaCl}_{2}{ }^{\star} 2 \mathrm{H}_{2} \mathrm{O}$ solution is added to 20 grams of sample solution under a $\mathrm{CO}_{2}$-free atmosphere to precipitate a Ba-salt that contains carbonate. After 12 hours, the solution is tested by adding a few extra drops of Ba-solution. If no new precipitate is observed the solid may be separated by vacuum filtration using a pre-weighed filter $(0.2 \mathrm{micron})$ and dried to constant weight. The mass of solid is determined by weight difference and the solid is then homogenized with a mortar and pestle. An aliquot of known weight $(\sim 10 \pm 0.005 \mathrm{mg})$ is loaded into an Inconel boat and placed in the sidearm of a common acid bath extraction vessel which is attached to a vacuum extraction line. The sample is digested in orthophosphoric acid, the resulting $\mathrm{CO}_{2}$ is purified cryogenically, and measured manometrically to compute the number of moles of $\mathrm{CO}_{2}$ generated by acid digestion. From this measurement, the percentage of $C$ in the aliquot can be determined accurately and precisely $(+/-1 \%)$ and related to the mass of $C$ in the original liquid sample.

\subsubsection{Inductively Coupled Plasma- Mass Spectrometry (ICPMS)}

ICPMS was used to measure only non-radioactive Cs $\left({ }^{133} \mathrm{Cs}\right)$.

\subsection{Instrumentation}

Cesium analyses were performed using a Perkin-Elmer Sciex Elan DRC Plus inductively coupled plasma mass spectrometer (ICP-MS, Norwalk, CT) in standard operating mode. The sample introduction system was chosen based on the difficulty of the sample matrix (high dissolved solids and low detection limit requirements). Samples were introduced using a Perkin-Elmer AS91 autosampler, Gilson Minipuls 3 peristaltic pump, and a Twister cyclonic spray chamber coupled with a Sea Spray nebulizer (Glass Expansion, West Melbourne, Australia).

\subsection{Method}

Germanium, Yttrium, and Indium were used as internal standards to check for instrument drift and matrix effects on all samples, standards, and blanks. All solutions were manually spiked at $20 \mu \mathrm{g} / \mathrm{L}$.

\subsection{Dilutions}

Dilutions of samples depended on the type of sample delivered (FC, CK, PD, etc.). Initial analysis utilized different dilutions, as expected concentrations were not known 
and concentrations varied by several order of magnitudes. Subsequently, similarity in order of magnitudes for certain types of sample allowed simultaneous analyses in two categories:

$\mathrm{CK}, \mathrm{CO}, \mathrm{PD}(\mathrm{X}): 1,000$ fold dilution

$F(X), L Q, R W, S R, P R, S W: 5,000$ and 10,000 fold dilution.

The instrument detection limit (IDL) was calculated as the average concentration of a blank analyzed 10-12 times throughout an analysis day, plus three times the standard deviation. The IDL for Cs averaged $0.022 \mu \mathrm{g} / \mathrm{L}$.

\subsubsection{Inductively Coupled Plasma- Optical Emission Spectroscopy (ICPOES)}

ICPOES was used by SREL to measure $\mathrm{Na}, \mathrm{Al}, \mathrm{K}, \mathrm{P}, \mathrm{Ca}, \mathrm{Mg}$, and $\mathrm{Si}$. The Process Science Analytical Laboratory (PSAL) and AD laboratory were utilized in addition to SREL for analysis of some samples where additional verification was needed; these labs also analyzed for $S$ by ICPOES.

\subsection{Instrumentation}

A Perkin-Elmer ICPOES Optima series 4300 DV was used providing the ability for simultaneous measurement in both an axial and radial view mode. A Perkin-Elmer AS91 autosampler was used for sample introduction.

\subsection{Method}

Yttrium at $2 \mathrm{mg} / \mathrm{L}$ was used as an Internal Standard to check for matrix effects on all samples, standards, and blanks. It was introduced online to the sample line using a spare channel on the peristaltic pump.

The method for sodium ( $\mathrm{Na}$ ) analysis included adding a Cesium ionization buffer at $1 \% \mathrm{~W} / \mathrm{v}$ for all standards, samples and $\mathrm{QC}$ samples.

\subsection{Dilutions}

Dilutions of samples depended on the element and the type of sample delivered (FC, $\mathrm{CK}, \mathrm{PD}$, etc.). Initial analysis entailed running one element at a time because concentrations were not known and concentrations of specific element varied by several order of magnitudes. Subsequently, relative similarity in concentrations for some elements enabled them to be run simultaneously on one dilution. Elements were divided into 3 groups with dilutions depending on the sample type:

Na: 5000 and 10,000 fold dilution $\mathrm{Al}$ and $\mathrm{K}: 10,20$, and 100 fold dilution.

$\mathrm{Ca}, \mathrm{Mg}, \mathrm{Si}, \mathrm{P}: \mathrm{5}, 10,20$, and 100 fold dilution. 


\subsubsection{Ion Chromatography, Anions (ICA)}

Ion Chromatography for anions (ICA) was used to measure oxalate, nitrate, nitrite, sulfate, phosphate, chloride, and fluoride. Only anions that were soluble in the sample or diluted sample were measured; any solids present were filtered out.

\subsection{Instrumentation}

A Dionex system fitted with a CD20 Conductivity Detector and a chromatography oven was used. The column used is a Dionex IONPAC ${ }^{\circledR}$ AS11-HC 4-mm analytical column preceded with an IONPAC ${ }^{\circledR}$ AG11-HC 2-mm guard column and an ATC-3 4-mm anion ion trap.

\subsection{Method}

Two methods were developed to account for samples matrix and interferences:

$\mathrm{NO}_{2}^{-}$and $\mathrm{NO}_{3}^{-}$

Eluent: $10 \mathrm{mM} \mathrm{NaOH}$

Eluent flow rate: $1.5 \mathrm{ml} / \mathrm{min}$

Sample Volume: $10 \mu \mathrm{L}$

$\mathrm{F}, \mathrm{Cr}, \mathrm{SO}_{4}^{2-}, \mathrm{C}_{2} \mathrm{O}_{4}^{2-}, \mathrm{PO}_{4}^{2-}$

Eluent: $25 \mathrm{mM} \mathrm{NaOH}$

Eluent Flow Rate: $1.5 \mathrm{ml} / \mathrm{min}$

Sample Volume: $10 \mu \mathrm{L}$

\subsection{Dilutions}

Multiple dilutions of samples were necessary to account for differences in order of magnitudes in specific anions concentrations. Typical dilutions were dependent on the sample type:

For $\mathrm{NO}_{2}^{-}$and $\mathrm{NO}_{3}^{-}: 100,1000,5000$ and 10,000 fold dilution

For $\mathrm{F}, \mathrm{Cl}^{-}, \mathrm{SO}_{4}{ }^{2-}, \mathrm{C}_{2} \mathrm{O}_{4}{ }^{2-}, \mathrm{PO}_{4}{ }^{2-}: 25,50,100$ and 1000 fold dilution

\subsubsection{Samples Requiring Immediate Dilution}

Samples requiring immediate dilution to prevent crystallization/precipitation of solids that may form upon cooling were taken from the sample point into a bottle containing sufficient deionized water to dissolve water soluble solids. The amount of deionized water used was typically about $10: 1$ by mass. The mass data were recorded so that the original concentration could be back-calculated. Because the dilutions performed were on a mass basis and the analyses of the diluted samples were reported on a mass per volume $(\mathrm{mg} / \mathrm{L})$ basis, the density of the original and diluted samples were also measured. 


$$
\begin{gathered}
\text { RPP-39091, Rev. } 0 \\
\text { RPT-3000755 Rev. } 000 \\
{[X]_{\text {original }}=[X]_{\text {diluted }} \times \frac{\rho_{\text {sample }}}{W_{\text {sample }}} \times \frac{W_{\text {water }}+W_{\text {sample }}}{\rho_{\text {diluted }}}}
\end{gathered}
$$

\subsubsection{Archive Samples}

Numerous archive samples were taken throughout the tests. All samples analyzed also had a duplicate archive sample taken.

\subsection{SRNL Work Instructions}

The pilot scale testing was performed at the EDL. The testing was conducted following step by step instructions to operate various subsystems of the test facility. The Work Instructions were revised during testing as the test program progressed. The following is a list of all the revisions:

1. Fractional Crystallization Test Facility (U) Work Instruction, ITS-WI0028 Rev. 0, 4-9-2008

2. Fractional Crystallization Test Facility (U) Work Instruction, ITS-WI0028 Rev. 1, 4-14-2008

3. Fractional Crystallization Test Facility (U) Work Instruction, ITS-WI0028 Rev. 2, 4-24-2008

4. Fractional Crystallization Test Facility (U) Work Instruction, ITS-WI0028 Rev. 3, 5-5-2008

These work instructions are organized into sections that address how to run individual subsystems of the test facility. For each testing sequence, a detailed "run" plan identified the specific test objective, parameters of interest, acceptance criteria, and any special precautions to be observed.

The overall operation of the test facility for a particular test was achieved by executing the "run" plan following the instructions for individual subsystems.

While the detailed instructions are documented in above references, Figure 9 is an outline of instructions that provide an organization of instructions. 
Figure 9. Work Instructions Outline

\subsection{PURPOSE}

2.0 SCOPE

3.0 Precautions/Limitations

3.1 Safety Considerations

3.2 PPE Requirements

3.3 Emergency Responses

4.0 Responsibilities
4.1 Acronyms
4.2 Responsibilities
4.2.1 Overall Program Responsibilities
4.2.2 SRNL Staff Responsibilities

\subsection{Pilot Scale Test Facility Description}

5.1 System Overview

5.2 Slurry Loop

5.3 Feed/Receipt Subsystem

5.4 Steam Supply

5.5 Condensate Subsystem

5.6 Centrifuge Subsystem

5.7 Product Dissolver Subsystem

5.8 Recycle Wash Subsystem

5.9 Spent Wash Subsystem

5.10 Cooling Water

5.11 Plant Air

5.12 Process Control

6.0 Data Acquisition
6.1 DAS
6.2 Note Book Records
6.3 Data Sheets/Rounds

7.0 Instructions for Fractional Crystallization Operations

7.1 Condensate System Startup and Shutdown

7.2 Operation of Steam Generator

7.3 Operation of Vacuum System

7.4 Material Transfer/Handling

7.4.1 Filling Feed/Receipt Tanks from Simulant Totes

7.4.2 Filling Crystallizer and Draw off Loop if they are at Atmospheric 
Pressure

7.4.3 Deinventoring Crystallizer

7.4.4 Rinsing Crystallizer

7.4.5 Feed Mixing

7.4.6 Feed Reconstitution on the Fly

7.4.7 Feed Composition Changes

7.4.8 Taking Samples

7.4.9 Preparing Samples

7.4.10 Filling Crystallizer and Draw off Loop Already at Vacuum

7.4.11 Starting Crystallizer Feeding

7.4.12 Feed Tank to Feed Tank Transfer

7.4.13 Initial Fill of Product Dissolver tank

7.5 Process Tanks Startup and Shutdown

7.5.1 Product Dissolver Tank Startup and Shutdown

7.5.2 Recycle Wash Tank Startup and Shutdown

7.5.3 Spent Wash Tank Startup and Shutdown

7.6 Centrifuge Operation

7.6.1 Principal Operational Modes

7.6.2 Recovery and Restart after Excessive Vibration Trip

7.7 Pump Operation

7.7.1 Pump Seal Water System Startup

7.7.2 Draw off pump startup

7.7.3 Seal Water System Shutdown

7.8 Crystallizer Start Up

7.9 Instructions for System Alignment/Start Up

7.10 Crystallizer Shut Down

7.10.1 Partial Shutdown

7.10.2 Full Shutdown

7.10.3 Reflux Mode

7.10.4 Rapid Shutdown

7.11 Crystallizer Vessel Entry Instructions

7.12 Instructions for Abnormal Conditions

7.12.1 Failure of Steam Condensate to Drain from Reboiler

7.12.2 Loss of Cooling Water to Primary Condenser

7.12.3 Loss of Vacuum System

7.12.4 Loss of Recirculation Pump Flow with Failure of Steam Supply Trip

7.12.5 Loss of Crystallizer Level Control

7.12.6 Reboiler Over-Pressurization

7.12.7 Leakage of Chemicals

7.12.8 Loss of Electrical Power

7.12.9 Loss of DAS

7.12 .10

Loss of Plant Air

7.12.11 Loss of Centrifuge Operation

7.12.12 Loss of Condensate Header 


\subsection{Instructions for Fractional Crystallization Tests}
8.1 Pre-Test Inspections
8.2 Post-Test Inspections
8.3 Test Run Plan
8.4 System Boilout with Water
8.5 Benchmark Chemical Tests
8.6 Baseline Chemical Tests
8.7 Feed Variability Tests

\subsection{Attachments}

9.1 Fractions Crystallization Pilot Scale Facility P\&ID

9.2 Equipment List

9.3 Instrumentation List

9.4 Valve List

9.5 Fractional Crystallization Simulant Formula

9.6 Data Sheets/Rounds for Every Shift

9.7 Data Sheets/Rounds for Every Hour

9.8 Chemical Hazards Summary

9.9 Shift Turnover Form

9.10 Test Run Plan

\subsection{Data Acquisition System}

The DAS System was composed of National Instruments $\otimes(\mathrm{NI})$ Signal Processing and Acquisition hardware and NI Labview $B$ DAS software coupled with a Dell Workstation computer.

\subsubsection{DAS Hardware}

Computer:

Dell® Precision WorkStation 690

UltraSharp $® 2408$ WFP 24-inch Widescreen Flat Panel Monitor with Height

Adjustment Stand

UltraSharp $® 1908$ FP 19-inch Flat Panel Monitor with Height Adjustable Stand

Signal Processing and Acquisition Hardware:

National Instruments ${ }^{\circledR}$

SCXI-1001 12-Slot Chassis, U.S. 120 VAC

SCXI-1600, USB Data Acquisition and Control Module

SCXI-1102 32 ch Thermocouple Amplifier (3 Boards)

With SCXI-1303 $32 \mathrm{ch}$ Isothermal Terminal Blocks (3)

SCXI-1124 $6 \mathrm{ch}$ Isolated DAC Module

With SCXI-1325 Screw Terminal Block

SCXI-1161 8-Channel Power Relay Module 
Figure 10. Wiring Schematic of DAS Hookup

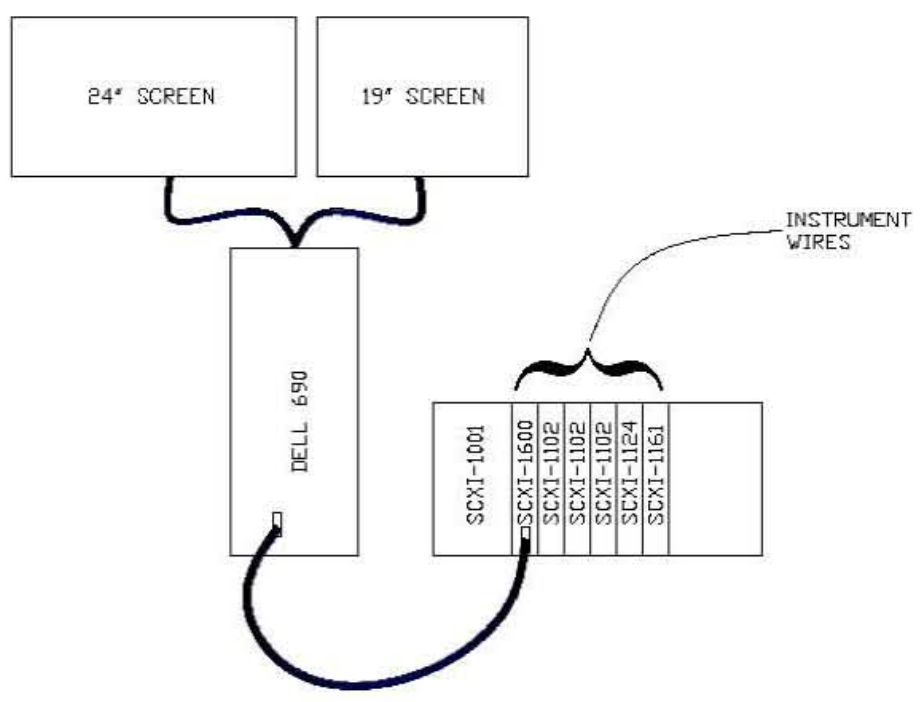

EDL staff developed tables to correlate each instrument with a specific channel on the DAS (Tables 5 and Table 6).

\subsubsection{DAS Software}

EDL used National Instruments® Labview 8.2 Data Acquisition (and Control) Software for the DAS system. Each instrument was calibrated per the following SRNL procedures:

- ITS-0138, M\&TE Calibration and Evaluation Process at Engineering Development Lab.

- Temperature Calibrations-ITS-0139, Comparative Temperature Calibrations at the Engineering Development Lab.

- Pressure Instrumentation-ITS-0140, Calibration of Pressure Measurement Devices Using a Mansfield and Green Pneumatic Weight Tester, Model RK.

Each instrument calibration resulted in mADC output versus sensed variable curve fit. Using this information and the calibration of the DAS system, a scale (transfer function) was developed for each instrument that provided an accurate readout in desired engineering units versus the read signal. These results are shown in Table 7. 
Table 5. DAS Input Channel Allocation List for FC Instruments

\begin{tabular}{|c|c|c|c|c|c|c|}
\hline DAS Chan. & Loop ID \# & Instrument & M\&TE\# & Make & Model/Serial & Calibrated Range \\
\hline 0 & $\mathrm{COO} 1$ & Thermocouple & TR-03858 & Omega & 1/16" , 12"L, Type E, Omega \# GEQSS-116(G)-12 & $32-212 \mathrm{~F}$ \\
\hline 1 & CW01 & Thermocouple & TR-03857 & Omega & 1/16", 12"L, Type E, Omega \# GEQSS- $116(\mathrm{G})-12$ & $32-212 \mathrm{~F}$ \\
\hline 2 & CW03 & Thermocouple & TR-03846 & Omega & 1/16", 12 L, Type E, Omega \# GEQSS- $116(\mathrm{G})-12$ & $32-212 \mathrm{~F}$ \\
\hline 3 & $\mathrm{CO} 10$ & Thermocouple & TR-03908 & Omega & 1/16" $12^{\prime \prime} \mathrm{L}$, Type E, Omega \# GEQSS-116(G)-12 & $32-212 \mathrm{~F}$ \\
\hline 4 & CW06 & Thermocouple & TR-03899 & Omega & 1/16", 12"L, Type E, Omega \# GEQSS-116(G)-12 & $32-212 \mathrm{~F}$ \\
\hline 5 & CW08 & Thermocouple & TR-03901 & Omega & 1/16", 12"L, Type E, Omega \# GEQSS-116(G)-12 & $32-212 \mathrm{~F}$ \\
\hline 6 & CW10 & Thermocouple & TR-03856 & Omega & 1/16", $12 " \mathrm{~L}$, Type E, Omega \# GEQSS- $116(\mathrm{G})-12$ & $32-212 \mathrm{~F}$ \\
\hline 7 & FR03 & Thermocouple & TR-03851 & Omega & 1/16", 12"L, Type E, Omega \# GEQSS-116(G)-12 & $32-212 \mathrm{~F}$ \\
\hline 8 & PD01 & Thermocouple & TR-03862 & Omega & 1/16" $12^{\prime \prime L}$, Type E, Omega \# GEOSS-116(G)-12 & $32-212 \mathrm{~F}$ \\
\hline 9 & RW01 & Thermocouple & TR-03906 & Omega & 1/16", 12"L, Type E, Omega \# GEQSS-116(G)-12 & $32-212 \mathrm{~F}$ \\
\hline 10 & RW05 & Thermocouple & TR-03843 & Omega & 1/16", 12"L, Type E, Omega \# GEQSS-116(G)-12 & $32-212 \mathrm{~F}$ \\
\hline 11 & SL12 & Thermocouple & TR-03845 & Omega & $1 / 16 ", 12 " \mathrm{~L}$, Type E, Omega \# GEQSS-116(G)-12 & $32-212 \mathrm{~F}$ \\
\hline 12 & ST02 & Thermocouple & TR-03904 & Omega & 1/16" $12^{\prime \prime} \mathrm{L}$, Type E, Omega \# GEQSS-116(G)-12 & $32-392 \mathrm{~F}$ \\
\hline 13 & SW01 & Thermocouple & TR-03852 & Omega & 1/16" , 12"L, Type E, Omega \# GEQSS-116(G)-12 & $32-212 \mathrm{~F}$ \\
\hline 14 & SL04 & Thermocouple & TR-03861 & Omega & $1 / 4 ", 12 " \mathrm{~L}$, Type E, Omega \# GEQSS-14(G)-12 & $32-212 \mathrm{~F}$ \\
\hline 15 & ST04 & Thermocouple & TR-03905 & Omega & 1/16" 12 L, Type E, Omega \# GEQSS- $116(\mathrm{G})-12$ & $32-212 \mathrm{~F}$ \\
\hline 16 & ST05 & Thermocouple & TR-03851 & Omega & 1/16", $12^{\prime \prime} \mathrm{L}$, Type E, Omega \# GEQSS-116(G)-12 & $32-212 \mathrm{~F}$ \\
\hline 17 & PD05 & Thermocouple & 03848 destrc & Omega & $1 / 16^{\prime \prime}, 12$ L, Type E, Omega \# GEQSS-116(G)-12 & $32-212 \mathrm{~F}$ \\
\hline 18 & 0 & Thermocouple & 0 & & 0 & 0 \\
\hline 19 & 0 & Thermocouple & 0 & & 0 & 0 \\
\hline 20 & 0 & Thermocouple & 0 & & 0 & 0 \\
\hline 21 & 0 & Thermocouple & 0 & & 0 & 0 \\
\hline 22 & SL10 & Transmitter & TR-03891 & Omega & Omega CDTX $45 \mathrm{~T} 1$ Conductivity analyzer & $0-2 \mathrm{~s} / \mathrm{cm}$ \\
\hline 23 & PD06 & Diff. Press Trans & TR-03490 & Rosemount & Rosemount & $0-100$ in $w c$ \\
\hline 24 & 전요 & Diff prest T & $\mathrm{TR}-03493$ & t & thantant & 0100 in \\
\hline 25 & SL06 & Diff. Press Trans & TR-03691 & Rosemount & Rosemount & $0-200$ in $w c$ \\
\hline 26 & SL08 & Diff. Press Trans & TR-03106 & Rosemount & Rosemount & $0-30$ in wc \\
\hline 27 & SL02 & Diff. T/couple & TR-03889 & Omega & Omega 5TC-GG-E-20-72 & $0-20 \mathrm{C}$ \\
\hline 28 & ST01 & DP across orifice & TR-03688 & Rosemount & Rosemount & $0-30$ in wc \\
\hline 29 & $\mathrm{CO} 11$ & Magnetic FM & TR-03563 & & 0 & $0-2 \mathrm{gpm}$ \\
\hline 30 & $\mathrm{CO} 18$ & Magnetic FM & TR-03677 & & 0 & $0-2 \mathrm{gpm}$ \\
\hline 31 & FR01 & Magnetic FM & TR-03678 & & 0 & $0-2 \mathrm{gpm}$ \\
\hline 32 & PD09 & Magnetic FM & TR-03276 & & 0 & $0-2 \mathrm{gpm}$ \\
\hline 33 & PD10 & Magnetic FM & TR-03704 & & 0 & $0-5 \mathrm{gpm}$ \\
\hline 34 & SW06 & Magnetic FM & TR-03721 & & TR-03721 & $0-2 \mathrm{gpm}$ \\
\hline 35 & SW09 & Magnetic FM & TR-03705 & & TR-03705 & $0-2 \mathrm{gpm}$ \\
\hline 36 & $\mathrm{CO} 12$ & Press Transd & TR-03717 & & : & $0-15$ psia \\
\hline 37 & SL07 & Pressure Trans & TR-03885 & Omega & Omega, PX4200-30VACI & $0-15$ psia \\
\hline 38 & ST06 & Pressure Transd & TR-03883 & Omega & Omega, PX4200-30VACI & $0-15$ psia \\
\hline 39 & PD07 & Ultrasonic & N/A & Omega & Omega LVCN-51 & $0.3-6 \mathrm{ft}$ \\
\hline 40 & RW07 & Ultrasonic & TR-03918 & Omega & Omega LVU91 & $0.3-6 \mathrm{ft}$ \\
\hline 41 & SW07 & 0 & N/A & & Omega LVCN-51 & $0.3-6 \mathrm{ft}$ \\
\hline 42 & SL03 & Ultrasonic FM & TR-03892 & GE & GE TransPort PT 878 & $0-1000 \mathrm{gpm}$ \\
\hline 43 & $\mathrm{COO} 2$ & 0 & TR-03884 & Omega & Omega CDCN-91AC & 0 \\
\hline 44 & SL01 & 0 & $\mathrm{~N} / \mathrm{A}$ & $\mathrm{ABB} / \mathrm{ITT}$ & 0 & $0-20$ amps \\
\hline 45 & SL01 & 0 & N/A & $\mathrm{ABB} / \mathrm{TT}$ & 0 & $0-3550 \mathrm{rpm}$ \\
\hline 46 & SL14 & Magnetic FM & TR-03601 & & TR-03601 & $0-100 \mathrm{gpm}$ \\
\hline 47 & CW02 & Magnetic FM & TR-03687 & & 0 & $0-200 \mathrm{gpm}$ \\
\hline 48 & SL05 & Diff. Press Trans & TR-03493 & Rosemount & Rosemount & $0-100$ in $w C$ \\
\hline 49 & SL15 & Ultrasonic FM & CDS-4714 & & Controllotron System 990 & $0-60 \mathrm{gpm}$ \\
\hline 50 & SL12 & Mass Flow Meter & N/A & Brooks & Brooks flow controller Model \# 58501A1BT 342BEA & $0-20$ SLPM \\
\hline 51 & 0 & 0 & 0 & & 0 & 0 \\
\hline 52 & 0 & 0 & 0 & & 0 & 0 \\
\hline 53 & 0 & 0 & 0 & & 0 & 0 \\
\hline 54 & 0 & 0 & 0 & & 0 & 0 \\
\hline 55 & 0 & 0 & 0 & & 0 & 0 \\
\hline 56 & 0 & 0 & 0 & & 0 & 0 \\
\hline 57 & 0 & 0 & 0 & & 0 & 0 \\
\hline 58 & 0 & 0 & 0 & & 0 & 0 \\
\hline 59 & 0 & 0 & 0 & & 0 & 0 \\
\hline 60 & PD 05 & Switch & 0 & & 0 & On/off \\
\hline 61 & sw05 & Switch & 0 & & 0 & On/off \\
\hline 62 & PD 07 & Switch & 0 & & 0 & On/Off \\
\hline 63 & $\mathrm{CO} 08$ & Switch & 0 & & 0 & On/Off \\
\hline 64 & $\mathrm{CO} 33$ & Switch & 0 & & 0 & On/Off \\
\hline 65 & PD08 & Switch & 0 & & 0 & On/Off \\
\hline 66 & RW05 & Switch & 0 & & 0 & On/Off \\
\hline 67 & SW14 & Switch & 0 & & 0 & On/Off \\
\hline 68 & RW06 & Switch & 0 & & 0 & On/Off \\
\hline 69 & SW09 & Switch & 0 & & 0 & On/Off \\
\hline 70 & SL06 & Switch & 0 & & 0 & On/Off \\
\hline 71 & ALL LAH & Float Switches & 0 & & 0 & On/Off \\
\hline
\end{tabular}


RPP-39091, Rev. 0

RPT-3000755 Rev. 000

Table 6. DAS Output Channel Allocation for FC Instruments

\begin{tabular}{|c|c|c|c|c|c|c|c|c|}
\hline \multicolumn{9}{|c|}{ Analog Out } \\
\hline $\mathrm{AO}-0$ & $\mathrm{AO}-0$ & SV & $\mathrm{CO} 32$ & Output to SV CO32 & Valve Position Input & DAS & 4-20 mA & MR \\
\hline $\mathrm{AO}-1$ & $\mathrm{AO}-1$ & SV & SL12 & Output to SV SL12 & Valve Position Input & DAS & 4-20 mA & MR \\
\hline $\mathrm{AO}-2$ & $\mathrm{AO}-2$ & SV & FR05 & Output to VFD for Pump FR Pump 1 & Speed Control & DAS & 4-20 mA & MR \\
\hline $\mathrm{AO}-3$ & $\mathrm{AO}-3$ & & & Spare Analog Output Channel & & & & \\
\hline $\mathrm{AO}-4$ & $\mathrm{AO}-4$ & & & Spare Analog Output Channel & & & & \\
\hline $\mathrm{AO}-5$ & $\mathrm{AO}-5$ & & & Spare Analog Output Channel & & & & \\
\hline $\mathrm{AO}-6$ & $\mathrm{AO}-6$ & & & Spare Analog Output Channel & & & & \\
\hline $\mathrm{AO}-7$ & $\mathrm{AO}-7$ & & & Spare Analog Output Channel & & & & \\
\hline \multicolumn{9}{|c|}{ Digital Input/Output } \\
\hline DIO-0 & DIO-0 & & & FR05 Power/Leeson VFD 174917 & Power Supply Switch & DAS & NO Contact & MR \\
\hline DIO-1 & DIO-1 & & & Spare Digital Input/Output Channel & & & & \\
\hline DIO-2 & DIO-2 & & & Spare Digital Input/Output Channel & & & & \\
\hline DIO-3 & DIO-3 & & & Spare Digital Input/Output Channel & & & & \\
\hline DIO-4 & $\mathrm{DIO}-4$ & & & Spare Digital Input/Output Channel & & & & \\
\hline DIO-5 & DIO-5 & & & Spare Digital Input/Output Channel & & & & \\
\hline DIO-6 & DIO-6 & & & Spare Digital Input/Output Channel & & & & \\
\hline DIO-7 & DIO-7 & & & Spare Digital Input/Output Channel & & & & \\
\hline
\end{tabular}

The DAS was calibrated per SRNL procedure L9.5-9133. Below are the results of each channel calibration. 


\section{Table 7. DAS Channel Calibrations}

(Calibration check of all DAS channels was done on 1/30/2008)

\begin{tabular}{|c|c|c|c|c|c|c|c|c|c|c|c|c|c|c|}
\hline \multirow{3}{*}{$\begin{array}{l}\text { Temperature } \\
{ }^{\circ} \mathrm{C}\end{array}$} & \multicolumn{14}{|c|}{ Themocouples } \\
\hline & Channel 0 & Channel 0 & Current & Channel 1 & Channel 1 & Temperature & Channel 2 & Channel 2 & Temperature & Channel 3 & Channel 3 & Temperatur & Channel 4 & Channel 4 \\
\hline & T, applied & $T$, reading & & T, applied & $T$, reading & & T, applied & $T$, reading & & T, applied & $T$, reading & ${ }^{\circ} \mathrm{C}$ & T applied & $T$, reading \\
\hline 0 & 0.0 & 0.1 & 0 & 0.0 & 0.1 & 0 & 0.0 & 0.4 & 0 & 0.0 & 0.3 & 0 & 0.0 & 0.2 \\
\hline 25 & 25.0 & 25.1 & 25 & 25.0 & 25.1 & 25 & 25.0 & 25.3 & 25 & 25.0 & 25.2 & 25 & 25.0 & 25.2 \\
\hline 50 & 50.0 & 50.2 & 50 & 50.0 & 50.1 & 50 & 50.0 & 50.3 & 50 & 50.0 & 50.2 & 50 & 50.0 & 50.2 \\
\hline 75 & 75.0 & 75.2 & 75 & 75.0 & 75.1 & 75 & 75.0 & 75.3 & 75 & 75.0 & 75.2 & 75 & 75.0 & 75.2 \\
\hline 100 & 100.0 & 100.2 & 100 & 100.0 & 100.1 & 100 & 100.0 & 100.3 & 100 & 100.0 & 100.2 & 100 & 100.0 & 100.2 \\
\hline 125 & 125.0 & 125.2 & 125 & 125.0 & 125.1 & 125 & 125.0 & 125.3 & 125 & 125.0 & 125.2 & 125 & 125.0 & 125.2 \\
\hline Temperature & Channel 5 & Channel 5 & Temperature & Channel 6 & Channel 6 & Temperature & Channel 7 & Channel 7 & Temperature & Channel 8 & Channel 8 & Temperaturs & Channel 9 & Channel 9 \\
\hline${ }^{\circ} \mathrm{C}$ & T, applied & $T$, reading & & T, applied & $T$, reading & & T, applied & $T$, reading & & T, applied & $T$, reading & & T, applied & $T$, reading \\
\hline 0 & 0.0 & 0.2 & 0 & 0.0 & 0.2 & 0 & 0.0 & 0.2 & 0 & 0.0 & 0.5 & 0 & 0.0 & 0.6 \\
\hline 25 & 25.0 & 25.2 & 25 & 25.0 & 25.2 & 25 & 25.0 & 25.2 & 25 & 25.0 & 25.5 & 25 & 25.0 & 25.5 \\
\hline 50 & 50.0 & 50.2 & 50 & 50.0 & 50.2 & 50 & 50.0 & 50.2 & 50 & 50.0 & 50.5 & 50 & 50.0 & 50.6 \\
\hline 75 & 75.0 & 75.2 & 75 & 75.0 & 75.1 & 75 & 75.0 & 75.2 & 75 & 75.0 & 75.4 & 75 & 75.0 & 75.6 \\
\hline 100 & 100.0 & 100.2 & 100 & 100.0 & 100.1 & 100 & 100.0 & 100.2 & 100 & 100.0 & 100.4 & 100 & 100.0 & 100.6 \\
\hline 125 & 125.0 & 125.1 & 125 & 125.0 & 125.1 & 125 & 125.0 & 125.2 & 125 & 125.0 & 125.4 & 125 & 125.0 & 125.6 \\
\hline Temperature & Channel 10 & Channel 10 & Temperature & Channel 11 & Channel 11 & Temperature & Channel 12 & Channel 12 & Temperature & Channel 13 & Channel 13 & Temperatur & Channel 14 & Channel 14 \\
\hline${ }^{\circ} \mathrm{C}$ & T, applied & $T$, reading & ${ }^{\circ} \mathrm{C}$ & T, applied & $T$, reading & ${ }^{\circ} \mathrm{C}$ & T, applied & $T$, reading & ${ }^{\circ} \mathrm{C}$ & T, applied & T, reading & ${ }^{\circ} \mathrm{C}$ & T, applied & $T$, reading \\
\hline 0 & 0.0 & 0.6 & 0 & 0.0 & 0.7 & 0 & 0.0 & $1.0^{\circ}$ & 0 & 0.0 & 1.0 & 0 & 0.0 & 1.0 \\
\hline 25 & 25.0 & 25.5 & 25 & 25.0 & 25.7 & 25 & 25.0 & 26.0 & 25 & 25.0 & 26.0 & 25 & 25.0 & 25.9 \\
\hline 50 & 50.0 & 50.5 & 50 & 50.0 & 50.7 & 50 & 50.0 & 50.9 & 50 & 50.0 & 50.9 & 50 & 50.0 & 50.8 \\
\hline 75 & 75.0 & 75.5 & 75 & 75.0 & 75.6 & 75 & 75.0 & 75.9 & 75 & 75.0 & 75.9 & 75 & 75.0 & 75.8 \\
\hline 100 & 100.0 & 100.5 & 100 & 100.0 & 100.6 & 100 & 100.0 & 100.9 & 100 & 100.0 & 100.9 & 100 & 100.0 & 100.8 \\
\hline 125 & 125.0 & 125.5 & 125 & 125.0 & 125.6 & 125 & 125.0 & 125.9 & 125 & 125.0 & 125.8 & 125 & 125.0 & 125.8 \\
\hline Temperature & Channel 15 & Channel 15 & Temperature & Channel 16 & Channel 16 & Temperature & Channel 17 & Channel 17 & Temperature & Channel 18 & Channel 18 & Temperatur & Channel 19 & Channel 19 \\
\hline${ }^{\circ} \mathrm{C}$ & T. applied & $T$, reading & ${ }^{\circ} \mathrm{C}$ & T, applied & $T$, reading & ${ }^{\circ} \mathrm{C}$ & T, applied & T, reading & ${ }^{\circ} \mathrm{C}$ & T, applied & T. reading & ${ }^{\circ} \mathrm{C}$ & T. applied & T, reading \\
\hline 0 & 0.0 & 1.1 & 0 & 0.0 & $1.1^{\circ}$ & 0 & 0.0 & $1.1^{\circ}$ & 0 & 0.0 & & 0 & 0.0 & \\
\hline 25 & 25.0 & 26.0 & 25 & 25.0 & 26.1 & 25 & 25.0 & 26.1 & 25 & 25.0 & & 25 & 25.0 & \\
\hline 50 & 50.0 & 50.9 & 50 & 50.0 & 51.1 & 50 & 50.0 & 51.1 & 50 & 50.0 & & 50 & 50.0 & \\
\hline 75 & 75.0 & 75.9 & 75 & 75.0 & 76.0 & 75 & 75.0 & 75.9 & 75 & 75.0 & & 75 & 75.0 & \\
\hline 100 & 100.0 & 100.9 & 100 & 100.0 & 100.9 & 100 & 100.0 & 100.9 & 100 & 100.0 & & 100 & 100.0 & \\
\hline 125 & 125.0 & 125.9 & 125 & 125.0 & 125.9 & 125 & 125.0 & 125.9 & 125 & 125.0 & & 125 & 125.0 & \\
\hline $\begin{array}{l}\text { Temperature } \\
{ }^{\circ} \mathrm{C}\end{array}$ & $\begin{array}{l}\text { Channel } 20 \\
\text { T, applied }\end{array}$ & $\begin{array}{l}\text { Channel } 20 \\
\text { T, reading }\end{array}$ & $\begin{array}{l}\text { Temperature } \\
{ }^{\circ} \mathrm{C} \text {. }\end{array}$ & $\begin{array}{l}\text { Channel } 21 \\
\text { T, applied }\end{array}$ & $\begin{array}{l}\text { Channel } 21 \\
\mathrm{~T} \text {, reading }\end{array}$ & $\begin{array}{l}\text { Current } \\
\mathrm{mA}\end{array}$ & $\begin{array}{l}\text { Channel } 22 \\
\vee \text {, meas. }\end{array}$ & $\begin{array}{l}\text { Channel } 22 \\
\vee \text {, calc. }\end{array}$ & $\begin{array}{l}\text { Current } \\
\mathrm{mA}\end{array}$ & $\begin{array}{l}\text { Channel } 23 \\
\vee \text {, meas. }\end{array}$ & $\begin{array}{l}\text { Channel } 23 \\
\text { V, calc. }\end{array}$ & $\begin{array}{l}\text { Current } \\
\mathrm{mA}\end{array}$ & $\begin{array}{l}\text { Channel } 24 \\
\vee \text {, meas. }\end{array}$ & $\begin{array}{l}\text { Channel } 24 \\
\vee \text {, calc. }\end{array}$ \\
\hline 0 & 0.0 & & 0 & 0.0 & & 4 & 2 & & 4 & 2 & & 4 & & \\
\hline 25 & 25.0 & & 25 & 25.0 & & 8 & 4 & & 8 & 3.99 & & 8 & & \\
\hline 50 & 50.0 & & 50 & 50.0 & & 12 & 6 & & 12 & 5.99 & & 12 & $B A D$ & \\
\hline 75 & 75.0 & & 75 & 75.0 & & 16 & 8 & & 16 & 7.98 & & 16 & & \\
\hline 100 & 100.0 & & 100 & 100.0 & & 20 & 10 & & 20 & 9.98 & & 20 & & \\
\hline Current & Channel 25 & Channel 25 & Current & Channel 26 & Channel 26 & Voltage & Channel 27 & Channel 27 & Current & Channel 28 & Channel 28 & Current & Channel 29 & Channel 29 \\
\hline $\mathrm{mA} \quad 4$ & $\mathrm{~V}$, meas. & $\vee$, calc. & $\mathrm{mA}$ & $\mathrm{V}$, meas. & $\mathrm{V}$, calc & $\mathrm{mVDC}$ & $T$, meas. & $T$, calc. & & $\checkmark$, meas. & $\mathrm{V}$, calc. & $\mathrm{mA}$ & $V$, meas. & $V_{\text {, calc. }}$ \\
\hline & & & 4 & & & & & & 4 & 2 & & 4 & 1.99 & \\
\hline 8 & 3.99 & & 8 & 4.01 & & 0.3 & & & 8 & 3.99 & & 8 & 3.99 & \\
\hline 12 & 5.98 & & 12 & 6.01 & & 0.6 & & & 12 & 5.99 & & 12 & 5.98 & \\
\hline 16 & 7.98 & & 16 & 8.02 & & 0.9 & & & 16 & 7.99 & & 16 & 7.97 & \\
\hline 20 & 9.97 & & 20 & 10 & & 1.3 & & & 20 & 9.98 & & 20 & 9.96 & \\
\hline Current & Channel 30 & Channel 30 & Current & Channel 31 & Channel 31 & Current & Channel 32 & Channel 32 & Current & Channel 33 & Channel 33 & Current & Channel 34 & Channel 34 \\
\hline $\mathrm{mA}$ & $\checkmark$, meas. & $\vee$, calc. & & $V$, meas. & $\vee$, calc. & $\mathrm{mA}$ & $\checkmark$, meas. & $\checkmark$, calc. & $\mathrm{mA}$ & $\checkmark$, meas. & $\checkmark$, calc. & $\mathrm{mA}$ & $\checkmark$, meas. & $\checkmark$, calc. \\
\hline 4 & 1.99 & & 4 & 2 & & 4 & 2 & & 4 & 2 & & 4 & 2 & \\
\hline 8 & 3.99 & & 8 & 3.99 & & 8 & 3.99 & & 8 & 3.99 & & 8 & 3.99 & \\
\hline 12 & 5.98 & & 12 & 5.99 & & 12 & 5.99 & & 12 & 5.99 & & 12 & 5.99 & \\
\hline 16 & 7.98 & & 16 & 7.98 & & 16 & 7.98 & & 16 & 7.98 & & 16 & 7.98 & \\
\hline 20 & 9.97 & & 20 & 9.98 & & 20 & 9.98 & & 20 & 9.97 & & 20 & 9.97 & \\
\hline Current & Channel 35 & Channel 35 & Current & Channel 36 & Channel 36 & Current & Channel 37 & Channel 37 & Current & Channel 38 & Channel 38 & Current & Channel 39 & Channel 39 \\
\hline & $V$. meas. & $\checkmark$, calc. & & $V$, meas. & $\checkmark$, calc. & & $\checkmark$, meas. & $\checkmark$, calc. & & $V$, meas. & V, calc. & $\mathrm{mA}$ & $\checkmark$, meas. & $\checkmark$, calc. \\
\hline 4 & 2 & & 4 & 2 & & 4 & 2 & & 4 & 2 & & 4 & 2 & \\
\hline 8 & 3.99 & & 8 & 3.99 & & 8 & 3.99 & & 8 & 4 & & 8 & 4 & \\
\hline 12 & 5.99 & & 12 & 5.99 & & 12 & 5.99 & & 12 & 6 & & 12 & 6 & \\
\hline 16 & 7.98 & & 16 & 7.98 & & 16 & 7.98 & & 16 & 8 & & 16 & 8 & \\
\hline 20 & 9.98 & & 20 & 9.98 & & 20 & 9.97 & & 20 & 10 & & 20 & 9.99 & \\
\hline Current & Channel 40 & Channel 40 & Current & Channel 41 & Channel 41 & Current & Channel 42 & Channel 42 & Current & Channel 43 & Channel 43 & Current & Channel 44 & Channel 44 \\
\hline & $\checkmark$, meas. & V. calc. & $\mathrm{mA}$ & $\checkmark$, meas. & $\checkmark$, calc. & $\mathrm{mA}$ & $\checkmark$, meas. & $V$, calc. & $\mathrm{mA}$ & $\checkmark$, meas. & $\checkmark$, calc. & $\mathrm{mA}$ & $\vee$ meas. & $\checkmark$, calc. \\
\hline 4 & 2 & & 4 & 1.99 & & 4 & 2 & & 4 & 2 & & 4 & 2 & \\
\hline 8 & 4.01 & & 8 & 3.98 & & 8 & 4 & & 8 & 3.99 & & 8 & 4 & \\
\hline 12 & 6.01 & & 12 & 5.98 & & 12 & 6 & & 12 & 5.98 & & 12 & 6 & \\
\hline 16 & 8.01 & & 16 & 7.97 & & 16 & 8 & & 16 & 7.97 & & 16 & 8 & \\
\hline 20 & 10 & & 20 & 9.96 & & 20 & 10 & & 20 & 9.96 & & 20 & 10 & \\
\hline Current & Channel 45 & Channel 45 & Current & Channel 46 & Channel 46 & Current & Channel 47 & Channel 47 & Current & Channel 48 & Channel 48 & Current & Channel 49 & Channel 49 \\
\hline & $\checkmark$, meas. & $\checkmark$, calc. & $\mathrm{mA}$ & $\checkmark$. meas. & $\checkmark$, calc. & $\mathrm{mA}$ & $\checkmark$. meas. & $\mathrm{V}$, calc. & $\mathrm{mA}$ & $\checkmark$, meas. & $\checkmark$, calc. & $\mathrm{mA}$ & $\checkmark$, meas. & $\checkmark$, calc. \\
\hline 4 & 2 & & 4 & 2 & & 4 & 2.01 & & 4 & 1.99 & & 4 & & \\
\hline 8 & 4 & & 8 & 4 & & 8 & 4.01 & & 8 & 3.99 & & 8 & & \\
\hline 12 & 6 & & 12 & 5.99 & & 12 & 6.02 & & 12 & 5.98 & & 12 & & \\
\hline 16 & 8 & & 16 & 8 & & 16 & 8.02 & & 16 & 7.98 & & 16 & & \\
\hline 20 & 10 & & 20 & 9.99 & & 20 & 10 & & 20 & 9.97 & & 20 & & \\
\hline
\end{tabular}


Table 8. Transfer Functions developed for each Channel on DAS

\begin{tabular}{|c|c|c|c|c|c|}
\hline & & Transfer Functio & DAS (Conversion fr & $\mathrm{aVDC}$ to $\mathrm{E}$ & d Units) \\
\hline DAS Channel & Instrument & Output & Slope (unit/VDC) & & Intercept (Unit) \\
\hline 0 & $\mathrm{CO} 01$ & $\operatorname{deg} F$ & & & \\
\hline 1 & CW01 & $\operatorname{deg} F$ & & & \\
\hline 2 & CW03 & $\operatorname{deg} F$ & & & \\
\hline 3 & $\mathrm{CO} 10$ & $\operatorname{deg} F$ & & & \\
\hline 4 & CW06 & $\operatorname{deg} F$ & & & \\
\hline 5 & CW08 & $\operatorname{deg} F$ & & & \\
\hline 6 & CW10 & $\operatorname{deg} F$ & & & \\
\hline 7 & FR03 & $\operatorname{deg} F$ & & & \\
\hline 8 & PD01 & $\operatorname{deg} F$ & & & \\
\hline 9 & RW01 & $\operatorname{deg} F$ & & & \\
\hline 10 & RW05 & $\operatorname{deg} F$ & & & \\
\hline 11 & SL12 & $\operatorname{deg} F$ & & & \\
\hline 12 & ST02 & $\operatorname{deg} F$ & & & \\
\hline 13 & SW01 & $\operatorname{deg} F$ & & & \\
\hline 14 & SL04 & $\operatorname{deg} F$ & & & \\
\hline 15 & ST04 & $\operatorname{deg} F$ & & & \\
\hline 16 & ST05 & $\operatorname{deg} F$ & & & \\
\hline 17 & PD05 & $\operatorname{deg} F$ & & & \\
\hline 18 & 0 & & & & \\
\hline 19 & 0 & & & & \\
\hline 20 & 0 & & & & \\
\hline 21 & 0 & & & & \\
\hline$\overline{22}$ & SL10 & $\overline{\mathrm{mS} / \mathrm{cm}}$ & 250.0000 & $=\mathrm{xVDC}+$ & -500.0000 \\
\hline 23 & PD06 & in we & 0.5306 & $\mathrm{x}$ VDC + & -0.0596 \\
\hline 24 & SLOS. & in & \#DIV/O! & \#VPC+ & \#DEVO: \\
\hline 25 & SL06 & in we & 25.0501 & $\mathrm{x}$ VDC + & -49.8247 \\
\hline 26 & SL08 & in we & 3.7519 & $\mathrm{xVDC}+$ & -7.5404 \\
\hline 27 & SL02 & $\operatorname{deg} F$ & 29.7652 & $x$ VDC + & -36.3335 \\
\hline 28 & ST01 & in we & 3.7585 & x VDC + & -7.5106 \\
\hline 29 & CO11 & gpm & 0.2542 & x VDC + & -0.5046 \\
\hline 30 & CO18 & gpm & 0.2497 & x VDC + & -0.4952 \\
\hline 31 & FR01 & gpm & 0.2506 & $\mathrm{x}$ VDC + & -0.4989 \\
\hline 32 & PD09 & gpm & 0.2546 & $\mathrm{x}$ VDC + & -0.5078 \\
\hline 33 & PD10 & gpm & 0.6483 & x VDC + & -1.2963 \\
\hline 34 & SW06 & gpm & 0.2570 & $\mathrm{x}$ VDC + & -0.5162 \\
\hline 35 & SW09 & $\mathrm{gpm}$ & 0.2515 & $\mathrm{x}$ VDC + & -0.5035 \\
\hline 36 & $\mathrm{CO} 12$ & psia & 3.7587 & $\mathrm{x}$ VDC + & -7.5060 \\
\hline 37 & SL07 & psia & -1.8805 & x VDC + & 18.7472 \\
\hline 38 & ST06 & psia & 1.8699 & $\mathrm{x}$ VDC + & -3.7499 \\
\hline 39 & PD07 & gallons & 76.7298 & $\mathrm{x}$ VDC + & -240.3978 \\
\hline 40 & RW07 & gallons & 77.0141 & x VDC + & -245.7047 \\
\hline 41 & SW07 & gallons & 78.2501 & x VDC + & -258.8283 \\
\hline 42 & SL03 & gpm & 123.6250 & $\mathrm{x}$ VDC + & -247.2500 \\
\hline 43 & $\mathrm{CO} 02$ & $\mu \mathrm{S} / \mathrm{cm}$ & 125.6627 & $\mathrm{x}$ VDC + & -255.9902 \\
\hline 44 & SL01 & amps & 2.1000 & $\mathrm{x}$ VDC + & -4.2000 \\
\hline 45 & SL01 & $\mathrm{rpm}$ & 450.0000 & $\mathrm{x}$ VDC + & -900.0000 \\
\hline 46 & SL14 & gpm & 12.6223 & $\mathrm{x}$ VDC + & -25.0668 \\
\hline 47 & CW02 & gpm & 24.5897 & x VDC + & 49.3739 \\
\hline 48 & SL05 & Sp. Gr. & 0.3913 & $\mathrm{x}$ VDC + & 0.2170 \\
\hline 49 & SL15 & gpm & 6.0069 & $\mathrm{xVDC}+$ & 0.0979 \\
\hline 50 & SL12 & slpm & 2.5000 & x VDC + & -5.0000 \\
\hline 51 & 0 & & & $\mathrm{x}$ VDC + & \\
\hline 52 & 0 & & & $\mathrm{x}$ VDC + & \\
\hline 53 & 0 & & & $\mathrm{x}$ VDC + & \\
\hline 54 & 0 & & & $\mathrm{x}$ VDC + & \\
\hline 55 & 0 & & & $\mathrm{x}$ VDC + & \\
\hline 56 & 0 & & & $\mathrm{x}$ VDC + & \\
\hline 57 & 0 & & & $\mathrm{x}$ VDC + & \\
\hline 58 & 0 & & & $\mathrm{x}$ VDC + & \\
\hline 59 & 0 & & & x VDC + & \\
\hline 60 & PD05 & On/Off & & x VDC + & \\
\hline 61 & SW05 & On/Off & & $\mathrm{x}$ VDC + & \\
\hline 62 & PD07 & On/Off & & $\mathrm{x}$ VDC + & \\
\hline 63 & CO08 & On/Off & & $\mathrm{x}$ VDC + & \\
\hline 64 & $\mathrm{CO} 33$ & On/Off & & x VDC + & \\
\hline 65 & PD08 & On/Off & & $\mathrm{x}$ VDC + & \\
\hline 66 & RW05 & On/Off & & $\mathrm{x}$ VDC + & \\
\hline 67 & SW14 & On/Off & & $\mathrm{x}$ VDC + & \\
\hline 68 & RW06 & On/Off & & x VDC + & \\
\hline 69 & SW09 & On/Off & & x VDC + & \\
\hline 70 & SL06 & On/Off & & x VDC + & \\
\hline 71 & ALL LAH & On/Off & & $\mathrm{x}$ VDC + & \\
\hline
\end{tabular}


RPP-39091, Rev. 0

\subsubsection{DAS Pictures}

Figures 11 and 12 are examples of the DAS screens available to operating staff.

Figure 11. Main DAS Screen

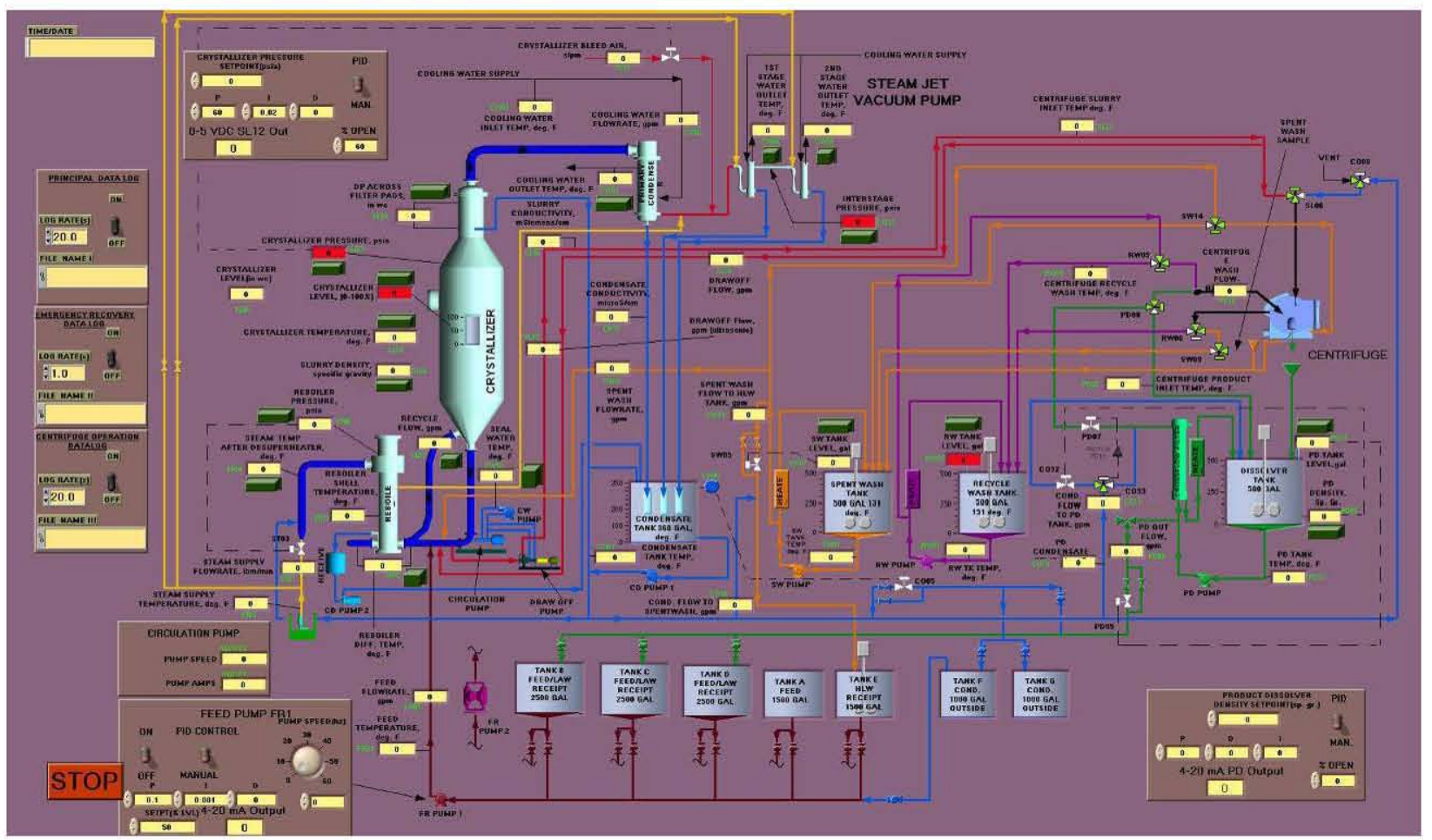

The main screen displayed digital values of all DAS instrumentation. Solenoid valve positions were also indicated by color change (green open, white closed). Tank levels in the PD, RW, and SW tanks were also displayed as an analog fill line. Additional displays on the main DAS screen included control panels for the FR Pump 1 (main simulant feed pump), SL12 (bleed air upstream of steam jet pumps, and PD tank density (controlled through valve $\mathrm{CO} 32$ condensate addition to PD Tank). Three dialog boxes provided file name and location, frequency (seconds between logging), and status of three separate data logs.

In addition to the main DAS screen, a trending screen was provided to display critical parameter changes historically. This was useful in trending system operations.

Figure 12 shows a trending screen without the charted values displayed. 
Figure 12. Trend Chart Screen on Additional Monitor for the FC Test Rig DAS.

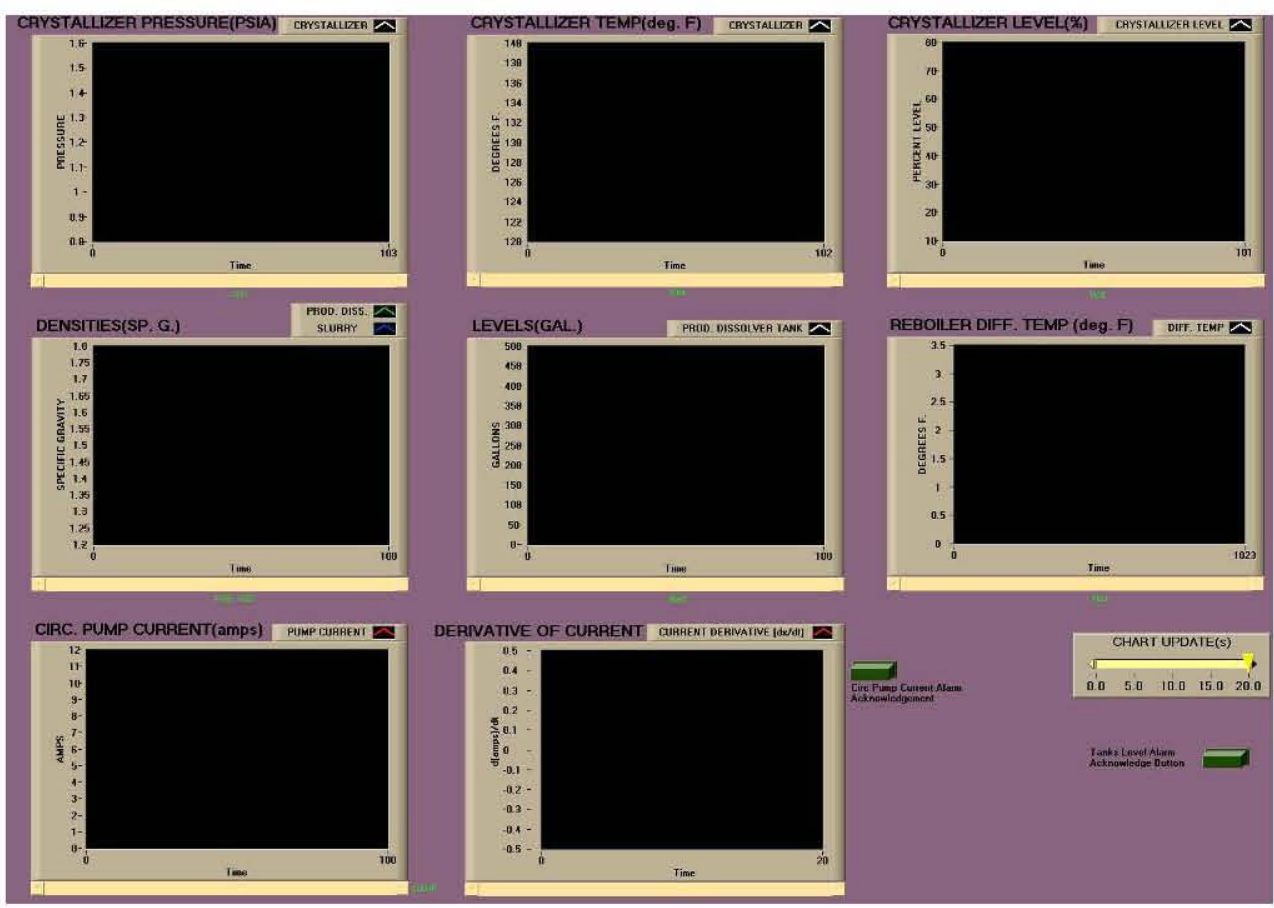

Additionally, Figures $13 \mathrm{~A}$ through $13 \mathrm{E}$ show the hardware installation.

Figure 13. DAS Hardware Installation.

Figure 13A

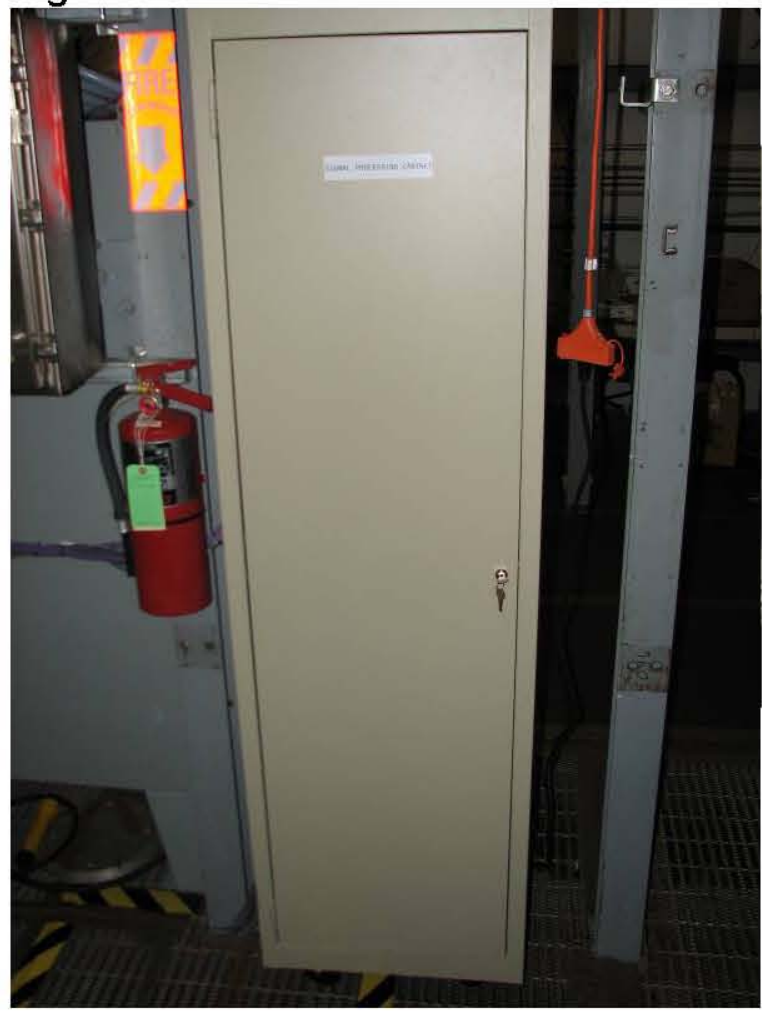

Figure 13B

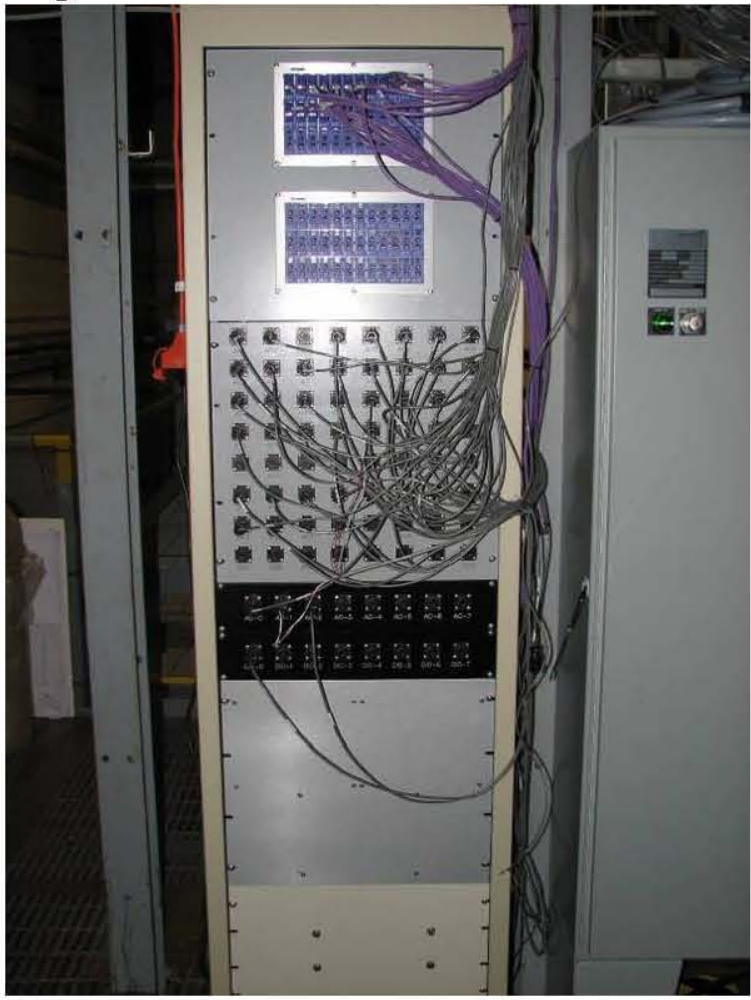


Figure 13C

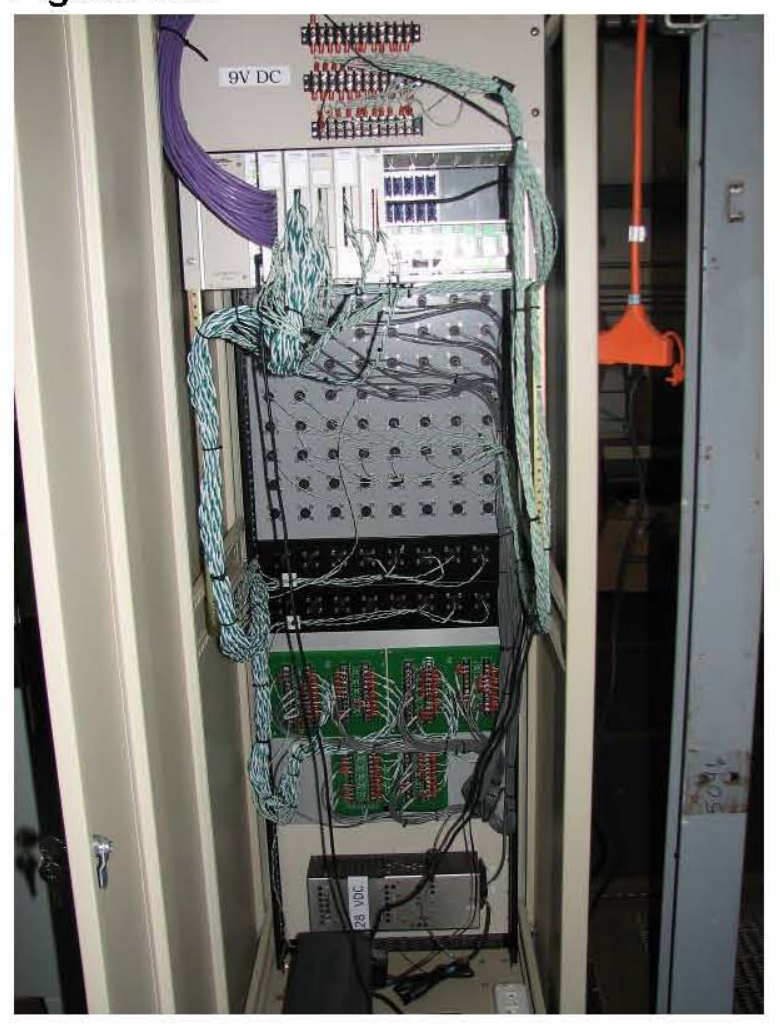

Figure 13D

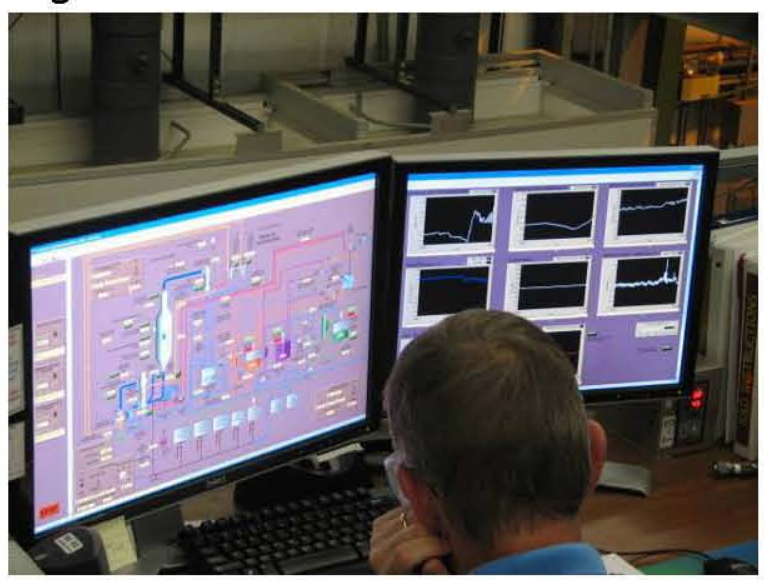

Figure 13E

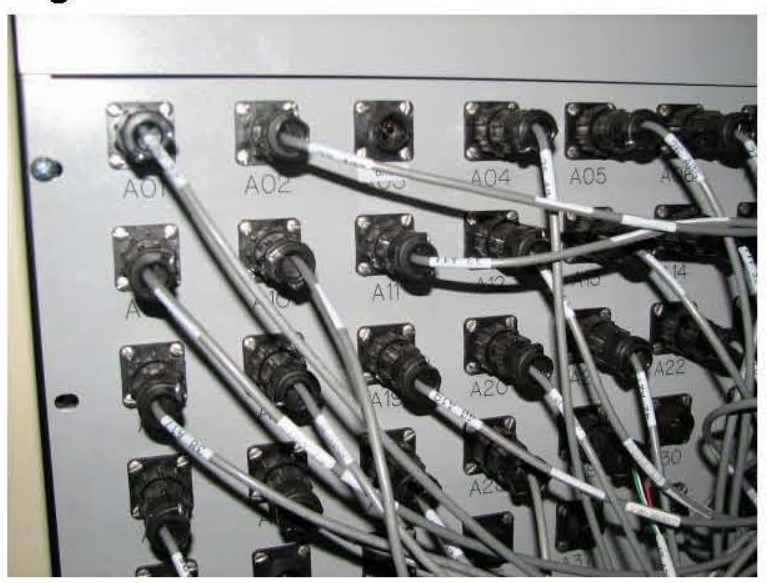

\subsubsection{DAS References}

- P\&ID, latest version

- SRNL Procedure L9.5-9133

- ITS-0138, M\&TE Calibration and Evaluation Process at Engineering Development Lab

- Temperature Calibrations-ITS-0139, Comparative Temperature Calibrations at the Engineering Development Lab

- Pressure Instrumentation-ITS-0140, Calibration of Pressure Measurement Devices Using a Mansfield and Green Pneumatic Weight Tester, Model RK.

\subsection{FCPP Training}

Training the EDL engineers and operators was an important part of the FCPP test planning because the process fundamentals and some of the pilot equipment, e.g. centrifuge and crystallizer, were new to the existing staff. A two-phase approach 
was adopted. The first phase was vendor training for the EDL engineers followed by vendor presentations to the operators. The second phase was called "in-house" training conducted by EDL staff and the training was focused on the implementing procedures the operators would use during the tests.

\subsubsection{Vendor Training}

Initial vendor training for EDL staff was conducted December 11 and 12, 2007 by Swenson. The focus of the training was the theory and operation of the crystallizer system and theory and operation of the centrifuge. The Swenson draft "Operating Instructions" for the crystallizer was reviewed with the staff because they would become the basis for EDL "Work Instructions" used for day-to-day operations. Following classroom training staff assembled in the EDL to become familiar with the actual hardware during installation. The second vendor training was conducted February 26, 27, and 28, 2008 and included Swenson along with two Field Engineers from Krauss Maffei Process Technology (KMPT) who discussed the theory and operation of the centrifuge. During this time the centrifuge was operated for the first time (using only water) to check machine functions and load the latest software modifications in the centrifuge PLC.

\subsubsection{In-House Training}

In addition to the vendor training described above, EDL performed in-house training based upon the vendor training material as well as Work Instructions written specifically to operate the Pilot-Scale Test Facility. The training was conducted by the $\mathrm{PI}$ and the Lead Designer of the Test Facility. The following staff received this training:

1. Four Test Engineers

2. Four Laboratory Technicians

3. Four other Support Engineers

The training was performed in two phases:

1. Classroom training based upon the Work Instructions and Vendor Material.

2. Practical Factors: This included hands-on training on the centrifuge and a detailed facility walkdown.

All the training material was prepared and documented in accordance with the guidelines provided by the SRNL Training Group. 
RPP-39091, Rev. 0

RPT-3000755 Rev. 000

\subsection{TEST EXECUTION AND RESULTS}

The testing period was initiated April 17, 2008 when initial benchmark tests began and was concluded on May 31, 2008 upon completion of the baseline testing. Benchmark testing was performed from April 17 through May 20, 2008. Baseline testing was begun on May 20 immediately after cesium nitrate addition to the $\mathrm{FC}$ feed stream and continued through May 31, 2008.

The baseline objectives of a cesium DF of at least 50 and the sodium reporting to the product stream were attained. Actual operations during benchmark testing produced an average product cake cesium DF of 130 and an average product dissolver cesium DF of 58. The difference between the cesium DF determined in the product dissolver vs. the filter cake was the result of cesium contaminated liquor overflow from the centrifuge to the product dissolver. The estimated sodium yield based on overall mass balances during the period May 28 through May 31 was approximately $52 \%$.

Due to operational and instrumentation difficulties, it was necessary to operate the process in a manual mode throughout the test period. Manual operation of crystallizer pressure and level resulted in large fluctuations in crystallizer temperature and slurry density which reduced the efficiency of the centrifuge operation and reduced throughput of the system. In addition, the failure of the crossflow filter in the product dissolver circuit allowed fines to be recycled to the centrifuge, further reducing centrifuge capacity.

While manual operations stretched the test engineer's capabilities and response times, the overall system functioned acceptably with some periods of stable operations.

\subsection{Benchmark Testing}

Benchmark testing consisted of adjusting parameters to produce crystals that allowed for easy dewatering and efficient washing of the centrifuge cake, adjusting centrifuge parameters to consistently deliquor and wash process crystals, and perform shutdown tests to demonstrate the ability to shutdown or idle the system and return the system to normal operations.

Acceptance criteria for successfully completing Benchmark Testing included:

- The system should operate smoothly to produce crystals that allow for easy dewatering (deliquoring) and efficient washing of the centrifuge cake.

- From previous laboratory simulant work, the dominant crystal (sodium nitrate) should have a CSD mode size in the range of 300 to 450 microns.

- The centrifuge should cycle (spin, wash, \& discharge) smoothly in an automatic mode while producing an easily removable cake.

- The crystallizer system should shutdown safely to a condition that facilitates restart of the system. 
The pilot system was mainly operated in manual control because of instrumentation problems. Even so, operators were able to control the most important system parameters, i.e. temperature and pressure in the crystallizer and various system flows and tank levels. The burkeite and sodium carbonate crystals remained small, as observed in previous laboratory testing, and were slow to dissolve in the Product Dissolver Tank. Slow dissolution had been evaluated by the earlier laboratory work so the EDL staff had designed a cross-flow filter system to remove the "fines" (generally considered to be crystals in the 10 micron range). However the unit soon became unusable due to low permeability and was removed from service. The slurry CSD was checked on a regular basis and confirmed a primary mode size in the range of 300 to 450 microns. Problems in the centrifuge feed system (from the slurry draw-off loop) resulted in erratic centrifuge operation. However once the system was reconfigured the centrifuge was able to operate in an automatic mode to control the feed, spin, wash, and discharge cycles. As noted above operational problems caused unplanned shutdowns, but the system was easily restarted.

Due to operational difficulties, primarily related to the centrifuge production capacity, pilot feed rates were limited to one-half or less of the design rate. When operating at low feed rates, other plant parameters were adjusted accordingly. The reduced pilot feed rates were used throughout the remainder of testing and are presented in Table 9.

\subsubsection{Crystallizer Loop}

The crystallizer loop performed as anticipated and crystals formed as predicted, i.e., burkeite (a sodium double salt containing sulfate and carbonate) formed first followed by sodium carbonate monohydrate, followed by sodium nitrate and then other sodium salts. Due to the non-functionality of the cross-flow filter in the Product Dissolver Tank, the small crystals were continually recycled to the centrifuge and crystallizer and impacted the overall crystal size distribution in the crystallizer and, may have impacted centrifuge solids separation and decontamination capability.

Based on earlier model projections and experiments, the key operating conditions and parameters for the crystallizer loop were identified in the test plan and are included in Table 10 below. 
RPP-39091, Rev. 0

RPT-3000755 Rev. 000

Table 9. Reduced Pilot Feed Rates

\begin{tabular}{|c|c|c|c|c|c|}
\hline & $\begin{array}{l}\text { Control } \\
\text { Valve }\end{array}$ & Flowmeter & $\begin{array}{c}\text { Flowsheet } \\
\text { based on } \\
\text { expected } \\
\text { centrifuge } \\
\text { performance }\end{array}$ & $\begin{array}{c}\text { Flowsheet } \\
\text { based on actual } \\
\text { centrifuge } \\
\text { performance }\end{array}$ & Notes \\
\hline Centrifuge Cycle, sec & & & 240 & 961 & \\
\hline Number of cycles & & & 50 & 8 & \\
\hline Total cleanout time, min & & & 2 & 30 & \\
\hline Wash 1 instantaneous flow & & & 5.00 & 3.50 & \\
\hline Wash 2 instantaneous flow & & & 5.00 & 3.10 & \\
\hline Cake/cycle (Ib) & & & 27 & 29.6 & 1 \\
\hline Cake (lb/min) & & & 6.61 & 1.50 & \\
\hline Crystallizer Feed Rate & & & 1.50 & 0.34 & \\
\hline Wash 1 duration/cycle, sec & & & 23 & 36 & \\
\hline Wash 1 average flow & & & 0.47 & 0.11 & \\
\hline Wash 2 duration/cycle, sec & & & 22 & 40 & \\
\hline Wash 2 average flow & & & 0.46 & 0.10 & \\
\hline Condensate to PD Tank & $\mathrm{CO} 32$ & Co11 & 0.56 & 0.13 & 2 \\
\hline PD Product (average) & & & 0.53 & 0.12 & \\
\hline $40 \%$ of PD Product & PD04 & PD09 & 0.21 & 0.05 & 3 \\
\hline $80 \%$ of PD Product & PD06 & PD09 & 0.42 & 0.10 & 3 \\
\hline Condensate added to make LAW & & & 0.42 & 0.10 & \\
\hline $40 \%$ of cond added to LAW & $\mathrm{CO03}$ & $\mathrm{CO} 24$ & 0.17 & 0.04 & 4 \\
\hline $80 \%$ of cond added to LAW & $\mathrm{COO4}$ & $\mathrm{CO} 24$ & 0.34 & 0.08 & 4 \\
\hline SW recycle to crystallizer & SW07 & Sw09 & 1.30 & 0.29 & 5 \\
\hline SW Product (average) & & & 0.29 & 0.07 & \\
\hline Flow through valve SWO4 & SW04 & SW06 & 0.12 & 0.03 & 6 \\
\hline Flow through valve SW06 & SW06 & SW06 & 0.23 & 0.05 & 6 \\
\hline Condensate to make HLW & $\mathrm{CO} 31$ & Co18 & 0.29 & 0.07 & 7 \\
\hline Steam (lb/min) & ST03 & ST01 & 11.0 & 2.5 & \\
\hline
\end{tabular}

Notes:

1 This is determined based on the peel start height averaged over all the cycles between heel removals.

2 This flow should be controlled to maintain the PD tank specific gravity at 1.44 . Unfortunately, valve CO32 leaks through about $0.12 \mathrm{gpm}$, so it will be necessary to close valve $\mathrm{CO} 35$ if the flow needs to be stopped completely.

At very low flow rates there is not much point in trying to set the flow through valve PD06. Simply set the flow through valve

3 PD04 to about $0.30 \mathrm{gpm}$, and let the PD tank level controller stop and start flow as necessary to maintain level in the tank. Unfortunately, the level control tends to give false highs when the level is either too high or too low, so it may be necessary to manually shut off the flow to prevent draining the tank.

At very low flow rates there is not much point in trying to set the flow through valve CO04. Simply set the flow through valve

$4 \mathrm{CO} 03$ to about $0.30 \mathrm{gpm}$, and let the Condensate tank level controller stop and start flow as necessary to maintain level in the tank.

5 Unfortunately, at very low flows the recycle line tends to plug, so it may be necessary to flush it occasionally with a high flow (or condensate) and then reset the desired flow.

At very low flow rates there is not much point in trying to set the flow through valve SW06. Simply set the flow through valve SW04 to about $0.30 \mathrm{gpm}$, and let the SW tank level controller stop and start flow as necessary to maintain level in the tank.

6 Unfortunately, the level control tends to give false highs when the level is either too high or too low, so it may be necessary to manually shut off the flow to prevent draining the tank.

7 The centrifuge cleanout procedure adds more than enough water into the SW tank, so flow through valve CO31 is not actually needed. 
Table 10. Test Plan Initial Key Operating Conditions/Parameters

\begin{tabular}{|c|c|c|c|c|}
\hline Parameter & Units & Minimum & Nominal & Maximum \\
\hline $\begin{array}{l}\text { Recirc Pump } \\
\text { Flow Rate } \\
\text { (SL03) }\end{array}$ & $\mathrm{gpm}$ & 550 & 600 & 650 \\
\hline $\begin{array}{l}\text { Recirc Pump } \\
\text { Speed (SL01) }\end{array}$ & $\mathrm{rpm}$ & TBD & 1907 & TBD \\
\hline $\begin{array}{l}\text { Feed Flow } \\
\text { Rate (FR01) } \\
\end{array}$ & $\mathrm{gpm}$ & 0.5 & 1.5 & 2.0 \\
\hline $\begin{array}{l}\text { Reboiler Shell } \\
\text { Side Steam } \\
\text { Pressure } \\
\text { (ST06) }\end{array}$ & psia & 2 & 12.8 & 14.7 \\
\hline $\begin{array}{l}\text { Reboiler Inlet } \\
\text { Steam Temp } \\
\text { (ST04) }\end{array}$ & ${ }^{\circ} \mathrm{F}$ & 50 & 96 & 100 \\
\hline $\begin{array}{l}\text { Slurry Reboiler } \\
\text { Delta T (SL02) }\end{array}$ & ${ }^{\circ} \mathrm{F}$ & 0 & 2 & 3 \\
\hline $\begin{array}{l}\text { Crystallizer } \\
\text { Level (SL06) }\end{array}$ & $\%$ & 20 & 50 & 80 \\
\hline $\begin{array}{l}\text { Crystallizer } \\
\text { Pressure } \\
\text { (SLO7) }\end{array}$ & psia & 0.97 & 1.35 & 1.74 \\
\hline $\begin{array}{l}\text { Slurry Density } \\
\text { (SL05) }\end{array}$ & SpG & 1 & 1.6 & 2 \\
\hline $\begin{array}{l}\text { Slurry Temp in } \\
\text { Crystallizer } \\
\text { (SLO4) }\end{array}$ & ${ }^{\circ} \mathrm{F}$ & 131 & 140 & 149 \\
\hline
\end{tabular}

Benchmark testing demonstrated that the recirculation pump flow rate and speed were controllable, even operating the equipment in the manual mode. The same was true for the slurry reboiler inlet steam temperature control and control of the differential temperature across the slurry reboiler. However, due to the non-steady state of the overall FC system, control of the feed flow rate, crystallizer level and pressure, and the slurry level within the crystallizer required constant attention to maintain process control. The causes for non-steady state operations include lower than planned centrifuge feed rates, plugged lines, varying crystal size distribution causing centrifuge solids separation difficulties, instrumentation difficulties, and test engineers undergoing the learning curve.

The following graphs demonstrate the variability in parameter conditions during normal operations of the crystallizer loop during the later stages (May 16 beginning at 1409 hours through May 18 at 1055 hours) of benchmark testing when operations were considered more stable, but not steady state. 
RPP-39091, Rev. 0

Figure 14. Graph of Crystallizer Temperature and Pressure

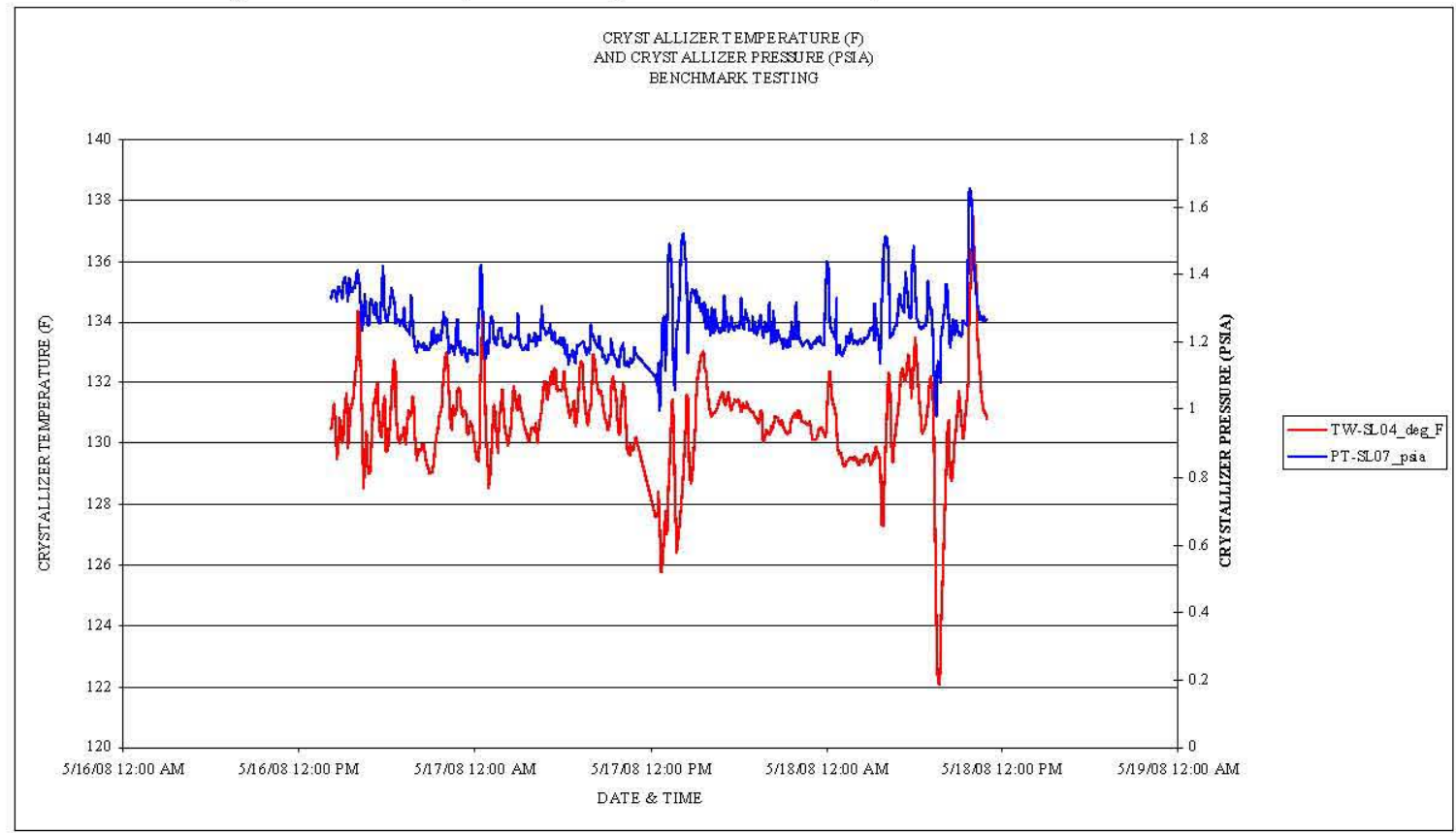

Figure 14 indicates that small fluctuations in manual pressure control $( \pm 0.25$ psia $)$ resulted in large changes in crystallizer temperature $\left( \pm 10^{\circ} \mathrm{F}\right)$ due to raising and lowering the boiling point pressure and temperature. A sudden drop in boiling point temperature causes a drop in solubility of sodium nitrate resulting in the nucleation of fine particles. Fine sodium nitrate crystals reduce the efficiency of the centrifuge by creating a low permeability filter cake.

Figure 15. Graph of Reboiler Steam Temperature, Delta T and Pressure

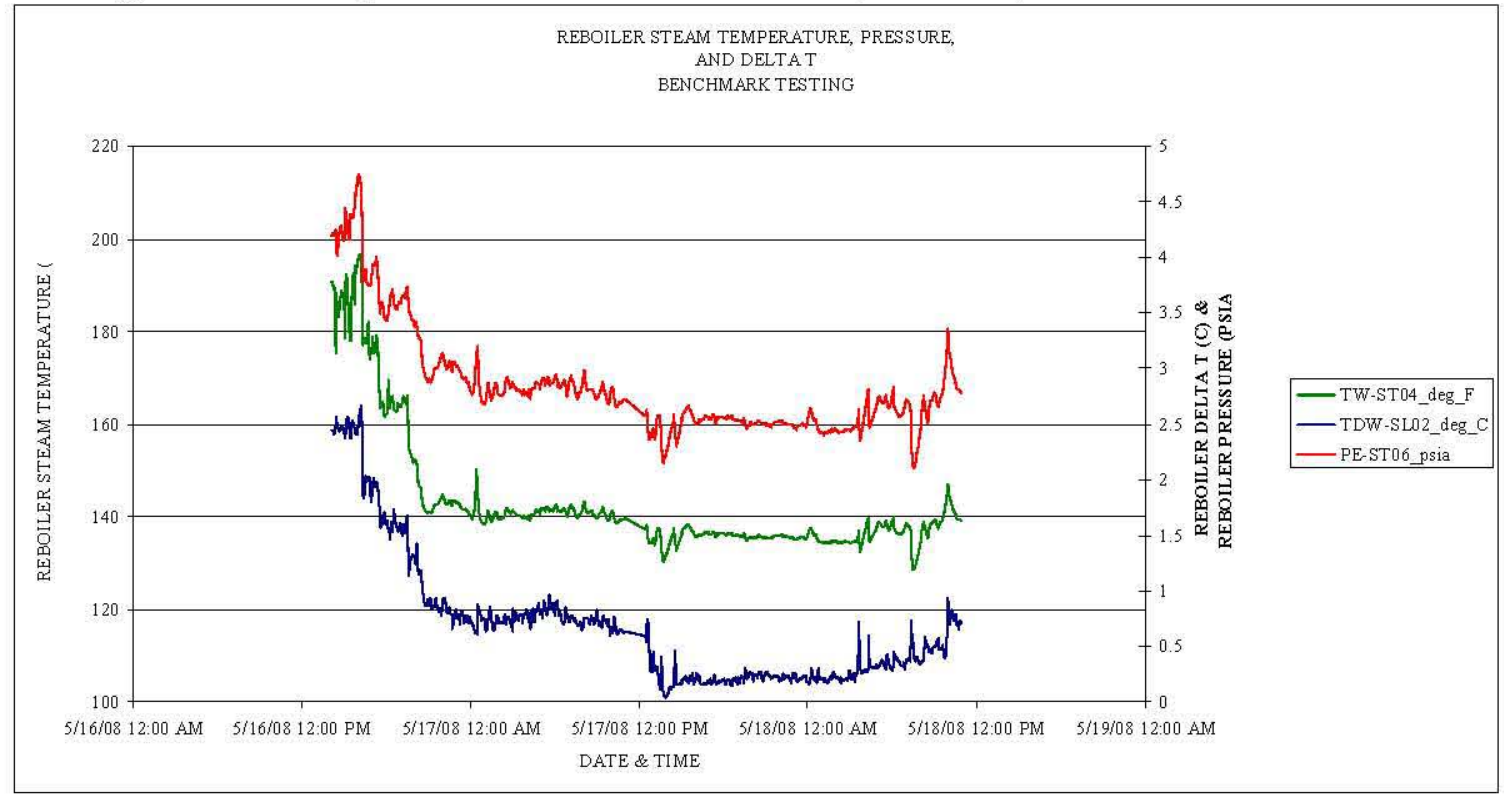


Figure 15 indicates that reboiler steam temperature and pressure and the process heating rate $(\Delta T)$ responded normally. The steam condensed at its saturation temperature at the shell operating pressure; heat transferred to the process in direct proportion to the temperature difference between the steam and the process.

Figure 16. Graph of Crystallizer Level and Slurry Density

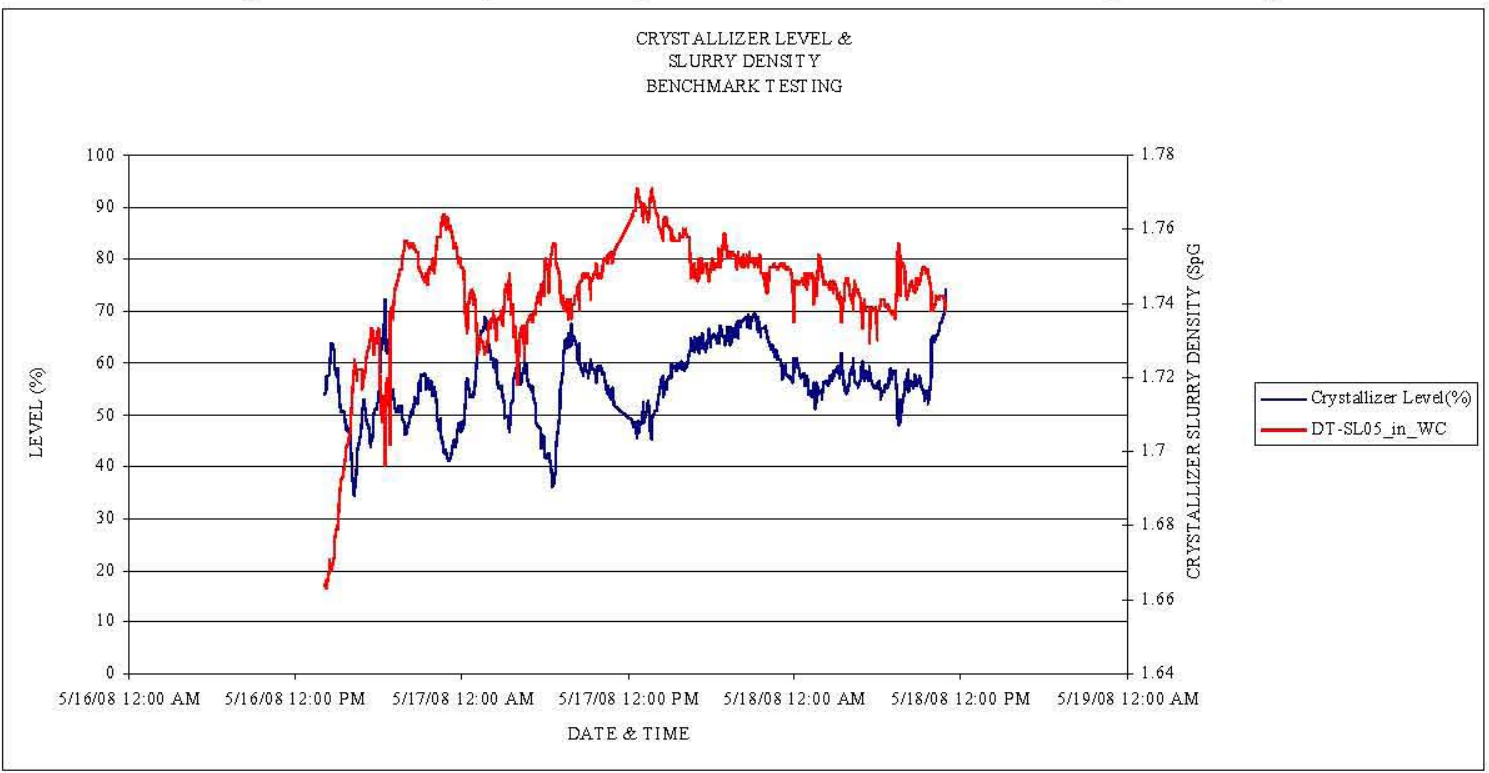

Figure 16 indicates that the crystallizer density had an opposite response to the crystallizer level. When the level was low, slurry density was high. When the level was high, slurry density was low. This effect indicates an imbalance between the feed and the evaporation rates caused by manual control of the crystallizer level and reboiler steaming rate.

Although slurry density varied by only $3.5 \%(1-1.76 / 1.70=3.5 \%)$ during this period, measurements of undissolved solids (solids/total mass) varied by $10 \%(50 \pm 5 \%)$. This indicates that small variations in slurry density (caused by dilution, evaporation, and/or temperature swings) caused large variations in the crystal mass in the crystallizer. Rapid changes in crystal mass results in poor crystal size distribution and morphology and poor solid/liquid separation. 
RPP-39091, Rev. 0

Figure 17. Graph of Crystallizer Circulation Pump Flowrate and Speed

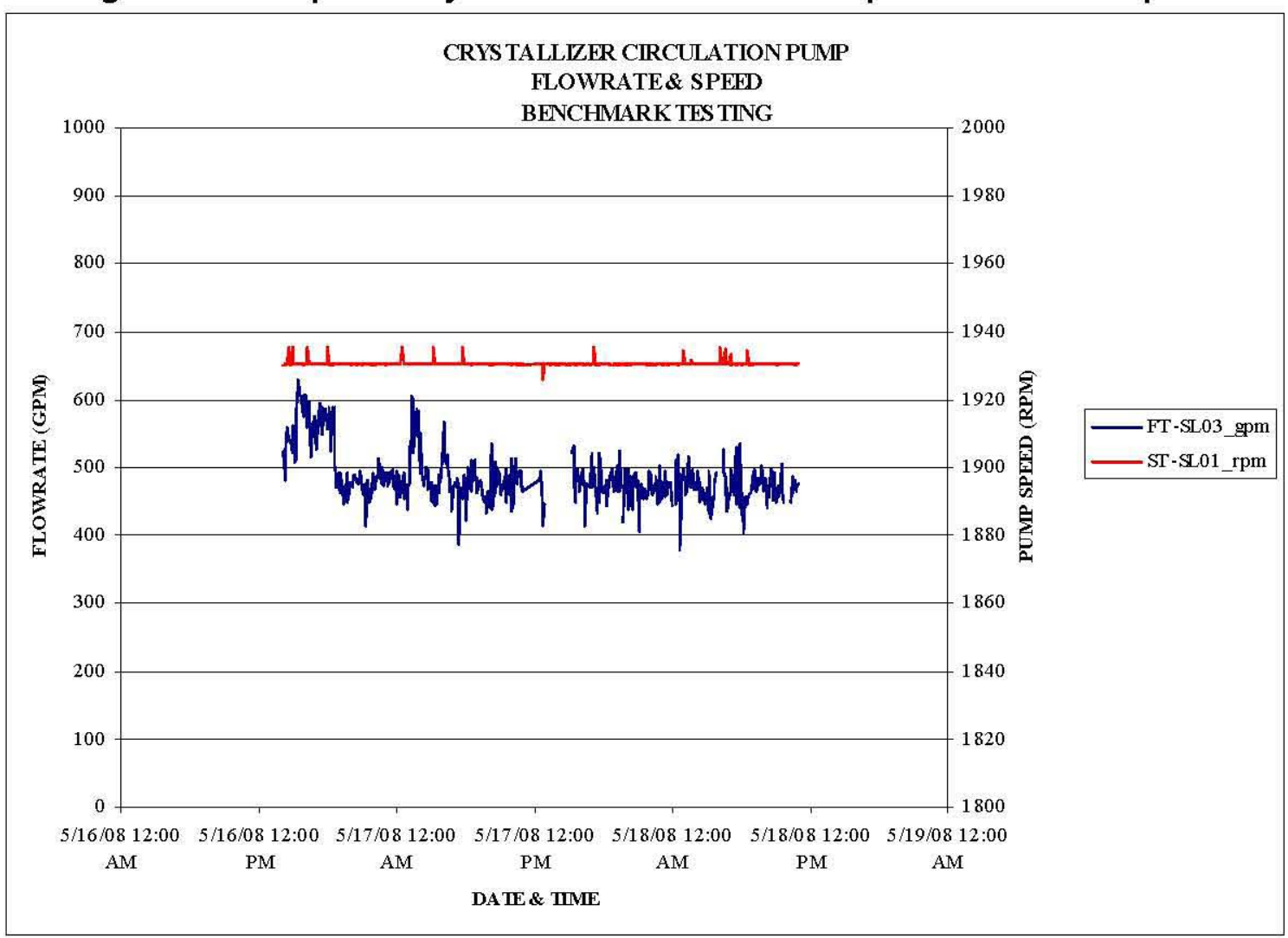

The crystallizer circulation pump flowrate and speed were set at a constant flowrate of $600 \mathrm{gpm}$ and $1907 \mathrm{rpm}$ per the test plan. Figure 17 indicates a relatively constant actual flow rate of about $500 \mathrm{gpm}$. The pump speed was consistently about $1930 \mathrm{rpm}$. This indicates that the fluid in the crystallizer was pumpable and didn't exert undo stress on the pump. It is unknown why the flowrate was lower and speed was higher but both are within the operating limits for the pump.

\subsubsection{Centrifuge Loop}

During the early stages of benchmark testing, numerous problems occurred in the centrifuge loop. Those problems included feed line blockages, overfeeding or slugging the centrifuge such that feed materials overflowed the centrifuge into the discharge lines during centrifuge operations, difficulties with salt cake removal and centrifuge plugging. Numerous changes were made to the centrifuge loop to correct these problems; restrictor valves and line flushes were installed and tested to reduce pluggage of the feed line and allow the proper feed volume to be charged to the centrifuge such that slugging of the centrifuge was minimized or eliminated, proper cleaning cycles and frequencies were determined to assure adequate heel removal and more automatic mode operations, the salt cake discharge chute was modified to include a Teflon liner to enhance the dry solids discharge from the centrifuge during the peel step and better attention to the slurry feed density was identified as a requirement to provide a uniform feed stream to the centrifuge. 
Again choosing the later stages of the benchmark testing (May 16 to May 18) as the period for final benchmark testing, most if not all of the problems encountered early in the testing had been resolved such that extended centrifuge loop operations could occur. During the final testing the operating conditions were generally stable with some intermittent process upsets and recovery periods. The slurry feed density variability and the amount of fines in the feed resulting from the failure of the crossflow filters impacted extended centrifuge operations. During the final benchmark testing the centrifuge was operated for between 9 and 12 batches before heel removal was required. Before cake removal, each batch received 2 wash cycles of between 6 and 10 seconds each. During the testing period the centrifuge loop received only one emergency shutdown and this was due to the peel knife being stuck at the $2 \mathrm{~mm}$ peel position which caused excessive vibration and automatic shutdown.

Figure 18. Product Dissolver Density

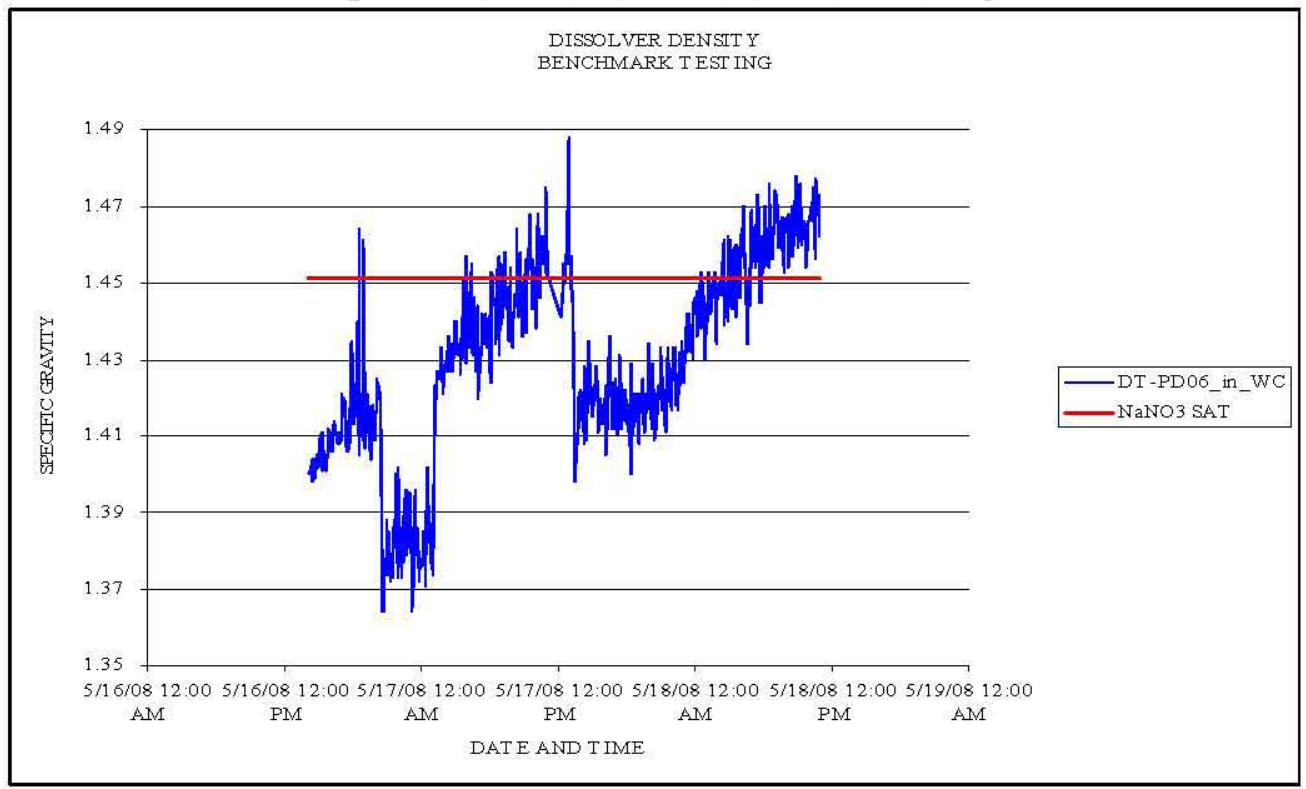

Figure 18 shows a wide variation in product dissolver density during benchmark testing because of manual control of the dissolution water feed rate. The set point for product dissolver density was 1.45 , the saturation point for sodium nitrate at $131^{\circ} \mathrm{F}$. At a density of 1.45 , the wash solution recycled to the centrifuge does not dissolve sodium nitrate in the centrifuge cake. At lower density, the wash solution partially dissolves the centrifuge cake thereby reducing yield, crystal size distribution, cake permeability, and the extent of deliquoring.

Centrifuge cake permeability was further reduced by the recycle of entrained fines from the dissolver product because of the failure of the cross-flow filter. At a density of 1.45 , sodium sulfate and carbonate are supersaturated and are entrained in the centrifuge wash solution. The recycled fines reduce cake permeability and the extent of cake deliquoring. 
RPP-39091, Rev. 0

RPT-3000755 Rev. 000

\subsubsection{Support Systems}

Support systems to the FC Pilot Plant included SRNL provided HVAC, condenser cooling water and plant air. No proven problems were identified with these systems. It was thought that the cooling water flow rates decreased about 0300 and 1500 every day causing pilot process swings but investigations provided no data to support this theory.

\subsubsection{Sample Drawing and Analysis}

Changes and additions made to the analytical plan have been previously described in Section 3.2. In this section, the general frequencies of samples and analyses are described for the Benchmark test.

From startup of the crystallizer on 4/16/08 at 1200 hours (hrs) until the occurrence of crystal nucleation, slurry recirculation (SR) samples were taken periodically and analyzed for density, total solids (TS), and undissolved solids (UDS). Nucleation of sodium carbonate monohydrate and burkeite occurred much more quickly than anticipated (4/16/08 $1800 \mathrm{hrs})$, so the sampling frequency was not switched to that specified for the time period from nucleation until $30 \mathrm{wt} \%$ UDS was reached. Due to confusion about the definition of nucleation, this switch was not made until 4/18/08 at $1700 \mathrm{hrs}$. Nucleation had been assumed to mean nucleation of the sodium nitrate, which had not yet occurred. It was decided that nucleation would mean any crystal species that had nucleated. On 4/16/08 at $2000 \mathrm{hrs,} \mathrm{the} \mathrm{UDS} \mathrm{in} \mathrm{the} \mathrm{crystallizer} \mathrm{was}$ about 4 wt $\%$.

At 4/18/08 $1700 \mathrm{hrs}$, the SR samples began to be analyzed by TEASV at a $2 \mathrm{hr}$ frequency. TS and UDS were also analyzed at a $2 \mathrm{hr}$ frequency. Occasional PLM samples were also taken. At this time the UDS in the crystallizer was about $11 \mathrm{wt} \%$. At about 2100 hrs on 4/18/08, the UDS jumped from about 14 to $36 \mathrm{wt} \%$ and remained at 36-45 wt\% until the system was shut down on 4/19/08 at about 1700 hrs.

The FC system was restarted on $4 / 25 / 08$ at $1200 \mathrm{hrs}$. Sampling SR began and samples were analyzed for density, TS, and UDS. On 4/26/08 at $0800 \mathrm{hrs}$ TEASV and TS/UDS samples were taken at 2 hour intervals and CSD samples were taken at $4-8$ hour intervals.. On $4 / 26 / 08$ at 0800 hrs the UDS in the crystallizer was about $20 \mathrm{wt} \%$. The CSD frequency was switched to 8 hours on $4 / 27 / 08$ at $0800 \mathrm{hrs}$.

On 5/1/08 at $1200 \mathrm{hrs,}$, regular SW density samples, occasional cake samples, and a daily PD archive sample were started. On 5/7/08at $2100 \mathrm{hrs}$, the first daily RW density sample was taken. These samples were continued until 5/10/08 at $0600 \mathrm{hrs}$ when a pump seal failure forced the system to be shut down.

Several typical TEASV plots are shown in Figure 19. Note that the data for $5 / 5 / 08$ go to about 330 minutes versus 240 minutes for the other plots. For most plots made, only the last data point was graphed because the data was very close to linear over the 4 hour interval. These data do show that the settling rate did increase from 
$5 / 2 / 08$ to $5 / 4 / 08$ and that after restart, on $5 / 14 / 08$ the settling rate was about the same as it was on $5 / 5 / 08$.

Figure 19. Typical TEASV Plots

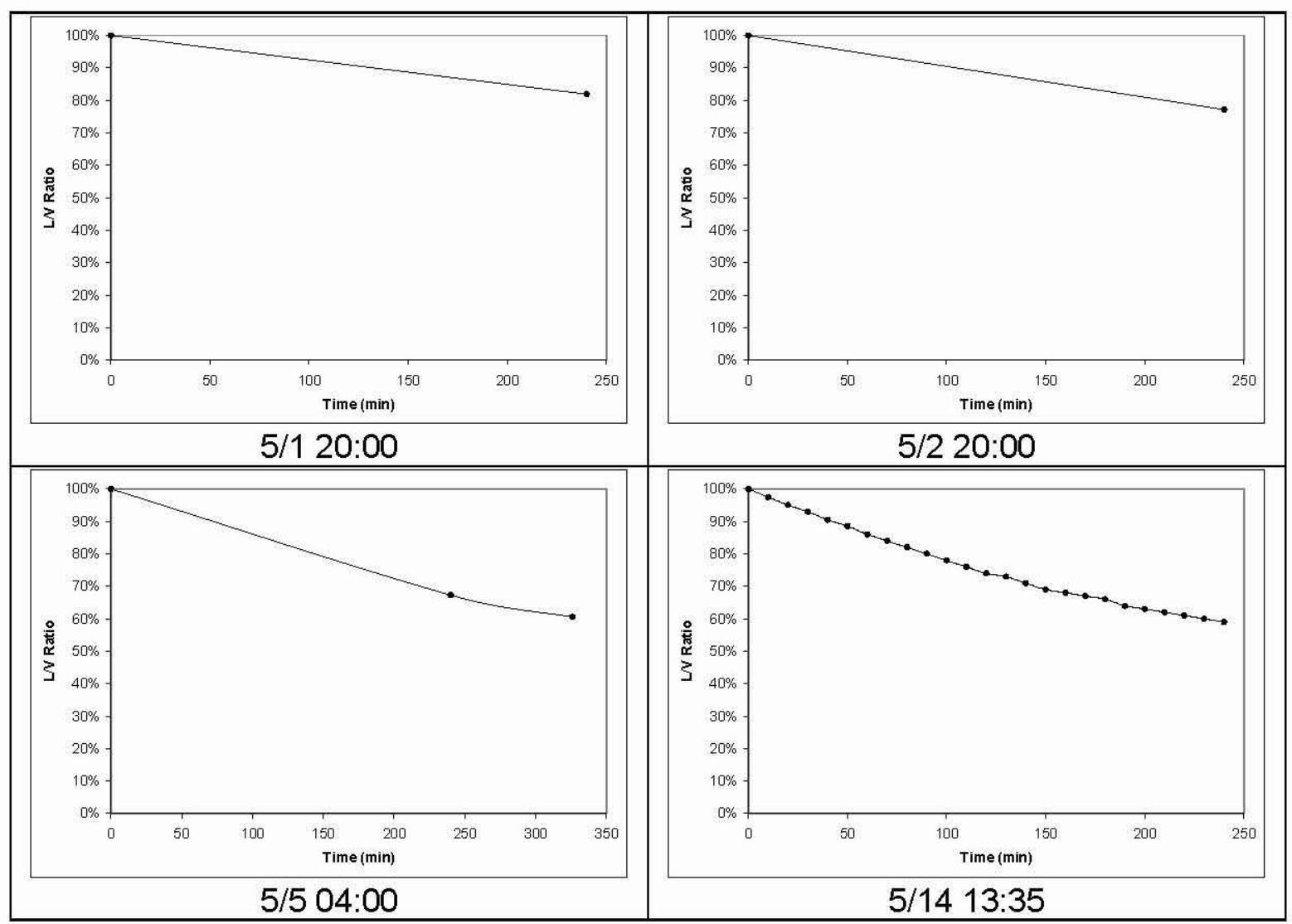

The system was again restarted on 5/16/08 at $1900 \mathrm{hrs}$ and SR sampling and analysis for density and TS/UDS began at $2100 \mathrm{hrs}$. On 5/17/08 at $1400 \mathrm{hrs}$, regular 4 hour SW samples for density were begun. The SR samples were analyzed for TEASV for 4 hour duration at 4 hour intervals, density was measured every 2 hours, CSD samples taken every 8 hours, PLM samples every 2-4 hours, and TS/UDS and Quick UDS samples every 4 hours. RW samples were taken once per day and analyzed for density. These sampling frequencies were maintained until the Baseline test began on $5 / 20 / 08$.

CSD was performed on 74 washed, dried slurry recirculation (SR) samples and two $\mathrm{CK}$ samples. Of the SR samples, 25 were taken during the baseline testing and 49 during the benchmark testing. The data shown below are for the entire test, both benchmark and baseline. The mean CSD of all the SR samples is shown in Figure 20 along with the maximum and minimum percentages at each sieve size and the average \pm 1 standard deviation. Typical CSD plots for maxima at 300,425 , and $600 \mu \mathrm{m}$ are also shown. The CSD maximum location for each sample is shown in the last graph. A value of 513 was plotted for samples where the wt $\%$ at 425 and $600 \mu \mathrm{m}$ were approximately equal. 
Figure 20. Average CSD for Slurry Samples
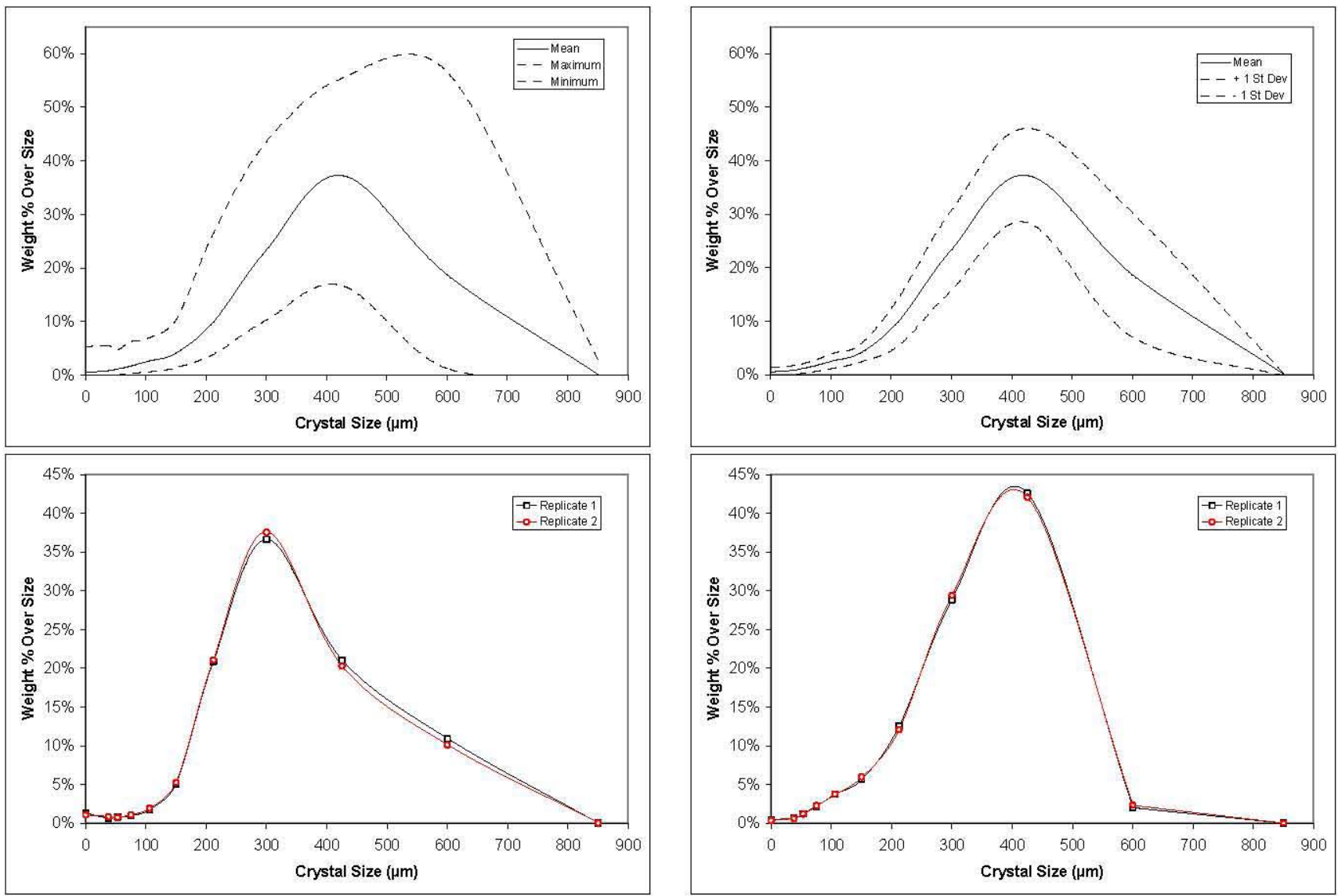

\section{SR-0428-1000; maximum at $300 \mu \mathrm{m}$}

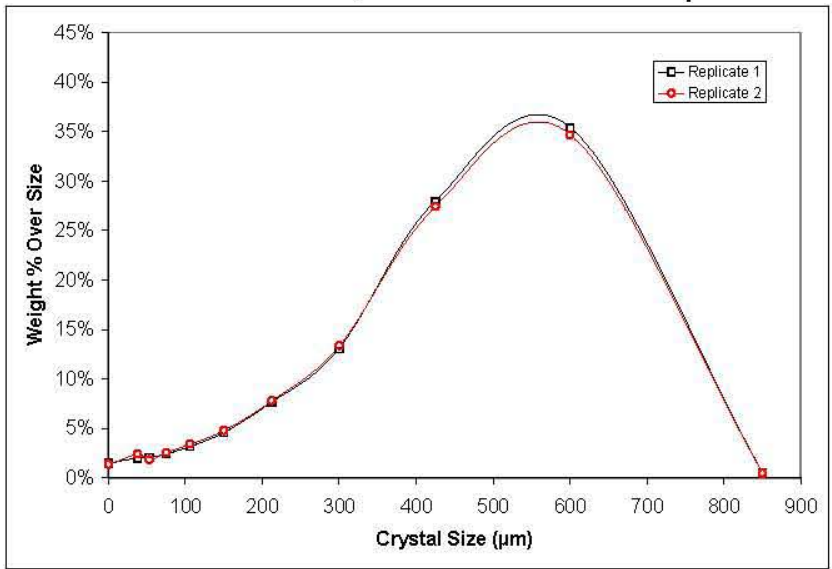

SR-0509-0200; maximum at $600 \mu \mathrm{m}$

\section{SR-0505-1000; maximum at $425 \mu \mathrm{m}$}

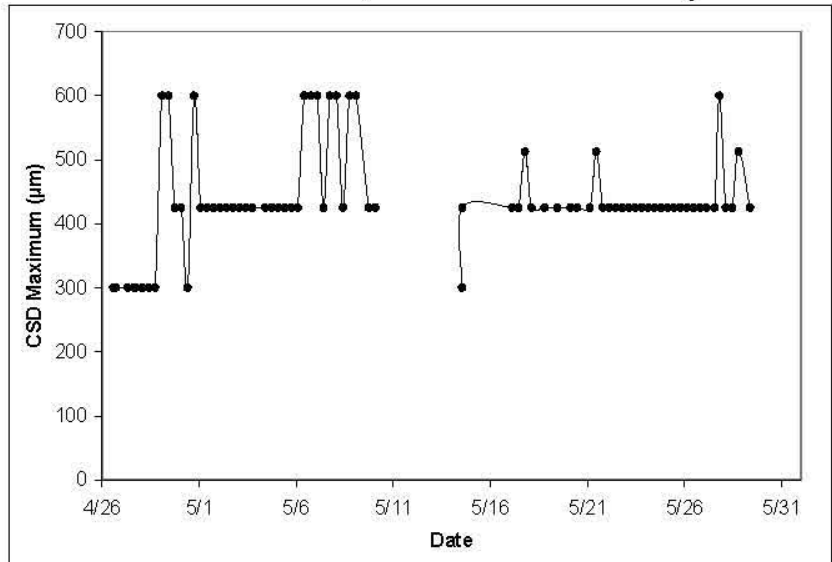

CSD Maxima 


\subsubsection{Off-Normal Operations}

During the pilot testing period a variety of equipment and operational problems allowed a full suite of casualty recoveries to be implemented that had originally been planned as drills for testing mode 5 . The following actual casualties occurred during this period of testing:

- Loss of steam.

- Loss of feed and condensate.

- Loss of instrumentation (Data Acquisition System - DAS).

- Pipe break and pipe plugging.

- Loss of power.

- Trip of the centrifuge.

- Loss of crystallizer control (temperature, level, and pressure).

- Loss of process tank pumps (spent wash, recycle, \& product dissolver).

- Loss of process tank recirculation line heaters. The process tank heaters were installed with fast burn fuses. Replacement with slow burn fuses appeared to solve the problem

\subsection{Baseline Testing}

Baseline Testing established a continuous mode of system operation using the full SST Early Feed simulant, except for chromium which was omitted for continued safety concerns. The main objective was to establish that the pilot system could meet the product sodium yield and Cs decontamination predictions/expectations. In support of the IPS Project, an additional objective was to determine the ability of the system to separate sulfate from the LAW stream and produce a high sulfate coproduct stream. The acceptance criteria for successfully completing Baseline Testing were that the simulated LAW product had to meet or exceed:

- Cs DF of at least 50 .

- $\mathrm{Na}$ fraction in LAW product is equal to or greater than $50 \%$ of the $\mathrm{Na}$ content in the feed stream as determined by laboratory analysis.

Baseline testing began on May $20^{\text {th }} 2008$ after the addition of $\mathrm{Cs}$ and continued until process shutdown on May $31^{\text {st }} 2008$. 
Due to the limited baseline testing window it was agreed that no testing time was available to evaluate IPS Project requirements.

As during benchmark testing the baseline operating condition was operated in manual control. Pilot feed rates were the same as those developed and used during the benchmark testing. All centrifuge improvements (i.e., Teflon sleeve for the discharge chute, wash rates and frequencies, charge rates, etc) continued to be used for baseline testing. Overall, the FC Pilot system was easily and consistently controlled. The test engineers and on-shift staff seemed much more comfortable with the operation of the system.

\subsubsection{Crystallizer Loop}

The crystallizer loop continued to perform as planned and utilized the same operating parameters and conditions as utilized during benchmark testing.

Baseline testing demonstrated that the recirculation pump flow rate and speed was controllable, even operating the equipment in the manual mode. The same was true for the slurry reboiler inlet steam temperature control and control of the differential temperature across the slurry reboiler. However, due to the non-steady state of the overall FC system, control of the feed flow rate, crystallizer level and pressure, and the slurry level within the crystallizer required constant attention to maintain process control. The causes for non-steady state operations include lower than planned centrifuge feed rates, plugged lines, varying crystal size distribution causing centrifuge solids separation difficulties, instrumentation difficulties. It deserves note here that operator experience and improved response to process upsets resulted in improved process control.

The following graphs demonstrate the variability in parameter conditions during normal operations of the crystallizer loop the baseline testing activities. 
RPP-39091, Rev. 0

Figure 21. Graph of Crystallizer Temperature and Pressure

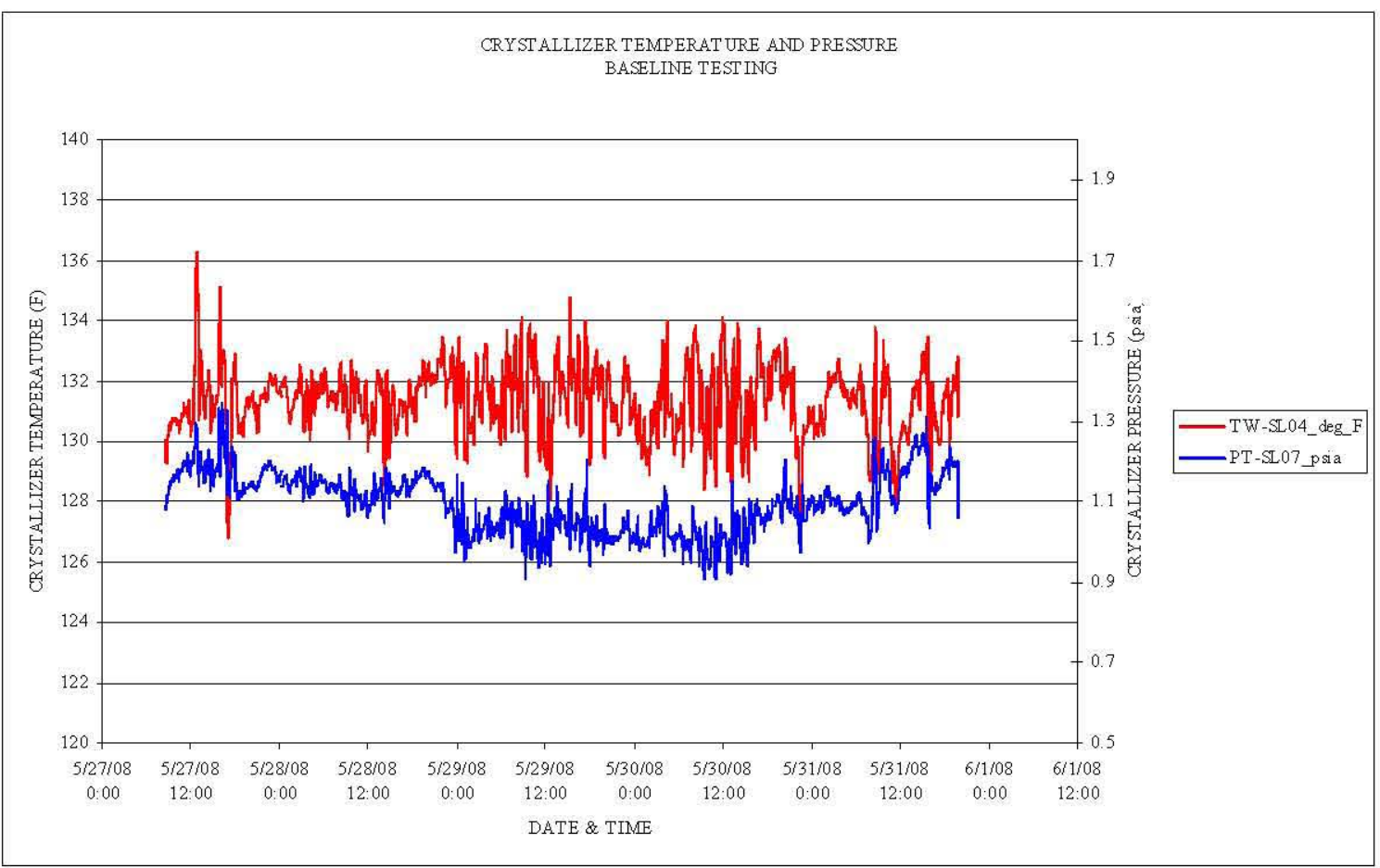

During baseline testing, crystallizer pressure and temperature fluctuated due to manual control of the crystallizer vacuum. Small pressure fluctuations cause changes in boiling point temperature and solubility of sodium nitrate. A sudden drop in boiling point temperature causes a drop in solubility of sodium nitrate resulting in the nucleation of fine particles. Increases in boiling point temperature and pressure increase the solubility of sodium nitrate and result in dissolution of fine crystals and edge rounding of large crystals.

Figure 22 indicates that reboiler steam temperature and pressure and the process heating rate $(\Delta \mathrm{T})$ responded normally during baseline testing. The steam condensed at its saturation temperature at the shell operating pressure; heat transferred to the process in direct proportion to the temperature difference between the steam and the process. 
Figure 22. Graph of Reboiler Temperature, Pressure, and Delta T.

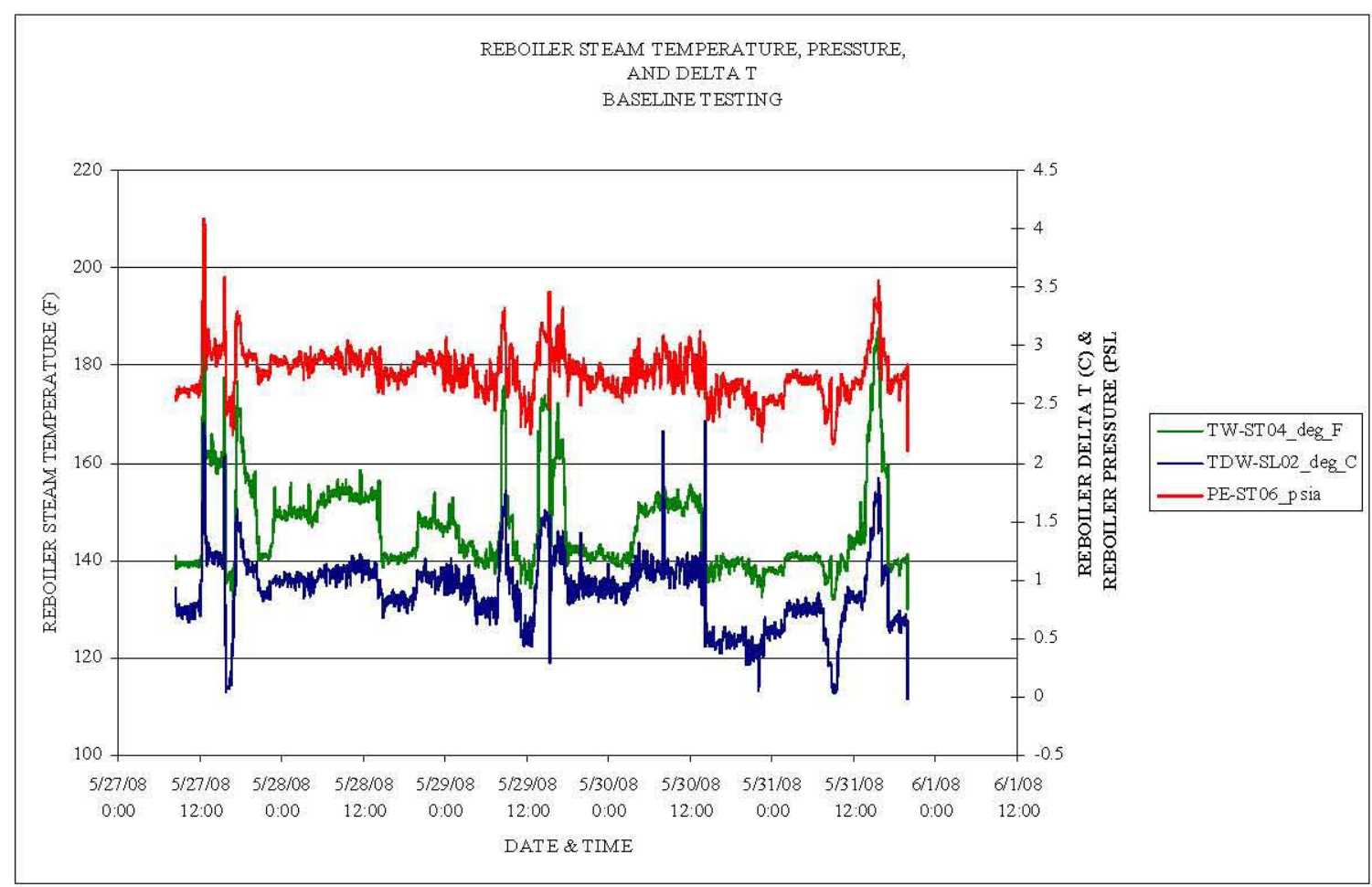

Figure 23. Graph of Crystallizer Level and Slurry Density.

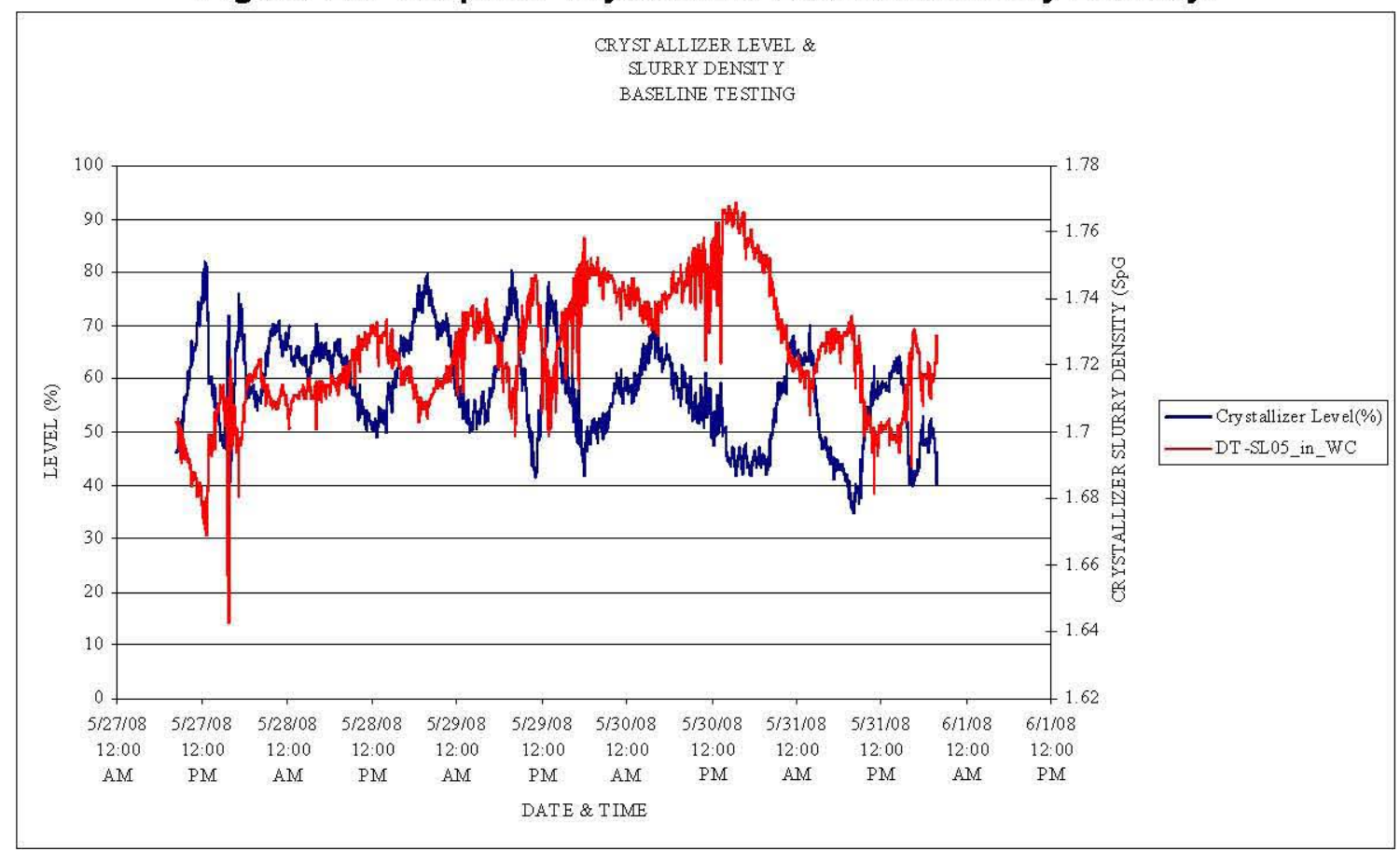


RPP-39091, Rev. 0

Figure 23 indicates that the crystallizer density had an opposite response to the crystallizer level. When the level was low, slurry density was high. When the level was high, slurry density was low. This effect indicates an imbalance between the feed and the evaporation rates caused by manual control of the crystallizer level and reboiler steaming rate.

Although slurry density varied by only $5.0 \%(1-1.68 / 1.70=5.0 \%)$ during this period, measurements of undissolved solids (solids/total mass) varied by $\sim 10 \%(50 \pm 5 \%$ see Figure 23). This indicates that small variations in slurry density (caused by dilution, evaporation, and/or temperature swings) caused large variations in the crystal mass in the crystallizer. Rapid changes in crystal mass results in poor crystal size distribution and morphology and poor solid/liquid separation.

It is important to note that only limited data were available for the crystallizer circulation pump flow rate and speed during the baseline testing. It is assumed that the crystallizer circulation pump continued to perform as indicated earlier during benchmark testing. Checks of the operating logs and alarms indicated no problems with the system.

\subsubsection{Centrifuge Loop}

During the final testing the operating conditions were generally stable with some intermittent process upsets and recovery periods. The slurry feed density variability and the amount of fines in the feed resulting from the failure of the cross-flow filters impacted extended centrifuge operations. During the final baseline testing the centrifuge was operated for between 9 and 12 batches before heel removal was required. During baseline testing it was determined that the number of washes and duration of the wash had an impact on the Cs decontamination factor achieved. Centrifuge Cs DF is shown in Figure 24 for the period 5/21-5/28/2008. The average centrifuge cake Cs DF was 130. The large variability in DFs observed in Figure 24 were the result of varying cake washing time and volume of wash solution. The large DFs (100 to 300 ) shown during $5 / 21 / 08$ and $5 / 22 / 08$ were the result of following the flowsheet values for wash time and wash volume for the cake before cake removal. The reduced DFs (50 to 170 ) obtained from 5/23/08 until the end of baseline testing were the result of reducing the wash times and wash volumes to $1 / 4$ and $1 / 2$ of the flowsheet values. 
RPP-39091, Rev. 0

Figure 24. Centrifuge Cake Cs DF

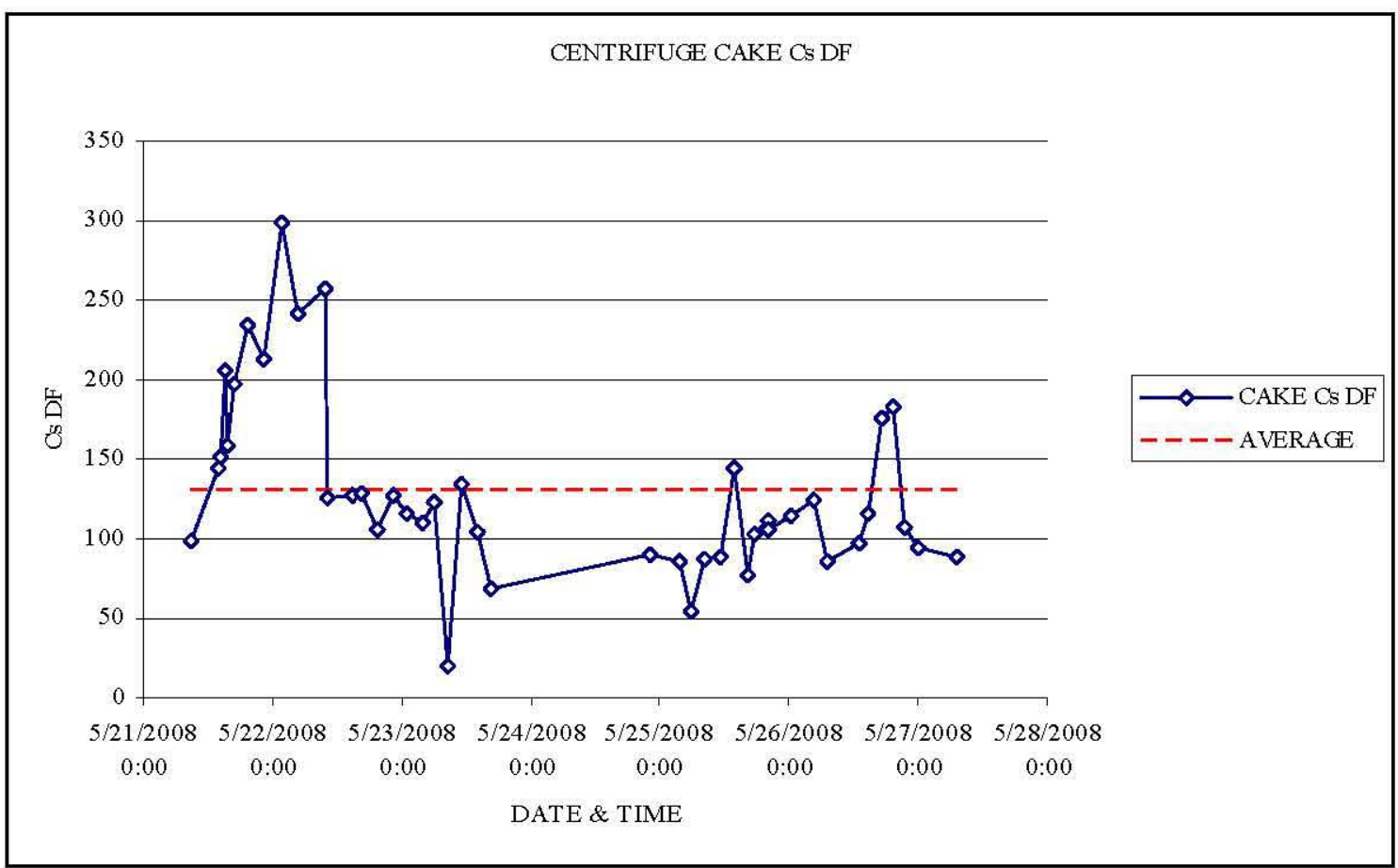

Figure 25 shows that during baseline testing the dissolver slurry density was manually controlled closer to sodium nitrate saturation, thus reducing the amount of dissolution of the centrifuge cake. However, the extent of cake decontamination may have been reduced by the recycle of entrained fines from the dissolver product because of the failure of the cross-flow filter. At a density of 1.45 , sodium sulfate and carbonate are supersaturated and are entrained in the centrifuge wash solution. The recycled fines reduced cake permeability and the extent of cake decontamination. 
RPP-39091, Rev. 0

Figure 25. Product Dissolver Slurry Density.

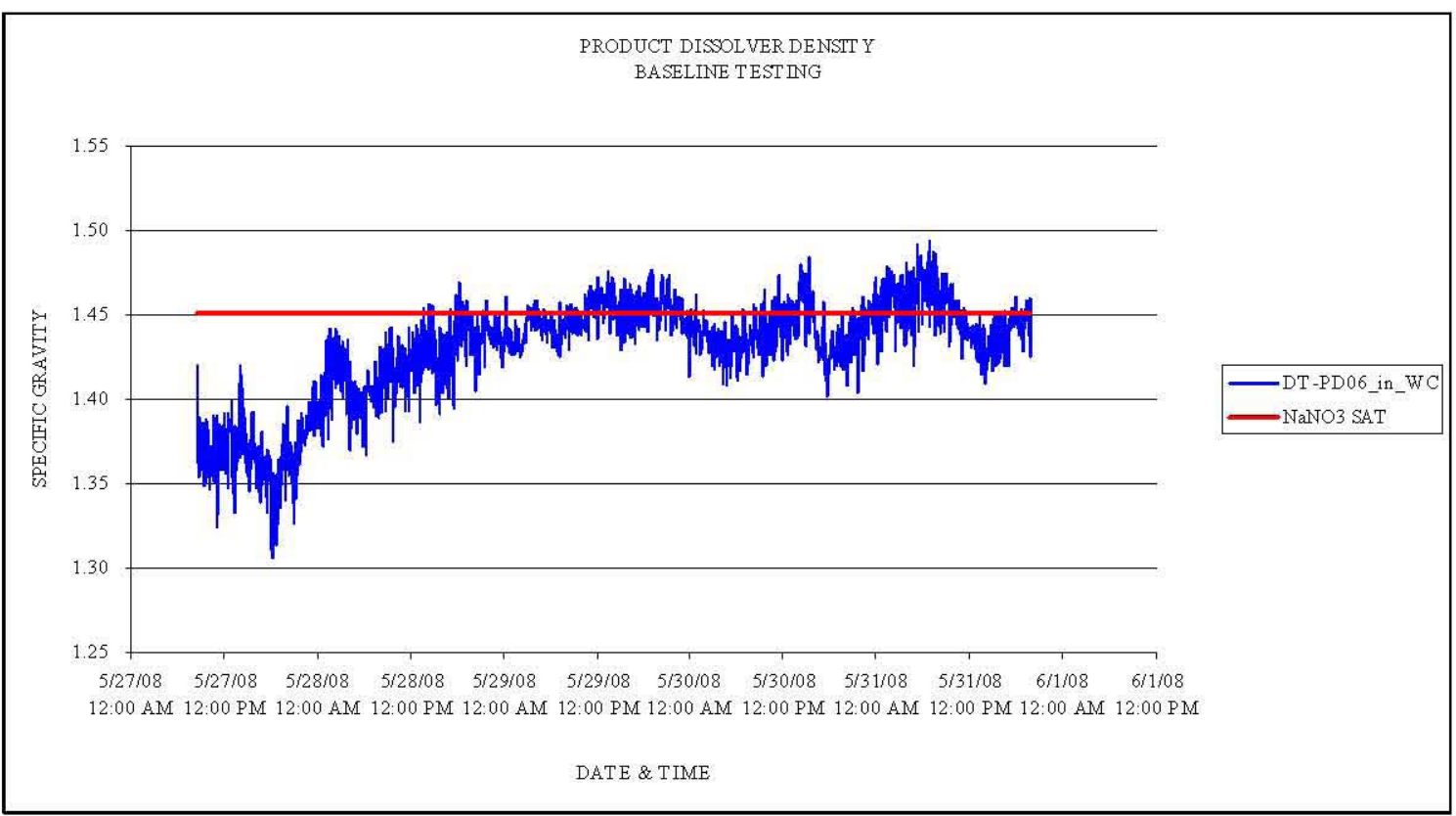

Cesium DF measured in the product dissolver averaged 58 for the period 5/23$5 / 28 / 2008$. Product Cs DF is calculated as:

$$
\text { Cs DF }=(\mathrm{Na} / \mathrm{Cs})_{\text {PRODUCT }} /(\mathrm{Na} / \mathrm{Cs})_{\text {FEED }}
$$

Product dissolver Cs DF values are shown in Figure 26. However, since only two values of feed $(\mathrm{Na} / \mathrm{Cs})$ were measured $(488 \& 347)$, the uncertainty in this calculation is $\pm 15 \%$, which is shown as the high and low points on the graph.

The product Cs DF is substantially lower than product cake DF measurements (58 vs. 130) and results achieved in laboratory tests. This may have been due to occasional cesium contaminated liquor overflow from the centrifuge to the product dissolver. 
Figure 26. Product Dissolver Cs DF.

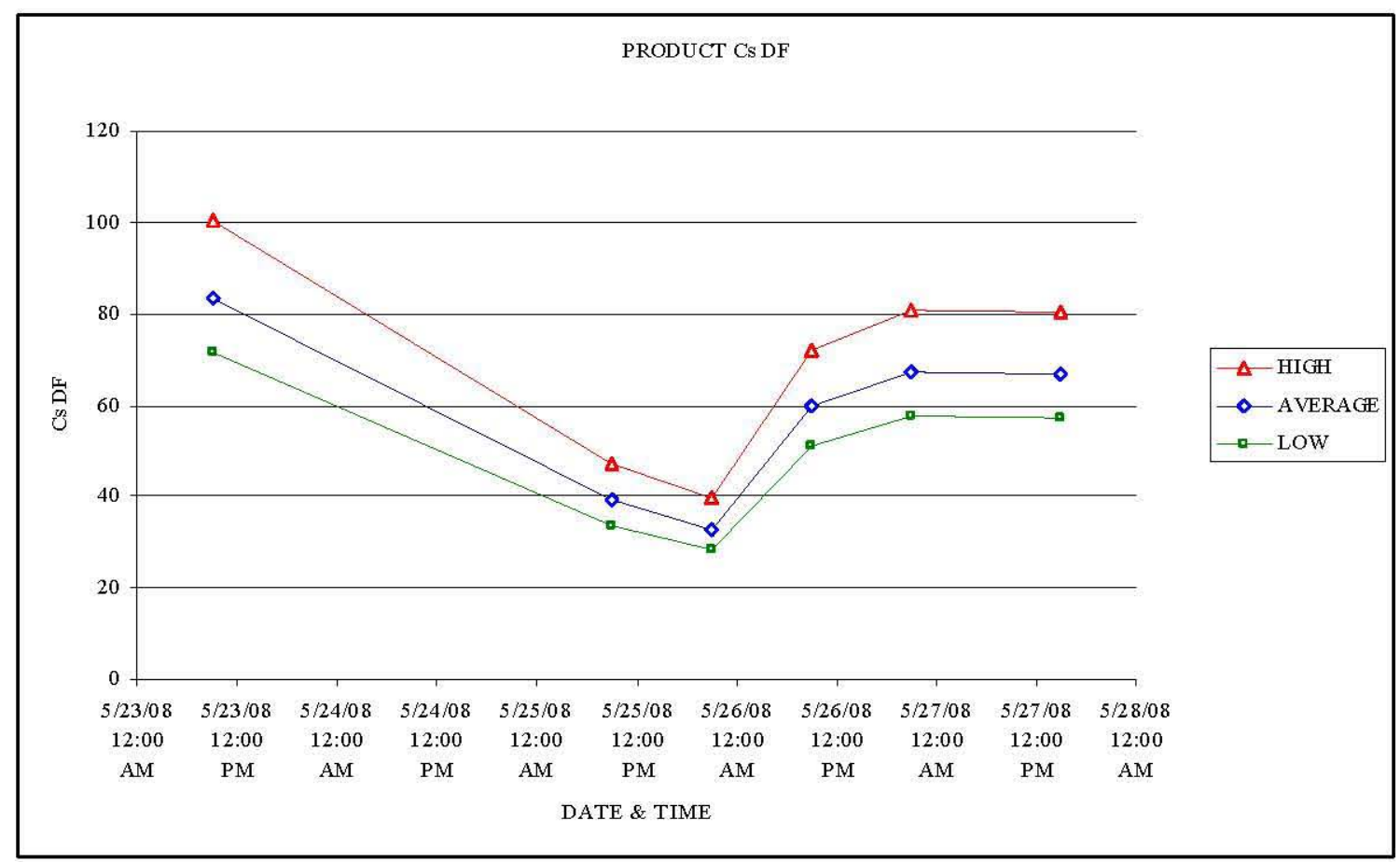

\subsubsection{Support Systems}

Support systems to the FC Pilot Plant included SRNL provided HVAC, condenser cooling water and plant air. No proven problems were identified with these systems.

\subsubsection{Sample Drawing and Analysis}

On $5 / 20 / 08$, the Cs was added to the feed and the crystallizer. On 5/21/08 at 0200 hrs, cake samples at about 4 hour intervals were taken for archive; the SR and SW samples remained the same, while RW samples were now taken every 4 hours. At $1000 \mathrm{hrs}$, archive samples of the HLW receipt tank E (PR) began to be taken at 4 hour intervals, and one sample per day was analyzed for elements and Cs by ICPOES and ICPMS. At $1700 \mathrm{hrs}$, the SR sampling load was reduced to PLM samples every 4 hours and CSD samples every 8 hours plus two samples per day for elements and Cs. CK samples from every $2^{\text {nd }}$ peel began to be analyzed for elements and Cs. At $1300 \mathrm{hrs}$ a complete analysis of Feed Tanks A and B were performed; analyses included elements, $\mathrm{Cs}$, anions, carbonate, and free $\mathrm{OH}$.

\subsubsection{Results}

Graphs of the TS, UDS, supernate solids (SS), and densities for both the benchmark and baseline tests are shown in Figures 27-29. Figure 27 shows that the TS and UDS both increased during the benchmark test (the data were fit linearly with selected outliers removed); there are less data for the baseline test, but the average values shown are very close to the last fitted values from the benchmark test. 
RPP-39091, Rev. 0

Figure 27. Total Solids and Undissolved Solids in Slurry Recirculation Samples.

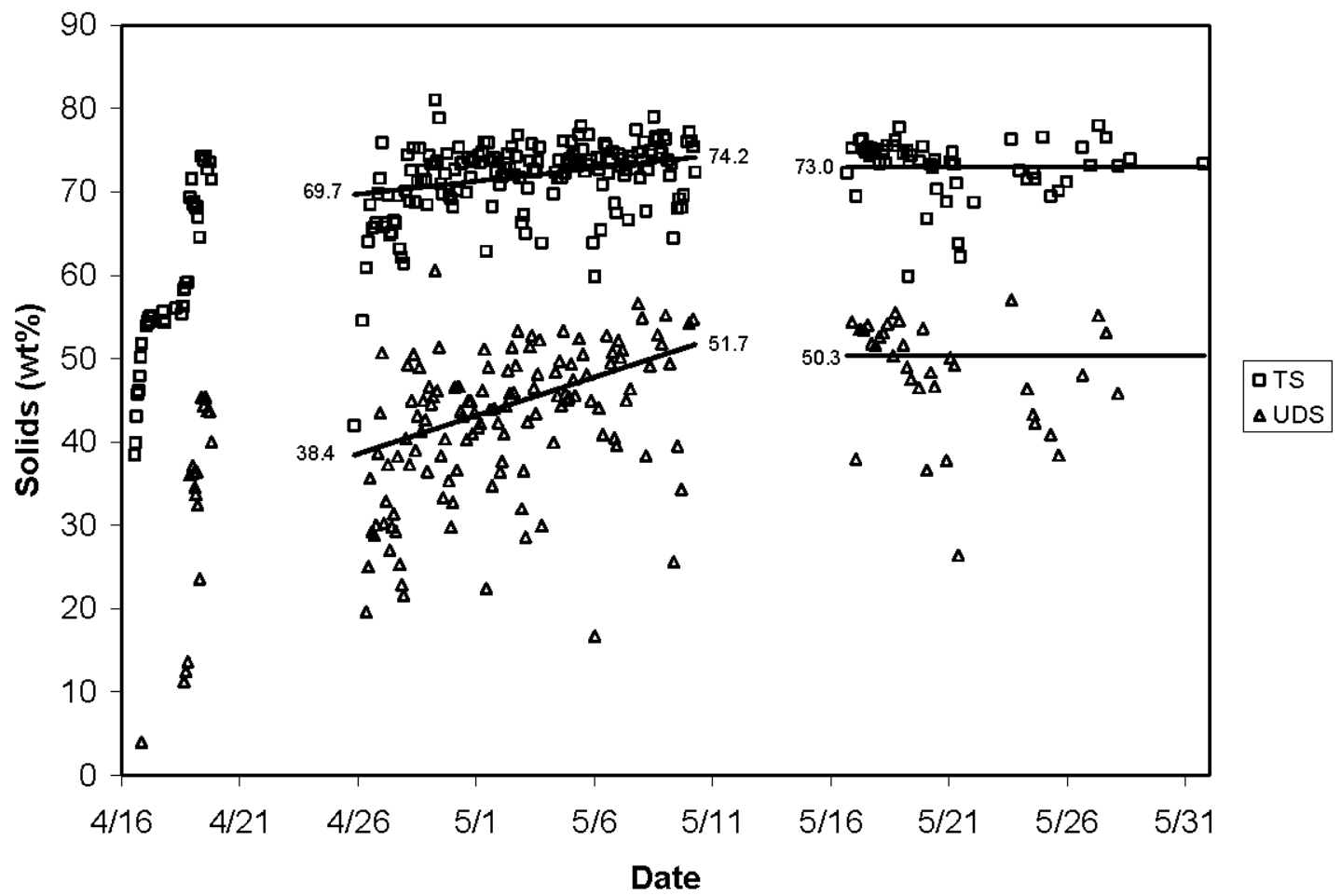

The supernate solids (SS), which are the total solids in the supernate decanted at $131^{\circ} \mathrm{F}$ from the ASV test, are shown along with the TS in Figure 28. The SS values decreased slightly after the start of the tests and reached a fairly constant value of about $49 \mathrm{wt} \%$. Figure 29 shows the UDS measured from the TS and SS compared with the Quick UDS (Q-UDS) analysis results. As expected, the Quick UDS values were higher than the UDS values because of the residual supernate liquid in the filtered solids. On average, the Q UDS values were about $10-15 w t \%$ higher than the UDS values (e.g., 60 wt\% vs. $45-50$ wt\%). Or, in other words, The Q-UDS values were about $133 \%$ of the UDS values. 
Figure 28. Total and Supernate Solids in Slurry Recirculation Samples

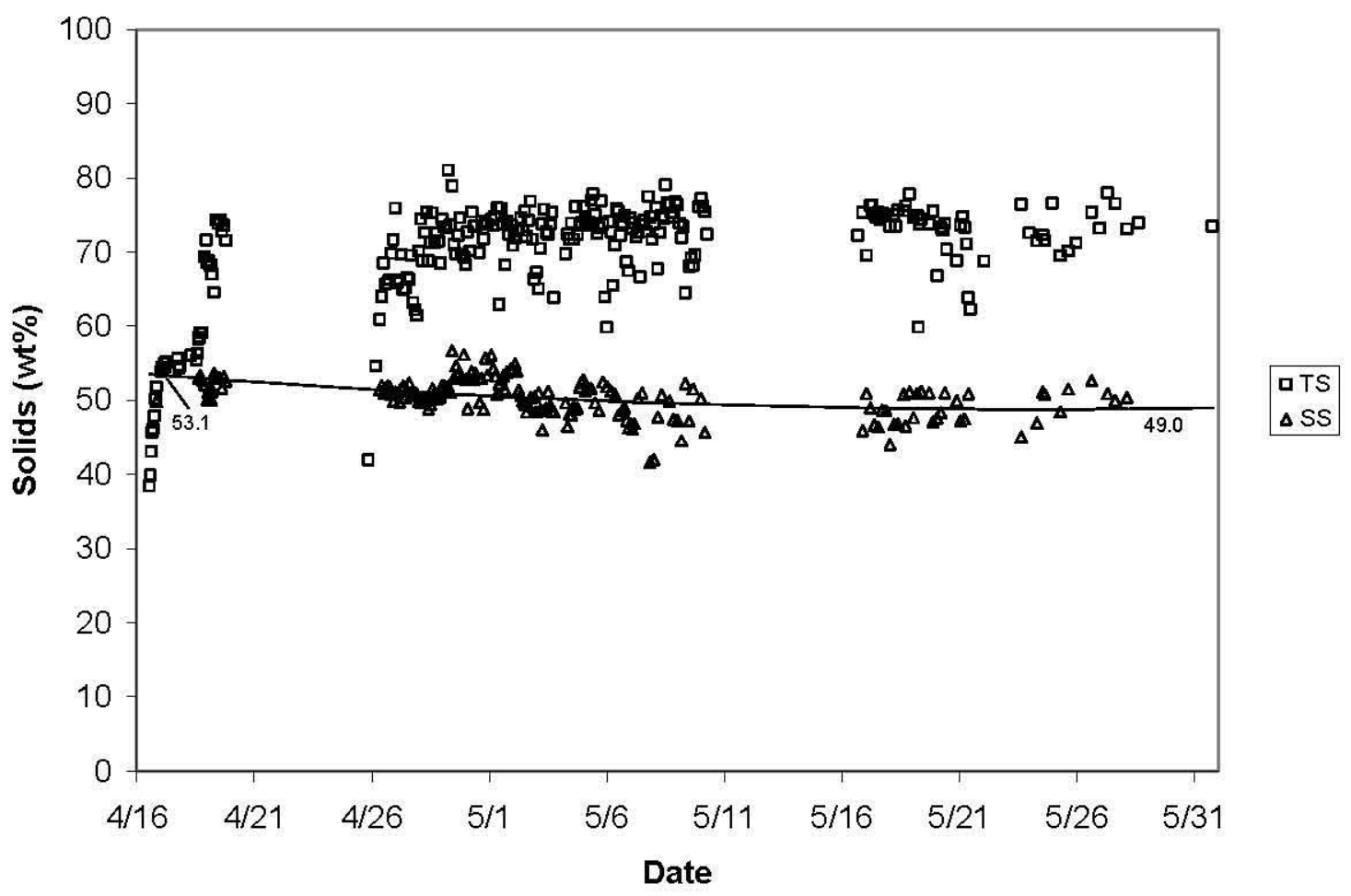

Figure 29. Slurry Recirculation UDS and Quick UDS Values

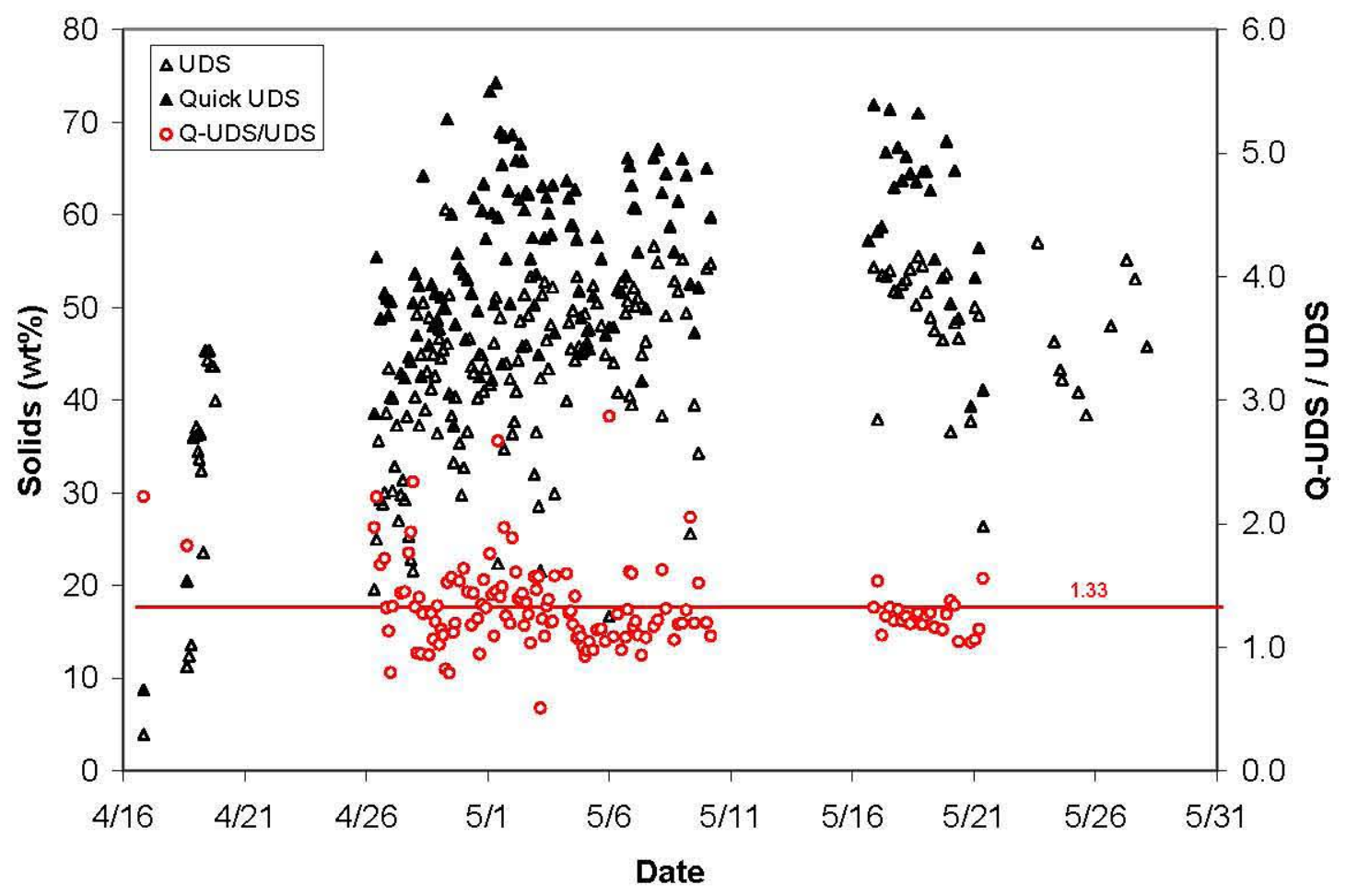

Page 60 
The only other sample type where more than a few TS measurements were made was the Product Dissolver (PD) samples. These data are shown in Table 11. The TS values varied from about 35 to $53 \mathrm{wt} \%$.

Table 11. Solids in Product Dissolver Samples

\begin{tabular}{|c|c|c|c|}
\hline Sample & $\begin{array}{l}\text { Total } \\
\text { Solids } \\
\text { (wt\%) }\end{array}$ & $\begin{array}{c}\text { Supernate } \\
\text { Solids } \\
\text { (wt\%) }\end{array}$ & $\begin{array}{l}\text { Undissolved } \\
\text { Solids (wt\%) }\end{array}$ \\
\hline PD-0502-0900 & 35.28 & & \\
\hline PD-0502-1300 & 36.83 & & \\
\hline PD-0502-1700 & 37.90 & & \\
\hline PD-0502-2100 & 38.96 & & \\
\hline PD-0503-0100 & 39.96 & & \\
\hline PD-0503-0500 & 42.23 & & \\
\hline PD-0503-0900 & 46.21 & & \\
\hline PD-0503-1300 & 46.21 & & \\
\hline PD-0503-1700 & 45.57 & & \\
\hline PD-0504-0500 & 44.48 & & \\
\hline PD-0504-0900 & 43.63 & & \\
\hline PD-0504-1300 & 48.13 & & \\
\hline PD-0504-1700 & 48.13 & & \\
\hline PD-0504-2100 & 48.81 & & \\
\hline PD-0505-0100 & 50.21 & & \\
\hline PD-0505-0500 & 52.50 & & \\
\hline PD-0506-2100 & 48.54 & & \\
\hline PD-0507-0100 & 44.57 & & \\
\hline PD-0507-0500 & 43.69 & & \\
\hline PD-0520-0600 & 42.25 & & \\
\hline PD-0520-1000 & 44.15 & & \\
\hline PD-0520-1400 & 44.84 & & \\
\hline PD-0528-1700 & 55.06 & 44.82 & 18.56 \\
\hline PD-0531-1800 & 48.49 & & \\
\hline
\end{tabular}

The densities measured on process samples are shown in Figure 30. The SR samples generally were $1.7-1.8 \mathrm{~kg} / \mathrm{L}$, the $\mathrm{SR}$ supernate was about 1.5 , the $\mathrm{PD}$ and RW samples were both around 1.4-1.5, and the SW samples were about 1.15-1.25, except for $5 / 28-5 / 31 / 08$ where they were consistently $1.28 \mathrm{~kg} / \mathrm{L}$.

The feed samples (FA, FB) and LAW Product (FC) are also shown. The initial feed was about $1.30 \mathrm{~kg} / \mathrm{L}$; an initial tote sample was 1.289 and the initial FB sample was $1.318 \mathrm{~kg} / \mathrm{L}$. Figure 30 shows that these feed densities dropped as the tests progressed because the reconstitution scheme involved adding water to the products; more water was added than needed to exactly reconstitute, so the feeds became continually more dilute. Similarly, the LAW product in Tank $\mathrm{C}$ became more dilute, going from an initial $\sim 1.3$ to a final $\sim 1.1 \mathrm{~kg} / \mathrm{L}$. Figure 30 shows both the density and total solids of Tanks $A$ and $B$ versus time. 
Figure 30. Density of Process Samples
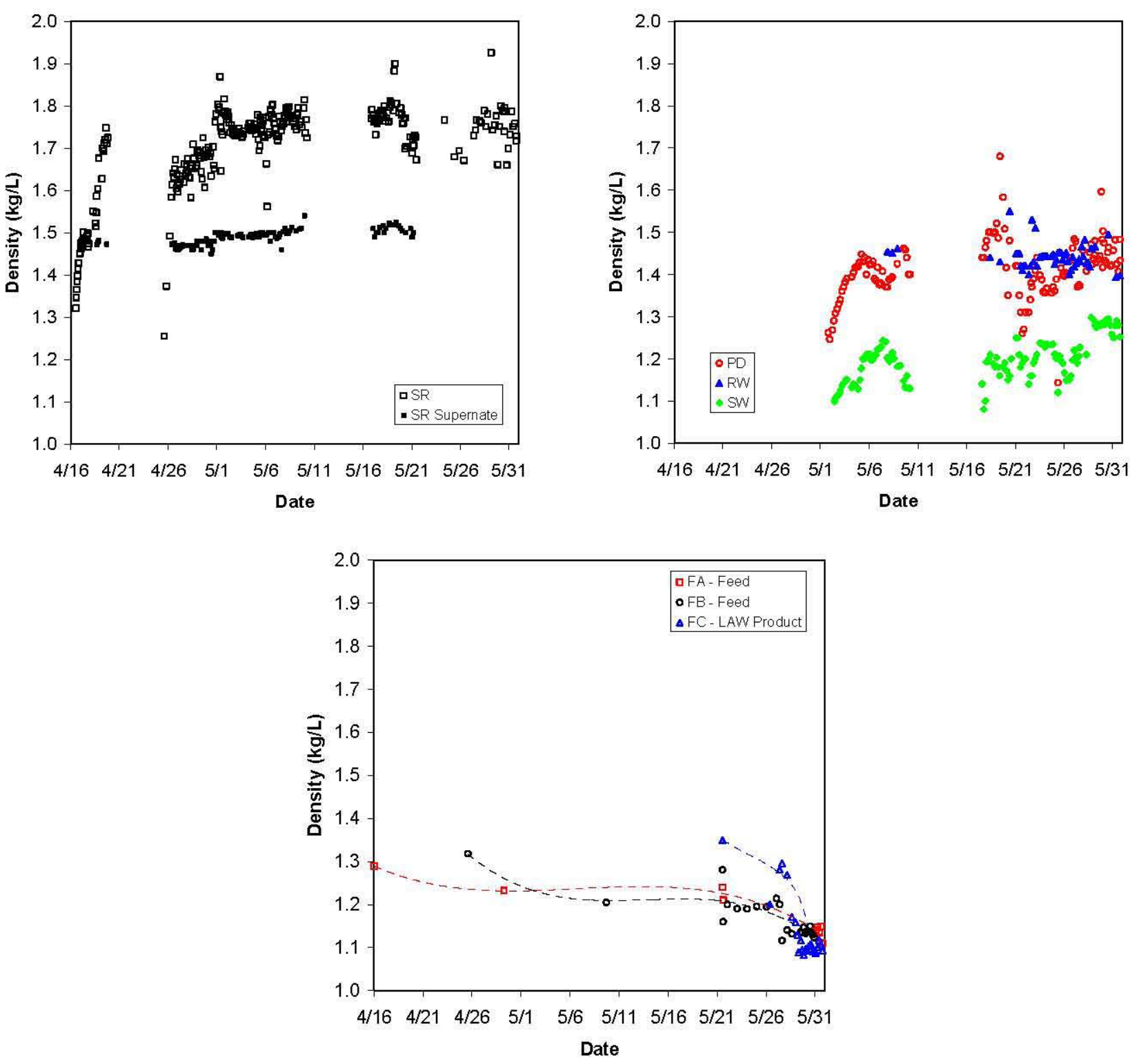

The density and TS of the feed samples FA and FB are both shown in Figure 31.

The density and TS of each sample show similar downward trends. 
Figure 31 Density and Total Solids of Feed Samples

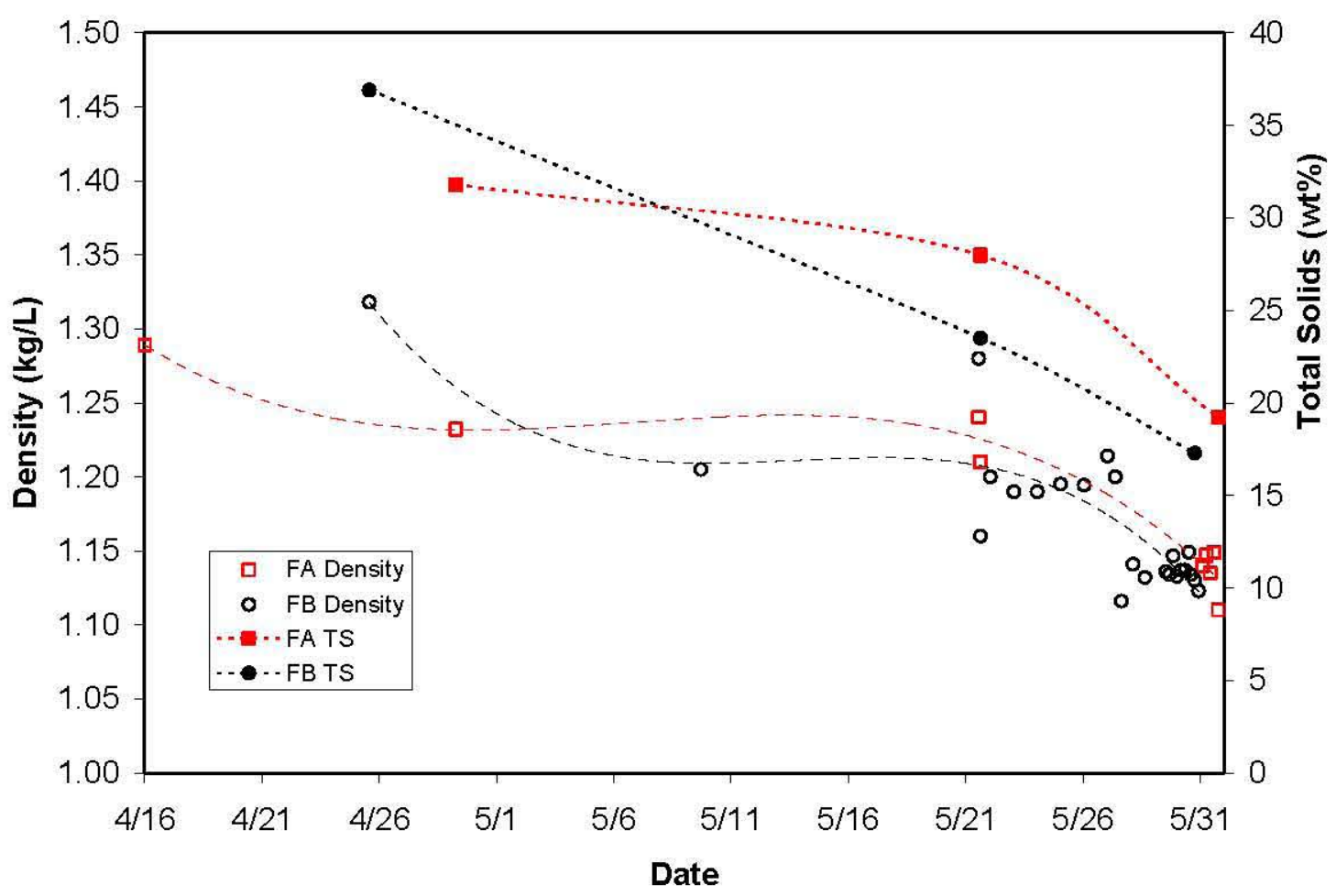

On 5/27/08 at about $1800 \mathrm{hrs,} \mathrm{the} \mathrm{"steady-state"} \mathrm{test} \mathrm{was} \mathrm{begun.} \mathrm{Complete} \mathrm{analyses}$ were done on samples from Feed Tanks $B$ and $C$ (C was the LAW receipt tank), SR, $\mathrm{CK}, \mathrm{SW}, \mathrm{RW}$, and the HLW product in Tank E (PR). From then until the completion of the testing, the CK samples were examined by PLM as needed and analyzed for elements and Cs at 4 hour intervals. The SW, HLW, and PD tanks and SR had density measured every 4 hours. One elements and Cs analysis was done on a PD sample each day. An SR sample was analyzed for elements and Cs every 4 hours.

Figures 32-37 show plots of the CK, SR, PD, SW, feed FB, and product FC LAW and Tank E HLW elemental analyses. These data are shown from 5/21/08 to $6 / 1 / 08$, except for the feed and products which are shown from $4 / 25 / 08$ to $6 / 1 / 08$.

The data in Figure 32 show that the $\mathrm{Na}, \mathrm{K}$, and $\mathrm{Cs}$ in the cake samples stayed relatively constant. There are a few higher Cs values after $5 / 29 / 08$, but these may be incorrect analyses; the Cs results for the last several days of operation were much more inconsistent than for the previous days. The Al and P both appear to have decreased.

The limited number of SR samples taken indicates that the composition did not change significantly, as shown in Figure 33. The small amount of data and the scatter make it difficult to determine if there were any trends in the compositions.

Figure 34 indicates that the product dissolver $\mathrm{Al}$ and $\mathrm{K}$ concentrations both decreased starting on $5 / 21 / 08$, which is consistent with the implementation of the full washing cycle in the centrifuge. The $\mathrm{Cs}$ concentration increased after introduction to 
the feed until it reached a steady value of about $8 \mathrm{mg} / \mathrm{L}$. The Na concentration remained steady as expected. Note the final data points on $6 / 1 / 08$ are probably incorrect.

The few SW samples shown in Figure 35 indicate that the concentrations of all species may have gone up slightly. The sum of the washes data shown for 5/30/08 agrees with what would be expected. All species in the sum of washes 1-4 are at higher concentrations than in washes $5-8$.

The RW samples (Figure 36) show that all species except Cs remained at approximately constant values. The $\mathrm{Cs}$ increased as expected after it was added to the feed and appears to have reached a steady concentration of about 250-300 $\mathrm{mg} / \mathrm{L}$.

Figures 37 and 38 show that all of the feed species in Tank B decreased over time due to the dilution that occurred during reconstitution. For the time period from $5 / 27 / 08$ to $5 / 31 / 08$, the concentrations of all Tank E HLW species increased with time, except $\mathrm{P}$ which remained approximately constant. For the Tank C LAW product, all species concentrations decreased over this same time interval. 
Figure 32. Elemental Analyses of Centrifuge Cake Samples
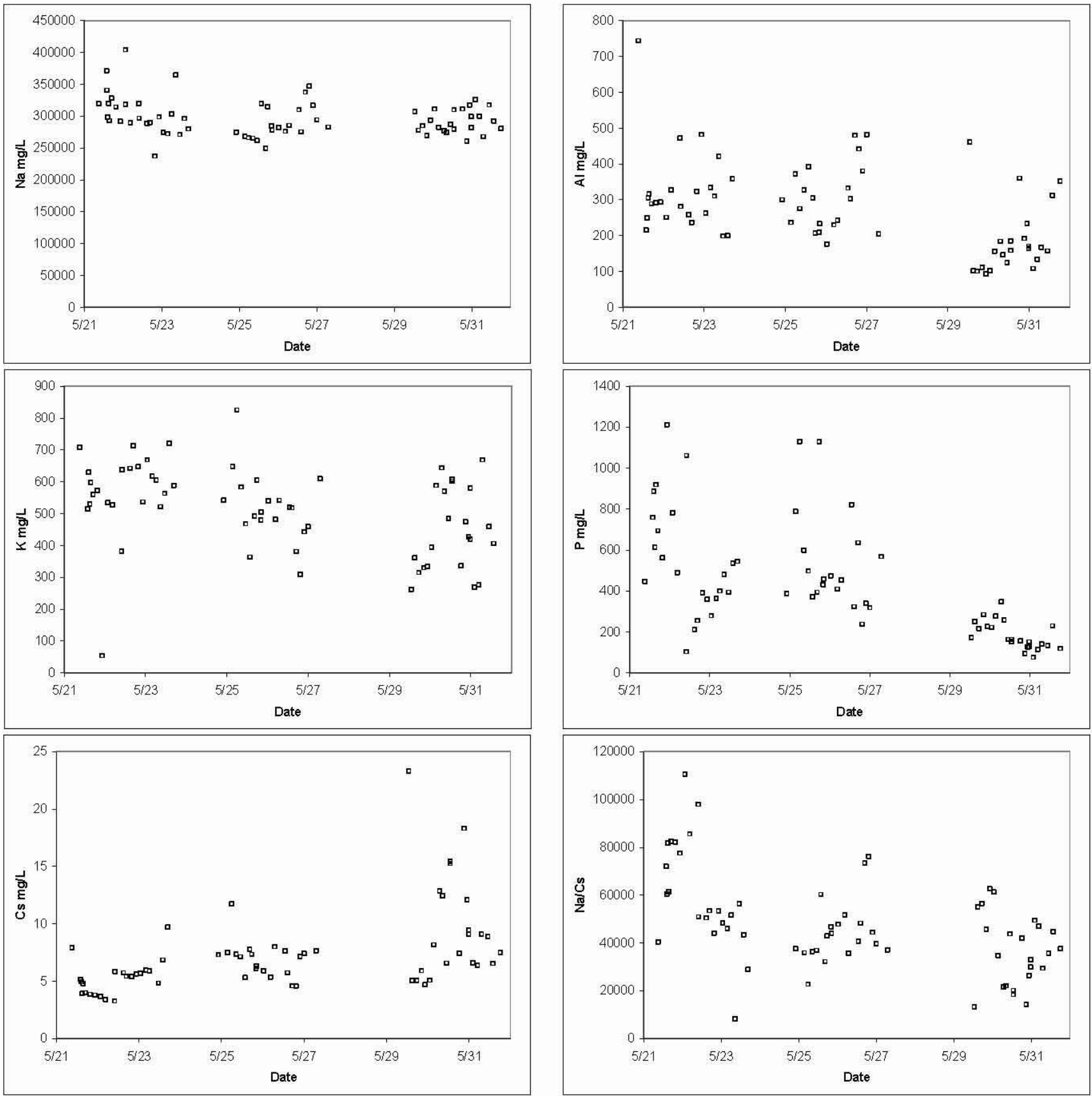
RPP-39091, Rev. 0

RPT-3000755 Rev. 000

Figure 33. Elemental Analyses of Slurry Recirculation Samples
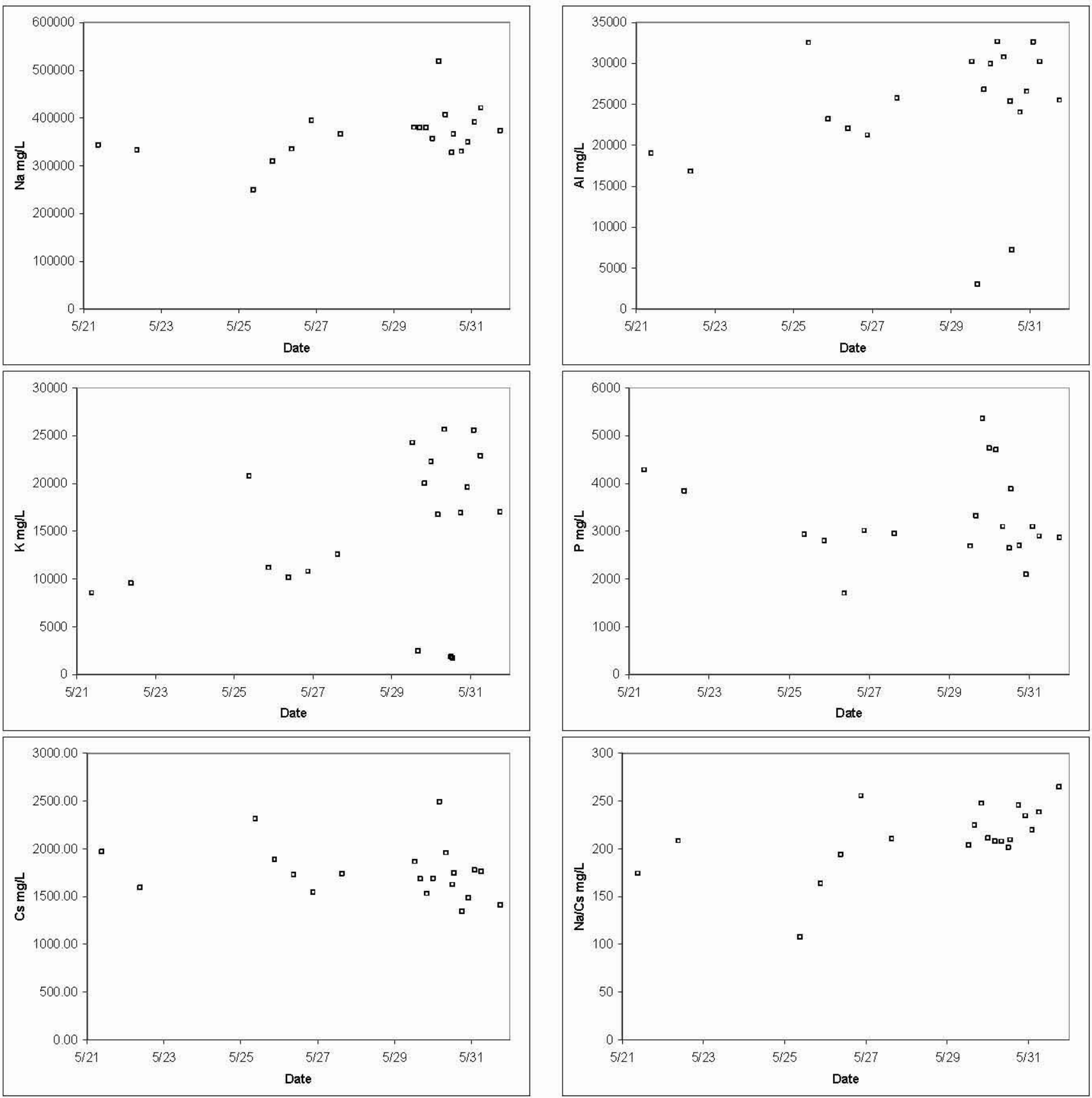
RPP-39091, Rev. 0

RPT-3000755 Rev. 000

Figure 34. Elemental Analyses of Product Dissolver Samples
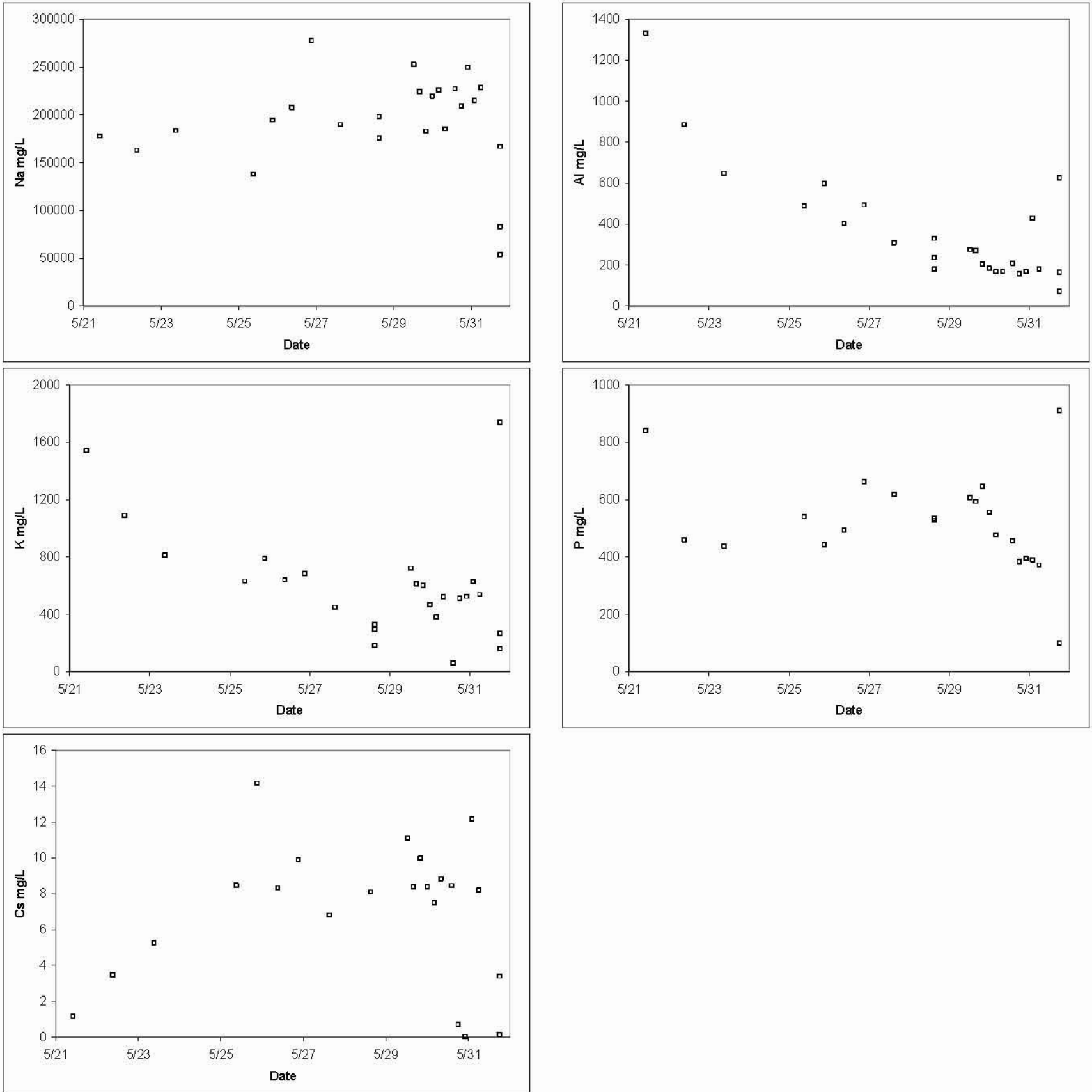
RPP-39091, Rev. 0

RPT-3000755 Rev. 000

Figure 35. Elemental Analyses of Spent Wash Samples
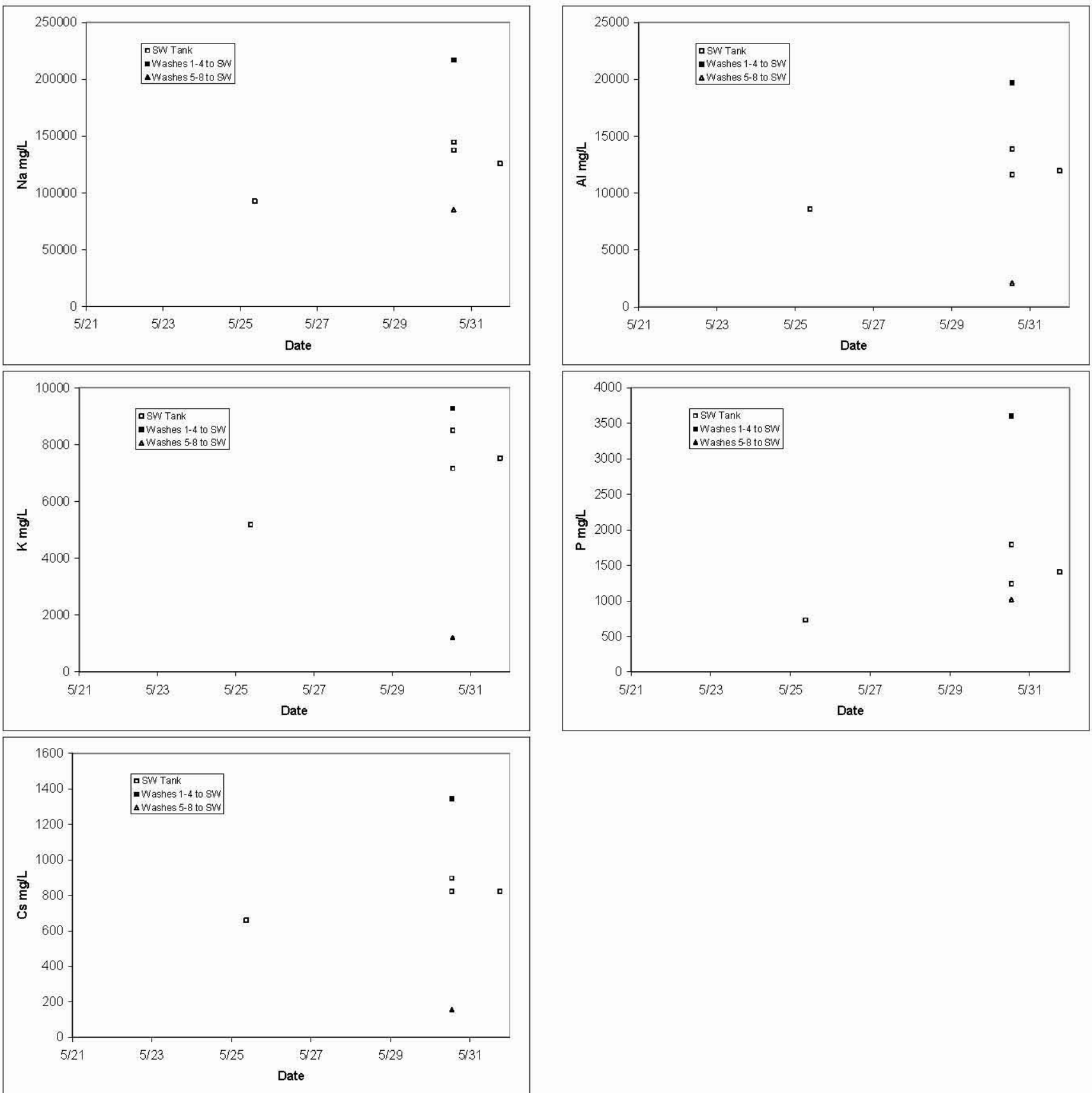
RPP-39091, Rev. 0

RPT-3000755 Rev. 000

Figure 36. Elemental Analyses of Recycle Wash Samples
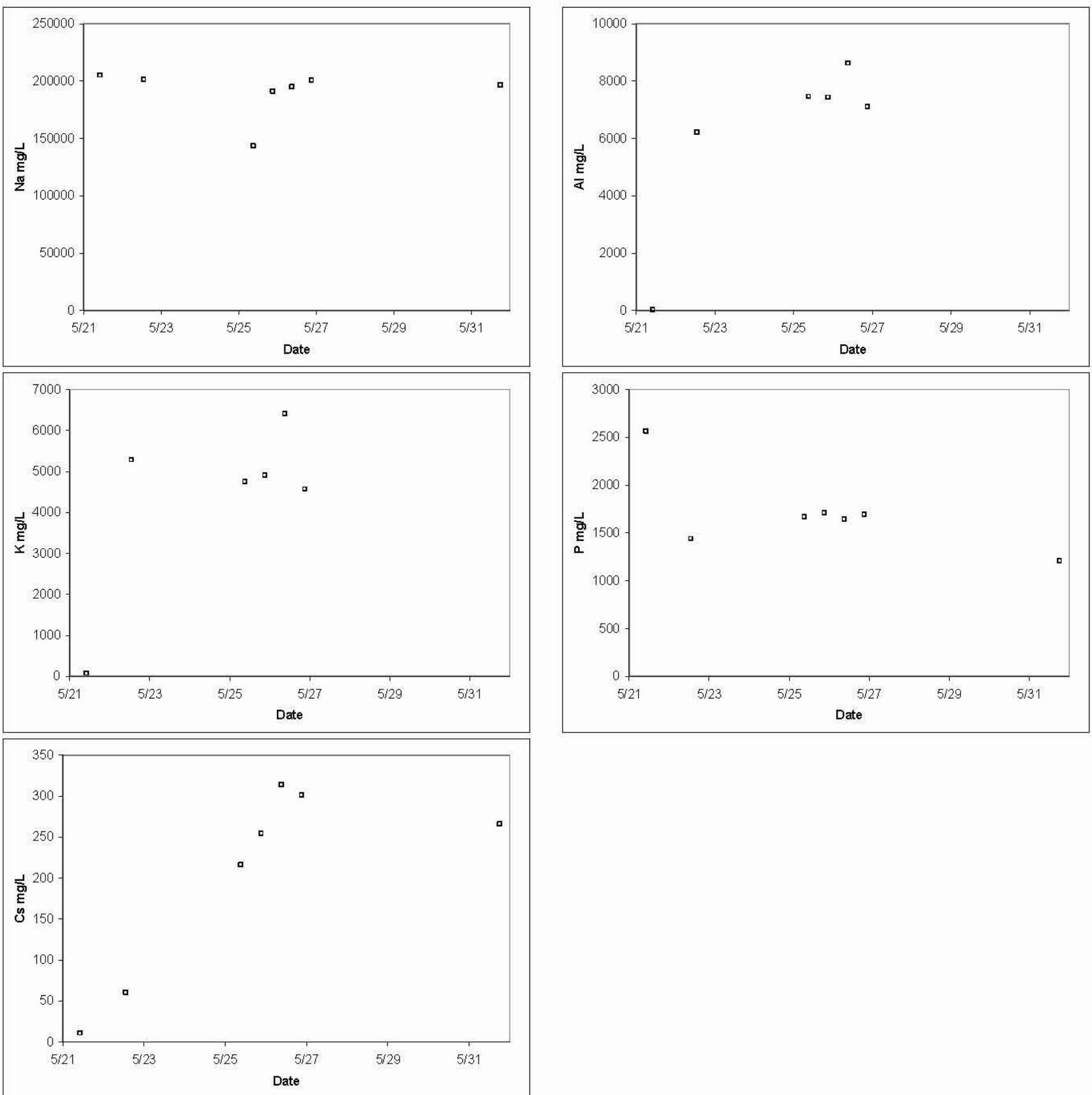
Figure 37. Elemental Analyses of Feed and Product Samples
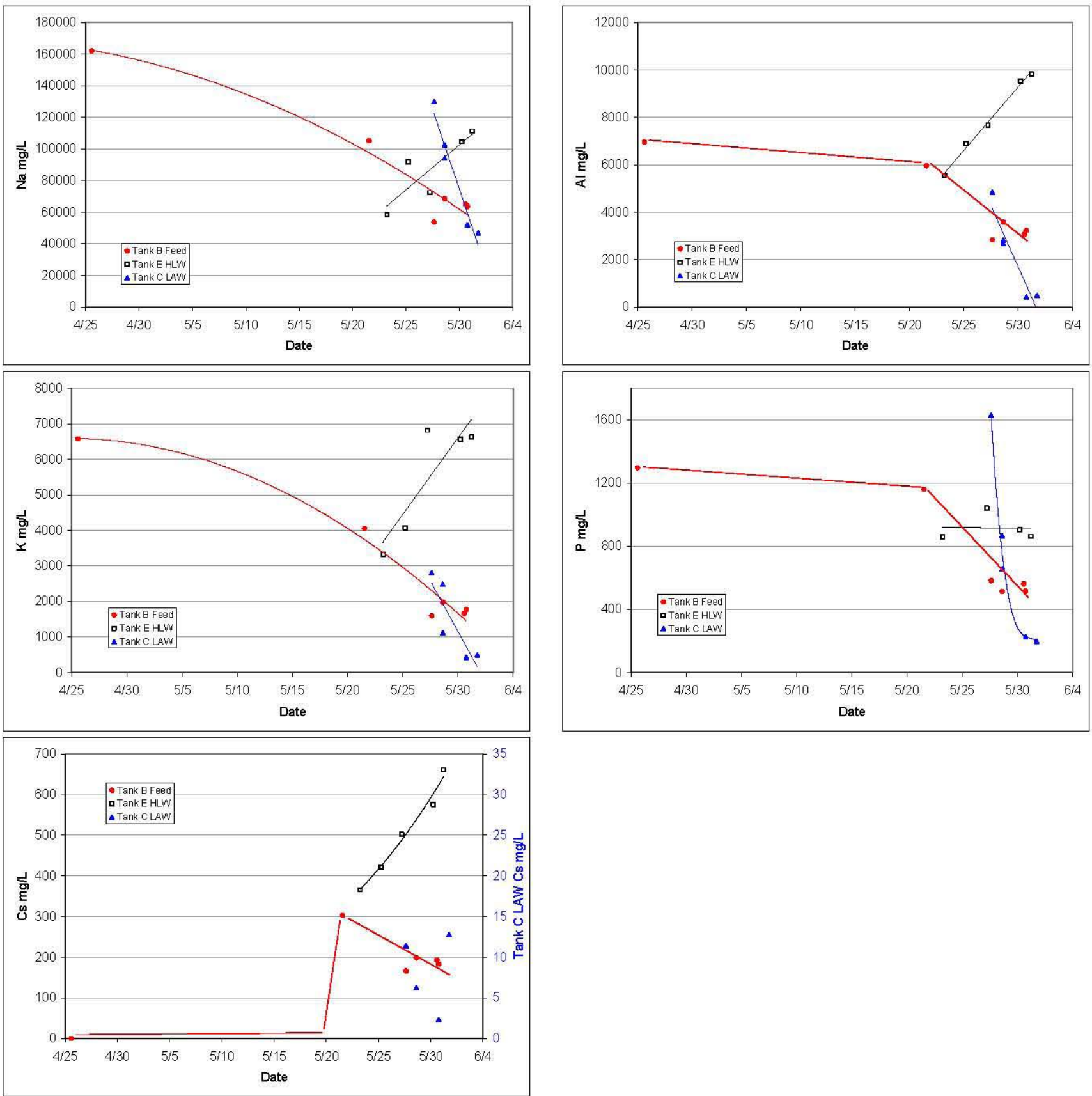
Figure 38. Anion Chromatography Analyses of Feed and Product Samples
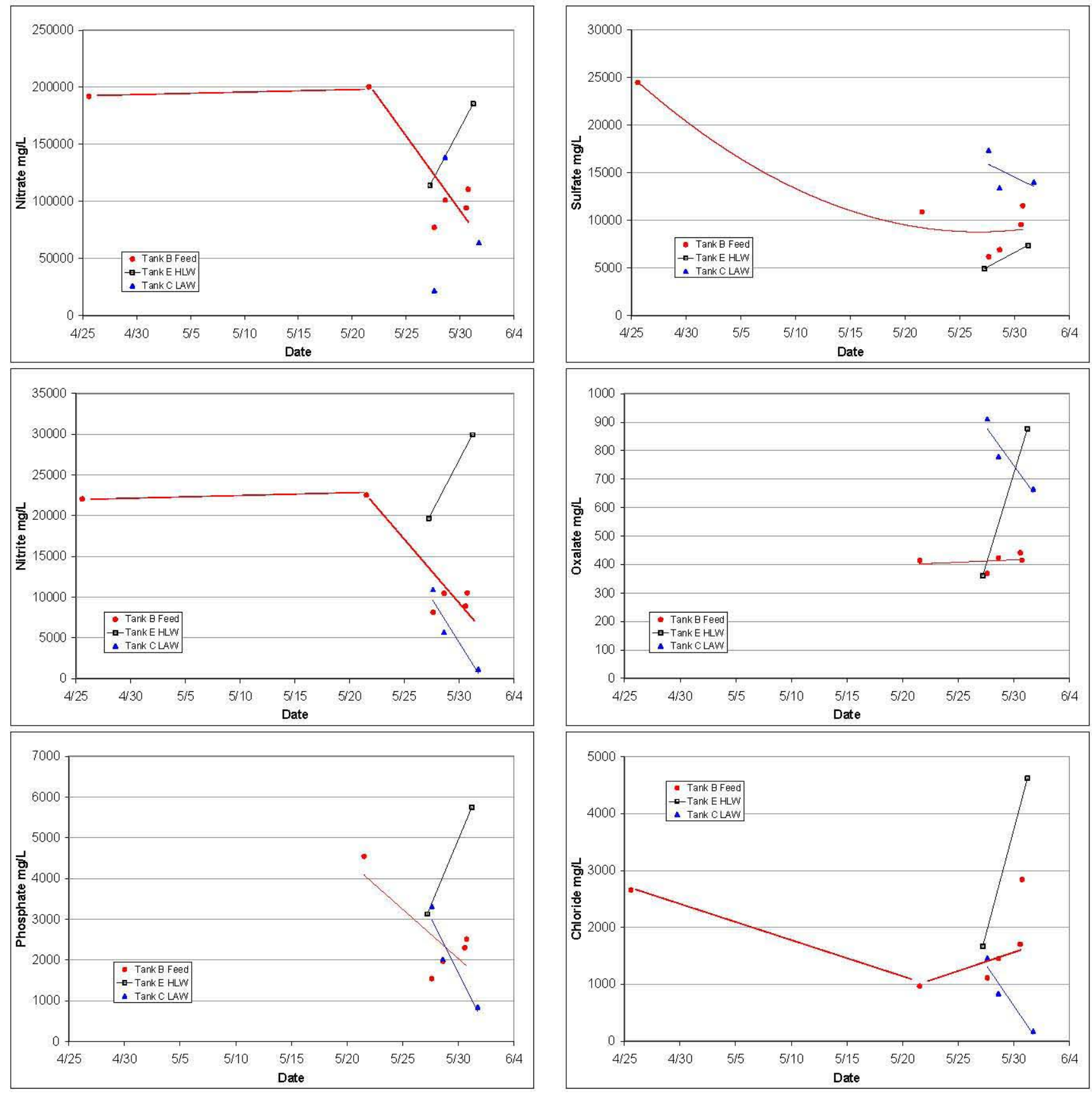


\subsubsection{PLM Results}

PLM was used throughout the SST test campaign to analyze salt crystals for the effects of changes in Crystallizer operating conditions. Standards of SST simulant with various salt crystals were prepared by Whitney Thomas and a hard copy catalog developed of slide pictures for reference in file labeled FC PLM Crystal Examples provided with training for FC operations. The crystals were grown in pure binary solutions (water + salt). An example of reference crystal for sodium nitrate is sodium in Figure 39.

Figure 39. Reference PLM of Sodium Nitrate Crystal.

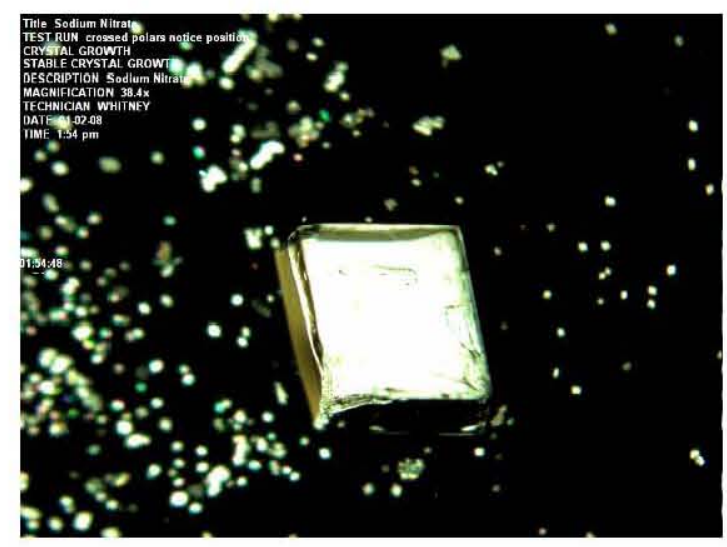

The reference sodium nitrate crystal shows sharp edges indicating steady growth conditions.

Feed Tank Samples were analyzed for the presence of undissolved salt crystals in the simulant as shown in Figure 40.

Figure 40. Undissolved Salts in Feed Sample.

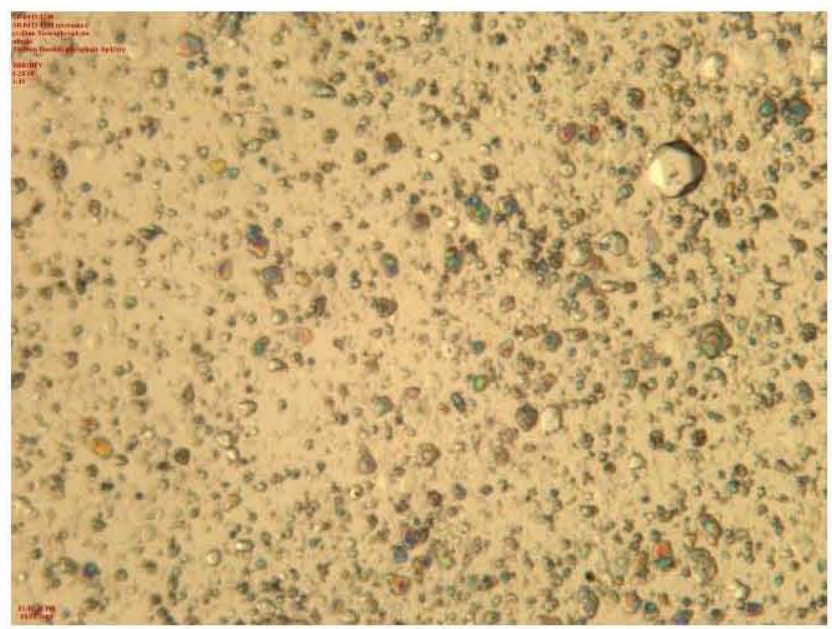


During storage at cold conditions $\left(<50^{\circ} \mathrm{F}\right)$, sodium nitrate and sodium fluoridephosphate crystals formed in the feed simulant. Sodium nitrate dissolved upon warming to room temperature $\left(70^{\circ} \mathrm{F}\right)$, while some sodium fluoride-phosphate remained as a metastable solid in the feed tanks.

During crystallizer operation, the slurry samples analyzed showed sodium nitrate crystals growing to the size of several hundred microns. A good example of the large sodium nitrate crystals can be seen in Figure 41.

Figure 41. Large Sodium Nitrate Crystals in Crystallizer Slurry

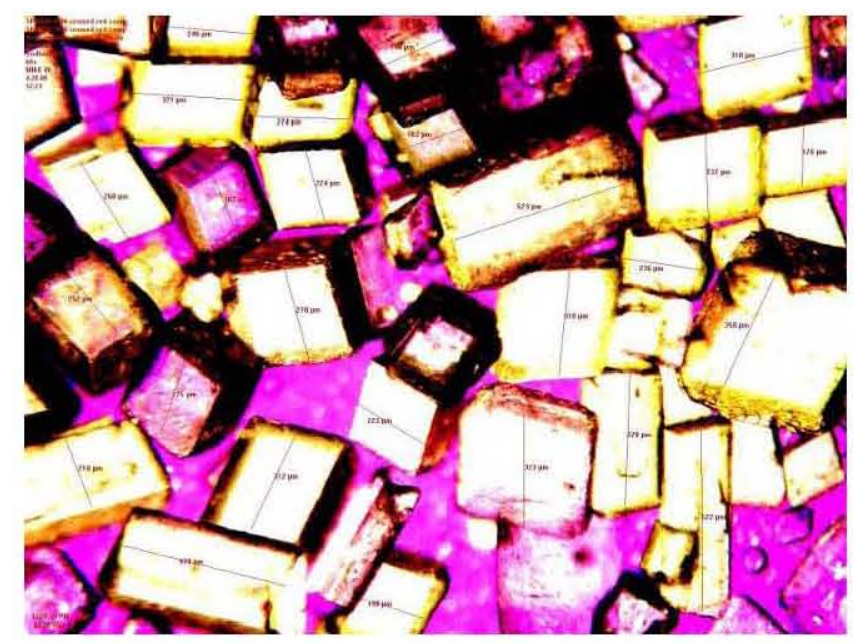

In this sample, large sodium nitrate crystals had edge lengths of $200-500 \mu \mathrm{m}$. This indicates a large mean crystal size and narrow size distribution that allows efficient solid/liquid in the centrifuge.

When the crystallizer was operated at suboptimal conditions, due to pressure and temperature fluctuations and/or water dilution, the edges of the sodium nitrate crystals were rounded, and the average crystal size was reduced as shown in Figure 42.

Figure 42. Crystal Matrix with Poor Morphology

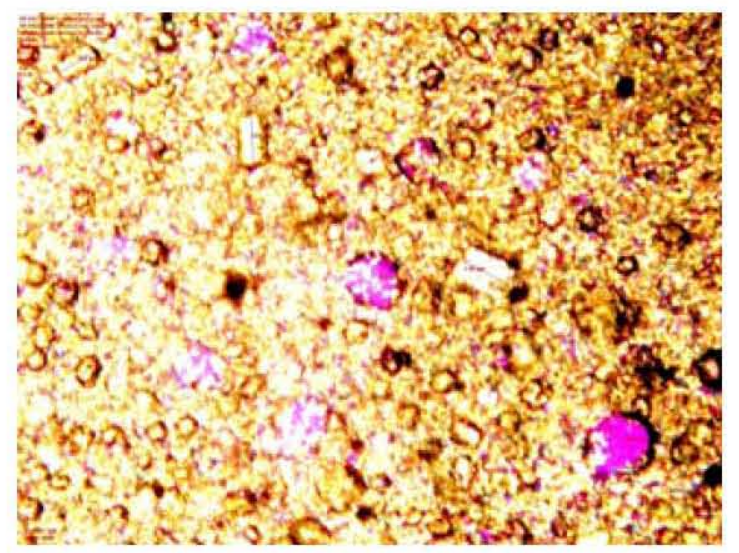


In this sample, crystal crystalline edges are poorly defined, small mean crystal size $(<100 \mu \mathrm{m})$ and wide size distribution. This slurry "mush" exhibits poor solid/liquid separation in the centrifuge.

Most frequently, the crystals exhibited a bimodal size distribution as shown in Figure 43.

Figure 43. Typical Bimodal Crystal Size Distribution

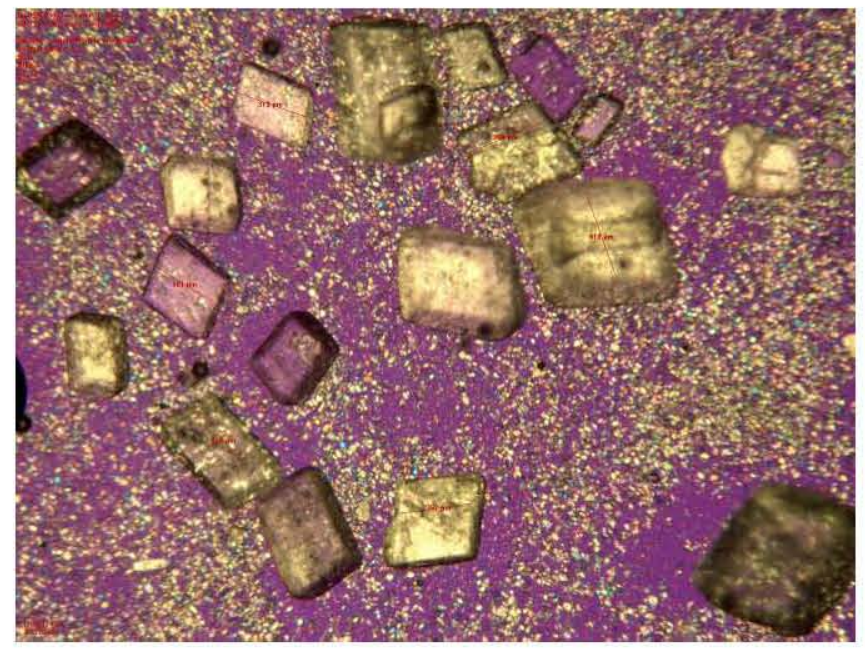

The bimodal size distribution is partly caused by the differing crystal growth rates of large sodium nitrate (fast) and small sodium carbonate and sulfate (slow). However, this sample exhibits rounded crystal edges and excessive nucleation of fine crystals.

These forms are indicative of temperature cycling; fine crystals form upon cooling and edges dissolve upon heating or dilution. This particle size distribution separates poorly in the centrifuge. Large crystals do not capture small particles in the cake and small crystals flow through the centrifuge screen or form a low-permeability rind around the outside perimeter of the cake. This stratification requires frequent backwashing of the centrifuge to remove the rind and restore proper operation to the centrifuge.

Samples of centrifuge cake typically exhibited smaller crystal size distribution than the crystallizer slurry samples as shown in Figure 44. 
Figure 44. Typical Centrifuge Cake Sample

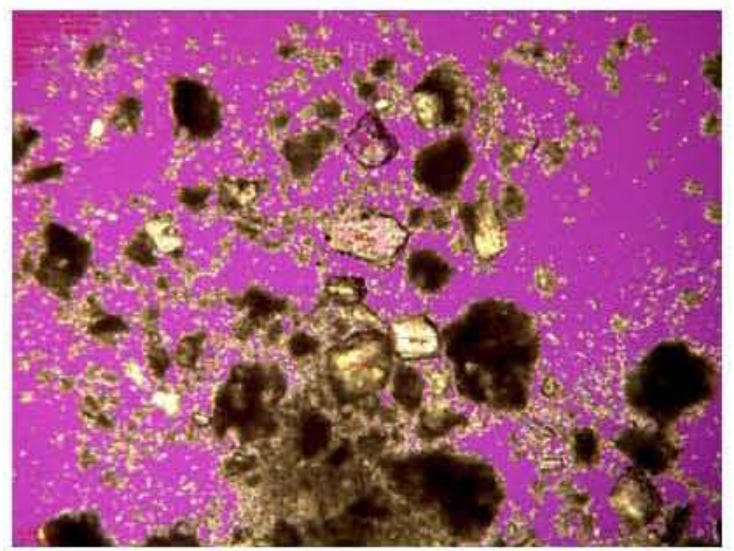

Compared to crystallizer slurry, the centrifuge cake typically contained a much higher fraction of fine crystals. Fine crystals in the cake may be caused by in situ dissolution of large crystals by unsaturated wash liquor or recycle of fines from unfiltered wash solution. Due to the high fraction of fines in this sample, this type of centrifuge cake exhibited poor liquid/solid separation and required frequent centrifuge backwashing to remove the low permeability rind.

Because small crystals agglomerate to form larger particles, screen analysis of crystal size distribution is often inaccurate in determining actual crystal size distribution of slurry and centrifuge samples. PLM analysis allowed visual analysis of crystal type, size distribution, and morphology. Thus, PLM analysis was helpful in determining the causes of poor solid/liquid separation in the centrifuge.

\subsubsection{Sodium Aluminosilicate (NAS) Gel in Simulant}

During FC Pilot Plant operation, a brown gel was observed in a retain sample of the simulant. Centrifuge cake, product, and purge samples also contained brown gel. Upon standing, the brown gel gradually settled out of feed material that was reconstituted from product and purge streams. This material was not observed in laboratory simulant or actual waste experiments. The settled brown gel layer in Tank A is shown in Figure 45. 
Figure 45. Brown Gel Settling in Tank A

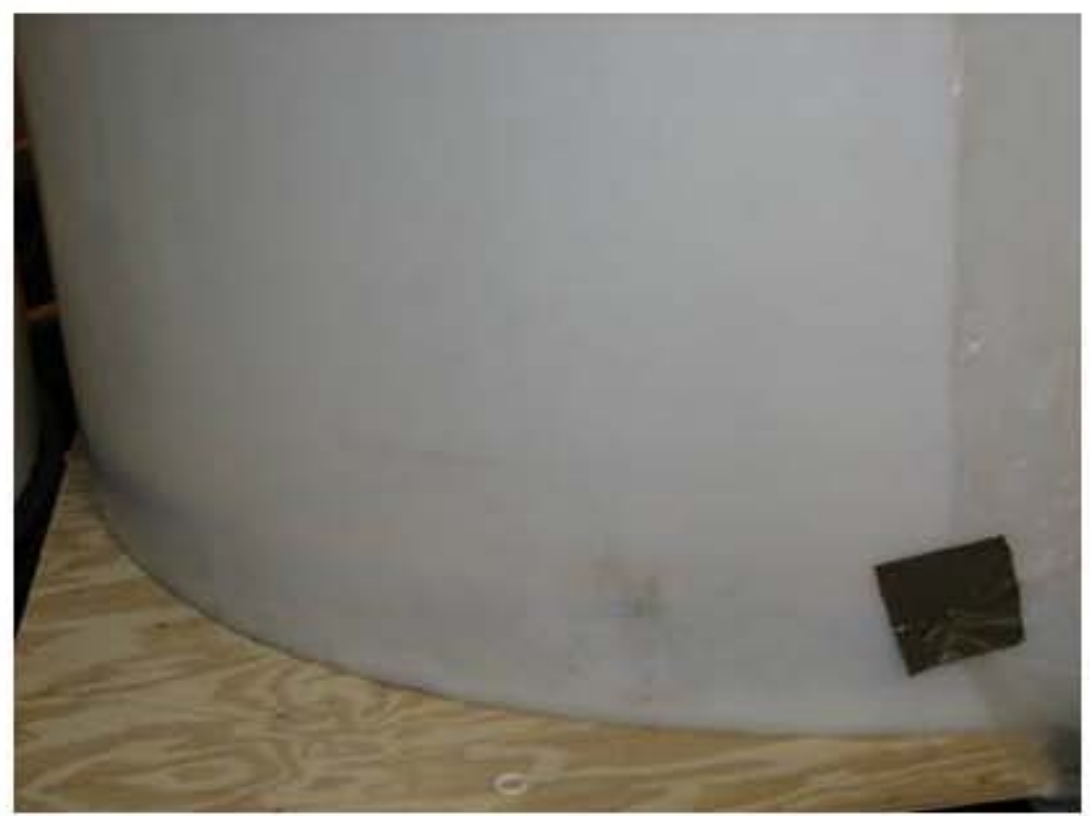

The gel layer was sampled from the tank and filtered for analysis as shown in Figure 46 .

Figure 46. Brown Gel Filtration

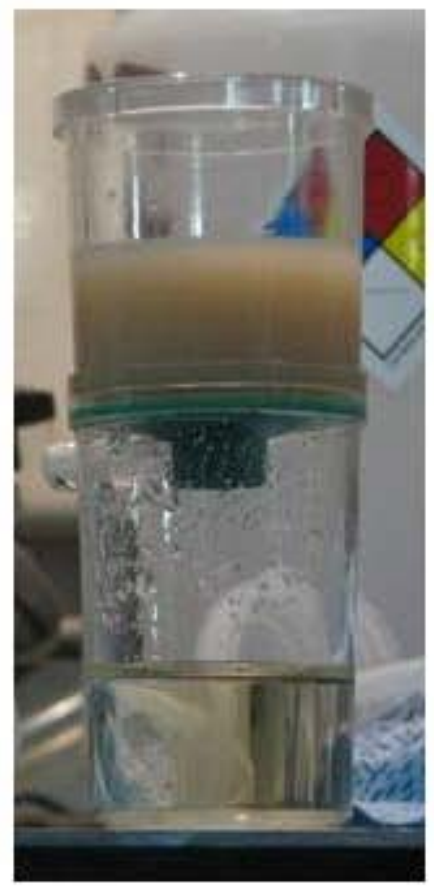


However, the gel filtered poorly, and after four days of vacuum filtration, less than one-half of the sample passed through the filter, thus the gel was unsuitable for XRD analysis. Another sample of the gel was leached in sodium hydroxide to determine if the gel was precipitated alumina. The caustic leached sample is shown in Figure 47.

Figure 47. Caustic Leached Gel

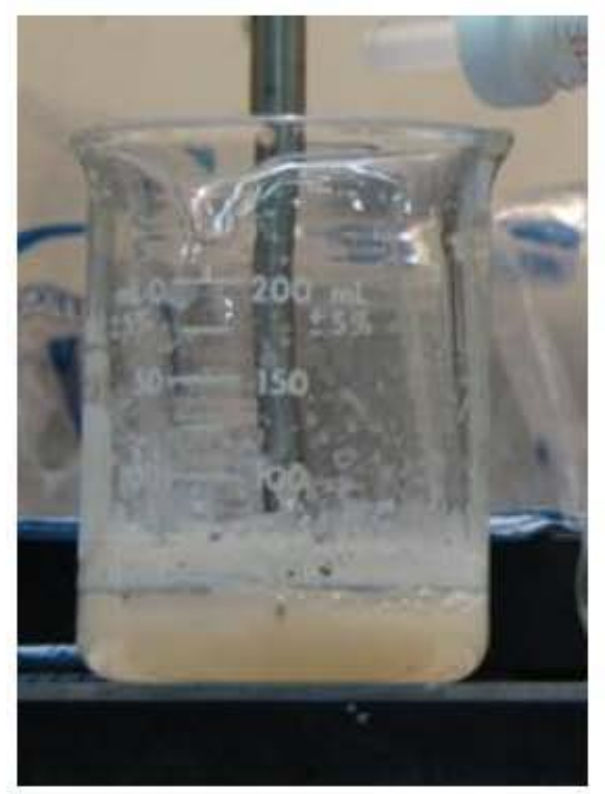

As shown above, the caustic leach of the gel did not improve the filterability of the material or allow XRD analysis.

Another portion of the gel sample was heated, followed by a lithium nitrate addition. The gel solution decomposed to a thin slurry that filtered rapidly. XRD analysis of the filter cake is shown in Figure 48.

Figure 48. XRD of Lithium Hydrotalcite/Hydroxy Sodalite

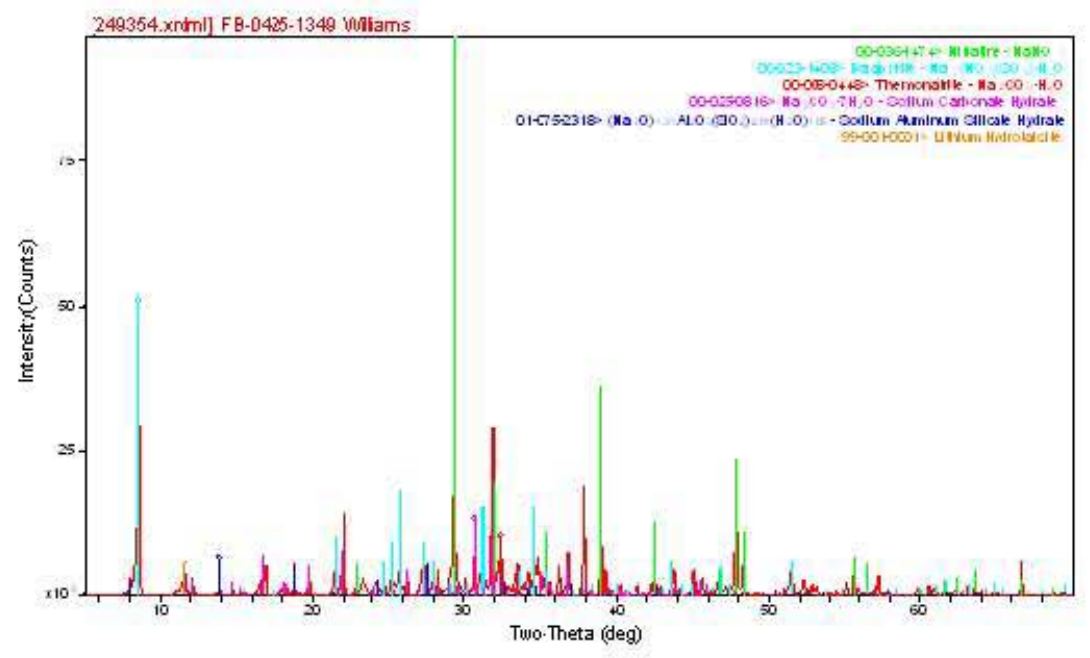


XRD analysis of the filter cake identified the presence of sodium salts $\left(\mathrm{NaNO}_{3}\right.$, $\mathrm{Na}_{3} \mathrm{NO}_{3} \mathrm{SO}_{4} . \mathrm{H}_{2} \mathrm{O}, \mathrm{Na}_{2} \mathrm{CO}_{3} .1 \mathrm{H}_{2} \mathrm{O}, \mathrm{Na}_{2} \mathrm{CO}_{3} .7 \mathrm{H}_{2} \mathrm{O}$ ) from the waste simulant liquor, the formation of Lithium Hydrotalcite $\mathrm{Li}_{2} \mathrm{CO}_{3} \cdot 4 \mathrm{Al}(\mathrm{OH})_{3} \cdot 3 \mathrm{H}_{2} \mathrm{O}$ precipitated from lithium nitrate and alumina, and Sodium Aluminum Silicate Hydrate (likely hydroxy sodalite $\left.\mathrm{Na}_{8} \mathrm{Al}_{6} \mathrm{Si}_{6} \mathrm{O}_{24}(\mathrm{OH})_{2} \cdot 2 \mathrm{H}_{2} \mathrm{O}\right)$.

ICP analysis of the feed retained sample indicated $17 \mathrm{ppm}$ silica in the supernatant. The origin of the $\mathrm{Si}$ is unknown but was suspected to originate as impurities in the original simulant chemicals. ICP analysis of the brown layer indicated roughly equal amounts of sodium, aluminum, and silicon.

Based on the ICP and XRD analysis, the gel was initially comprised of a very small amount $(\ll<1 \%)$ sodium aluminosilicate (NAS) gel $\left(\mathrm{Na}_{5} \mathrm{Al}_{6} \mathrm{Si}_{7} \mathrm{O}_{25}{ }^{\circ}{ }^{\circ} 15 \frac{1}{2} \mathrm{H}_{2} \mathrm{O}\right)$ that contained large inclusions of simulant liquor. During settling, the gel coalesced by reducing liquor inclusions.

As demonstrated by the slow filtration of the sample, NAS gel in very low concentrations can be very problematic to waste treatment. NAS gelation can result in filter and line pluggage as well as poor product quality due to inadequate solid/liquid separation.

To reduce NAS gel in the crystallizer system, feed tanks containing brown gel layers were isolated. Clear supernatant was decanted from the tops of the tanks for recycle to the process, and brown gel layers were exported to tote bins.

\subsubsection{Sodium Yield Calculations and Comparison to Flowsheet Yield}

Based on the tank inventory and specific gravity data, estimated Na yield for the period $5 / 28-5 / 31$ was approximately $52 \%$. The estimate is based upon the relative rates-of-gain of sodium inventory in the Product Tank $\mathrm{C}$ and Purge Tank $\mathrm{E}$.

The Na rate-of-gain in Product Tank $C$ is shown by the slope of the lines in Figure 49 and averaged $5.8 \mathrm{lb} \mathrm{Na} / \mathrm{hr}$ over the period. 
Figure 49. Product Tank Fill Rate

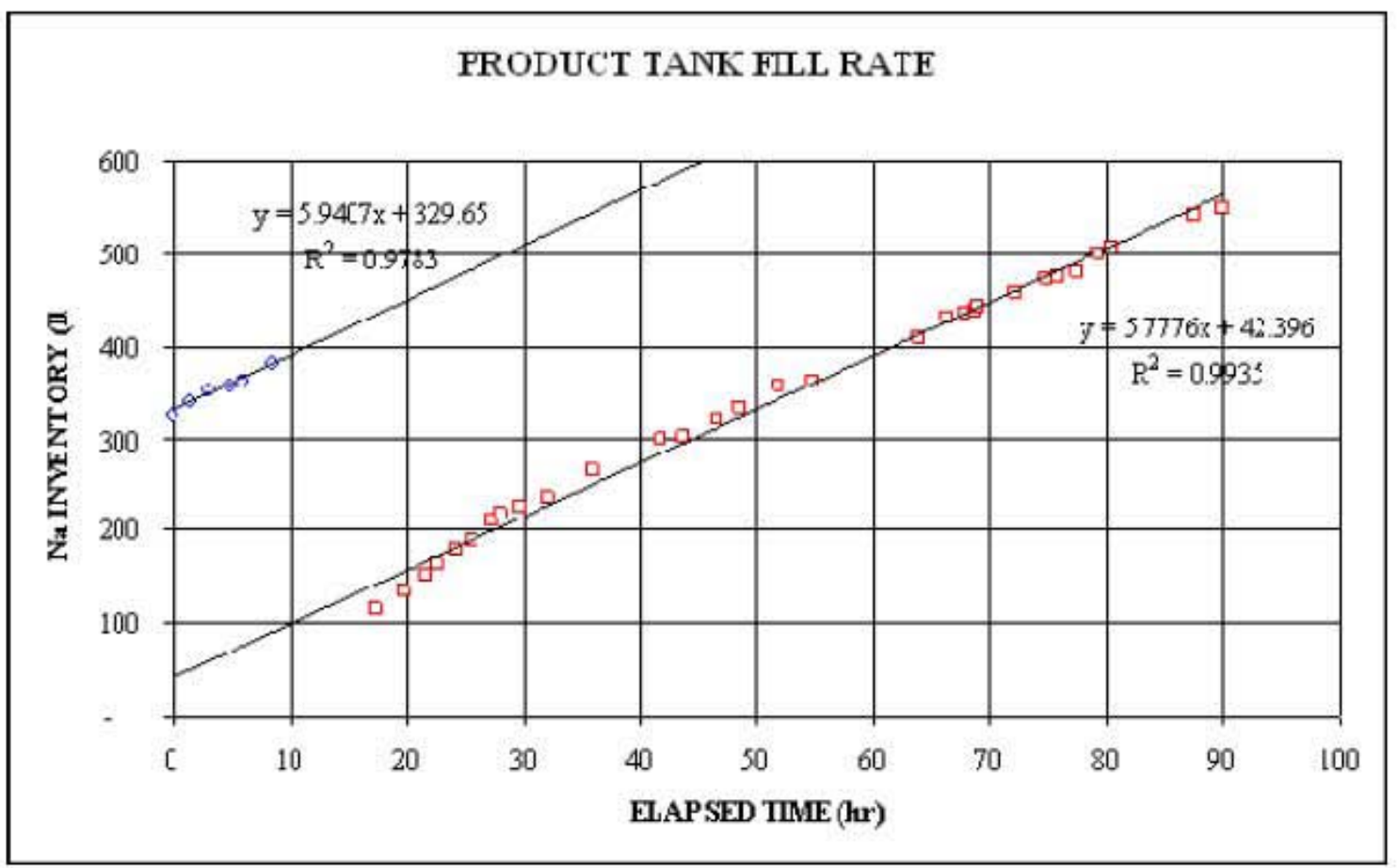

The Na rate-of-gain in Purge TankE is shown by the slope of the line in Figure 50 and averaged $5.2 \mathrm{lb} \mathrm{Na} / \mathrm{hr}$. The final 5 data points were discontinuous and were omitted from the rate calculation.

Figure 50. Purge Tank Fill Rate

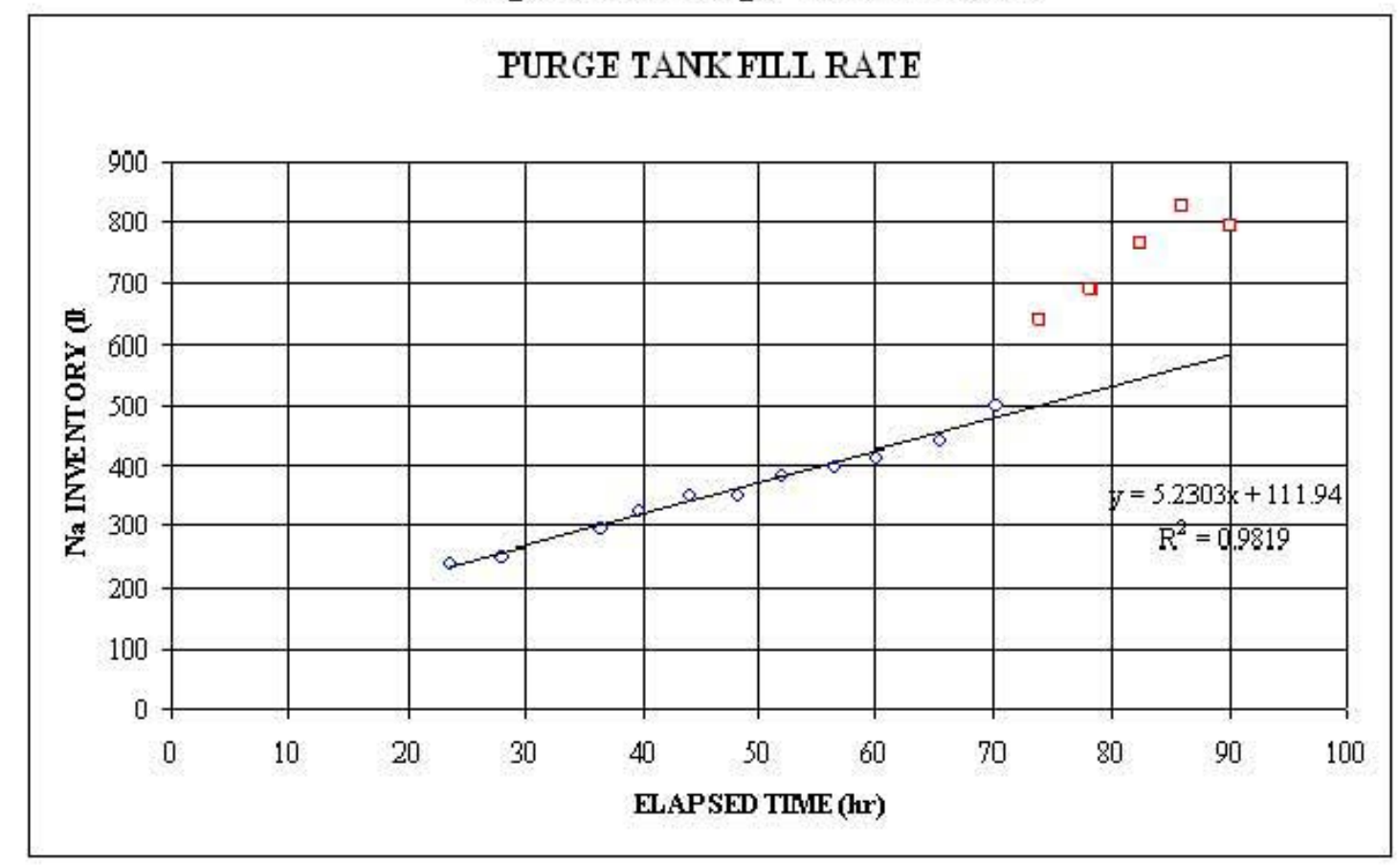


Based on the relative rates, the Na yield is Product/(Product + Purge $)=5.8 /(5.8+5.3)$ $=52 \%$

The sodium feed rate from Feed Tanks A \& B averaged $9.7 \mathrm{lb} \mathrm{Na} / \mathrm{hr}$ as shown in Figure 51.

The Na Product + Purge rate $(5.8+5.3=11.1)$ exceeds the Feed Rate $(9.3 \mathrm{lb} / \mathrm{min})$ because the sodium inventory (as indicated by specific gravity) in the crystallizer was decreasing at an average rate of $-1.96 \mathrm{lb} \mathrm{Na} / \mathrm{hr}$ as shown in Figure 52.

Figure 51. Sodium Feed Rate

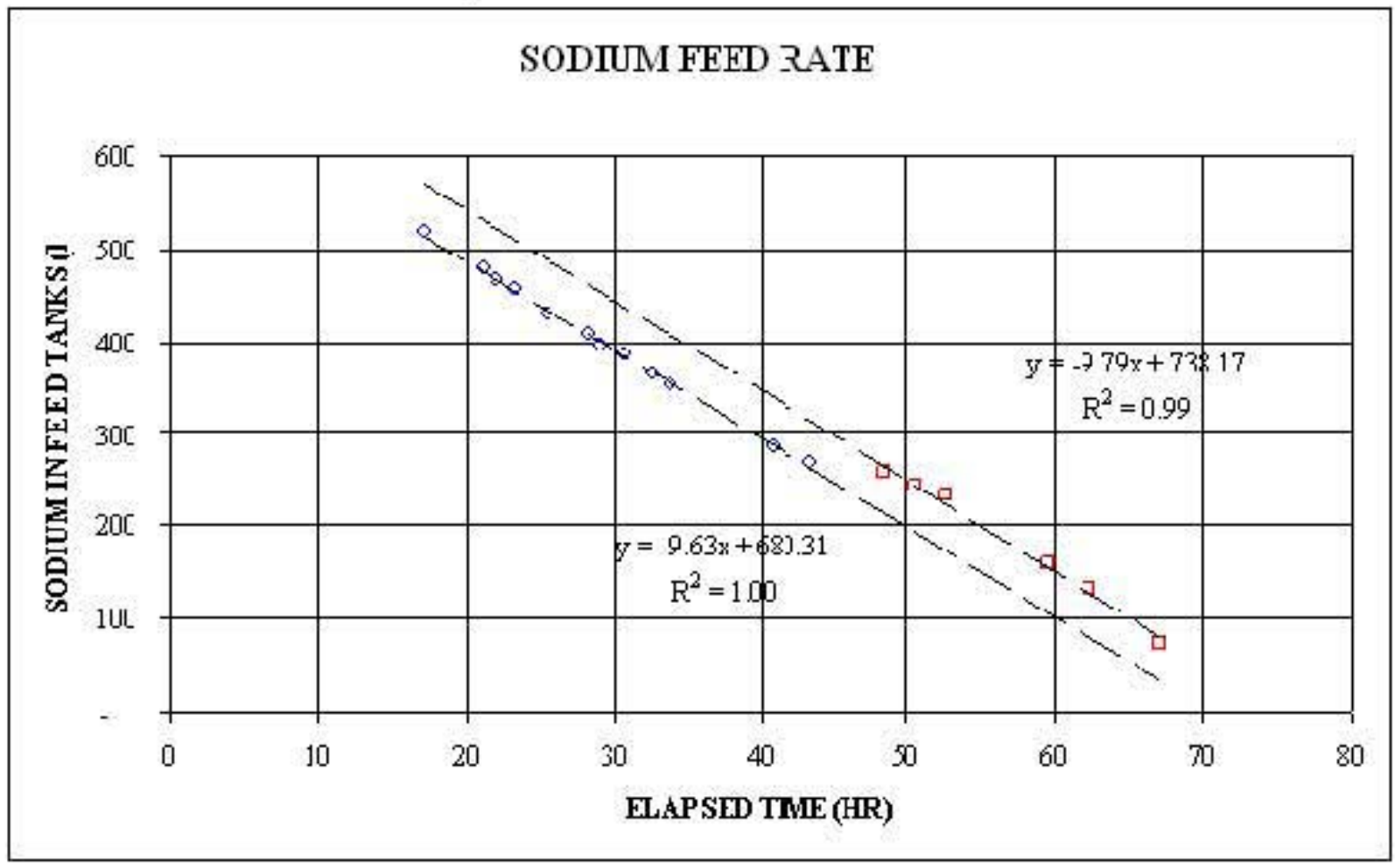


Figure 52. Crystallizer Sodium Inventory

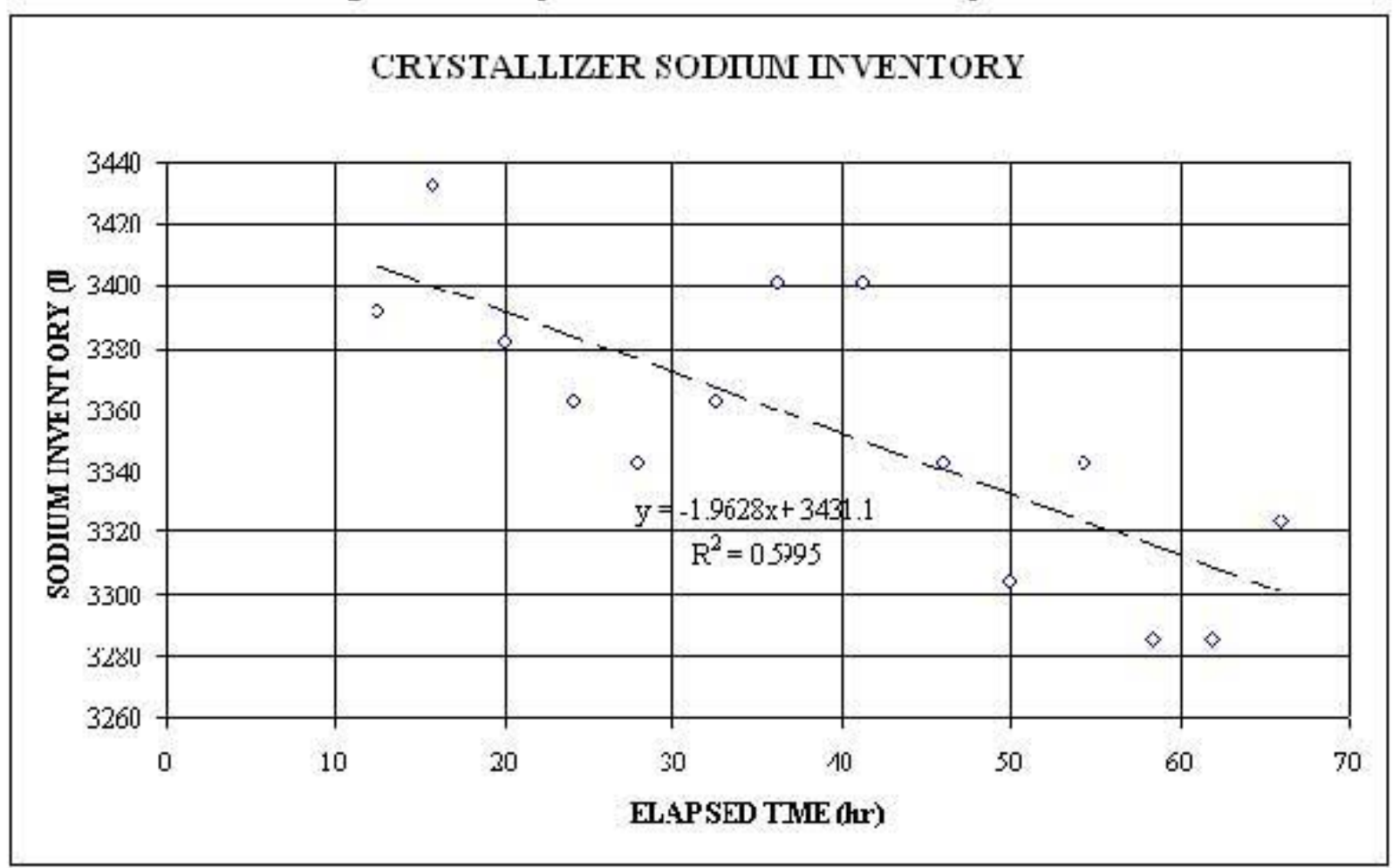

Total In $=9.63+1.96=11.6 \mathrm{Na} / \mathrm{hr}$

Total Out $=5.8+5.3=11.1 \mathrm{Na} / \mathrm{hr}$

Difference $(11.6-11.1 \mathrm{y} 11.6=4 \%$

For a specific feed composition (e.g. SST Early) a correlation between the sodium yield and crystallizer vapor pressure at constant temperature is possible, since the vapor pressure decreases with the extent of evaporation and the sodium yield is proportional to the solids fraction (solidsitotal slumy). This correlation assumes that all solids formed in the crystallizer are separated in the centrifuge. A graph of the correlation of crystallizervapor pressure at $131^{\circ} \mathrm{F}$ to sodium yield is shown in Figure 53. 
RPP-39091, Rev. 0

RPT-3000755 Rev. 000

Figure 53. Correlation of Crystallizer Vapor Pressure to Sodium Yield at $131^{\circ} \mathrm{F}$

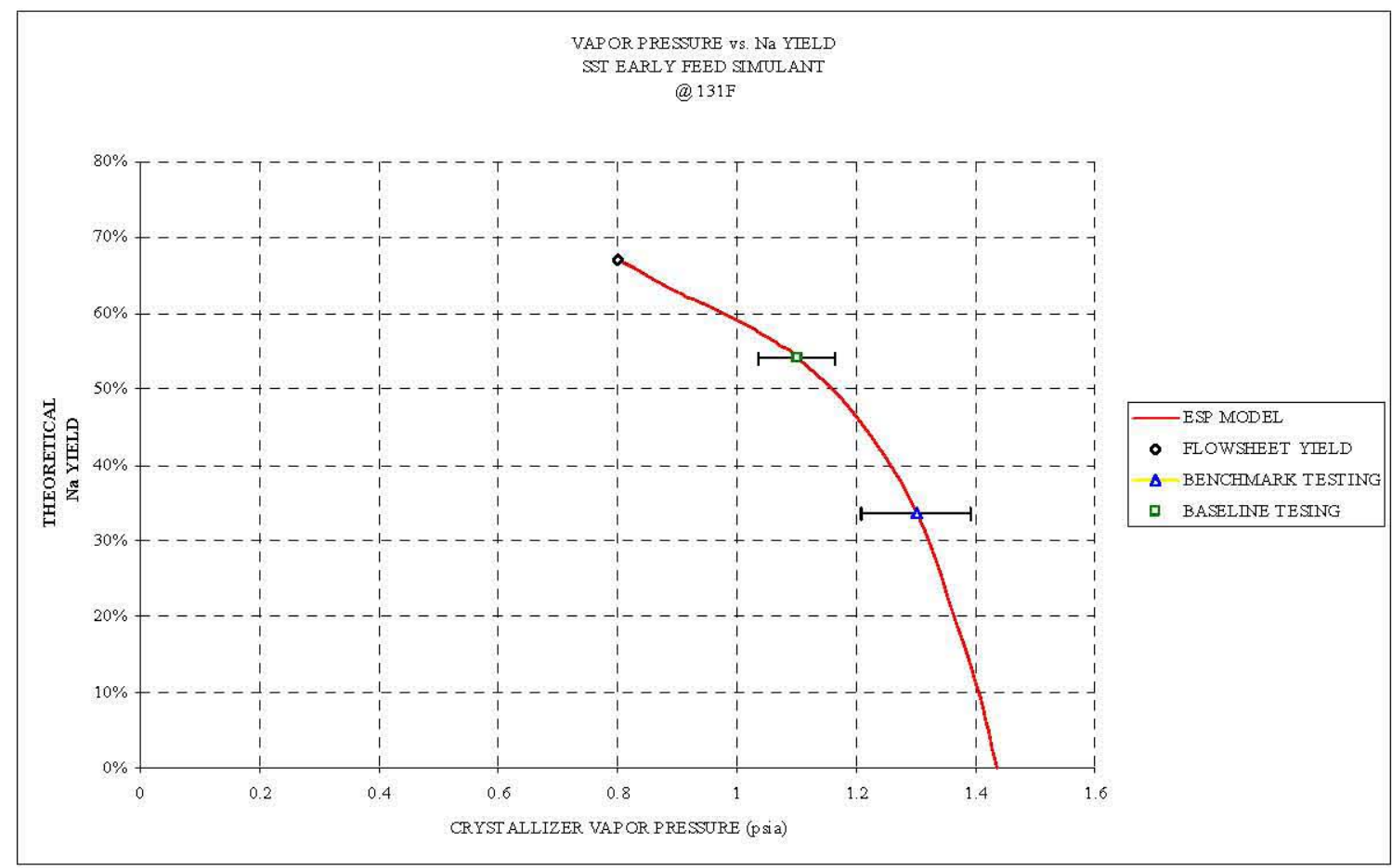

During benchmark testing, liquor was not recycled from the spent liquor tank to the crystallizer. By this method, the crystallizer acts as a one-pass crystallizer where the yield is limited by the maximum slurry density. During benchmark testing, crystallizer pressure averaged 1.3 psia at $131^{\circ} \mathrm{F}$, which corresponds to a $34 \%$ sodium yield.

During baseline testing, liquor was recycled from the spent wash tank to the centrifuge. This lowers slurry density in the crystallizer and allows a greater extent of evaporation. During baseline testing, crystallizer pressure averaged $1.1 \mathrm{psia}$ at $131^{\circ} \mathrm{F}$, which corresponds to a $54 \%$ sodium yield. This value agrees with the mass balance yield calculated above $(52 \pm 4 \%)$.

Flowsheet sodium yield was $67 \%$. This yield was demonstrated in two-stage laboratory tests, and it is possible in a continuous system at higher liquor recycle rates and a greater extent of evaporation. At the flowsheet sodium yield, crystallizer vapor pressure is $0.8 \mathrm{psia}$ at $131^{\circ} \mathrm{F}$.

\subsection{LESSONS LEARNED}

One of the most important aspects of any pilot-scale testing is to identify lessons learned during pilot scale design, construction, and operations because they may be used for scale-up. In nuclear facilities, this is even more important since design changes and maintenance issues become very challenging in a full-scale facility. 
RPP-39091, Rev. 0

RPT-3000755 Rev. 000

\subsection{Hardware}

\subsubsection{Centrifuge}

The single most important piece of hardware that needs upgrade is the centrifuge. Many process upset conditions resulted from the mismatch of centrifuge capacity to the rest of the system as elaborated below.

\subsubsection{Centrifuge Capacity}

The centrifuge capacity turned out to be much lower than the production rate of the crystallizer. Cycle time for centrifuge operation was approximately 16 minutes. The process flowsheet was based upon the assumption that the cycle time would be 4 to 5 minutes. Longer cycle times resulted in lowered production capacity.

Centrifuge throughput was low due to high fines loading because of temperature cycling of the crystallizer and the recycle of fines from the product dissolver due to failure of the cross-flow filter. Fine particles, high rotational speed, and long cycle times caused centrifuge cake to compact, thus lowering cake porosity and the extent of deliquoring and decontamination. As a result, the centrifuge required frequent heel removals to clean the screen and improve cake permeability for successive cycles.

Additionally, the centrifuge was operated conservatively (thinner cake thickness) to minimize or limit feed overflow into the product tank. More-frequent-than-expected heel removals also reduced capacity. Thus, the combined effect was that the centrifuge capacity was about $5-8$ times lower than the crystallizer and balance of the pilot facility.

\subsubsection{Product Chute Pluggage}

The centrifuge peeled product discharged by gravity through a 4 inch diameter product chute which penetrated through the centrifuge door. The peeler knife and other internal hardware leading to the product chute were configured in a way that peeled wet cake tended to buildup at the mouth of the chute. After about a dozen centrifuge cycles, the chute entrance plugged and required extensive washing and clearing. If the crystal cake was not deliquored completely, the pluggage occurred earlier.

Chute pluggage was the primary reason that the spin cycles were long and the overall cycle time was much longer than anticipated. Long cycle time resulted in cake compaction and lower cake permeability. Thus, by increasing the cycle time and extent of deliquoring, the frequency of backwashing the screen also increased, thereby lowering the production rate.

Larger (production-scale) centrifuges are equipped with a screw auger that is essential to preclude the pluggage experienced in the pilot scale tests. 


\subsubsection{Centrifuge Cleaning}

Due to the pluggage described above, a considerable time was spent on cleaning the centrifuge through the product chute after pluggage. This also caused processupset conditions because a lot of condensate was added for cleaning. The excess condensate diluted the in-process tanks, as well as the product and reconstituted feed. A diluted feed dissolved slurry in the crystallizer and potentially reduced crystal quality.

Large pharmaceutical centrifuges have self-cleaning hardware, thus minimizing the amount of wash liquids. Additionally, the centrifuge should have PLC control of speed for heel removal.

\subsubsection{Crystallizer}

\subsubsection{Crystallizer Control}

The crystallizer's function was to concentrate the slurry to the desired density while maintaining the temperature within a narrow operational range. The temperature was controlled by the system vacuum. The crystallizer vacuum was controlled by bleed air into the vacuum system.

The bleed-air control valve was undersized for the application. To increase the bleed air rate, compressed air was connected to the bleed valve and the compressed air was manually controlled by a mass flow controller. However, the air controller required continuous monitoring and adjustments. Stable pressure control was not attained, and crystallizer pressure and boiling temperature fluctuated erratically.

Because of temperature fluctuations, crystal size distribution in the crystallizer varied from sample-to-sample. When the temperature dropped, fine crystals nucleated; when the temperature rose, coarse crystals dissolved. As a result of the irregular size distribution, the non-uniform slurry was difficult to process in the centrifuge.

It is recommended that the crystallizer pressure control system be upgraded before further testing.

\subsubsection{Sampler Hardware}

Initially, a $1 / 2$ " valve and a length of pipe were installed to pull slurry samples from the slurry loop. This arrangement resulted in frequent pluggage. Later on, another sampling scheme with condensate flush line was implemented with reasonable success. It is recommended that an Isolok type of sampler be installed prior to further work. 


\subsubsection{Pumps}

\subsubsection{Double Seal Pumps}

The existing process tank pumps were selected based upon the information that there will be no solids in the process tanks. However, during the testing, it was observed that the process tank did have solids as testing progressed. This caused two process tank pump failures. Future testing will need pumps with double seals and clean flush liquids.

\subsubsection{Double Diaphragm Pump}

The existing double diaphragm pump in the Feed/Receipt Tanks area caused a great deal of vibration in the associated piping. This pump should be replaced by a large capacity centrifugal pump with priming capability.

\subsubsection{Heaters}

The electric heaters for the process tanks required more power to reduce the time to reach process temperature. As a result, the heater fuses frequently blew, and the wash solutions did not achieve the required process temperature. Additionally, the heater controls need to be reevaluated for a trouble free operation.

\subsubsection{Instrumentation}

Several instrumentation systems need re-evaluation or improvements as listed below.

- Replace level instrumentation for process tanks

- Use diaphragm type pressure gauges on process tanks

- Re-evaluate deaereators on crystallizer level and density measurements

- Lower PD density pressure tap

- More accurate steam flow measurement

\subsubsection{System Configuration}

Prior to further testing on the FCPP many system configuration changes will be needed as provided below.

- Need additional condensate flush lines

- Consider circulating loop with small draw-off for feed and SW recycle

- Consider automatic SW flush of centrifuge feed line

- Provide double valve isolation or other hardware changes to facilitate lock $\&$ tag

- Consider additional proportional flow control valves 
RPP-39091, Rev. 0

RPT-3000755 Rev. 000

\subsubsection{Controls}

For a complex system like this facility, it is very important for various control functions to operate properly. Otherwise, it becomes very labor intensive to monitor and adjust parameters manually. The following control functions need to be reevaluated.

- Better evaluation of control loops

- Automatically adjust bleed air to crystallizer temperature

- Automatic control of crystallizer level by feed rate

- Automatic control of reboiler steam

- Working DAS PID controls

- Robust process tank heater controls

\subsubsection{Reboiler Steam Supply}

The original design of the desuperheater in the steam supply for the reboiler used a single conical spray nozzle to inject water into the 6" steam supply pipe downstream of the control valve that dropped the pressure from 125 psig to about 3 psia. It was observed that the conical spray nozzle did not work above about $5 \mathrm{lbs} / \mathrm{hr}$ of steam even when considerable excess water was supplied. The single conical spray nozzle was replaced with two back-to-back "fog" nozzles (Bete 1/4PJ40) operated at about 3 times the flowrate theoretically needed to desuperheat. That provided satisfactory operation up to the maximum $11.5 \mathrm{lb} / \mathrm{hr}$ of steam the generators could produce.

\subsubsection{Rapid Isolation From Vacuum System}

Originally, a valve in the air supply to the reboiler steam control valve was provided that allowed manual shut off of the steam as part of emergency shutdown. This valve was located near the control station to allow very rapid response. Whenever steam was suddenly shut off, the pressure would rapidly change in the crystallizer unless immediate and correct action was taken to control the bleed air to the vacuum system. After operating for a while, it was determined that rapid isolation of the crystallizer from the vacuum system was the appropriate action to be taken. The crystallizer has very little air in-leakage and is so large that the pressure does not rise appreciably for several hours. However, if the pressure decreases slightly the crystallizer contents boil violently leading to a rapid temperature decrease and subsequently further reduces the pressure. The rapid temperature drop drives the formation of many fine crystals which adversely impacts centrifuge efficiency and operations. Isolating the crystallizer from the vacuum system significantly reduces pressure decreases. An air actuated isolation valve needs to be installed between the crystallizer and the vacuum system. 
RPP-39091, Rev. 0

RPT-3000755 Rev. 000

\subsection{Operations}

\subsubsection{Operating Philosophy}

Operation of the FC pilot scale facility required a unique blend of conduct of operations and conduct of R\&D activities. In the operations arena, the processes are well defined and well understood. The operations require a set of instructions that any operator can follow to yield the same results. In R\&D world, the sole purpose of testing is often to learn the process itself while maintaining safe conditions. Thus every possible off-normal condition cannot be identified prior to testing. This requires process knowledge and operational experience to make decisions during testing. After a decision is made to resolve a given off-normal condition, step by step instructions are needed to guide the remaining shift staff. Under such conditions, it is not practical to revise the entire set of work instructions. Instead, R\&D directions were written to address a specific issue. This mode of operation requires a complete and consistent understanding of system by all test engineers. Future testing will require more training on off-normal conditions and their response. For successful pilot scale operations, it has been SRNL's experience that the same people who build the system should operate it. This provides the best opportunity to learn such a complex system.

Another aspect of operations is to plan lockouts and the associated paperwork ahead of time. Often, the system lockouts are needed to resolve a technical problem immediately and any delay due to lockout preparations can further degrade the process condition.

\subsubsection{Training}

During the pilot scale tests it became obvious that more in-depth understanding of the system was needed for all test staff. During any unanticipated off-normal conditions, the operational instructions were not always written and ready. Hence, a thorough understanding of the process and various subsystem interactions is paramount in restoring the normal operations. Future work must be started after more training on the science behind various processes.

Similarly, more training on DAS operations will be needed before future testing. In case of unexpected shutdown of DAS or power interruptions, all test staff must have a clear understanding of how to restart DAS and create new data logs.

\subsubsection{Staffing}

Due to the mismatch of the centrifuge and the crystallizer and unsatisfactory performance of P\&ID controllers, operations of the pilot facility became very labor intensive. Additionally, sample drawing and their preparation were also time consuming. Based upon the operational experience to date it is recommended that the following additional staff be considered for future testing: 
RPP-39091, Rev. 0

RPT-3000755 Rev. 000

- One more technician per shift

- An additional engineer per shift

- QEW on each shift

- Lock \& Tag worker on every shift

\subsubsection{Shift Turnover}

The pilot scale facility was operated around the clock for several weeks by two 12-hour shifts. Each shift was comprised of a Test Engineer and a Lab Technician. At the end of every shift, a formal turnover was performed and documented by outgoing and incoming shifts. This process needs to be revised to ensure better understanding of the facility status at turnover. Since many control functions were performed manually, a detailed turnover process is needed. In particular, shift personnel coming after long breaks require more briefing about the facility status and test history during their time off.

\subsection{FULL-SCALE PROCESS DESCRIPTION}

The full-scale fractional crystallization system is similar to the pilot facility. However, due to the hazardous properties of the actual waste, the system is shielded and remotely operated. Process control is automatic and control systems are remote from the process.

In the full-scale system, two crystallizer systems are used. Depending upon the composition of the feed and product requirements, the crystallizer systems may be operated in series or in parallel. Parallel operation allows the highest throughput; the first stage may be used to evaporate a dilute feed to saturation prior to crystallization. Series operation allows the highest extent of cesium decontamination.

In series operation, the first crystallizer produces a rough separation of low solubility sodium nitrate, carbonate, and sulfate from high solubility cesium nitrate, sodium hydroxide, sodium aluminate, other high solubility salts (e.g. potassium hydroxide, organic salts). After product dissolution, the second crystallizer recrystallizes the lowsolubility salts and decontaminates the product to the required Cs DF.

By this method, the extent of cesium decontamination is greatly increased, since the results of two-stage crystallization on Cs DF are multiplicative (e.g. Cs DF Stage $1=$ 124 , Stage $2=56$, Overall Cs DF $=124 \times 56=6,944$ ). Overall sodium yield is similar to an one-stage crystallization, since the second stage purge is recycled to the first stage.

A process flow diagram of the proposed two-crystallizer system is shown in Figure 54. A block flow diagram and mass balances are shown in Figure 55 and 56 , respectively. The mass balances are based on Group 1 IPS feed with a 1,175 MT $\mathrm{Na} /$ year at a $70 \%$ onstream factor. Estimated theoretical sodium yield is $67 \%$ and cesium DF is 6,937 . 
RPP-39091, Rev. 0

RPT-3000755 Rev. 000

Figure 54. Two Stage Crystallization Process Flow Diagram

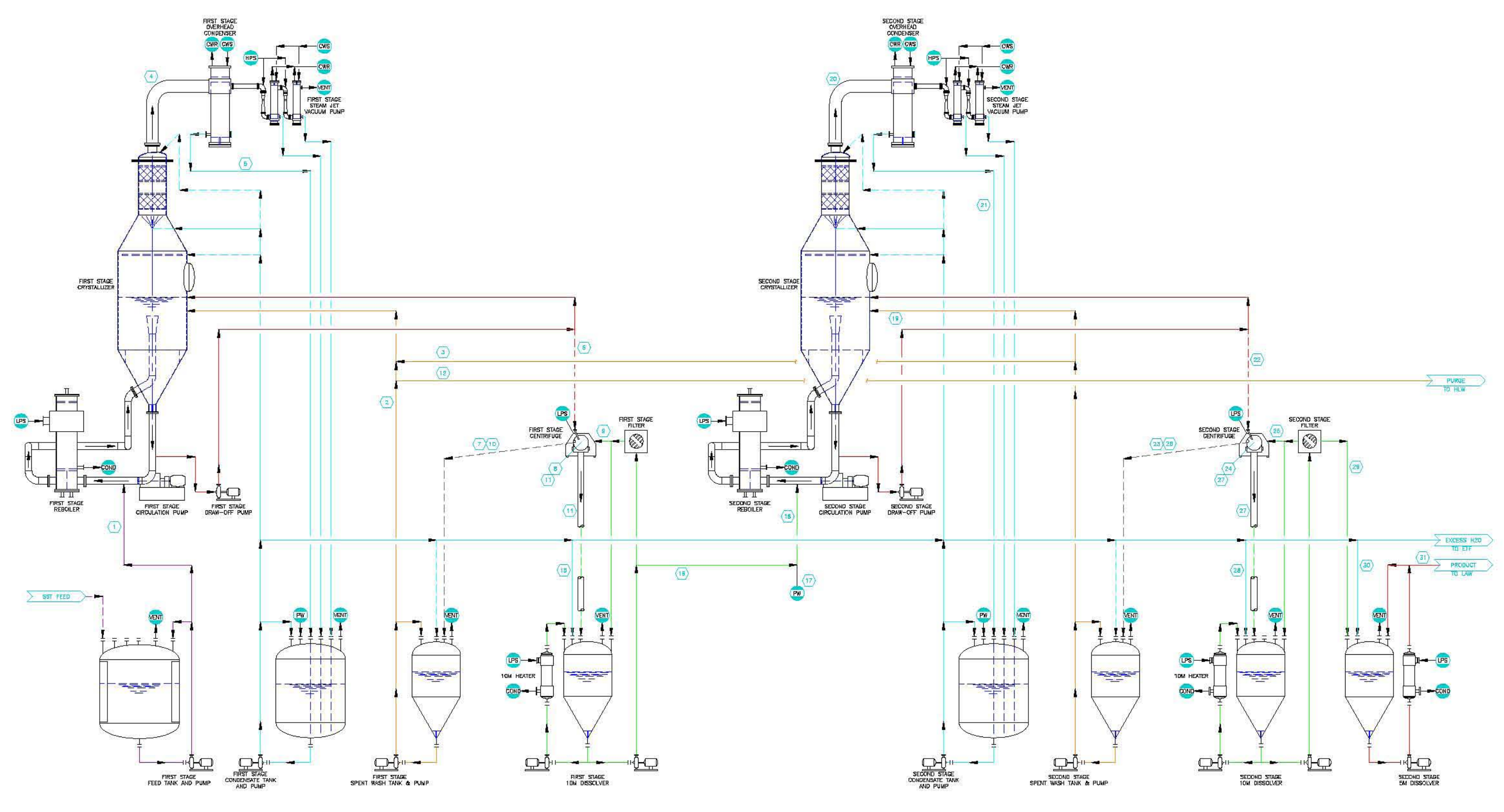

Page 89 
Figure 55. Two Stage Crystallization Block Flow Diagram

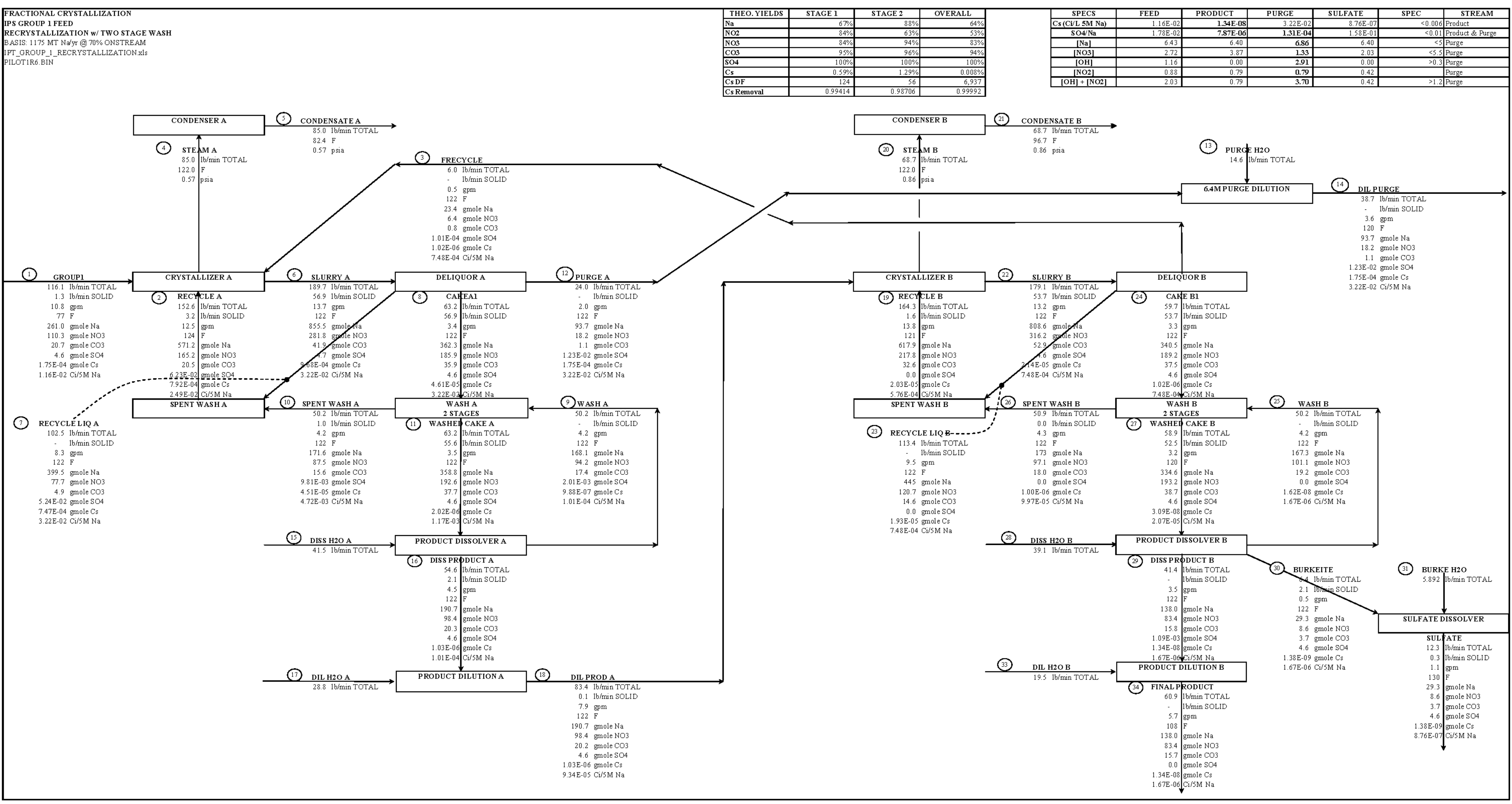


Figure 56. Two-Stage Crystallization Mass Balance

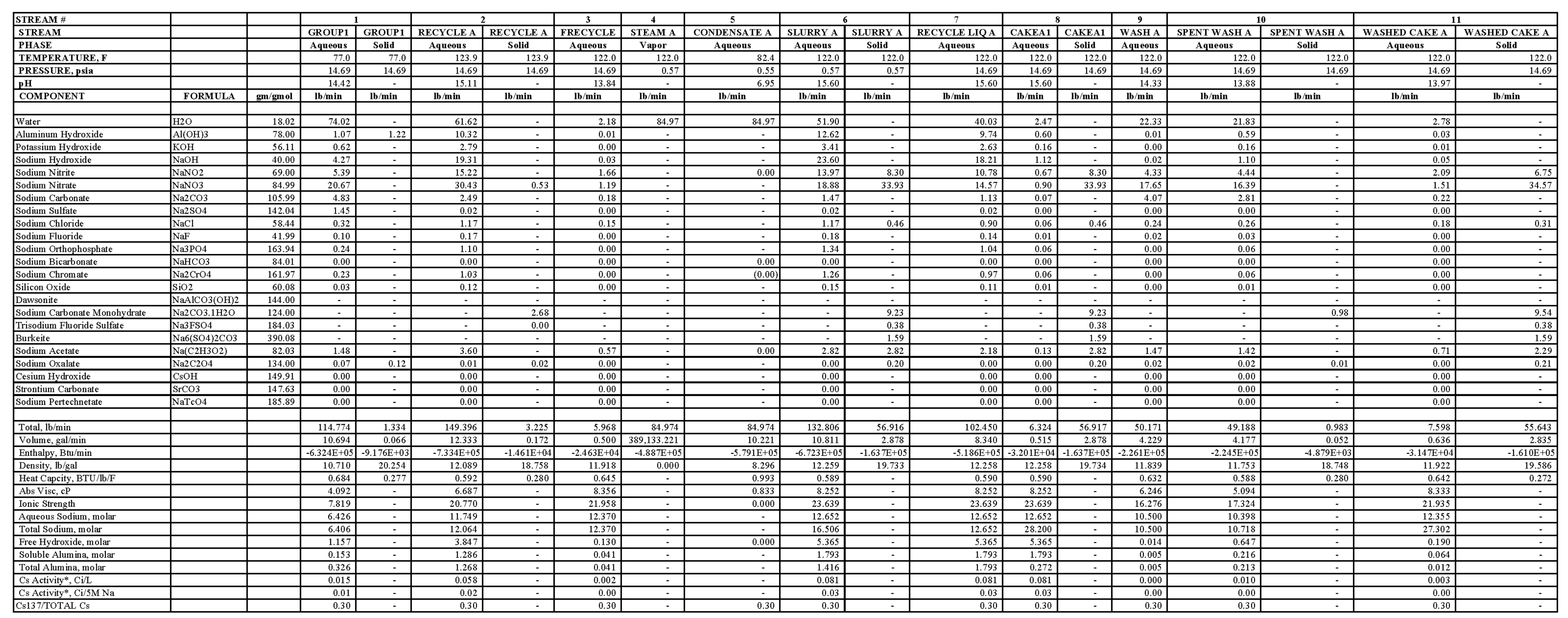




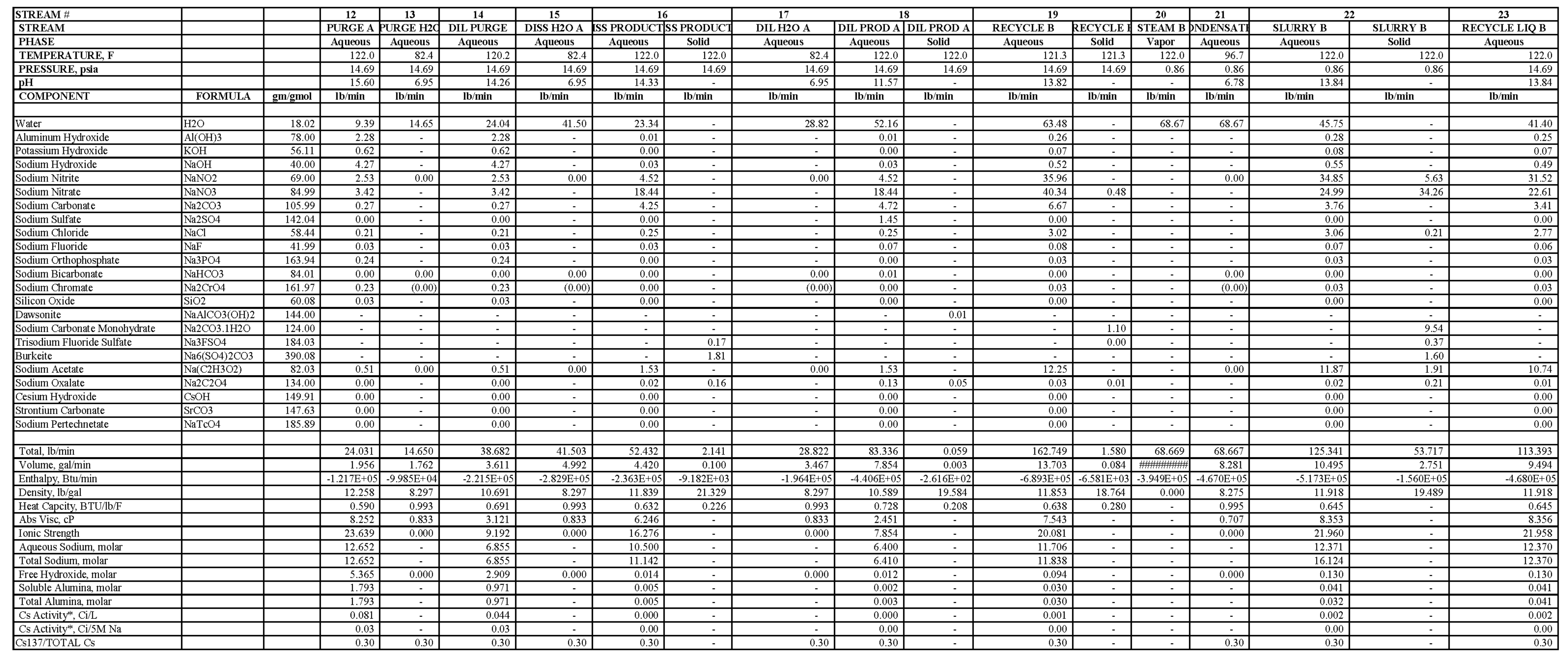




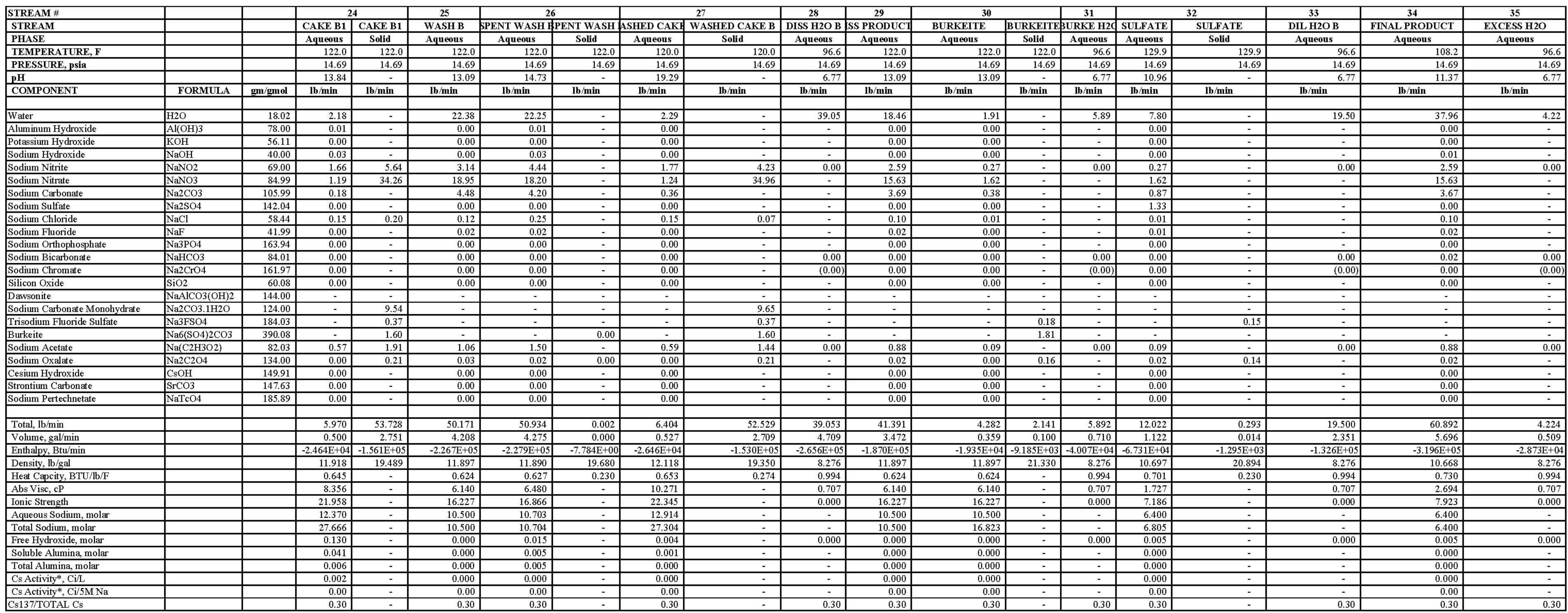


RPP-39091, Rev. 0

RPT-3000755 Rev. 000

Tank waste is first filtered to remove suspended solids. Filtrate flows to the Feed Receipt Tank, which provides buffer storage capacity. Waste feed is transferred continuously to the first stage crystallizer to maintain stable steady-state operating conditions.

The crystallizer is operated under vacuum (typically .035 to 0.1 atmospheres absolute) to maintain boiling temperatures in the 40 to $60^{\circ} \mathrm{C}$ range needed for crystallization. A relatively large recirculation stream flows from the bottom of the crystallizer through the steam-heated reboiler, which provides heat for evaporation. The crystallizer is sized for an eight-hour residence time.

Steam from the crystallizer flows through a demister in the top of the crystallizer to remove droplets and aerosols, and then flows to the first stage condenser where the bulk of the water vapor is condensed. Remaining water vapor and non-condensable gases then flow through two steam jet eductors with condensers that maintain vacuum on the crystallizer. Pressure on the crystallizer is maintained by control of purge air into the steam jet system. Non-condensables are filtered prior to discharge to the environment

Process condensate is collected from the primary condenser and steam jets and is used for dissolution and dilution of product as needed. Surplus process condensate is transferred to an external treatment facility, assumed to be the Effluent Treatment Facility (ETF). Efficient de-entrainment is required to remove waste particles from steam generated in the crystallizer. To assure ETF acceptance requirements for ${ }^{137} \mathrm{Cs}$ are met a minimum decontamination factor of $3 \times 10^{5}$ is specified as a design requirement for the crystallizer overhead steam system.

Slurry containing crystals and liquor is drawn off the crystallizer and pumped to a centrifuge for deliquoring and decontamination. The slurry is initially deliquored to $90 \%$ solids by centrifugal force in the centrifuge. Then a recycled product stream (10 M Na) is sprayed on the centrifuge cake to displace interstitial contamination.

The centrifuge cake is discharged to a product tank where dissolution, heating, and filtration occur. The product is dissolved to $10 \mathrm{M} \mathrm{Na}$ to produce liquor that is saturated in sodium nitrate for recycle washing of the filter cake. A heater maintains the heat during endothermic dissolution of sodium nitrate. The liquor is oversaturated in sodium sulfate and carbonate. A filter removes the suspended solids from the recycle to the centrifuge.

A portion of the spent liquor stream discharged from the centrifuge is recycled to the crystallizer, while the remainder is purged to the Cesium Product Tank. The purge is diluted with water to $6 \mathrm{M} \mathrm{Na}$ in the Cesium Product Tank prior to return to a DST to prevent crystallization upon cooling.

The second stage crystallizer system operates essentially the same as the first stage, except that feed comes from the first stage dissolver and the purge is recycled to the first stage crystallizer. The second stage dissolver and product filter separates undissolved sulfate from the LAW product. Sodium concentration is controlled at $10 \mathrm{M}$ Na so that the sulfate remains as undissolved crystals. It is separated from the bulk of the LAW product by filtration. The high-sulfate stream from the filter is collected in a separate High Sulfate 
RPP-39091, Rev. 0

RPT-3000755 Rev. 000

Product Tank and may be split between the LAW Product Tank and the Cesium Product Tank in order to control the amount of sulfate in the LAW product. The combined LAW products are accumulated in the LAW Product Tanks and the final product is further diluted with water to dissolve remaining crystals prior to transfer to WTP.

Because the first stage delivers a concentrated product, the second-stage crystallizer evaporation duty is lower than the first stage. Operating conditions and stream properties in the second stage may also be different because of the reduced concentration of high solubility waste components such as sodium and potassium hydroxide and sodium aluminate. The absence of these components in the second stage allows a higher extent of evaporation and a higher sodium yield ( $88 \mathrm{vs.} 67 \%$ ) than the first stage. As a result, the second stage requires a higher liquor recycle rate from the centrifuge to maintain the slurry solids fraction $<30 \%$. At the same operating temperature, the second crystallizer has higher vapor pressure due to the lack of high-solubility salts.

The process is controlled to maintain steady-state operation of the entire crystallizer system. Process variables, including temperatures, pressures, crystallizer slurry density, flow rates, tank levels, etc. are measured and controlled to maintain process variables at set point values. The crystallizer level is maintained constant by feed makeup. The crystallizer temperature is controlled by vacuum control in the overhead system. The evaporation rate is controlled by the steaming rate in the reboiler. The slurry density and solids fraction are maintained by the centrifuge production rate and spent liquor recycle rate.

Routine sampling and analysis is not expected to be needed for process control, assuming the feed has been characterized in advance for each batch. Sampling of selected process streams is performed occasionally on an as-needed basis to support optimization, troubleshooting, and regulatory compliance documentation. Efficiency of ${ }^{137} \mathrm{Cs}$ decontamination in each crystallizer stage is monitored in real time by measuring gamma radiation dose rates of the dissolved product. Amount of dissolved product recycled for washing centrifuge cake is adjusted as needed to assure target ${ }^{137} \mathrm{Cs}$ decontamination is achieved. Off-specification product is diluted and recycled to the crystallizer feed tank.

Process lines containing slurry are heat traced and insulated to prevent cold spots where pluggage may occur. Draining and flushing capability is provided to prevent line pluggage, reduce personnel dose rate, and allow certain maintenance functions to be performed. Capability is provided to empty the crystallizer contents to the feed tank during unplanned shutdowns.

\subsection{Full-Scale Equipment List}

The following equipment list and facility layouts are excerpted from report RPP-RPT-37551, 2008, Project W-551 Interim Pretreatment System Pre-conceptual Candidate Technology Descriptions. The equipment sizing was based the flowsheet and mass balances from the previous section. Design capacity was based on Group 1 IPS feed with a 1,175 MT Na/year at a $70 \%$ onstream factor. 
Table 12. Fractional Crystallization Equipment List (11 sheets)

\begin{tabular}{|c|c|c|c|c|c|}
\hline Qty & Component & Process Sizing & Physical Dimensions & Features & Comments \\
\hline$\overline{1}$ & Feed Receipt Tank & $\begin{array}{l}32,000 \text { gal total } \\
\text { capacity }\end{array}$ & 17.6-ft D x 17.6-ft H & $\begin{array}{l}\text { Clean out jet to empty } \\
\text { tank in case of failed } \\
\text { pump } \\
\text { Nozzles: (3) process } \\
\text { piping } \\
\begin{array}{l}\text { (1) off gas } \\
\text { (1) pump } \\
\text { (3) }\end{array} \\
\text { instrumentation } \\
\text { (1) PRV } \\
\text { I\&C: Level } \\
\text { Temperature } \\
\text { Pressure control } \\
\text { (offgas) }\end{array}$ & $\begin{array}{l}\text { Provides } 1 \text { day of crystallizer feed for } \\
\text { the worst case feed flow rate }\end{array}$ \\
\hline 1 & $\begin{array}{l}\text { Feed Pump, Crystallizer } \\
1\end{array}$ & $25 \mathrm{gpm}$ & & $\begin{array}{l}\text { Tank top mounted, vertical } \\
\text { pump } \\
\text { I\&C: Discharge pressure } \\
\text { Flow control } \\
\text { VFD }\end{array}$ & $\begin{array}{l}\text { Flow rate is the maximum waste feed } \\
\text { flow rate of } 17.3 \mathrm{gpm} \text {. }\end{array}$ \\
\hline
\end{tabular}


Table 12. Fractional Crystallization Equipment List (11 sheets)

\begin{tabular}{|c|c|c|c|c|c|}
\hline Qty & Component & Process Sizing & Physical Dimensions & Features & Comments \\
\hline 2 & LAW Product Tanks & $\begin{array}{l}23,000 \text { gal total } \\
\text { capacity }\end{array}$ & 15.8-ft D x 15.8-ft H & 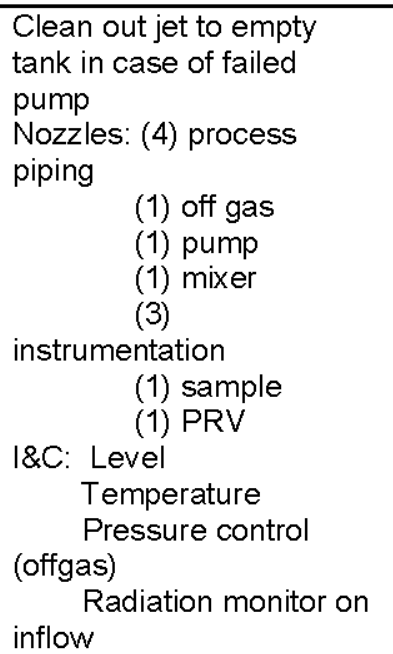 & $\begin{array}{l}\text { Working volume for storing four days } \\
\text { of treated LAW at the maximum } \\
\text { production rate in each tank }\end{array}$ \\
\hline 2 & LAW Product Pumps & $100 \mathrm{gpm}$ & & $\begin{array}{l}\text { Tank top mounted, vertical } \\
\text { pump } \\
\text { I\&C: Discharge pressure } \\
\text { Flow control } \\
\text { VFD } \\
\end{array}$ & $\begin{array}{l}\text { Design basis flow rate for feed to } \\
\text { LAW is } 88 \mathrm{gpm} \text {. }\end{array}$ \\
\hline 1 & Cs Product Tank & $\begin{array}{l}8,600 \text { gal total } \\
\text { capacity }\end{array}$ & 11.4-ft D x 11.4-ft H & 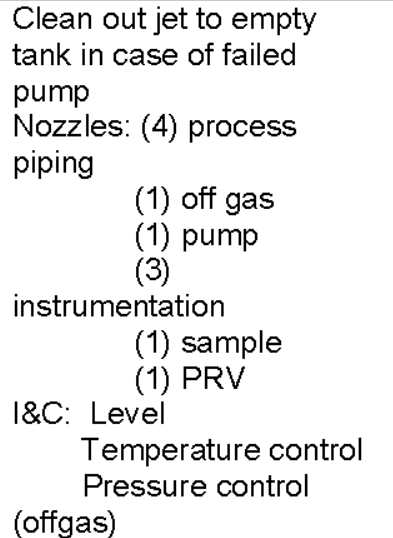 & $\begin{array}{l}\text { Volume for storing one day of input } \\
\text { from the worst case throughput. }\end{array}$ \\
\hline
\end{tabular}


Table 12. Fractional Crystallization Equipment List

(11 sheets)

\begin{tabular}{|c|c|c|c|c|c|}
\hline Qty & Component & Process Sizing & Physical Dimensions & Features & Comments \\
\hline 1 & Cs Product Pump & $100 \mathrm{gpm}$ & & $\begin{array}{l}\text { Tank top mounted, vertical } \\
\text { pump } \\
\text { I\&C: Discharge pressure } \\
\text { Flow control } \\
\text { VFD }\end{array}$ & $\begin{array}{l}\text { Flow rate for return to tank farms } \\
\text { assumed to be approximately } 75 \\
\text { gpm. }\end{array}$ \\
\hline \multicolumn{6}{|c|}{$\begin{array}{l}\text { 1st Stage } \\
\text { Crystallization }\end{array}$} \\
\hline 1 & Reboiler, 1st stage & $\begin{array}{l}11,000,000 \\
\text { BTU/hr }\end{array}$ & & $\begin{array}{l}\text { Includes small condensate } \\
\text { pump }\end{array}$ & Sized based on highest boilup rate. \\
\hline 1 & Crystallizer, 1st stage & $\begin{array}{l}6200 \text { gal working } \\
\text { volume }\end{array}$ & $\begin{array}{l}8 \mathrm{ft} \mathrm{minimum} \text { freeboard including } \\
\text { transition to demister. Approx } 9 \\
\mathrm{ft} 9 \text { inch outside diameter } X 23 \mathrm{ft} \\
\text { tall vessel plus } 4 \mathrm{ft} \text { dia } X 4 \mathrm{ft} \\
\text { demister section on top. }\end{array}$ & Design for full vacuum & $\begin{array}{l}\text { Crystallizer volume is sized to } \\
\text { provide an } 8 \text { hour residence time at } \\
\text { the maximum centrifuge feed rate } \\
\text { (Stream } 19) \text {. }\end{array}$ \\
\hline 1 & $\begin{array}{l}\text { Crystallizer } \\
\text { Recirculation Pump, 1st } \\
\text { stage }\end{array}$ & $\begin{array}{l}5600 \mathrm{gpm} \text { low } \\
\text { head } \\
20 \mathrm{psig} \\
125 \mathrm{HP}\end{array}$ & & & $\begin{array}{l}\text { Flow based on scale factor } \\
\text { comparing the boilup rate with that of } \\
\text { the } 242 \mathrm{~A} \text { Evaporator }(0.4 \text { for Stage } \\
\text { 1). }\end{array}$ \\
\hline 1 & Condenser, 1st stage & $8,500,000 \mathrm{Btu} / \mathrm{hr}$ & & $\begin{array}{l}\text { Includes small condensate } \\
\text { pump }\end{array}$ & $\begin{array}{l}\text { Sized to condense maximum boilup } \\
\text { rate. }\end{array}$ \\
\hline 1 & $\begin{array}{l}\text { Condenser Vacuum } \\
\text { Pump (steam powered } \\
\text { eductor), 1st stage }\end{array}$ & $\begin{array}{l}131 \mathrm{lb} / \mathrm{hr} \text { saturated } \\
\text { air, } 0.035 \mathrm{~atm} \\
\text { suction pressure }\end{array}$ & & Steam Powered Eductor & $\begin{array}{l}\text { Non-condensable suction flow of } 40 \\
\mathrm{Ib} / \mathrm{hr} \text { based on scale factor } \\
\text { comparing the boilup rate with that of } \\
\text { the } 242 \mathrm{~A} \text { Evaporator }(0.4 \text { for Stage } \\
\text { 1). }\end{array}$ \\
\hline 1 & $\begin{array}{l}\text { Centrifuge Feed } \\
\text { Pump, 1st stage }\end{array}$ & $\begin{array}{l}15 \mathrm{gpm} \text { crystal } \\
\text { slurry, density } \\
1.74\end{array}$ & & & $\begin{array}{l}\text { Based on maximum steady state flow } \\
\text { of slurry from the crystallizer (Stream } \\
\text { 19) }\end{array}$ \\
\hline 1 & Centrifuge, 1st stage & $\begin{array}{l}15 \text { gpm crystal } \\
\text { slurry, feed, } 1800 \\
\mathrm{~kg} / \mathrm{hr}(4000 \mathrm{lb} / \mathrm{hr}) \\
\text { solids product }\end{array}$ & & Peeler type centrifuge & $\begin{array}{l}\text { Based on maximum steady state flow } \\
\text { of slurry from the crystallizer (Stream } \\
\text { 19) }\end{array}$ \\
\hline
\end{tabular}


Table 12. Fractional Crystallization Equipment List (11 sheets)

\begin{tabular}{|c|c|c|c|c|c|}
\hline Qty & Component & Process Sizing & Physical Dimensions & Features & Comments \\
\hline 1 & $\begin{array}{l}\text { Dissolver Tank, 1st } \\
\text { stage }\end{array}$ & $\begin{array}{l}1,000 \text { gal working } \\
\text { volume }\end{array}$ & 5.0-ft D x 10.0-ft H & $\begin{array}{l}\text { Nozzles: (4) process } \\
\text { piping } \\
\text { (1) off gas } \\
\text { (1) pump } \\
\text { (3) } \\
\text { instrumentation } \\
\text { (1) PRV } \\
\text { I\&C: Level } \\
\text { Temperature } \\
\text { Pressure control } \\
\text { (offgas) }\end{array}$ & Standardized in-cell process tank \\
\hline 1 & $\begin{array}{l}\text { Dissolver Recirculation } \\
\text { Pump, 1st stage }\end{array}$ & $60 \mathrm{gpm}$ & & $\begin{array}{l}\text { Tank top mounted, vertical } \\
\text { pump } \\
\text { I\&C: Discharge pressure } \\
\text { Flow control } \\
\text { VFD }\end{array}$ & $\begin{array}{l}\text { Sized for maximum heat exchanger } \\
\text { temperature difference of } 20 \mathrm{~F} \text {. }\end{array}$ \\
\hline 1 & $\begin{array}{l}\text { Dissolver Discharge } \\
\text { Pump, 1st stage }\end{array}$ & $20 \mathrm{gpm}$ & & $\begin{array}{l}\text { Tank top mounted, vertical } \\
\text { pump } \\
\text { I\&C: Discharge pressure } \\
\text { Flow control } \\
\text { VFD }\end{array}$ & $\begin{array}{l}\text { Flow rate based on } 1.5 \mathrm{X} \text { the worst } \\
\text { case dissolver discharge flow rate. }\end{array}$ \\
\hline 1 & $\begin{array}{l}\text { Dissolver filter, 1st } \\
\text { stage }\end{array}$ & $\begin{array}{l}\text { Feed } 15 \mathrm{gpm}, \\
\text { filtrate } 6 \mathrm{gpm}\end{array}$ & & $\begin{array}{l}5 \text { micron pore size, } 70 \mathrm{psi} \\
\text { filter differential pressure }\end{array}$ & $\begin{array}{l}\text { Filtrate is } 1.5 \mathrm{X} \text { maximum steady } \\
\text { state rate (Batch } 2 \text { ) }\end{array}$ \\
\hline 1 & $\begin{array}{c}\text { Dissolver Heat } \\
\text { Exchanger, 1st stage }\end{array}$ & $600,000 \mathrm{Btu} / \mathrm{hr}$ & & & $\begin{array}{l}\text { Sized to heat highest flow rate of } \\
\text { added dissolution water from } 70 \mathrm{~F} \text { to } \\
140 \mathrm{~F} \text {, times } 2 \mathrm{X} \text {. }\end{array}$ \\
\hline 1 & $\begin{array}{l}\text { Condensate Tank, 1st } \\
\text { stage }\end{array}$ & $\begin{array}{l}2,000 \text { gal working } \\
\text { volume }\end{array}$ & 7.0-ft D x 7.0-ft H & $\begin{array}{l}\text { Outside, double wall tank } \\
\text { Nozzles: (2) process } \\
\text { piping } \\
\text { (1) off gas } \\
\text { (1) pump } \\
\text { (3) } \\
\text { (1) PRV } \\
\text { instrumentation } \\
\text { I\&C: Level } \\
\text { Temperature } \\
\text { Pressure control } \\
\text { (offgas) } \\
\text { Leak detection }\end{array}$ & $\begin{array}{l}\text { Volume to store } 2 \text { hour capacity for } \\
\text { worst case condensate flow rate. }\end{array}$ \\
\hline
\end{tabular}


Table 12. Fractional Crystallization Equipment List

(11 sheets)

\begin{tabular}{|c|c|c|c|c|c|}
\hline Qty & Component & Process Sizing & Physical Dimensions & Features & Comments \\
\hline 1 & $\begin{array}{l}\text { Condensate Pump, 1st } \\
\text { stage }\end{array}$ & $40 \mathrm{gpm}$ & & $\begin{array}{l}\text { Tank top mounted, vertical } \\
\text { pump } \\
\text { I\&C: Discharge pressure } \\
\text { Flow control } \\
\text { VFD }\end{array}$ & $\begin{array}{l}\text { Flow rate based on } 2.5 X \text { the worst } \\
\text { case condensate flow rate. }\end{array}$ \\
\hline 1 & $\begin{array}{l}\text { Spent Wash Tank, 1st } \\
\text { stage }\end{array}$ & $\begin{array}{l}1,000 \text { gal working } \\
\text { volume }\end{array}$ & $5.0-\mathrm{ft} \mathrm{D} \times 10.0-\mathrm{ft} \mathrm{H}$ & $\begin{array}{l}\text { Nozzles: (2) process } \\
\text { piping } \\
\text { (1) off gas } \\
\text { (1) pump } \\
\text { (3) } \\
\text { instrumentation } \\
\text { (1) PRV } \\
\text { I\&C: Level } \\
\text { Temperature } \\
\text { Pressure control } \\
\text { (offgas) }\end{array}$ & Standardized in-cell process tank \\
\hline 1 & $\begin{array}{l}\text { Spent Wash Pump, 1st } \\
\text { stage }\end{array}$ & $15 \mathrm{gpm}$ & & $\begin{array}{l}\text { Tank top mounted, vertical } \\
\text { pump } \\
\text { I\&C: Discharge pressure } \\
\text { Flow control } \\
\text { VFD }\end{array}$ & $\begin{array}{l}\text { Flow rate based on } 2.5 \mathrm{X} \text { the worst } \\
\text { case wash liquor flow rate. }\end{array}$ \\
\hline 1 & $\begin{array}{l}\text { Centrifuge Liquor } \\
\text { Tank, 1st stage }\end{array}$ & $\begin{array}{l}1,000 \text { gal working } \\
\text { volume }\end{array}$ & 5.0-ft D x 10.0-ft H & $\begin{array}{l}\text { Nozzles: (2) process } \\
\text { piping } \\
\text { (1) off gas } \\
\text { (1) pump } \\
\text { (3) } \\
\text { instrumentation } \\
\text { (1) PRV } \\
\text { I\&C: Level } \\
\text { Temperature } \\
\text { Pressure control } \\
\text { (offgas) }\end{array}$ & Standardized in-cell process tank \\
\hline 1 & $\begin{array}{l}\text { Centrifuge Liquor } \\
\text { pump, 1st stage }\end{array}$ & $25 \mathrm{gpm}$ & & $\begin{array}{l}\text { Tank top mounted, vertical } \\
\text { pump } \\
\text { I\&C: Discharge pressure } \\
\text { Flow control } \\
\text { VFD } \\
\end{array}$ & $\begin{array}{l}\text { Flow rate based on } 2.5 \mathrm{X} \text { the worst } \\
\text { case crystallizer product flow rate. }\end{array}$ \\
\hline
\end{tabular}


Table 12. Fractional Crystallization Equipment List

(11 sheets)

\begin{tabular}{|c|c|c|c|c|c|}
\hline Qty & Component & Process Sizing & Physical Dimensions & Features & Comments \\
\hline 1 & Reboiler, 2nd stage & $5,500,000 \mathrm{BTU} / \mathrm{hr}$ & & $\begin{array}{l}\text { Includes small condensate } \\
\text { pump }\end{array}$ & Sized based on highest boilup rate. \\
\hline 1 & Crystallizer, 2nd stage & $\begin{array}{l}6200 \text { gal working } \\
\text { volume }\end{array}$ & $\begin{array}{l}8 \mathrm{ft} \text { minimum freeboard including } \\
\text { transition to demister. Approx } 9 \\
\mathrm{ft} 9 \text { inch outside diameter } \times 23 \mathrm{ft} \\
\text { tall vessel plus } 4 \mathrm{ft} \text { dia } \times 4 \mathrm{ft} \\
\text { demister section on top. }\end{array}$ & Design for full vacuum & $\begin{array}{l}\text { Crystallizer volume is sized to } \\
\text { provide an } 8 \text { hour residence time at } \\
\text { the maximum centrifuge feed rate } \\
\text { (Stream } 19) .5000 \text { gal for Stage } 2 \text {, } \\
\text { but Crystallizer is sized to be equal to } \\
\text { Stage } 1 .\end{array}$ \\
\hline 1 & $\begin{array}{l}\text { Crystallizer } \\
\text { Recirculation Pump, 2nd } \\
\text { stage }\end{array}$ & $\begin{array}{l}2800 \mathrm{gpm} \text { low } \\
\text { head } \\
20 \mathrm{psig} \\
75 \mathrm{HP}\end{array}$ & & & $\begin{array}{l}\text { Flow based on scale factor } \\
\text { comparing the boilup rate with that of } \\
\text { the } 242 \mathrm{~A} \text { Evaporator ( } 0.2 \text { for Stage } \\
\text { 2). }\end{array}$ \\
\hline 1 & Condenser, 2nd stage & $4,500,000 \mathrm{Btu} / \mathrm{hr}$ & & $\begin{array}{l}\text { Includes small condensate } \\
\text { pump }\end{array}$ & $\begin{array}{l}\text { Sized to condense maximum boilup } \\
\text { rate. }\end{array}$ \\
\hline 1 & $\begin{array}{l}\text { Condenser Vacuum } \\
\text { Pump (Steam Powered } \\
\text { Eductor), 2nd stage }\end{array}$ & $\begin{array}{l}65 \mathrm{lb} / \mathrm{hr} \text { air } \\
\text { saturated with } \\
\text { water vapor, } 0.57 \\
\text { psia suction } \\
\text { pressure }\end{array}$ & & (Steam Powered Eductor) & $\begin{array}{l}\text { Non-condensable suction flow of } 20 \\
\text { Ib/hr based on scale factor } \\
\text { comparing the boilup rate with that of } \\
\text { the } 242 \mathrm{~A} \text { Evaporator ( } 0.2 \text { for Stage } \\
\text { 2). }\end{array}$ \\
\hline 1 & $\begin{array}{l}\text { Centrifuge Feed } \\
\text { Pump, 2nd stage }\end{array}$ & $\begin{array}{l}\text { Size same as first } \\
\text { stage }\end{array}$ & & & Size same as first stage \\
\hline 1 & Centrifuge, 2nd stage & $\begin{array}{l}\text { Size same as first } \\
\text { stage }\end{array}$ & & Peeler type centrifuge & Size same as first stage \\
\hline 1 & $\begin{array}{l}\text { Dissolver Tank, 2nd } \\
\text { stage }\end{array}$ & $\begin{array}{l}1,000 \text { gal working } \\
\text { volume }\end{array}$ & $5.0-\mathrm{ft} \mathrm{D} \times 10.0-\mathrm{ft} \mathrm{H}$ & $\begin{array}{l}\text { Nozzles: (4) process } \\
\text { piping } \\
\text { (1) off gas } \\
\text { (1) pump } \\
\text { (3) } \\
\text { instrumentation } \\
\text { (1) PRV } \\
\text { I\&C: Level } \\
\text { Temperature } \\
\text { Pressure control } \\
\text { (offgas) }\end{array}$ & Standardized in-cell process tank \\
\hline 1 & $\begin{array}{l}\text { Dissolver Recirculation } \\
\text { Pump, 2nd stage }\end{array}$ & $30 \mathrm{gpm}$ & & $\begin{array}{l}\text { Tank top mounted, vertical } \\
\text { pump } \\
\text { I\&C: Discharge pressure } \\
\text { Flow control } \\
\text { VFD }\end{array}$ & $\begin{array}{l}\text { Sized for maximum heat exchanger } \\
\text { temperature difference of } 20 \mathrm{~F} \text {. }\end{array}$ \\
\hline
\end{tabular}


Table 12. Fractional Crystallization Equipment List

(11 sheets)

\begin{tabular}{|c|c|c|c|c|c|}
\hline Qty & Component & Process Sizing & Physical Dimensions & Features & Comments \\
\hline 1 & $\begin{array}{l}\text { Dissolver Discharge } \\
\text { Pump, 2nd stage }\end{array}$ & $15 \mathrm{gpm}$ & & $\begin{array}{l}\text { Tank top mounted, vertical } \\
\text { pump } \\
\text { I\&C: Discharge pressure } \\
\text { Flow control } \\
\text { VFD } \\
\end{array}$ & $\begin{array}{l}\text { Flow rate based on } 1.5 \mathrm{X} \text { the worst } \\
\text { case dissolver discharge flow rate. }\end{array}$ \\
\hline 1 & $\begin{array}{c}\text { Dissolver Heat } \\
\text { Exchanger, 2nd stage }\end{array}$ & $300,000 \mathrm{Btu} / \mathrm{hr}$ & & & $\begin{array}{l}\text { Sized to heat highest flow rate of } \\
\text { added dissolution water from } 40 \mathrm{~F} \text { to } \\
140 \mathrm{~F} \text {, times } 2 X \text {. }\end{array}$ \\
\hline 1 & $\begin{array}{l}\text { Dissolver filter, 2nd } \\
\text { stage }\end{array}$ & $\begin{array}{l}\text { Feed } 10 \mathrm{gpm} \text {, } \\
\text { filtrate } 8 \mathrm{gpm}\end{array}$ & & $\begin{array}{l}5 \text { micron pore size, } 70 \mathrm{psi} \\
\text { filter differential pressure }\end{array}$ & $\begin{array}{l}\text { Feed is } 1.5 \mathrm{X} \text { and filtrate is } 1.4 \mathrm{X} \\
\text { maximum steady state rate for filter } \\
\text { feed (Batch } 2 \text { ). Sized to allow } \\
\text { flexibility to provide concentrated } \\
\text { sulfate product (filter product slurry) }\end{array}$ \\
\hline 1 & $\begin{array}{l}\text { Condensate Tank, 2nd } \\
\text { stage }\end{array}$ & $\begin{array}{l}2,000 \text { gal total } \\
\text { capacity }\end{array}$ & 7.0-ft D x 7.0-ft H & $\begin{array}{l}\text { Outside, double wall tank } \\
\text { Nozzles: (2) process } \\
\text { piping } \\
\text { (1) off gas } \\
\text { (1) pump } \\
\text { (3) } \\
\text { instrumentation } \\
\text { (1) PRV } \\
\text { I\&C: Level } \\
\text { Temperature } \\
\text { Pressure control } \\
\text { (offgas) } \\
\text { Leak detection } \\
\end{array}$ & $\begin{array}{l}\text { Volume to store } 2 \text { hour capacity for } \\
\text { worst case condensate flow rate. }\end{array}$ \\
\hline 1 & $\begin{array}{l}\text { Condensate Pump, } \\
\text { 2nd stage }\end{array}$ & $20 \mathrm{gpm}$ & & $\begin{array}{l}\text { Tank top mounted, vertical } \\
\text { pump } \\
\text { I\&C: Discharge pressure } \\
\text { Flow control } \\
\text { VFD } \\
\end{array}$ & $\begin{array}{l}\text { Flow rate based on } 2.5 \mathrm{X} \text { the worst } \\
\text { case condensate flow rate. }\end{array}$ \\
\hline
\end{tabular}


Table 12. Fractional Crystallization Equipment List (11 sheets)

\begin{tabular}{|c|c|c|c|c|c|}
\hline Qty & Component & Process Sizing & Physical Dimensions & Features & Comments \\
\hline 1 & $\begin{array}{l}\text { Spent Wash Tank, 2nd } \\
\text { stage }\end{array}$ & $\begin{array}{l}1,000 \text { gal working } \\
\text { volume }\end{array}$ & 5.0-ft D x 10.0-ft H & $\begin{array}{l}\text { Nozzles: (2) process } \\
\text { piping } \\
\text { (1) off gas } \\
\text { (1) pump } \\
\text { (3) } \\
\text { instrumentation } \\
\text { (1) PRV } \\
\text { I\&C: Level } \\
\text { Temperature } \\
\text { Pressure control } \\
\text { (offgas) }\end{array}$ & Standardized in-cell process tank \\
\hline 1 & $\begin{array}{l}\text { Spent Wash Pump, } \\
\text { 2nd stage }\end{array}$ & $10 \mathrm{gpm}$ & & $\begin{array}{l}\text { Tank top mounted, vertical } \\
\text { pump } \\
\text { I\&C: Discharge pressure } \\
\text { Flow control } \\
\text { VFD }\end{array}$ & $\begin{array}{l}\text { Flow rate based on } 2.5 X \text { the worst } \\
\text { case wash liquor flow rate. }\end{array}$ \\
\hline 1 & $\begin{array}{l}\text { Centrifuge Liquor } \\
\text { Tank, 2nd stage }\end{array}$ & $\begin{array}{l}1,000 \text { gal working } \\
\text { volume }\end{array}$ & 5.0-ft D x 10.0-ft H & $\begin{array}{l}\text { Nozzles: (2) process } \\
\text { piping } \\
\text { (1) off gas } \\
\text { (1) pump } \\
\text { (3) } \\
\text { instrumentation } \\
\text { (1) PRV } \\
\text { I\&C: Level } \\
\text { Temperature } \\
\text { Pressure control } \\
\text { (offgas) }\end{array}$ & Standardized in-cell process tank. \\
\hline 1 & $\begin{array}{l}\text { Centrifuge Liquor } \\
\text { pump, } 2 \text { nd stage }\end{array}$ & $20 \mathrm{gpm}$ & & $\begin{array}{l}\text { Tank top mounted, vertical } \\
\text { pump } \\
\text { I\&C: Discharge pressure } \\
\text { Flow control } \\
\text { VFD }\end{array}$ & $\begin{array}{l}2.5 \text { times maximum Stream } 31 \text { liquid } \\
\text { phase }\end{array}$ \\
\hline
\end{tabular}


Table 12. Fractional Crystallization Equipment List

(11 sheets)

\begin{tabular}{|c|c|c|c|c|c|}
\hline Qty & Component & Process Sizing & Physical Dimensions & Features & Comments \\
\hline 1 & $\begin{array}{l}\text { High sulfate product } \\
\text { Tank, 2nd stage }\end{array}$ & $\begin{array}{l}1,000 \text { gal working } \\
\text { volume }\end{array}$ & 5.0-ft D x 10.0-ft H & $\begin{array}{l}\text { Nozzles: (2) process } \\
\text { piping } \\
\text { (1) off gas } \\
\text { (1) pump } \\
\text { (3) } \\
\text { instrumentation } \\
\text { (1) PRV } \\
\text { I\&C: Level } \\
\text { Temperature } \\
\text { Pressure control } \\
\text { (offgas) }\end{array}$ & Standardized in-cell process tank \\
\hline 1 & $\begin{array}{l}\text { High sulfate product } \\
\text { Pump, 2nd stage }\end{array}$ & $10 \mathrm{gpm}$ & & $\begin{array}{l}\text { Tank top mounted, vertical } \\
\text { pump } \\
\text { I\&C: Discharge pressure } \\
\text { Flow control } \\
\text { VFD } \\
\end{array}$ & $\begin{array}{l}\text { Sized the same as the } 2 \text { nd stage } \\
\text { dissolver pump }\end{array}$ \\
\hline \multicolumn{6}{|c|}{ Miscellaneous } \\
\hline 1 & Steam Supply System & $\begin{array}{l}25,000 \mathrm{lb} / \mathrm{hr} \\
100 \mathrm{psig} \text { (vacuum } \\
\text { pumps) } \\
3 \mathrm{psig} \text { (reboilers) }\end{array}$ & & $\begin{array}{l}\text { Loads: (2) Reboilers } \\
\text { (2) Vacuum } \\
\text { Pumps } \\
\text { (2) Dissolver Hx }\end{array}$ & $\begin{array}{l}\text { Based on condensing } 3 \text { psig steam in } \\
\text { reboiler and dissolver plus vacuum } \\
\text { pump steam demand. }\end{array}$ \\
\hline \multicolumn{6}{|c|}{ Structures, FC System } \\
\hline 1 & Crystallizer Building & & $\begin{array}{l}80^{\prime} \mathrm{L} \times 30^{\prime} \mathrm{W} \times 38^{\prime} \mathrm{H} \\
\text { Base } 18^{\prime} \text { below grade }\end{array}$ & $\begin{array}{l}\text { Separate process, } \\
\text { maintenance and } \\
\text { operating areas. See } \\
\text { layout. } \\
\text { Process area below grade } \\
\text { with similar construction } \\
\text { as Tank/Equipment vaults. }\end{array}$ & $\begin{array}{l}\text { See section } 8 \text { for description of } \\
\text { layout }\end{array}$ \\
\hline
\end{tabular}


Table 12. Fractional Crystallization Equipment List (11 sheets)

\begin{tabular}{|c|c|c|c|c|c|}
\hline Qty & Component & Process Sizing & Physical Dimensions & Features & Comments \\
\hline 4 & $\begin{array}{l}\text { Tank/Equipment } \\
\text { Vaults } \\
\text { Feed Receipt Tank } \\
\text { Cs Product Tank } \\
\text { LAW Product Tank \#1 } \\
\text { LAW Product Tank \#2 }\end{array}$ & & $\begin{array}{l}22^{\prime} L \times 22^{\prime} W \times 25^{\prime} H \\
22^{\prime} L \times 16^{\prime} W \times 25^{\prime} H \\
23^{\prime} L \times 20^{\prime} W \times 25^{\prime} H \\
23^{\prime} L \times 20^{\prime} W \times 25^{\prime} H \\
\text { Internal Dimensions }\end{array}$ & $\begin{array}{l}\text { Concrete below grade } \\
\text { structure with } 3 \text {-ft thick } \\
\text { walls and floors } \\
3 \text {-ft thick concrete cover } \\
\text { blocks at grade consisting } \\
\text { of } 12 \text { " wide removable } \\
\text { concrete beams. } \\
\text { Stainless steel lined floor } \\
\text { and walls up to bottom of } \\
\text { cover blocks } \\
\text { Sump with remote read- } \\
\text { out leak detector and } \\
\text { sump pump for each vault } \\
\text { Remote connector heads }\end{array}$ & \\
\hline 1 & Valve Vault & & $\begin{array}{l}22^{\prime} \mathrm{L} \times 10^{\prime} \mathrm{W} \times 15^{\prime} \mathrm{H} \\
\text { Internal Dimensions }\end{array}$ & $\begin{array}{l}\text { One valve vault adjacent } \\
\text { to and serving all tank } \\
\text { vaults } \\
\text { Concrete below grade } \\
\text { structure with } 3 \text {-ft thick } \\
\text { walls and floors } \\
3 \text {-ft thick concrete cover } \\
\text { blocks at grade consisting } \\
\text { of } 12 \text { " wide removable } \\
\text { concrete beams. } \\
\text { Stainless steel lined floor } \\
\text { and walls up to bottom of } \\
\text { cover blocks } \\
\text { Sump with remote read- } \\
\text { out leak detector and } \\
\text { sump pump } \\
\text { Remote connector heads }\end{array}$ & \\
\hline 4 & $\begin{array}{l}\text { Equipment Pads } \\
\text { Condensate Tank, 1st } \\
\text { Stage } \\
\text { Condensate Tank, 2nd } \\
\text { Stage } \\
\text { Steam Boiler } \\
\text { Chiller (see Common } \\
\text { Equipment) }\end{array}$ & & $\begin{array}{l}17^{\prime} L \times 17^{\prime} W \\
14^{\prime} L \times 14^{\prime} W \\
16^{\prime} L \times 14^{\prime} W\end{array}$ & 8-in thick pad & \\
\hline
\end{tabular}


Table 12. Fractional Crystallization Equipment List

(11 sheets)

\begin{tabular}{|l|c|c|c|c|c|}
\hline Qty & Component & Process Sizing & Physical Dimensions & Features & Comments \\
\hline
\end{tabular}

1. All tanks are designed, fabricated and tested to ASME Section VIII

2. All process piping is designed, fabricated and tested to ASME B31.3

3. All process equipment, chemical equipment and offgas piping are manufactured from $304 \mathrm{~L}$ or $316 \mathrm{~L} \mathrm{SS}$.

4. See Common Equipment List for process offgas, vault ventilation, recirculation AHU, and chilled water systems.

5. Tanks are sized assuming a working volume equal to $80 \%$ of the total capacity. 
Figure 57. Full-Scale Equipment Layout

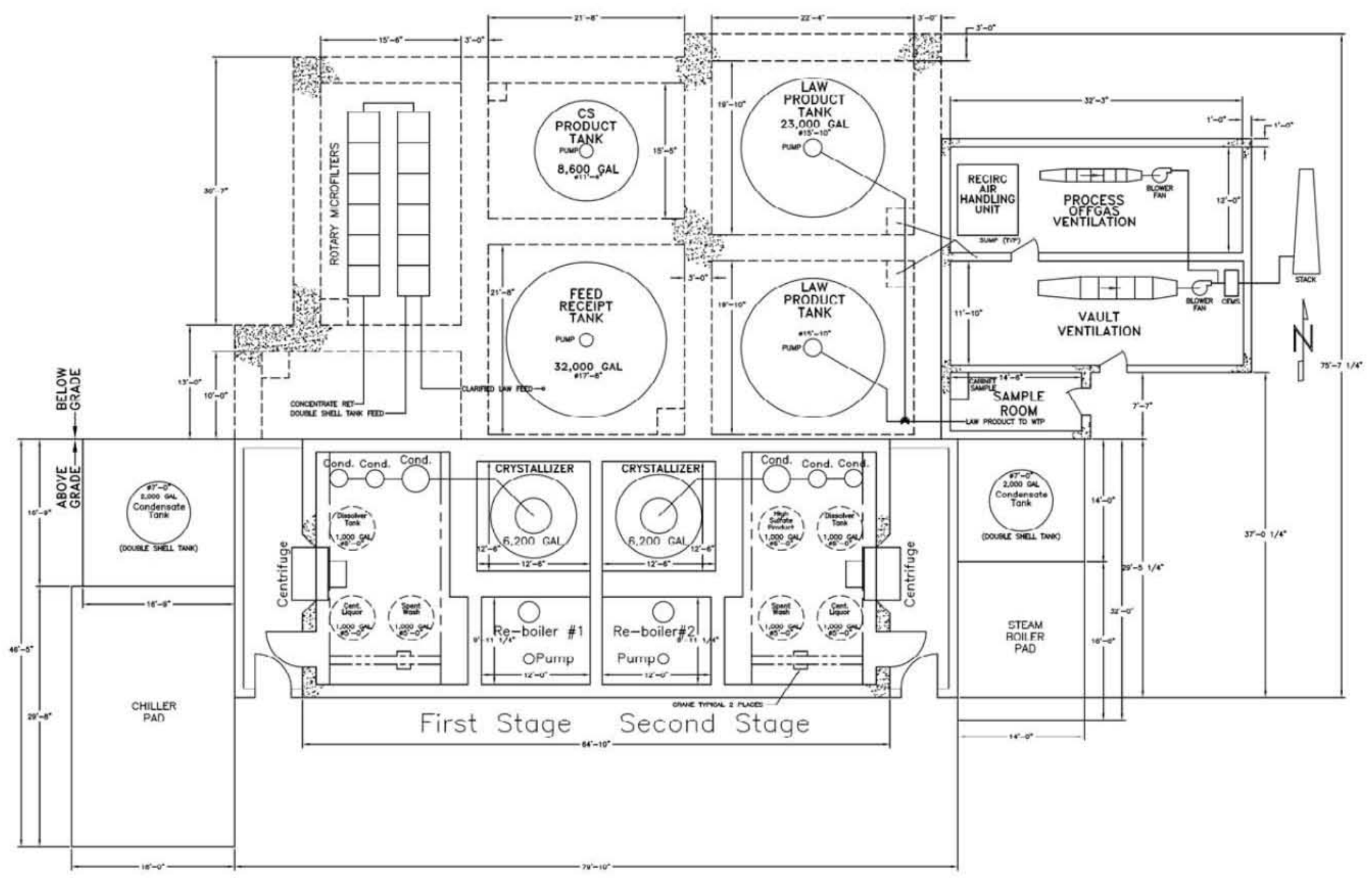


Figure 58. Full-Scale Equipment Elevation View

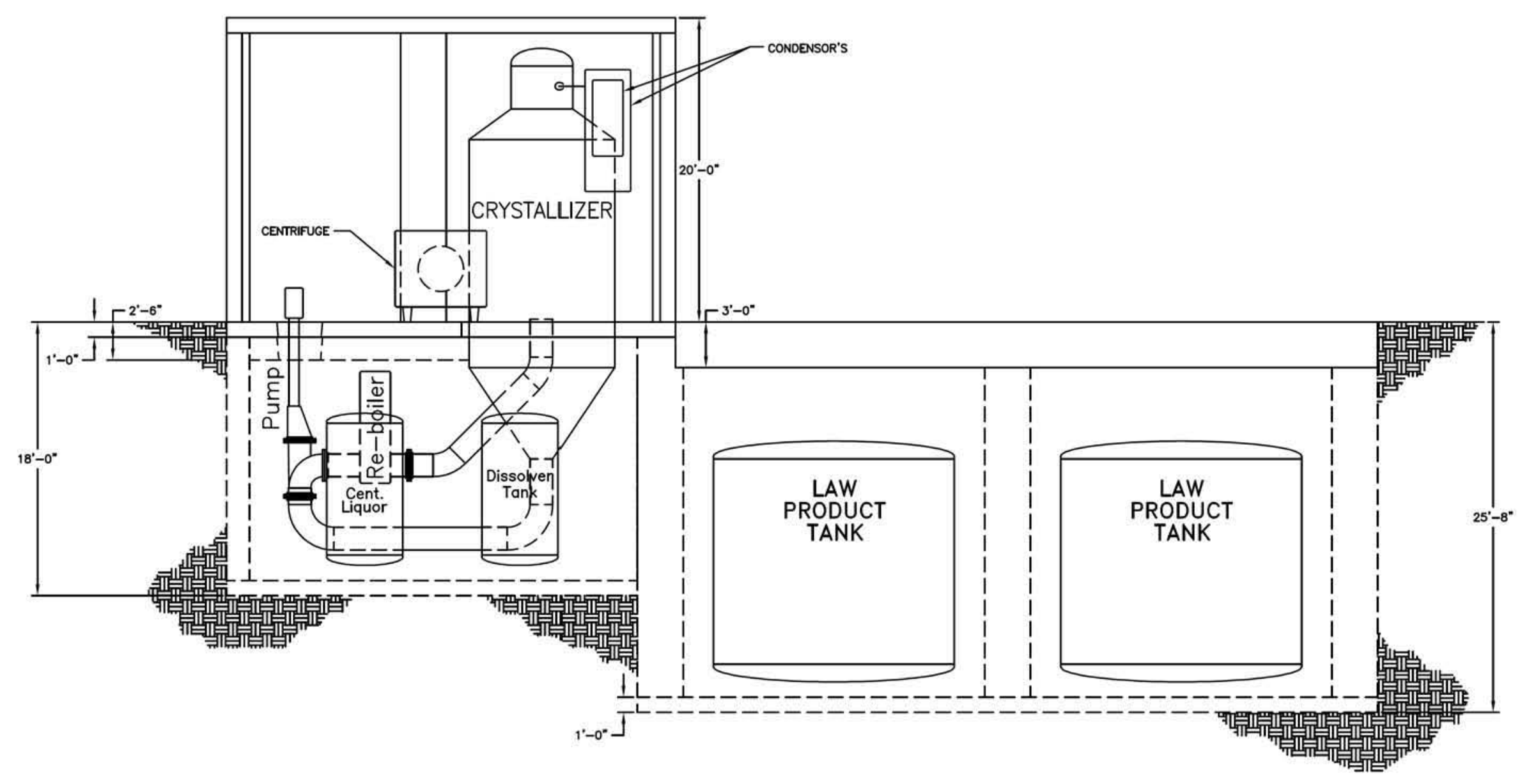


RPP-39091, Rev. 0

RPT-3000755 Rev. 000

\subsection{CONCLUSIONS}

As noted in Section 3.0, two important goals were set for the FCPP operations: 1) resolve the ITDP enabling assumptions and uncertainties and 2) meet contract process performance requirements.

\subsection{ITDP Enabling Assumptions}

The ITDP enabling assumptions were used as the basis for continuing project activities before results could demonstrate they were indeed factual.

\subsubsection{Modeling - Enabling Assumption}

"Modeling can be used to predict FC process performance with Hanford Waste" The same thermodynamic modeling program was used to accurately predict product yield and DF results for all laboratory, engineering, and pilot scale testing activities. Confirmation that the simulant and actual waste behaved in the same manner is documented in RPP-RPT-31352, Fractional Crystallization Flowsheet Tests with Actual Tank Waste. In addition, the model was used to guide simulant testing using different laboratory crystallizers, i.e. the Hanford Boildown Apparatus (HBA) vs. the Georgia Tech jacketed and stirred crystallizer, with both units producing similar results as reported in RPP-RPT-30905, Fractional Crystallization Simulant Test Comparisons. . Therefore since the same model was used and results did not differ between actual waste and simulant, or with the type of test apparatus, the enabling assumption is proved "true". The model was also used for the FCPP and was the starting point to establish the pilot system operating parameters.

\subsubsection{Simulant Performance - Enabling Assumption}

"Simulant can be used to investigate FC performance with actual Hanford Waste." Early in Phase II of the project the simulant and actual waste were tested "side-by-side" at the bench scale and found to yield similar results as noted in RPP-RPT-31352, Fractional Crystallization Flowsheet Tests with Actual Tank Waste. The laboratory simulant formulation (at a larger scale) was used in the pilot and behaved as it did during all bench top testing therefore the enabling assumption is proved "true".

\subsubsection{Scalability - Enabling Assumption}

"Fractional Crystallization is scalable; specifically lab scale, engineering scale, and pilot scale tests can be used to investigate full scale process performance." As noted in the reports referenced above, the simulant acted like the real waste and different laboratory crystallizers using the same simulant produced similar results. Testing at the Swenson development Laboratory in Harvey, IL utilized a 20 liter (5 gallon), continuous flow, draft tube entry (DTE) crystallizer as opposed to the $150 \mathrm{~mL}, 250 \mathrm{~mL}, 600 \mathrm{~mL}$, and $1 \mathrm{~L} \mathrm{semi-}$ batch crystallizers used in bench top testing. In addition, the Swenson tests used a centrifuge for solid-liquid separation instead of the Büchner funnel (vacuum assisted) apparatus used in the laboratory. Results demonstrated that crystal morphology remained the same, but dewatering of the cake improved dramatically with the centrifuge. Details of 
RPP-39091, Rev. 0

RPT-3000755 Rev. 000

the testing and results are contained in RPP-RPT-33228, Hanford medium/Low Curie Waste Pretreatment Alternatives Project - Phase II report on Pre-Pilot Work at Swenson Technology, Inc. In the pilot crystallizer volume increased to about 1200 gallons and crystal morphology was controlled to yield results similar to laboratory results as verified by PLM and CSD analyses. There fore the enabling assumption is proved "true."

\subsection{Uncertainties}

Even though crystallization with product removal is a common industrial process, it was new to normal Hanford operations so uncertainties arose concerning how the FCPP (and a potential production unit) would operate. The PTP and Analytical Test Plan were developed to address these uncertainties.

\subsubsection{Flexibility Uncertainty}

"Ability to handle feed variability including; solids, organics and recycle streams." Due to the curtailed testing program, the effects of high solids or organics content in the feed stream could not be tested in the FCPP. Recycling of the product wash stream within the crystallizer circuit had no adverse effects and was in fact necessary to maintain balanced chemistry conditions within the unit. This uncertainty, in respect to high solids and organics, remains "open."

\subsubsection{Efficiency Uncertainty}

"Efficiency of separating salt crystals from mother liquor containing Cs, Tc, and I". Only non-radioactive $\mathrm{Cs}$ was added to the simulant to determine the efficiency (as indicated by DF results) of the solid-liquid separation stage. In the proposed operating plant DF would normally be measured by analyzing the dissolved product, but because the product tank was contaminated with mother liquor (containing the non-radioactive Cs) DF analysis was performed on cake samples taken directly from the centrifuge discharge chute. The contractual requirement for product DF was 50 and even with the process upsets encountered during FCPP operations, final DFs ranged from 100 to 200 . Therefore pilot plant results indicate that $\mathrm{Cs}$ (and by extension Tc and I based on RPP-RPT-31352) can be effectively separated from solid product.

\subsubsection{Crystal Growth Uncertainty}

"Crystallizer retention time required for crystal growth". Several crystal species, e.g. sodium nitrate, sodium carbonate, burkeite, etc., nucleate concurrently in the simulant and need time to mature (grow) before harvesting in the centrifuge. Bench-top and engineering scale experiments indicated that the optimum size range for the predominant crystal species (sodium nitrate) should be 300 to $450 \mu$. Pilot results (by PLM and CSD analyses) indicate that this size range was easily achievable with the inlet extension pieces removed (yielding minimum retention time). Therefore the retention time is adequate. 
RPP-39091, Rev. 0

RPT-3000755 Rev. 000

\subsubsection{Complexity of Control System Uncertainty}

"Complexity of control system, ease of operation." The pilot system contained several instruments and controls for the purpose of gathering operational data "in case" it could be used for later evaluation. Some of the process control functions were never able to be properly adjusted e.g. crystallizer pressure control, crystallizer level control, density controller on the Product Dissolver Tank, reboiler steam flow control, speed control on the draw-off loop, etc. so that the entire system had to be controlled in "manual" mode. The centrifuge PLC operated satisfactorily (feed, spin, wash, and peel), but since an automatic speed control had not been purchased for the hydraulic circuit, manual speed changes were necessary for heel removal. Manual operation demonstrated that only a few key variables need to be manipulated to achieve satisfactory results.

\subsubsection{Robustness Uncertainty}

"Robustness to Process Upset." As noted above, automatic operation of the system was not achievable. This resulted in many cases of operator error causing process upsets in addition to other, sometimes concurrent, unplanned events like power outages, pipe breaks, pump failures, pipe plugging, etc. Throughout these events corrective actions were implemented that eventually returned the system to stable operation. Since the system was able to meet process requirements in spite of many upset conditions, robustness is not an issue.

\subsection{Summary}

Summarizing the above, the FCPP has:

- Achieved an Average Filter Cake Cesium Decontamination Factor of 130, compared to a goal of at least 50 .

- Achieved a Sodium Product Yield (percentage of sodium isolated to send to LAW vitrification) of $52 \%$, compared to a goal of $50 \%$.

The pilot system effectively operated with a varying range of operating parameters, e.g. crystallizer temperature, pressure and level, slurry density, product dissolver density, etc.

Operators were able to rapidly recover the system after major upsets, e.g. loss of steam, pipe breaks, line pluggage, loss of operating instrumentation, etc.

The thermodynamic model was again shown to be able to closely predict actual results within plant limitations.

Failure of key instruments (crystallizer pressure and level control and dissolver tank density control) and equipment (dissolver tank cross-flow filter) limited the performance of the fractional crystallization pilot system. 


\subsection{Future Work}

FC has been shown to be an effective pretreatment method for SST wastes. Completing the original scope of testing and making a few system modifications (based on recent operating observations) could erase any questions not answered by the current pilot plant data. Extrapolating the pilot data and combining them with results from recent DST simulant testing at 222-SA (see CH2M HILL Interoffice Memorandum 74A10-DLH-08-155) suggests that certain DST wastes could be processed effectively by FC with little or no modification to the basic process design. Before processing any new feed for the FC process, thermodynamic modeling should be performed to determine potential product solubilities and operating parameters.

\subsection{APPENDICES}

Appendix 8.1 - Process Flow Diagram

Appendix 8.2 - Process and Instrumentation Diagram

Appendix 8.3 - Northwest Copper Crystallizer Drawing

Appendix 8.4 - Northwest Copper Reboiler Drawing

Appendix 8.5 - Pilot Instrument List

Appendix 8.6 - 8.6 Pilot Valve List

Appendix 8.7 - Pilot DAS Indications

Appendix 8.8 - Pilot Equipment List

Appendix 8.9 - Readiness Certification Document

Appendix 8.10 - Final Benchmark Test Run Plan

Appendix 8.11 - Final Baseline Test Run Plan

Appendix 8.12 - Pilot Testing Time Line 
RPP-39091, Rev. 0

RPT-3000755 Rev. 000

APPENDIX 8.1

\section{PROCESS FLOW DIAGRAM}

(Consisting of 2 pages

Including coversheet) 


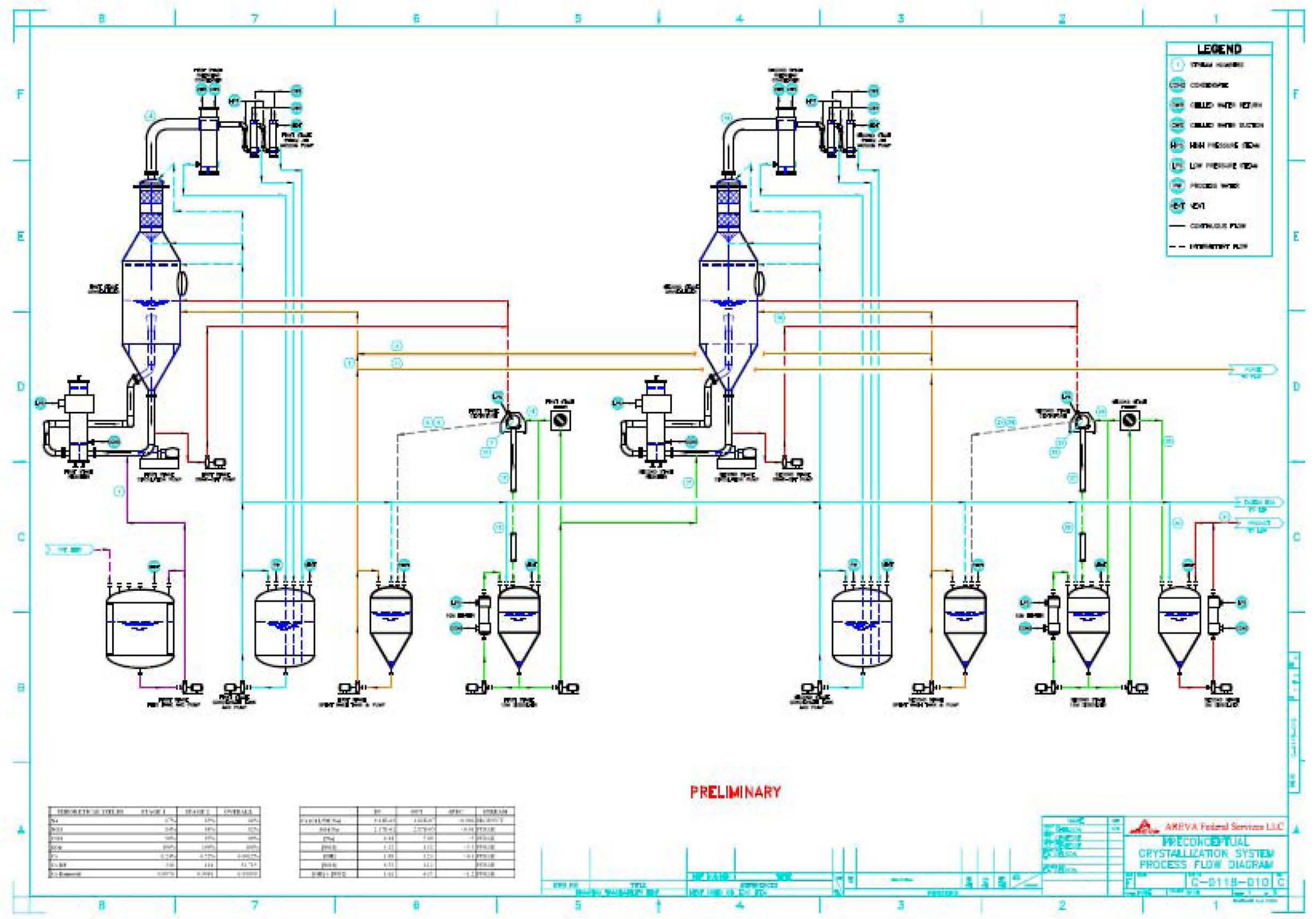


RPP-39091, Rev. 0

RPT-3000755 Rev. 000

APPENDIX 8.2

PROCESS AND INSTRUMENTATION DIAGRAM

(Consisting of 2 pages

Including coversheet) 
RPP-39091, Rev. 0

SAVANNAH RIVER NATIONAL LABORATORY

\section{PROPRIETARY}

DRAWING EES-23164-M6-001

FRACTIONAL CRYSTALLIZATION PILOT SCALE FACILITY P\&ID 
RPP-39091, Rev. 0

RPT-3000755 Rev. 000

APPENDIX 8.3

NORTHWEST COPPER CRYSTALLIZER DRAWING

(Consisting of 2 pages

Including coversheet) 

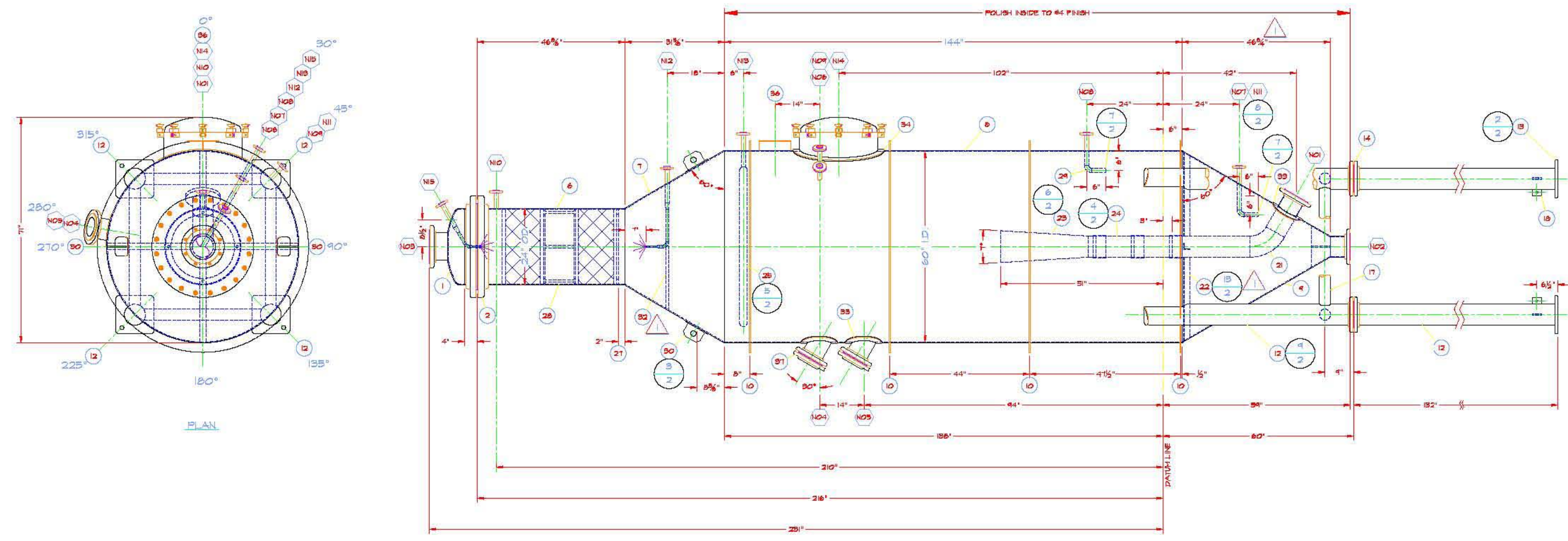

ELEVATON YIIEM

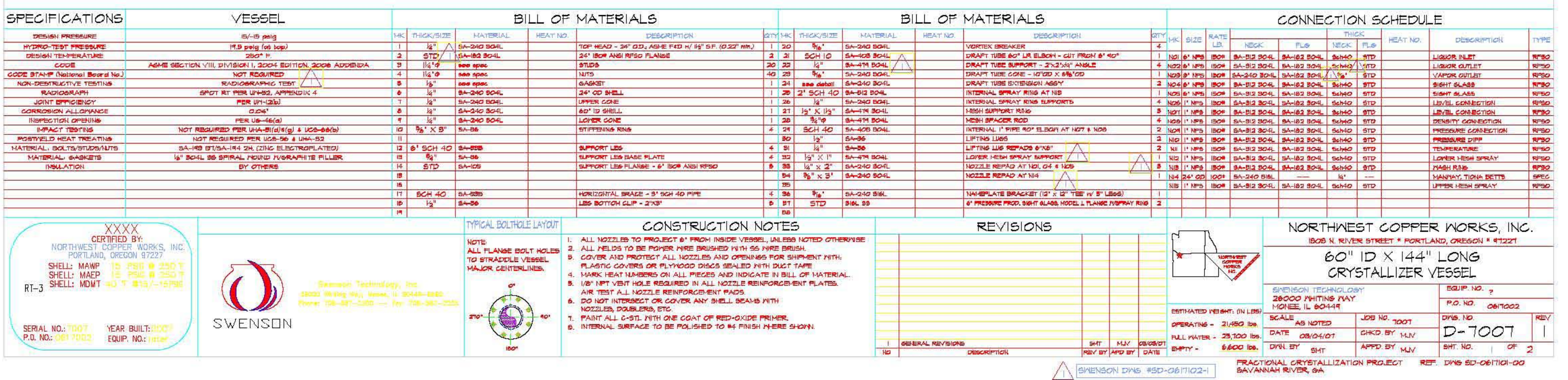


RPP-39091, Rev. 0

RPT-3000755 Rev. 000

APPENDIX 8.4

NORTHWEST COPPER REBOILER DRAWING

(Consisting of 2 pages

Including coversheet) 


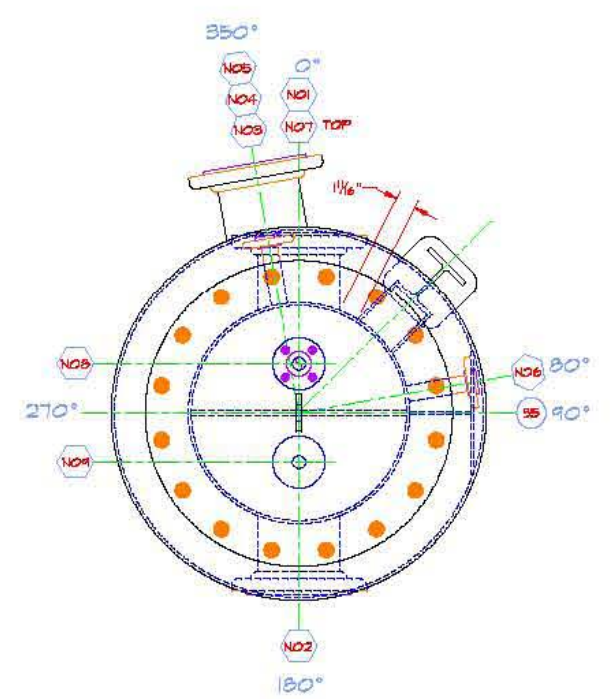

PLAN

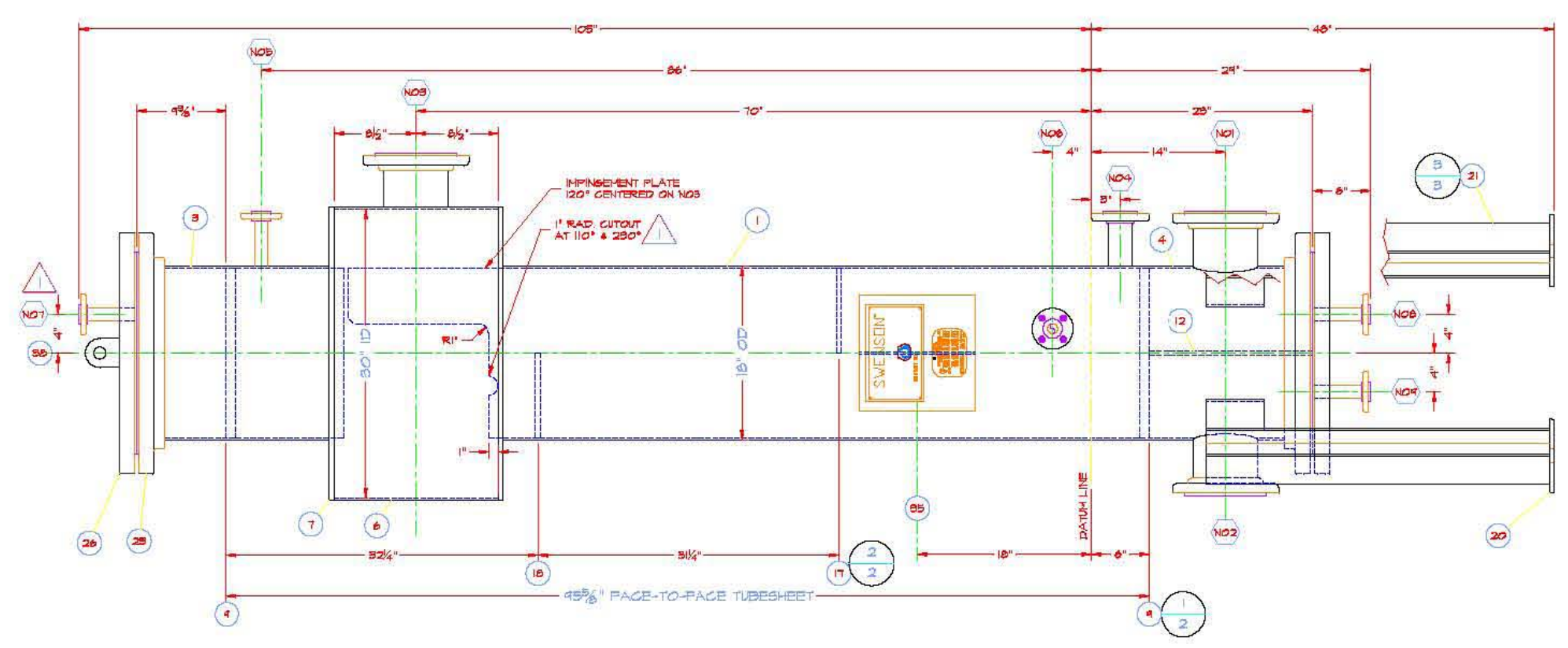

ELEVATON VEN

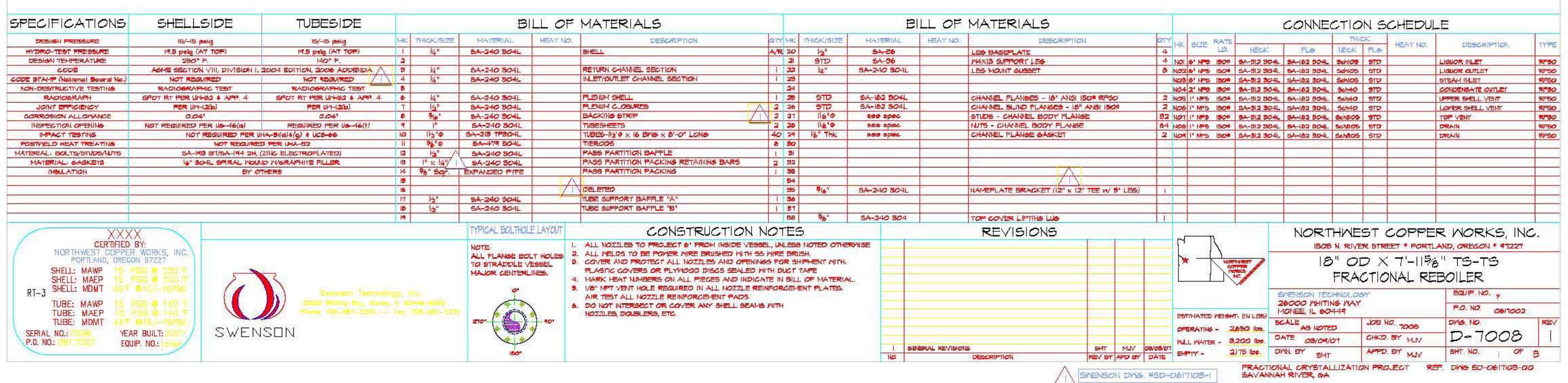


RPP-39091, Rev. 0

RPT-3000755 Rev. 000

APPENDIX 8.5

\section{PILOT INSTRUMENT LIST}

(Consisting of 3 pages

Including coversheet) 


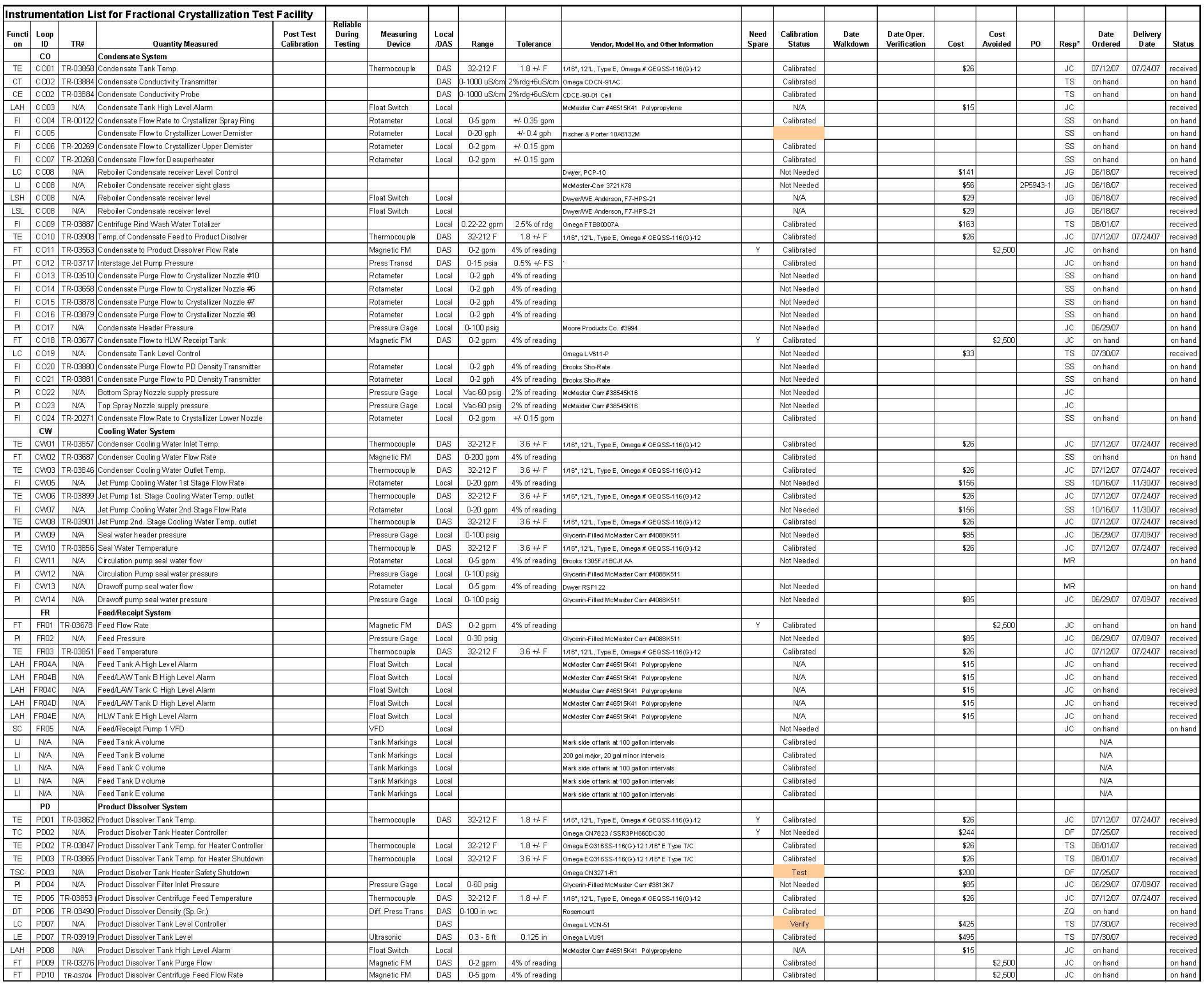




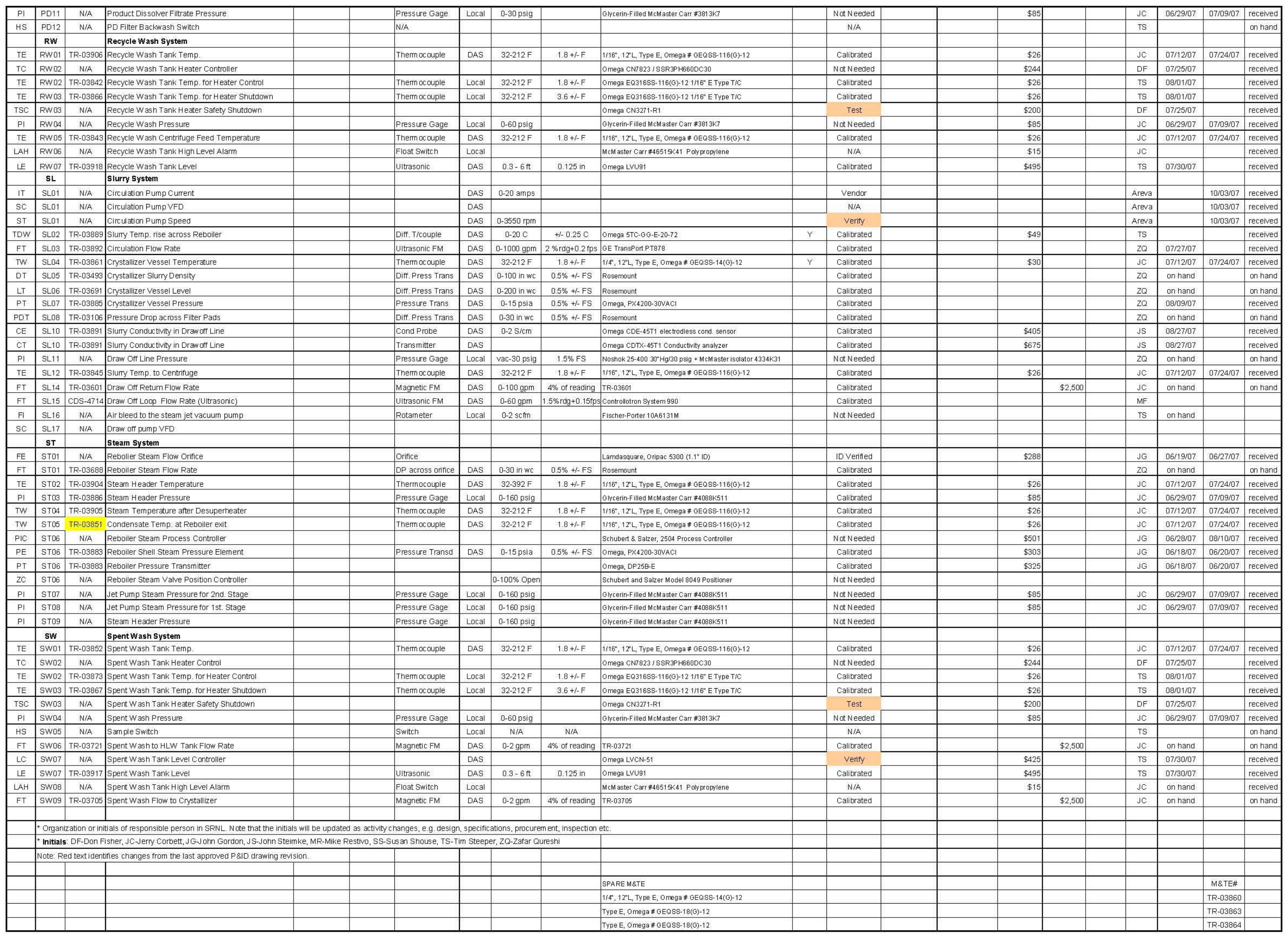


RPP-39091, Rev. 0

RPT-3000755 Rev. 000

APPENDIX 8.6

\section{PILOT VALVE LIST}

(Consisting of 5 pages

Including coversheet) 


\begin{tabular}{|c|c|c|c|c|c|c|c|c|c|c|c|c|c|c|c|}
\hline \multicolumn{16}{|c|}{ Valve List for Fractional Crystallization Test Facility } \\
\hline Line \# & sys & $\begin{array}{c}\text { Valve } \\
\text { No. }\end{array}$ & Type & Size & Material & Vendor, Model No., and Other Information & $\begin{array}{l}\text { P\&ID } \\
\text { Loc }\end{array}$ & Date Walkdown & $\begin{array}{l}\text { Date Oper. } \\
\text { Verification }\end{array}$ & Comments & \begin{tabular}{|c|} 
Dale \\
Order \\
Placed \\
\end{tabular} & $\begin{array}{c}\text { Delivery } \\
\text { Date }\end{array}$ & Status & cost & $\begin{array}{c}\text { Cost } \\
\text { Avoided }\end{array}$ \\
\hline 1 & co & 1 & $\mathrm{~B}$ & 11/2" Pipe & CPVC & 1-1/2" CPVC Ball Valve McMaster Carr \#4724K85 & V17 & & & & 7/10/2007 & 7/177/2007 & received & $\$ 20$ & \\
\hline 2 & co & 2 & $\mathrm{~B}$ & 1/2" Pipe & CPVC & 1/2" CPVC Ball Valve McMaster Carr \#4724K81 & w17 & & & & 7/10/2007 & 7/177/2007 & received & $\$ 7$ & \\
\hline 3 & $\mathrm{co}$ & 3 & $T$ & 1/4" Tube & s/s & Swagelok SS-1RS4 & v29 & & & & $6 / 18 / 2007$ & $6 / 27 / 2007$ & on hand & $\$ 49$ & \\
\hline 4 & co & 4 & 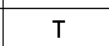 & 3/8" Tube & s/s & Swagelok SS-1VS6 & v29 & & & & 6/18/2007 & 6/27/2007 & on hand & $\$ 68$ & \\
\hline 5 & co & 5 & $s$ & 3/8" Pipe & BRASS & AUTOMATIC SWITCH CO. \#EF8210G34 & $\mathrm{v}_{2} 9$ & & & & & & on hand & & \\
\hline 6 & $\mathrm{co}$ & 6 & $\mathrm{~B}$ & 1/2" Pipe & CPVC & 1/2" CPVC Ball Valve McMaster Carr \#4724K81 & $w_{\text {W31 }}$ & & & & $7 / 10 / 2007$ & $7 / 17 / 2007$ & & 57 & \\
\hline 7 & co & 7 & $T$ & 1/2" Pipe & ss & Parker 494F 316 & F38 & & & & & & on hand & $\$ 200$ & \\
\hline 8 & $\mathrm{co}$ & 8 & AA $3 W$ & 1/2" Pipe & $s / s$ & Assured Automation Mod. C33DAX08S1E3A & F37 & & & & 7/23/2007 & & received & $\$ 417$ & \\
\hline 9 & co & 9 & B & 1/4" Tube & s/s & Swagelok SS-43S4 & N17 & & & & & & on hand & & $\$ 62$ \\
\hline 10 & $\mathrm{co}$ & 10 & $B$ & 3/8" Tube & $s / s$ & Swagelok SS-43S6 & $\mathrm{z5}$ & & & & & & on hand & & 564 \\
\hline 11 & co & 11 & $T$ & 3/4 Pipe & $\mathrm{s} / \mathrm{s}$ & McMaster Carr \#4742K14 3/4" SS Globe & Y6 & & & & 7/117/2007 & $2 / 23 / 2007$ & $\begin{array}{l}\text { received } \\
\text { rats }\end{array}$ & $\$ 81$ & \\
\hline 12 & co & 12 & $B$ & 1/2" Pipe & CPVC & 1/2" CPVC Ball Valve McMaster Carr \#4724K81 & AC1 & & & & $7 / 10 / 2007$ & $7 / 17 / 2007$ & & $\$ 7$ & \\
\hline 13 & co & 13 & $B$ & 1/2" Pipe & CPVC & 1/2" CPVC Ball Valve McMaster Carr \#4724K81 & AC5 & & & & $7 / 10 / 2007$ & 7/17/2007 & & $\$ 7$ & \\
\hline 14 & $\mathrm{co}$ & 14 & $\mathrm{~T}$ & 1/2" Pipe & ss & Parker 4945316 & $\mathrm{J13}$ & & & & & & on hand & $\$ 200$ & \\
\hline 15 & co & 15 & $T$ & 1/4" Tube & s/s & Swagelok SS-1RS4 & J14 & & & & $6 / 15 / 2007$ & $6 / 27 / 2007$ & received & $\$ 49$ & \\
\hline 16 & co & 16 & $T$ & 1/4" Tube & s/s & Swagelok SS-1RS4 & $\mathrm{J14}$ & & & & $6 / 15 / 2007$ & 6/27/2007 & received & $\$ 49$ & \\
\hline 17 & co & 17 & $T$ & 1/4" Tube & s/s & Part of Brooks rotameter & M3 & & & & $6 / 15 / 2007$ & 6/27/2007 & received & $\$ 49$ & \\
\hline 18 & $\mathrm{co}$ & 18 & $T$ & 1/4" Tube & s/s & Part of Brooks rotameter & M4 & & & & $6 / 15 / 2007$ & $6 / 27 / 2007$ & $\begin{array}{l}\text { received } \\
\text { s. }\end{array}$ & $\$ 49$ & \\
\hline 19 & co & 19 & $\mathrm{~T}$ & 1/4" Tube & $s / 2$ & Part of Brooks rotameter & $\mathrm{M4}$ & & & & $6 / 15 / 2007$ & $6 / 27 / 2007$ & received & $\$ 449$ & \\
\hline 20 & co & 20 & $\mathrm{~T}$ & 1/4" Tube & s/s & Part of Brooks rotameter & M5 & & & & $6 / 15 / 2007$ & 6/27/2007 & received & $\$ 49$ & \\
\hline 21 & $\mathrm{co}$ & $21 \mathrm{~A}$ & $\mathrm{c}$ & 1/2" Pipe & POLYPROPYLENE & McMaster Carr \#5492K53 & $\mathrm{V} 28$ & & & & $7 / 10 / 2007$ & $7 / 17 / 2007$ & received & $\$ 11$ & \\
\hline 22 & co & $21 \mathrm{~B}$ & $\mathrm{c}$ & 1/2" Pipe & POLYPROPYLENE & McMaster Carr \#5492K53 & U28 & & & & 7/10/2007 & $7 / 17 / 2007$ & received & $\$ 11$ & \\
\hline 23 & $\mathrm{co}$ & 22 & $\mathrm{~T}$ & 1/4" Pipe & ss & Integral part of rotameter & $\mathrm{U} 11$ & & & & & & on hand & & \\
\hline 24 & co & $23 \mathrm{~F}$ & $\mathrm{~B}$ & 1/2" Tube & CPVC & Whity SS-45F8 & $Y_{Y 27}$ & & & & $7 / 10 / 2007$ & $7 / 17 / 2007$ & $\begin{array}{l}\text { received } \\
\end{array}$ & \$7 & \\
\hline 25 & $\mathrm{co}$ & $23 \mathrm{G}$ & $\mathrm{B}$ & 1/2" Tube & CPVC & Whitey SS-45F8 & Y27 & & & & $7 / 10 / 2007$ & $7 / 17 / 2007$ & received & $\$ 7$ & \\
\hline 26 & co & 24 & $\mathrm{~B}$ & 2" Pipe & CPVC & 2" CPVC Ball Valve McMaster Carr \#4724K86 & AC23 & & & & & & received & & \\
\hline 27 & co & 25 & $\mathrm{~B}$ & 1/4" Tube & $s / s$ & Swagelok SS-43S4 & S37 & & & & & & on hand & & $\$ 62$ \\
\hline 28 & co & 26 & $B$ & 1/4" Tube & s/s & Swagelok SS-43S4 & 538 & & & & & & on hand & & $\$ 62$ \\
\hline 29 & $\mathrm{co}$ & 27 & $T$ & 1/4" Tube & s/s & Part mof Brooks rotameter & U38 & & & & $6 / 15 / 2007$ & $6 / 27 / 2007$ & received & $\$ 49$ & \\
\hline 30 & co & 28 & $T$ & 1/4" Tube & s/s & Part mof Brooks rotameter & U38 & & & & $6 / 15 / 2007$ & $6 / 27 / 2007$ & received & $\$ 49$ & \\
\hline 31 & $\mathrm{co}$ & 29 & B & 1/4" Tube & s/s & Swagelok SS-43S4 & T38 & & & & & & on hand & & $\$ 62$ \\
\hline 32 & co & $30 \mathrm{~A}$ & $\mathrm{c}$ & 1/2" Pipe & \begin{tabular}{|l} 
POLYPROPYLENE \\
\end{tabular} & McMaster Carr \#5492K53 & $\mathrm{z} 5$ & & & & $7 / 10 / 2007$ & 7/17/2007 & received & $\$ 11$ & \\
\hline 33 & $\mathrm{co}$ & $30 \mathrm{~B}$ & $\mathrm{c}$ & 1/2" Pipe & POLYPROPYLENE & McMaster Carr \#5492K53 & $\mathrm{z} 6$ & & & & $7 / 10 / 2007$ & $7 / 17 / 2007$ & $\begin{array}{c}\text { received } \\
\text { S }\end{array}$ & $\$ 11$ & \\
\hline 34 & co & 31 & $\mathrm{~T}$ & 3/8" Tube & $S / S$ & Swagelok SS-1VS6 & U18 & & & & $6 / 18 / 2007$ & $6 / 27 / 2007$ & received & $\$ 68$ & \\
\hline 35 & co & 32 & AT & 1/2" Tube & s/s & Omega PV14-B & Q29 & & & & & & received & $\$ 1,080$ & \\
\hline 36 & $\mathrm{co}$ & 33 & ANA $3 W$ & 1/2" Tube & $s / s$ & Assured Automation Mod. C33DAX08S1E3A & R30 & & & & 7/23/2007 & & received & $\$ 417$ & \\
\hline 37 & co & 34 & $\mathrm{~B}$ & 1/4" Tube & $s / s$ & Swagelok SS-43S4 & R31 & & & & & & on hand & & $\$ 62$ \\
\hline 38 & $\mathrm{co}$ & 35 & $B$ & 1/2" Tube & s/s & Whitey SS-45S8 & U30 & & & & & & on hand & & $\$ 62$ \\
\hline 39 & co & 36 & $B$ & 1/4" Tube & s/s & Swagelok SS-43S4 & N7 & & & & & & on hand & & $\$ 62$ \\
\hline 40 & co & 37 & $\mathrm{~B}$ & 1/4" Tube & $s / s$ & Swagelok SS-43S4 & $\mathrm{L} 6$ & & & & & & on hand & & 562 \\
\hline 41 & co & 38 & B & 1/4" Tube & s/s & Swagelok SS-43S4 & G5 & & & & & & on hand & & $\$ 62$ \\
\hline 42 & co & 39 & $B$ & 1/2" Tube & s/s & Swagelok SS-43S8 & H6 & & & & & & on hand & & $\$ 62$ \\
\hline 43 & co & 40 & $\mathrm{~B}$ & 1/4" Tube & $s / 5$ & Swagelok SS-43SS4 & D7 & & & & & & on hand & & 562 \\
\hline 44 & co & 41 & $B$ & 1/4" Tube & s/s & Swagelok SS-43S4 & T31 & & & & & & on hand & & 562 \\
\hline 45 & co & 42 & $\mathrm{c}$ & 3/4" Pipe & $s / s$ & Swagelok SS-CHF12-1/3 & Y6 & & & & 7/10/2007 & 7/17/2007 & received & & \\
\hline 46 & co & $43 \mathrm{~A}$ & c & 1/2" Pipe & POLYPROPYLENE & McMaster Carr \#5492K53 & W18 & & & & 7/10/2007 & 7/17/2007 & received & $\$ 11$ & \\
\hline 47 & co & $43 \mathrm{~B}$ & $\mathrm{c}$ & 1/2" Pipe & POLYPROPYLENE & McMaster Carr \#5492K53 & W18 & & & & $7 / 24 / 2007$ & & received & & \\
\hline 48 & $\mathrm{CO}$ & 44 & $\mathrm{~B}$ & 1/4" Tube & $s / s$ & Swagelok SS-43S4 & $\mathrm{J11}$ & & & & & & on hand & & \\
\hline 49 & co & 45 & $\mathrm{~B}$ & 1/4" Tube & $s / s$ & \begin{tabular}{|l|} 
Swagelok SS-43S4 \\
\end{tabular} & J11 & & & & & & on hand & & \\
\hline 50 & co & 46 & B & 11/2" Pipe & CPVC & 1-1/2" CPVC Ball Valve McMaster Carr \#4724K85 & $Y_{24}$ & & & & & & received & & \\
\hline
\end{tabular}




\begin{tabular}{|c|c|c|c|c|c|c|c|c|c|c|c|c|c|c|c|}
\hline \multicolumn{16}{|c|}{ Valve List for Fractional Crystallization Test Facility } \\
\hline Line \# & sys & $\begin{array}{l}\text { valve } \\
\text { No. }\end{array}$ & Type & Size & Material & Vendor, Model No., and Other Information & \begin{tabular}{|c|} 
P\&ID \\
Loc
\end{tabular} & Date Walkdown & $\begin{array}{l}\text { Date Oper. } \\
\text { Verification }\end{array}$ & Comments & $\begin{array}{l}\text { Oderer } \\
\text { Placed }\end{array}$ & $\begin{array}{c}\text { Delivery } \\
\text { Date }\end{array}$ & Status & cost & $\begin{array}{c}\text { Cost } \\
\text { Avoided }\end{array}$ \\
\hline 51 & co & 47 & $\mathrm{~B}$ & 1/2" Tube & $s / s$ & Swagelok SS-43S8 & U7 & & & & & & on hand & & \\
\hline 52 & co & 48 & B & 1/4" Tube & s/s & Swagelok SS-43S4 & D4 & & & & & & on hand & & \\
\hline 53 & $\mathrm{co}$ & 49 & $T$ & 1/2" Tube & s/s & Swagelok SS-1RS8 & R29 & & & & & & & & \\
\hline 54 & $c o$ & 50 & $B$ & 1/4" Tube & $s / s$ & Swagelok SS-43S4 & G34 & & & & & & & & \\
\hline 55 & co & 51 & B & 1/4" Tube & s/s & Swagelok SS-43S4 & G34 & & & & & & & & \\
\hline 56 & $\mathrm{co}$ & 52 & $\mathrm{~B}$ & 1/4" Tube & s/s & Swagelok SS-43S4 & M35 & & & & & & & & \\
\hline 57 & co & 53 & $\mathrm{~B}$ & 1/2" Pipe & s/s & Parker $494 \mathrm{~F} 316$ w/tube adapters & M35 & & & & & & & & \\
\hline 58 & co & 54 & B & 1/4" Tube & s/s & Swagelok SS-43S4 & G34 & & & & & & & & \\
\hline 59 & co & 55 & B & 1/4" Tube & s/s & Swagelok SS-43S4 & M35 & & & & & & & & \\
\hline 60 & $\mathrm{cW}$ & 1 & $T$ & 3" Pipe & Brass & Brass Gate & E17 & & & & & & on hand & & $\$ 250$ \\
\hline 61 & $\mathrm{cW}$ & 2 & $B$ & 1/2" Pipe & CPVC & 1/2" CPVC Ball Valve McMaster Carr \#4724K81 & B23 & & & & $7 / 17 / 2007$ & $7 / 23 / 2007$ & $\begin{array}{l}\text { received } \\
\text { rats }\end{array}$ & $\$ 89$ & \\
\hline 62 & cW & 3 & B & 1/2" Pipe & CPVC & 1/2" CPVC Ball Valve McMaster Carr \#4724K81 & $\mathrm{C} 23$ & & & & 7/17/2007 & 7/23/2007 & received & $\$ 89$ & \\
\hline 63 & cW & 4 & $T$ & 1/2" Pipe & Brass & Gate Valve Stockham 2005400 OWG & H19 & & & & & & on hand & $\$ 7$ & \\
\hline 64 & $\mathrm{CW}$ & 5 & $B$ & 1/2" Pipe & CPVC & 1/2" CPVC Ball Valve McMaster Carr \#4724K81 & s9 & & & & $7 / 10 / 2007$ & $7 / 17 / 2007$ & received & $\$ 7$ & \\
\hline 65 & CW & 6 & $T$ & 1/2" Tube & S/S & Swagelok SS-1RS8 & T10 & & & & & & on hand & & \\
\hline 66 & $\mathrm{cW}$ & 7 & $\mathrm{~B}$ & 1/2" Pipe & CPVC & 1/2" CPVC Ball Valve McMaster Carr \#4724K81 & s11 & & & & 7/10/2007 & 7/17/2007 & received & $\$ 7$ & \\
\hline 67 & $\mathrm{cW}$ & 8 & $T$ & 1/2" Tube & $\mathrm{s} / \mathrm{s}$ & Swagelok SS-1RS8 & U11 & & & & & & on hand & & \\
\hline 68 & $\mathrm{CW}$ & 9 & $\mathrm{~B}$ & 3/4" Tube & $\mathrm{s} / \mathrm{s}$ & Whitey SS-45S10 & R11 & & & & & & on hand & & \\
\hline 69 & $\mathrm{CW}$ & 10 & B & 1/2" Tube & s/s & Whitey SS-45S8 & R10 & & & & & & on hand & & \\
\hline 70 & $\mathrm{cW}$ & 11 & B & 3/4" Tube & s/s & Whitey SS-45S 10 & Q11 & & & & & & on hand & & \\
\hline 71 & FR & 1A & B & 3/4" Pipe & CPVC & 3/4" CPVC Ball Valve McMaster Carr \#4724K82 & AB20 & & & & $7 / 10 / 2007$ & $7 / 17 / 2007$ & received & $\$ 8$ & \\
\hline 72 & $\mathrm{FR}$ & $1 \mathrm{~B}$ & $\mathrm{~B}$ & 3/4" Pipe & CPVC & 3/4" CPVC Ball Valve McMaster Carr \#4724K82 & $\mathrm{AB} 12$ & & & & $7 / 10 / 2007$ & $7 / 17 / 2007$ & received & $\$ 8$ & \\
\hline 73 & $\mathrm{FR}$ & $1 \mathrm{C}$ & $\mathrm{B}$ & 3/4" Pipe & CPVC & 3/4" CPVC Ball Valve McMaster Carr \#4724K82 & AB14 & & & & $7 / 10 / 2007$ & $7 / 17 / 2007$ & received & $\$ 8$ & \\
\hline 74 & FR & $1 \mathrm{D}$ & $\mathrm{B}$ & 3/4" Pipe & CPVC & 3/4" CPVC Ball Valve McMaster Carr \#4724K82 & AB17 & & & & 7/110/2007 & 7/17/2007 & received & $\$ 8$ & \\
\hline 75 & FR & 2 & $\mathrm{~B}$ & 3/4" Pipe & CPVC & 3/4" CPVC Ball Valve Georg Fischer 163-346-303 & AB8 & & & & $7 / 10 / 2007$ & $7 / 17 / 2007$ & received & $\$ 8$ & \\
\hline 76 & FR & 3 & $B$ & 1/2" Pipe & CPVC & 1/2" CPVC Ball Valve McMaster Carr \#4724K81 & AC8 & & & & $7 / 10 / 2007$ & $7 / 17 / 2007$ & received & $\$ 7$ & \\
\hline 77 & FR & 4 & $\mathrm{~B}$ & 1/2" Pipe & CPVC & 1/2" CPVC Ball Valve McMaster Carr \#4724K81 & AB7 & & & & 7/10/2007 & 7/17/2007 & received & $\$ 7$ & \\
\hline 78 & FR & 5 & $T$ & 1/2" Pipe & ss & Parker 494F 316 & V7 & & & & & & on hand & $\$ 200$ & \\
\hline 79 & FR & $6 \mathrm{~A}$ & $B$ & 2" Pipe & CPVC & 2" CPVC Ball Valve McMaster Carr \#4724K86 & AB20 & & & & 7/10/2007 & $7 / 17 / 2007$ & received & $\$ 25$ & \\
\hline 80 & FR & $6 \mathrm{~B}$ & $\mathrm{~B}$ & 2" Pipe & CPVC & 2" CPVC Ball Valve McMaster Carr \#4724K86 & $\mathrm{AB} 12$ & & & & 7/10/2007 & $7 / 177 / 2007$ & received & $\$ 25$ & \\
\hline 81 & $\mathrm{FR}$ & $6 c$ & B & 2" Pipe & CPVC & 2" CPVC Ball Valve McMaster Carr \#4724K86 & AB15 & & & & $7 / 10 / 2007$ & $7 / 17 / 2007$ & received & $\$ 25$ & \\
\hline 82 & $\mathrm{FR}$ & $6 \mathrm{D}$ & $\mathrm{B}$ & 2" Pipe & CPVC & 2" CPVC Ball Valve McMaster Carr \#4724K86 & AB18 & & & & $7 / 10 / 2007$ & $7 / 177 / 2007$ & received & $\$ 25$ & \\
\hline 83 & FR & $6 \mathrm{E}$ & $\mathrm{B}$ & 2" Pipe & CPVC & 2" CPVC Ball Valve McMaster Carr \#4724K86 & AB22 & & & & 7/10/2007 & $7 / 17 / 2007$ & $\begin{array}{ll}\text { received } \\
\text { s. }\end{array}$ & $\$ 25$ & \\
\hline 84 & $\mathrm{FR}$ & 7 & $\mathrm{~B}$ & 2" Pipe & CPVC & 2" CPVC Ball Valve McMaster Carr \#4724K86 & AB10 & & & & $7 / 10 / 2007$ & $7 / 17 / 2007$ & received & $\$ 25$ & \\
\hline 85 & $F R$ & 8 & $\mathrm{~B}$ & 3/4" Pipe & CPVC & 3/4" CPVC Ball Valve McMaster Carr \#4724K82 & AA10 & & & & $7 / 10 / 2007$ & $7 / 17 / 2007$ & received & $\$ 7$ & \\
\hline 86 & $F R$ & 9 & $\mathrm{~B}$ & 2" Pipe & CPVC & $2 "$ CPVC Ball Valve McMaster Carr \#4724k86 & x9 & & & & 7/10/2007 & $7 / 7 / 7 / 2007$ & received & $\$ 25$ & \\
\hline 87 & $\mathrm{FR}$ & 10 & $\mathrm{~B}$ & 1/2" Pipe & CPVC & 1/2" CPVC Ball Valve McMaster Carr \#4724K81 & Y8 & & & & $7 / 10 / 2007$ & $7 / 17 / 2007$ & received & 57 & \\
\hline 88 & FR & $11 \mathrm{~A}$ & B & 2" Pipe & CPVC & 2" CPVC Ball Valve McMaster Carr \#4724K86 & Y20 & & & & $7 / 10 / 2007$ & $7 / 17 / 2007$ & received & $\$ 25$ & \\
\hline 89 & FR & $11 \mathrm{~B}$ & $B$ & 2" Pipe & CPVC & 2" CPVC Ball Valve McMaster Carr \#4724K86 & Y11 & & & & $7 / 10 / 2007$ & $7 / 17 / 2007$ & received & $\$ 25$ & \\
\hline 90 & $\mathrm{FR}$ & $11 \mathrm{C}$ & $\mathrm{B}$ & 2" Pipe & CPVC & 2" CPVC Ball Valve McMaster Carr \#4724K86 & Y14 & & & & $7 / 10 / 2007$ & $7 / 717 / 2007$ & received & $\$ 25$ & \\
\hline 91 & $F R$ & 110 & $\frac{D}{B}$ & 2" Pipe & CPVC & \begin{tabular}{|l}
2 " CPVC Ball Valve McMaster Carr $\# 4724 K 86$ \\
\end{tabular} & \begin{tabular}{l|l}
14 \\
Y17
\end{tabular} & & & & $7 / 10 / 2007$ & $7 / 177 / 2007$ & 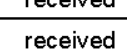 & $\begin{array}{c}2025 \\
\$ 25\end{array}$ & \\
\hline 92 & FR & $11 \mathrm{E}$ & $B$ & 2" Pipe & CPVC & 2" CPVC Ball Valve McMaster Carr \#4724K86 & Y22 & & & & 7/10/2007 & 7/17/2007 & received & $\$ 25$ & \\
\hline 93 & $\mathrm{FR}$ & $12 \mathrm{~A}$ & $\mathrm{~B}$ & 1/2" Pipe & CPVC & 1/2" CPVC Ball Valve McMaster Carr \#4724K81 & AA20 & & & & 7/10/2007 & $7 / 17 / 2007$ & received & $\$ 7$ & \\
\hline 94 & $F R$ & $12 \mathrm{~B}$ & $\mathrm{~B}$ & $1 / 2 "$ Pipe & CPVC & $1 / 2^{\prime \prime}$ CPVC Ball Valve McMaster Carr \#4724K81 & AA12 & & & & $7 / 10 / 2007$ & $7 / 17 / 2007$ & received & $\$ 7$ & \\
\hline 95 & $\mathrm{FR}$ & $12 \mathrm{C}$ & $\mathrm{B}$ & 1/2" Pipe & CPVC & 1/2" CPVC Ball Valve McMaster Carr \#4724K81 & AA15 & & & & $7 / 10 / 2007$ & $7 / 177 / 2007$ & received & $\$ 7$ & \\
\hline 96 & FR & $12 \mathrm{D}$ & B & 1/2" Pipe & CPVC & 1/2" CPVC Ball Valve McMaster Carr \#4724K81 & AA18 & & & & 7/10/2007 & 7/17/2007 & received & $\$ 7$ & \\
\hline 97 & $\mathrm{FR}$ & $12 \mathrm{E}$ & B & 1/2" Pipe & CPVC & 1/2" CPVC Ball Valve McMaster Carr \#4724K81 & AA23 & & & & 7/10/2007 & $7 / 17 / 2007$ & received & $\$ 7$ & \\
\hline 98 & $F R$ & 13 & $\mathrm{~B}$ & 11/2" Pipe & CPVC & 1-1/2" CPVC Ball Valve McMaster Carr \#4724K85 & W7 & & & & $7 / 10 / 2007$ & $7 / 17 / 2007$ & received & $\$ 20$ & \\
\hline 99 & $F R$ & 14 & $\mathrm{~B}$ & 1/2" Pipe & CPVC & 1/2" CPVC Ball Valve McMaster Carr \#4724K81 & $\mathrm{x} 10$ & & & & $7 / 10 / 2007$ & $7 / 17 / 2007$ & received & $\$ 7$ & \\
\hline$\frac{100}{100}$ & $F R$ & $\frac{14}{15}$ & $\frac{\mathrm{B}}{\mathrm{c}}$ & $1 / 2$ " Pipe & POLYPROPYLENE & McMaster Carr 籼492K53 & $\frac{100}{67}$ & & & & $7 / 24 / 2007$ & & $\begin{array}{l}\text { recelved } \\
\text { received }\end{array}$ & $\$ 7 /$ & \\
\hline
\end{tabular}




\begin{tabular}{|c|c|c|c|c|c|c|c|c|c|c|c|c|c|c|c|}
\hline \multicolumn{16}{|c|}{ Valve List for Fractional Crystallization Test Facility } \\
\hline Line \# & Sys & $\begin{array}{l}\text { Valve } \\
\text { No. }\end{array}$ & Type & Size & Material & Vendor, Model No., and Other Information & $\begin{array}{l}\text { P\&ID } \\
\text { Loc }\end{array}$ & Date Walkdown & $\begin{array}{l}\text { Date Oper. } \\
\text { Verification }\end{array}$ & Comments & \begin{tabular}{|c} 
Dale \\
order \\
Placed
\end{tabular} & $\begin{array}{c}\text { Delivery } \\
\text { Date }\end{array}$ & Status & Cost & $\begin{array}{c}\text { Cost } \\
\text { Avoided }\end{array}$ \\
\hline 101 & FR & 16 & B & 1/2" Pipe & CPVC & 1/2" CPVC Ball Valve McMaster Carr \#4724K81 & AB21 & & & & & & received & & \\
\hline 102 & $F R$ & 17 & $\mathrm{~B}$ & 1 1/2" Pipe & CPVC & 1-1/2" CPVC Ball Valve McMaster Carr \#4724K85 & ABg & & & & 7/10/2007 & $\mid 7 / 17 / 2007$ & received & $\$ 20$ & \\
\hline 103 & FR & 18 & B & 1" Pipe & CPVC & 1" CPVC Ball Valve & w9 & & & & & & & & \\
\hline 104 & FR & 19 & B & 1" Pipe & CPVC & 1" CPVC Ball Valve & AC11 & & & & & & & & \\
\hline 105 & FR & 20 & B & 1" Pipe & CPVC & 1" CPVC Ball Valve & $\mathrm{Y}_{10}$ & & & & & & & & \\
\hline 106 & PA & 1 & B & 3/4" Tube & $s / s$ & Whitey SS-45F 10 & $\mathrm{Z} 10$ & & & & & & on hand & & $\$ 180$ \\
\hline 107 & PA & $2 \mathrm{~A}$ & B & 1/4" Tube & $s / s$ & Swagelok SS-43S4 & & & & & & & on hand & & \\
\hline 108 & PA & $2 \mathrm{~B}$ & $B$ & 1/4" Tube & s/s & Swagelok SS-44F4 w/tube adapters & S4 & & & & & & on hand & & $\$ 62$ \\
\hline 109 & $\mathrm{PA}$ & 3 & $B$ & 1/4" Tube & s/s & Swagelok SS-43S4 & L38 & & & & & & on hand & & \\
\hline 110 & PA & 4 & $T$ & 1/4" Pipe & Brass & Part of centrifuge & & & & & & & & & \\
\hline 111 & PD & 1 & B & 2" Pipe & CPVC & 2" CPVC Ball Valve McMaster Carr \#4724K86 & U36 & & & & 7/110/2007 & $7 / 17 / 2007$ & received & $\$ 25$ & \\
\hline 112 & PD & 2 & B & 1/2" Pipe & CPVC & 1/2" CPVC Ball Valve McMaster Carr \#4724K81 & V36 & & & & 7/10/2007 & $7 / 17 / 2007$ & received & $\$ 7$ & \\
\hline 113 & PD & 3 & $T$ & 1" Pipe & s/s & 316 SS Globe Valve McMaster \#4742K15 & s34 & & & & 7/117/2007 & $7 / 23 / 2007$ & received & $\$ 89$ & \\
\hline 114 & PD & 4 & $T$ & 1/4" Tube & s/s & Swagelok SS-1RS4 & $\mathrm{V}_{31}$ & & & & $6 / 15 / 2007$ & 6/27/2007 & received & $\$ 49$ & \\
\hline 115 & PD & 5 & $\operatorname{ANA(NC)}$ & 1/4" Tube & $s / s$ & Assured Automation Mod. A26NRX08SCE3A & v31 & & & & 7/23/2007 & & 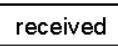 & $\$ 319$ & \\
\hline 116 & PD & 6 & $T$ & 3/8" Tube & s/s & Swagelok SS-1VS6 & $\mathrm{V} 31$ & & & & 6/18/2007 & 6/27/2007 & received & $\$ 68$ & \\
\hline 117 & PD & 7 & $\mathrm{AA}(\mathrm{NO})$ & 1/2" Pipe & $s / s$ & Assured Automation Mod. C26NRX08SOE3A & R31 & & & & 7/23/2007 & & received & $\$ 403$ & \\
\hline 118 & PD & 8 & AA 3 W & 1/2" Pipe & s/s & Assured Automation Mod. C33DAX08S1E3A & L32 & & & & $7 / 23 / 2007$ & & received & $\$ 417$ & \\
\hline 119 & PD & 10 & B & 1/2" Pipe & CPVC & 1/2" CPVC Ball Valve McMaster Carr \#4724K81 & P31 & & & & & & on hand & & $\$ 200$ \\
\hline 120 & PD & 11 & B3W & 3/8" Tube & s/s & Swagelok SS-44XS6 & $\$ 32$ & & & & & & on hand & & $\$ 62$ \\
\hline 121 & PD & 12 & $B 3 \mathrm{~W}$ & 3/8" Tube & $s / s$ & Swagelok SS-44XS6 & $\mathrm{T} 31$ & & & & & & on hand & & \\
\hline 122 & PD & 13B & $\mathrm{B}$ & 1/2" Pipe & CPVC & $1 / 2^{\prime \prime}$ CPVC Ball Valve McMaster Carr \#4724K81 & $\mathrm{x} 17$ & & & & 7/110/2007 & $7 / 117 / 2007$ & received & $\$ 7$ & \\
\hline 123 & PD & $13 \mathrm{C}$ & B & $1 / 2^{n}$ Pipe & CPVC & \begin{tabular}{|l|l|}
$1 / 2^{\prime \prime}$ CPVC Ball Valve McMaster Carr \#4724K81 \\
\end{tabular} & $\mathrm{x} 17$ & & & & 7/10/2007 & 7/117/2007 & received & $\$ 7$ & \\
\hline 124 & PD & 13D & B & 1/2" Pipe & CPVC & $1 / 2^{\prime \prime}$ CPVC Ball Valve McMaster Carr \#4724K81 & $\mathrm{Y} 18$ & & & & 7/110/2007 & $7 / 17 / 2007$ & received & $\$ 7$ & \\
\hline 125 & PD & 14 & B & 1/2" Pipe & CPVC & $1 / 2 "$ CPVC Ball Valve McMaster Carr \#4724K81 & U34 & & & & & & received & & \\
\hline 126 & PD & 15 & $B$ & 1" Pipe & CPVC & \begin{tabular}{|l} 
1" CPVC Ball Valve McMaster Carr \#4724K83 \\
\end{tabular} & U33 & & & & & & received & & \\
\hline 127 & PD & 17 & B & 1/2" Pipe & CPVC & 1/2" CPVC Ball Valve McMaster Carr \#4724K81 & & & & & & & received & & \\
\hline 128 & RW & 1 & B & 11/2" Pipe & CPVC & 1-1/2" CPVC Ball Valve McMaster Carr \#4724K85 & $\mathrm{U} 27$ & & & & 7/10/2007 & $7 / 17 / 2007$ & received & $\$ 20$ & \\
\hline 129 & RW & 2 & $B$ & 1/2" Pipe & CPVC & $1 / 2^{\prime \prime}$ CPVC Ball Valve McMaster Carr \#4724K81 & $\mathrm{V} 26$ & & & & $7 / 10 / 2007$ & $7 / 17 / 2007$ & received & $\$ 7$ & \\
\hline 130 & RW & 3 & $T$ & 1" Pipe & $s / s$ & 316 SS Globe Valve McMaster \#4742K15 & $\mathrm{U} 25$ & & & & 7/117/2007 & $7 / 23 / 2007$ & received & $\$ 89$ & \\
\hline 131 & $\mathrm{RW}$ & 4 & $T$ & 3/8" Tube & s/s & Swagelok SS-1VS6 & $\mathrm{U} 24$ & & & & $6 / 18 / 2007$ & $6 / 27 / 2007$ & received & $\$ 68$ & \\
\hline 132 & $\mathrm{RW}$ & 5 & AA $3 W$ & 1/2" Pipe & s/s & Assured Automation Mod. C33DAX08S1E3A & J33 & & & & 7/23/2007 & & received & $\$ 417$ & \\
\hline 133 & $\mathrm{RW}$ & $\frac{6}{6}$ & ANA $3 W$ & 3/4" Pipe & $s / s$ & Assured Automation Mod. D33DAX08S1E3A & L33 & & & & 7/23/2007 & & received & $\$ 462$ & \\
\hline 134 & RW & 7 & B 3 W & 3/4" Pipe & CPVC & McMaster Carr \#4697K42 & N28 & & & & 7/10/2007 & $7 / 17 / 2007$ & received & $\$ 107$ & \\
\hline 135 & RW & 8 & $\mathrm{~B} 3 \mathrm{~W}$ & 1/4" Tube & $s / s$ & Swagelok SS-43XS4 & T26 & & & & & & on hand & & \\
\hline 136 & SL & 1 & B & 11/2" Pipe & CPVC & 1-1/2" CPVC Ball Valve McMaster Carr \#4724K85 & v9 & & & & 7/10/2007 & $7 / 17 / 2007$ & received & $\$ 25$ & \\
\hline 137 & SL & 2 & B & 1/2" Pipe & CPVC & 1/2" CPVC Ball Valve McMaster Carr \#4724K81 & v9 & & & & 7/10/2007 & $7 / 17 / 2007$ & received & $\$ 7$ & \\
\hline 138 & SL & 3 & B & 1/2" Pipe & CPVC & 1/2" CPVC Ball Valve McMaster Carr \#4724K81 & F34 & & & & 7/10/2007 & $7 / 17 / 2007$ & received & $\$ 7$ & \\
\hline 139 & $\mathrm{SL}$ & 4 & $B 3 w$ & 11/2" Pipe & CPVC & McMaster Carr \#4697K44 & w8 & & & & 7/10/2007 & 7/1/7/2007 & received & $\$ 233$ & \\
\hline 140 & SL & 5 & $\mathrm{P}$ & 11/2" Pipe & Viton & Red Valve Series 70 & v8 & & & & $6 / 15 / 2007$ & $7 / 11 / 2007$ & on hand & $\$ 499$ & \\
\hline 141 & SL & 6 & ANA $3 W$ & 1" Pipe & s/s & Assured Automation Mod. E33DAX08S1E3A & G36 & & & & 7/23/2007 & & received & \begin{tabular}{|l|l}
547 \\
\end{tabular} & \\
\hline 142 & SL & 7 & B & 1/2" Pipe & CPVC & 1/2" CPVC Ball Valve McMaster Carr \#4724K81 & w9 & & & & 7/10/2007 & $7 / 17 / 2007$ & received & $\$ 7$ & \\
\hline 143 & SL & 8 & & & $s / s$ & Custom Design and SRNL Manufacture & D4 & & & & & & & & \\
\hline 144 & SL & 9 & $B$ & 1/2" Pipe & $\mathrm{CPVC}$ & $1 / 2^{\prime \prime}$ CPVC Ball Valve McMaster Carr $\# 4724 K 81$ & $x_{6}$ & & & & $7 / 10 / 2007$ & $7 / 17 / 2007$ & received & $\$ 7$ & \\
\hline 145 & SL & 10 & $\mathrm{~B}$ & 1" Pipe & CPVC & \begin{tabular}{|l|l|l}
$1 " C P V C$ Ball Valve McMaster Carr \#4724K83 \\
\end{tabular} & w6 & & & & 7/10/2007 & 7/1/7/2007 & received & $\$ 7$ & \\
\hline 146 & SL & 11 & B & 1/2" Tube & s/s & Swagelok SS-45S8 & P6 & & & & & & on hand & & \\
\hline 147 & SL & $12 \mathrm{~A}$ & AT & 1/4" Tube & s/s & Brooks flow controller Model \# 58501A1 B T342BEA & A18 & & & & 9/10/2007 & 9/25/2007 & received & & \\
\hline 148 & SL & $12 \mathrm{~B}$ & B & 1/2" Tube & $s / S$ & Swagelok SS-45S8 & & & & & & & on hand & & \\
\hline 149 & SL & $12 \mathrm{M}$ & $T$ & 1/2" Tube & $s / S$ & Hoke 2112G8V & B18 & & & & & & on hand & & \\
\hline 150 & SL & 13 & B & 1/4" Tube & S/S & Swagelok SS-43S4 & P8 & & & & & & on hand & & $\$ 62$ \\
\hline
\end{tabular}




\begin{tabular}{|c|c|c|c|c|c|c|c|c|c|c|c|c|c|c|c|}
\hline \multicolumn{16}{|c|}{ Valve List for Fractional Crystallization Test Facility } \\
\hline Line \# & sys & $\begin{array}{c}\text { Valve } \\
\text { No. }\end{array}$ & Type & Size & Material & Vendor, Model No., and Other Information & $\begin{array}{l}\text { P\&ID } \\
\text { Loc }\end{array}$ & Date Walkdown & $\begin{array}{l}\text { Date Oper. } \\
\text { Verification }\end{array}$ & Comments & $\begin{array}{l}\text { Date } \\
\text { Order } \\
\text { Placed }\end{array}$ & $\begin{array}{c}\text { Delivery } \\
\text { Date }\end{array}$ & Status & cost & $\begin{array}{c}\text { cost } \\
\text { Avoided }\end{array}$ \\
\hline 151 & SL & 14 & $\mathrm{~B}$ & 1/4" Tube & s/s & Swagelok SS-43S4 & M7 & & & & & & on hand & & $\$ 62$ \\
\hline 152 & SL & 15 & $\mathrm{~B}$ & 1/2" Tube & s/s & Swagelok SS-45S8 & $\mathrm{H} 7$ & & & & & & on hand & & $\$ 250$ \\
\hline 153 & SL & 16 & $\mathrm{~B}$ & 1/4" Tube & s/s & Swagelok SS-43S4 & D8 & & & & & & on hand & & $\$ 62$ \\
\hline 154 & SL & 17 & $\mathrm{~B}$ & 1" Pipe & CPVC & 1" CPVC Ball Valve Georg Fischer & G35 & & & & & & on hand & & \\
\hline 155 & SL & $18 \mathrm{~B}$ & B & 3/4" Tube & s/s & Swagelok SS-45S12 & E18 & & & & & & on hand & & \\
\hline 156 & $S L$ & ${ }_{18 \mathrm{~T}} \mathrm{Y}>\mathrm{C}$ & $B$ & 1/2" Tube & $s / s$ & & E19 & & & & & & on hand & & \\
\hline 157 & SL & 19 & $\mathrm{~B}$ & 1/2" Tube & s/s & Swagelok SS-45S8 & E3 & & & & & & on hand & & \\
\hline 158 & SL & 20 & $\mathrm{~B}$ & 1/2" Pipe & CPVC & $1 / 2^{\prime \prime}$ CPVC Ball Valve McMaster Carr \#4724K81 & & & & & & & & & \\
\hline 159 & SL & 21 & $\mathrm{~B}$ & 1/2" Pipe & CPVC & 1/2" CPVC Ball Valve McMaster Carr \#4724K81 & & & & & & & & & \\
\hline 160 & ST & 1 & $\mathrm{~B}$ & 1" Pipe & Brass & Brass Ball, Installed & AB2 & & & & & & Installed & & \\
\hline 161 & ST & 2 & $\mathrm{~B}$ & 1" Pipe & Brass & Brass Ball, Installed & AB4 & & & & 7/10/2007 & & received & $\$ 14$ & \\
\hline 162 & ST & 3 & AT & 1" Pipe & $s / s$ & Schubert \& Salzer 8021/025VGE106M-91-1ZR-S-2 & $\mathrm{V} 3_{3}$ & & & & 6/28/2007 & & received & $\$ 2,058$ & \\
\hline 163 & ST & 4 & $\mathrm{~T}$ & 1" Pipe & Brass & Stockham Fig. B-22T Brass $150 \mathrm{~S} 300 \mathrm{CWP}$ & K1 & & & & on hand & & installed & & $\$ 100$ \\
\hline 164 & ST & 5 & $T$ & 1" Pipe & Brass & Stockham Fig. B-22T Brass 150 S 300CWP & $\mathrm{K} 1$ & & & & on hand & & installed & & $\$ 100$ \\
\hline 165 & ST & 6 & B & 3/8" Tube & $\mathrm{s} / \mathrm{s}$ & Swagelok SS-43S6 & P5 & & & & & & on hand & & $\$ 64$ \\
\hline 166 & ST & 7 & $B$ & 1/2" Tube & s/s & Swagelok SS-43S8 & Q5 & & & & & & on hand & & $\$ 64$ \\
\hline 167 & ST & 8 & $T$ & 1/2" Tube & s/s & Hoke 2112G8V & $\mathrm{L} 11$ & & & & 6/18/2007 & 6/27/2007 & received & $\$ 68$ & \\
\hline 168 & ST & 9 & $B$ & 1/2" Tube & $s / s$ & Swagelok SS-43SB & 57 & & & & & & on hand & & 564 \\
\hline 169 & ST & 10 & $T$ & 1/4" Pipe & s/s & Hoke 2112F4Y & L35 & & & & & & on hand & & \\
\hline 170 & ST & 11 & $\mathrm{~T}$ & $1 / 2 "$ Pipe & BRASS & Gate Valve Stockham 2005400 oWG & AA5 & & & & & & on hand & & \\
\hline 171 & ST & 12 & $\mathrm{~T}$ & 1/4" Pipe & $s / s$ & Hoke 2112F4Y & M2 & & & & & & on hand & & \\
\hline 172 & SW & 1 & $\mathrm{~B}$ & 11/2" Pipe & CPVC & 1-1/2" CPVC Ball Valve McMaster Carr \#4724K85 & $\mathrm{U} 22$ & & & & 7/10/2007 & $7 / 17 / 2007$ & received & $\$ 20$ & \\
\hline 173 & SW & 2 & B & 1/2" Pipe & CPVC & 1/2" CPVC Ball Valve McMaster Carr \#4724K81 & V21 & & & & 7/10/2007 & 7/177/2007 & received & $\$ 7$ & \\
\hline 174 & sw & 3 & $T$ & 1" Pipe & s/s & 316 SS Globe Valve McMaster \#4742K15 & $\mathrm{U} 20$ & & & & 7/117/2007 & 7/23/2007 & received & $\$ 89$ & \\
\hline 175 & SW & 4 & $\mathrm{~T}$ & 1/4" Tube & s/s & Swagelok SS-1RS4 & Q19 & & & & 6/15/2007 & 6/27/2007 & received & $\$ 49$ & \\
\hline 176 & SW & 5 & AAA (NC) & 1/4" Tube & s/s & Assured Automation Mod. A26NRX08SCE3A & Q19 & & & & $7 / 23 / 2007$ & & received & $\$ 319$ & \\
\hline 177 & sw & 6 & $\mathrm{~T}$ & 3/8" Tube & $s / s$ & Swagelok SS-1VS6 & Q18 & & & & 6/18/2007 & 6/27/2007 & received & $\$ 68$ & \\
\hline 178 & sw & 7 & $\mathrm{~T}$ & 1/2" Pipe & ss & Parker 494F 316 & M17 & & & & & & on hand & & $\$ 200$ \\
\hline 179 & SW & 8 & $\mathrm{~B}$ & 1/2" Pipe & CPVC & 1/2" CPVC Ball Valve McMaster Carr \#4724K81 & T8 & & & & 7/10/2007 & $7 / 17 / 2007$ & received & $\$ 7$ & \\
\hline 180 & SW & 9 & AA $3 W$ & 3/4" Pipe & $\mathrm{s} / \mathrm{s}$ & Assured Automation Mod. D33DAX08S1E3A & M34 & & & & 7/23/2007 & & received & $\$ 462$ & \\
\hline 181 & sw & 10 & BзW & 3/4" Pipe & CPVC & McMaster Carr \#4697K42 & N23 & & & & & & received & $\$ 235$ & \\
\hline 182 & SW & 11 & B3WW & 3/8" Tube & $s / s$ & Swagelok SS-44XS6 & $\mathrm{T} 20$ & & & & & & on hand & & $\$ 62$ \\
\hline 183 & SW & 12 & B 3 W & 1/2" Pipe & CPVC & McMaster Carr \#4697K41 & M18 & & & & $7 / 10 / 2007$ & $7 / 17 / 2007$ & received & $\$ 95$ & \\
\hline 184 & SW & 13 & B 3 W & 1/2" Pipe & CPVC & McMaster Carr \#4697K41 & $\mathrm{N} 19$ & & & & $7 / 110 / 2007$ & $7 / 17 / 2007$ & received & $\$ 95$ & \\
\hline 185 & sw & 14 & AA $3 W$ & 1/2" Pipe & $s / s$ & Assured Automation Mod. C33DAX08S1E3A & H34 & & & & 7/23/2007 & & received & $\$ 417$ & \\
\hline 186 & SW & 15 & $\mathrm{~B}$ & 1/2" Pipe & $\mathrm{CPVC}$ & 1/2" CPVC Ball Valve McMaster Carr \#4724K81 & & & & & 7/10/2007 & $7 / 17 / 2007$ & received & $\$ 7$ & \\
\hline
\end{tabular}


RPP-39091, Rev. 0

RPT-3000755 Rev. 000

APPENDIX 8.7

PILOT DAS INDICATIONS

(Consisting of 5 pages

Including coversheet) 


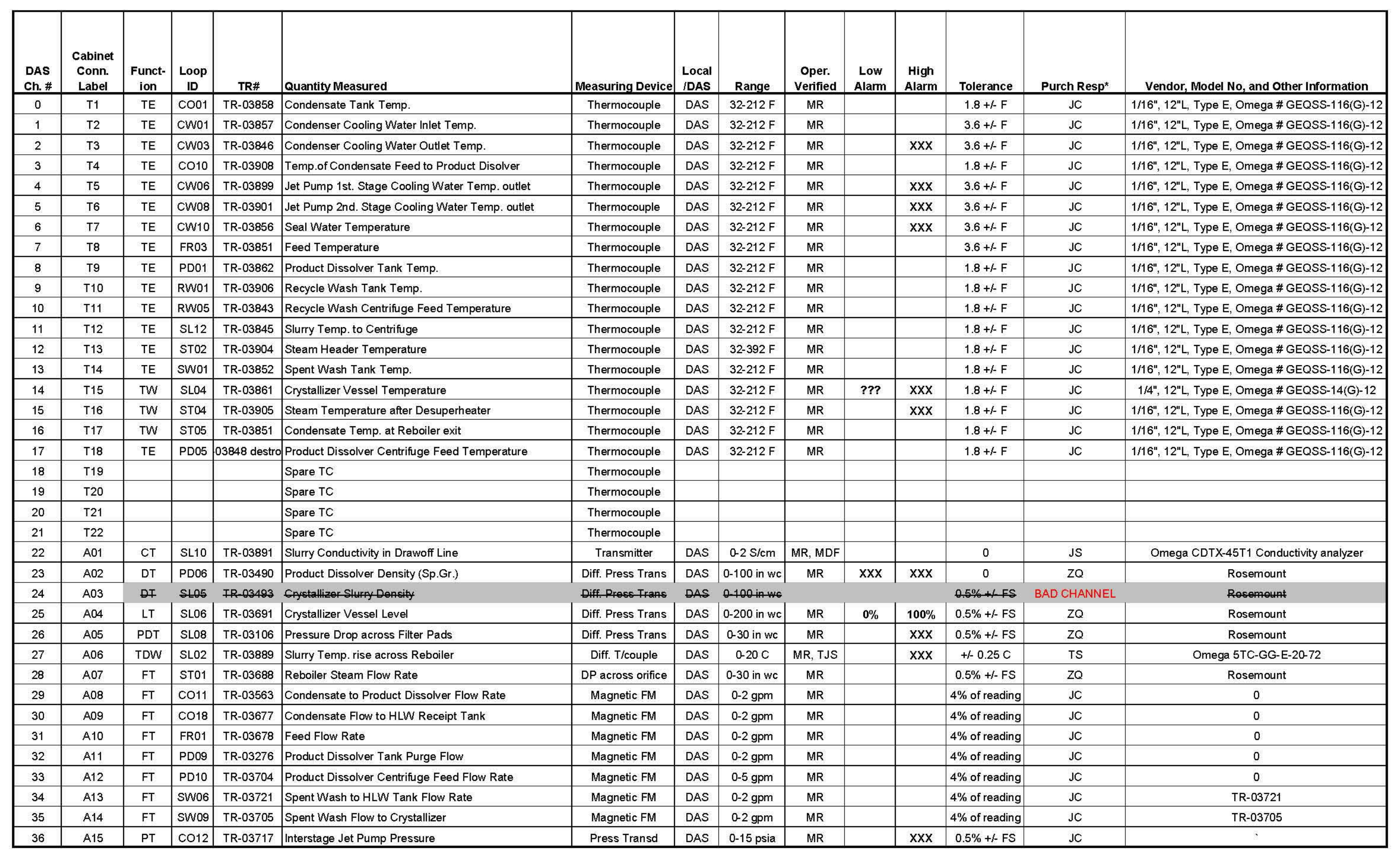




\begin{tabular}{|c|c|c|c|c|c|c|c|c|c|c|c|c|c|c|}
\hline $\begin{array}{l}\text { DAS } \\
\text { ch.\# }\end{array}$ & $\begin{array}{l}\text { Cabinet } \\
\text { conn. } \\
\text { Label }\end{array}$ & $\begin{array}{c}\text { Funct- } \\
\text { ion }\end{array}$ & $\begin{array}{l}\text { Loop } \\
\text { ID }\end{array}$ & $\mathbb{R} \#$ & Quantity Measured & Measuring Device & $\begin{array}{l}\text { Local } \\
\text { IDAS }\end{array}$ & Range & $\begin{array}{l}\text { Oper. } \\
\text { verified }\end{array}$ & 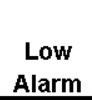 & $\begin{array}{l}\text { High } \\
\text { Alarm }\end{array}$ & Tolerance & Purch Resp ${ }^{*}$ & Vendor, Model $\mathrm{No}$, and Other Information \\
\hline 37 & A16 & PT & \begin{tabular}{|c|}
$S L 07$ \\
\end{tabular} & TR-03885 & Crystallizer Vessel Pressure & \begin{tabular}{|l|} 
Pressure Trans \\
\end{tabular} & DAS & 0 -15 psia & MR & $\mathrm{xxx}$ & $\mathrm{xxx}$ & $0.5 \%+$ +-FS & $\mathrm{zQ}$ & Omega, PX4200-30VACl \\
\hline 38 & A17 & $\mathrm{PE}$ & ST06 & TR-03883 & Reboiler Shell Steam Pressure Element & Pressure Transd & DAS & $0-15$ psia & MR & $\mathrm{xxx}$ & $\mathrm{xxx}$ & $0.5 \%+$ + FS & JG & Omega, PX4200-30VACI \\
\hline 39 & A18 & LC & PD07 & N/A & Product Dissolver Tank Level Controller & Ultrasonic & DAS & $0.3-6 \mathrm{tt}$ & MR & $\mathrm{xxx}$ & $\mathrm{xxx}$ & $0.125 \mathrm{in}$ & TS & Omega LVCN-51 \\
\hline 40 & A19 & LE & RW07 & TR-03918 & Recycle Wash Tank Level & Ultrasonic & DAS & $0.3-6 \mathrm{ft}$ & MR & $\mathrm{xxx}$ & $x x x$ & $0.125 \mathrm{in}$ & TS & Omega LVO91 \\
\hline 41 & A20 & LC & SW07 & $\mathrm{N} / \mathrm{A}$ & Spent Wash Tank Level Controller & 0 & DAS & $0.3-6 \mathrm{tt}$ & MR & $\mathrm{xxx}$ & $\mathrm{xxx}$ & $0.125 \mathrm{in}$ & TS & Omega LVCN-51 \\
\hline 42 & A21 & FT & SL03 & TR-03892 & Circulation Flow Rate & Ultrasonic FM & DAS & $0-1000 \mathrm{gpm}$ & MR & $\mathrm{xxx}$ & & $2 \% \mathrm{rdg}+0.2 \mathrm{fps}$ & 20 & GE TransPort PT878 \\
\hline 43 & A22 & ст & c002 & TR-03884 & Condensate Conductivity Transmitter & 0 & DAS & & MR, MDF & & & $2 \% \mathrm{rdg}+6 \mathrm{uS} / \mathrm{cm}$ & TS & Omega CDCN-91AC \\
\hline 44 & A23 & IT & SL01 & N/A & Circulation Pump Current & 0 & DAS & $0-20$ amps & MR & & High Po & sitive Rate of $\mathrm{Cr}$ & ange & 0 \\
\hline 45 & A24 & ST & SL01 & N/A & Circulation Pump Speed & 0 & DAS & $0-3550 \mathrm{rpm}$ & MR & & & 0 & MR & 0 \\
\hline 46 & A25 & FT & SL14 & TR-03601 & Draw Off Return Flow Rate & Magnetic FM & DAS & 0-100 gpm & MR & $\mathrm{xxx}$ & & $4 \%$ of reading & JC & TR-03601 \\
\hline 47 & A26 & FT & Cwo2 & TR-03687 & Condenser Cooling Water Flow Rate & Magnetic FM & DAS & 0-200 gpm & MR & & & $4 \%$ of reading & MR & 0 \\
\hline 48 & A27 & DT & SL05 & TR-03493 & Crystallizer Slurry Density & Diff. Press Trans & DAS & $0-100$ in wc & $\mathrm{TS}, \mathrm{MR}$ & $\mathrm{xxx}$ & $x \mathrm{xx}$ & $0.5 \%++$ FS & $z Q$ & Rosemount \\
\hline 49 & A28 & FT & SL15 & CDS-4714 & Draw Off Loop Flow Rate (Ultrasonic) & Ultrasonic FM & DAS & $0.60 \mathrm{gpm}$ & MR, MDF & & & $1.5 \%$ rdg+0.15f & MF & Controllotron System 990 \\
\hline 50 & A29 & FT & SL12 & N/A & SL12 Mass Flowmeter & Mass Flow Meter & DAS & $0-20$ SLPM & MR, MDF & & & & MR & Brooks flow controller Model \# 58501A1BT342BEA \\
\hline 51 & A30 & & & & Spare 4-20 mA Channel & & & & & & & & & \\
\hline 52 & A31 & & & & Spare 4-20 mA Channel & & & & & & & & & \\
\hline 53 & A32 & & & & Spare 4-20 mA Channel & & & & & & & & & \\
\hline 54 & A33 & & & & Spare 4-20 mA Channel & & & & & & & & & \\
\hline 55 & A34 & & & & Spare 4-20 mA Channel & & & & & & & & & \\
\hline 56 & A35 & & & & Spare 4-20 mA Channel & & & & & & & & & \\
\hline 57 & A36 & & & & Spare 4-20 mA Channel & & & & & & & & & \\
\hline 58 & A37 & & & & Spare 4-20 mA Channel & & & & & & & & & \\
\hline 59 & A38 & & & & Spare 4-20 mA Channel & & & & & & & & & \\
\hline 60 & A39 & sv & PD05 & & Valve Indication for PD05 & Switch & DAS & On/Off & MR & & & & & \\
\hline 61 & A40 & sv & sw05 & & Valve Indication for SW05 & Switch & DAS & On/Off & MR & & & & & \\
\hline 62 & A41 & sv & \begin{tabular}{|l|l|} 
PD07 \\
\end{tabular} & & Valve Indication for PD07 & Switch & DAS & On/Off & MR & & & & & \\
\hline 63 & A42 & sv & c008 & & Valve Indication for $\mathrm{CO08}$ & Switch & DAS & On/Off & MR & & & & & \\
\hline 64 & A43 & sv & $\mathrm{CO} 33$ & & Valve Indication for $\mathrm{CO} 33$ & Switch & DAS & On/Off & MR & & & & & \\
\hline 65 & A44 & sv & \begin{tabular}{|l|l|} 
PDO8 \\
\end{tabular} & & Valve Indication for PD08 & Switch & DAS & On/off & MR & & & & & \\
\hline 66 & A45 & sv & RW05 & & Valve Indication for RW05 & Switch & DAS & On/Off & MR & & & & & \\
\hline 67 & A46 & sv & \begin{tabular}{|l|l|l|} 
SW14 \\
\end{tabular} & & Valve Indication for SW14 & Switch & DAS & On/Off & MR & & & & & \\
\hline 68 & A47 & sv & RW06 & & Valve Indication for RW06 & Switch & DAS & On/Off & MR & & & & & \\
\hline 69 & A48 & sv & swog & & Valve Indication for SW09 & Switch & DAS & On/Off & MR & & & & & \\
\hline 70 & A49 & sv & SLO6 & & Valve Indication for SL06 & Switch & DAS & On/off & MR & & & & & \\
\hline 71 & A50 & LAH & ALL LAH & & All LAH High Level Alarms & Float Switches & DAS & On/Off & MR & & $\mathrm{xxx}$ & & & \\
\hline
\end{tabular}




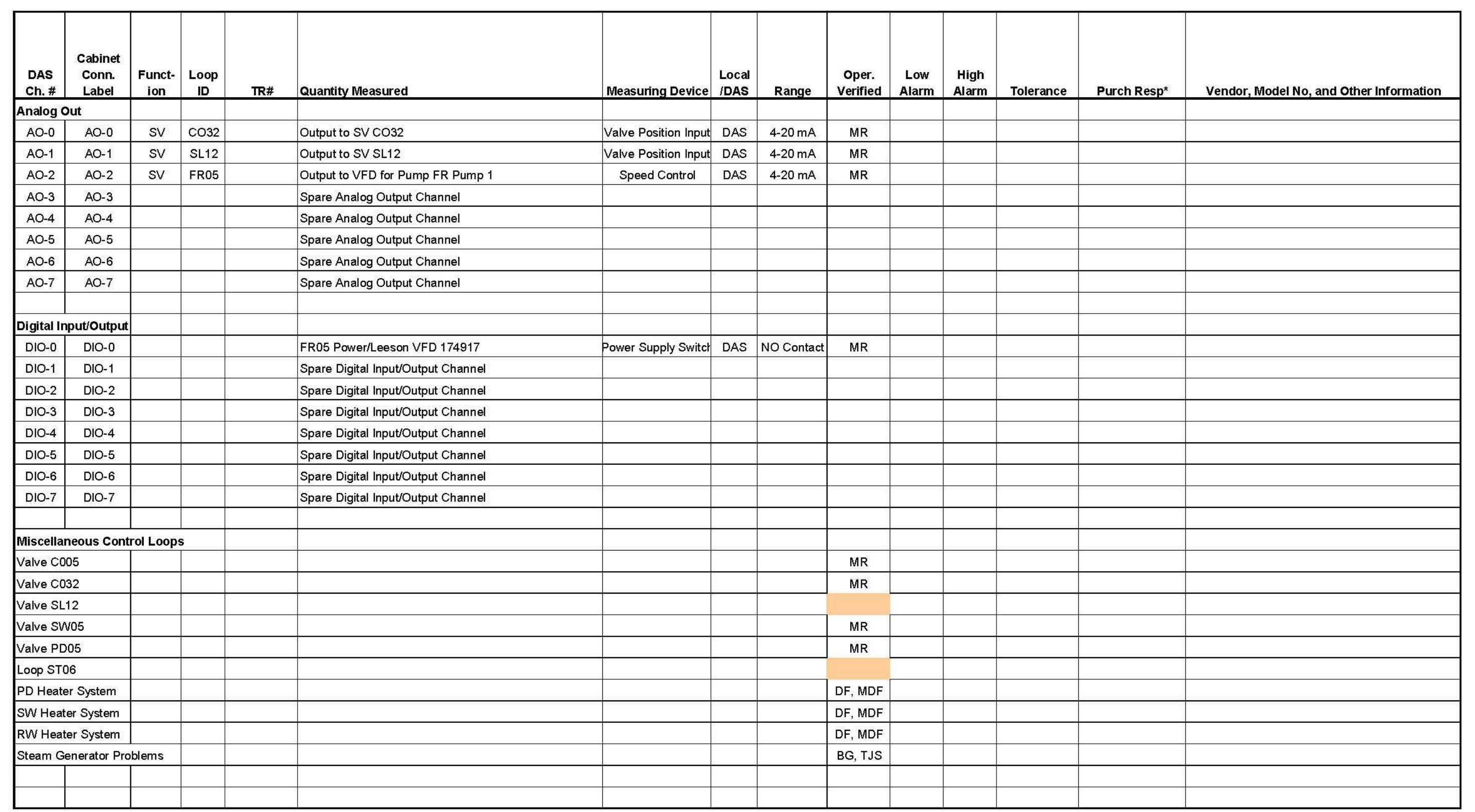




\begin{tabular}{|c|c|c|c|c|c|c|c|c|c|c|c|c|c|c|}
\hline $\begin{array}{l}\text { DAS } \\
\text { Ch. \# }\end{array}$ & $\begin{array}{l}\text { Cabinet } \\
\text { conn. } \\
\text { Label }\end{array}$ & $\begin{array}{c}\text { Funct- } \\
\text { ion }\end{array}$ & $\begin{array}{c}\text { Loop } \\
\text { ID }\end{array}$ & IR\# & Quantity Measured & Measuring Device & $\begin{array}{l}\text { Local } \\
\text { IDAS }\end{array}$ & Range & $\begin{array}{c}\text { Oper. } \\
\text { verified }\end{array}$ & $\begin{array}{c}\text { Low } \\
\text { Alarm }\end{array}$ & $\begin{array}{c}\text { High } \\
\text { Alarm }\end{array}$ & Tolerance & 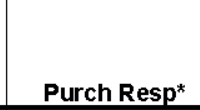 & Vendor, Model No, and Other Information \\
\hline & & & & & & & & & & & & & & \\
\hline & & $\mathrm{FI}$ & \begin{tabular}{|c|c|c|c|} 
\\
$c 005$ \\
\end{tabular} & $\frac{1 R-00122}{T R-20268}$ & $\begin{array}{l}\text { Condensate Flow Rate to Crystallizer Sraya Ring } \\
\text { Condensate Flow to Crystallizer Lower Demister }\end{array}$ & $\begin{array}{l}\text { Rotameter } \\
\text { Rotameter }\end{array}$ & \begin{tabular}{|l} 
Local \\
Loal
\end{tabular} & $0.5 \mathrm{gpm}$ & & & & $\mid+-0.35 \mathrm{gpm}$ & ss & 0 \\
\hline & & FI & coos & 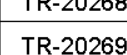 & $\begin{array}{l}\text { Condensate Flow to Crystallizer Lower Demister } \\
\text { Condensate Flow to Crystallizer Upper Demister }\end{array}$ & $\begin{array}{l}\text { Rotameter } \\
\text { Rotameter }\end{array}$ & \begin{tabular}{|l} 
Local \\
Loal
\end{tabular} & $0.2 \mathrm{gpm}$ & & & & \begin{tabular}{|c|c|c|}
$+0.15 \mathrm{gpm}$ \\
$+1-0.15 \mathrm{gmm}$ \\
\end{tabular} & 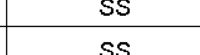 & 00 \\
\hline & & FI & coor & \#REFI & Condensate Flow for Desuperheater & Rotameter & \begin{tabular}{|l|l|l|l|l|l|l} 
Local \\
\end{tabular} & $0.20 \mathrm{gph}$ & & & & $+-0.4 \mathrm{gph}$ & ss & Fischer \& Porter 10A6132M \\
\hline & & $\mathrm{FI}$ & coog & TR-03887 & Centrifuge Rind Wash Water Totalizer & & Local & $0.22-22 \mathrm{gpm}$ & & & & $2.5 \%$ of rdg & TS & Omega FTB80007A \\
\hline & & $\mathrm{FI}$ & CO15 & TR-03878 & Condensate Purge Flow to Crystallizer Nozzle \#7 & Rotameter & Local & $0.2 \mathrm{gph}$ & & & & $4 \%$ of reading & ss & \\
\hline & & $\mathrm{FI}$ & Co16 & TR-03879 & Condensate Purge Flow to Crystallizer Nozzle \#8 & Rotameter & Local & $0-2 \mathrm{gph}$ & & & & $4 \%$ of reading & ss & \\
\hline & & LC & CO19 & N/A & Condensate Tank Level Control & 0 & 0 & 0 & & & & 0 & Omega LV611-P & Omega LV611-P \\
\hline & & $\mathrm{FI}$ & $\mathrm{CO} 20$ & TR-03880 & Condensate Purge Flow to PD Density Transmitter & Rotameter & Local & $0.2 \mathrm{gph}$ & & & & $4 \%$ of reading & ss & \\
\hline & & $\mathrm{FI}$ & co21 & TR-03881 & Condensate Purge Flow to PD Density Transmitter & Rotameter & Local & 0.2 gph & & & & | $4 \%$ of reading $\mid$ & ss & \\
\hline & & $\mathrm{FI}$ & CW05 & N/A & Jet Pump Cooling Water 1st Stage Flow Rate & Rotameter & Local & $0-20 \mathrm{gpm}$ & & & & $4 \%$ of reading & ss & \\
\hline & & $\mathrm{FI}$ & CW07 & N/A & Jet Pump Cooling Water 2nd Stage Flow Rate & Rotameter & Local & $0-20 \mathrm{gpm}$ & & & & $4 \%$ of reading & ss & \\
\hline & & LAH & RW06 & $\mathrm{N} / \mathrm{A}$ & Recycle Wash Tank High Level Alarm & Float Switch & Local & 0 & & & & 0 & $\mathrm{JC}$ & McMaster Carr \#46515K41 Polypropylene \\
\hline & & LSH & $\mathrm{co08}$ & N/A & Reboiler Condensate receiver level & Float Switch & Local & & & & & 0 & JG & Dwyer $M$ NE Anderson, F7-HPS-21 \\
\hline & & LSL & 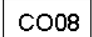 & N/A & Reboiler Condensate receiver level & Float Switch & Local & & & & & 0 & JG & DwyerME Anderson, F7-HPS-21 \\
\hline & & $\mathrm{PI}$ & CO17 & N/A & Condensate Header Pressure & Pressure Gage & Local & 0-100 psig & & & & 0 & $\mathrm{JC}$ & Moore Products Co. \#3994 \\
\hline & & $\mathrm{PI}$ & $\mathrm{CO} 22$ & N/A & Bottom Spray Nozzle supply pressure & Pressure Gage & Local & Vac-60 psig & & & & $2 \%$ of reading & $\mathrm{JC}$ & McMaster Carr \#38545K16 \\
\hline & & $\mathrm{PI}$ & $\mathrm{CO} 23$ & N/A & Top Spray Nozzle supply pressure & Pressure Gage & Local & Vac-60 psig & & & & $2 \%$ of reading & $\mathrm{JC}$ & McMaster Carr \#38545K16 \\
\hline & & $\mathrm{PI}$ & CW09 & N/A & Circulation Pump seal water pressure & Pressure Gage & Local & $0-100 \mathrm{psig}$ & & & & 0 & $\mathrm{JC}$ & Glycerin-Filled McMaster Carr \#4088K511 \\
\hline & & $\mathrm{PI}$ & FRO2 & N/A & Feed Pressure & Pressure Gage & Local & $0-30$ psig & & & & 0 & $\mathrm{JC}$ & Glycerin-Filled McMaster Carr \#4088K511 \\
\hline & & $\mathrm{PI}$ & PD04 & N/A & Product Dissolver Filter Inlet Pressure & Pressure Gage & Local & 0.60 psig & & & & 0 & $\mathrm{JC}$ & Glycerin-Filled McMaster Carr \#3813K7 \\
\hline & & $\mathrm{PI}$ & PD11 & N/A & Product Dissolver Filtrate Pressure & Pressure Gage & Local & $0-30$ psig & & & & 0 & $\mathrm{JC}$ & Glycerin-Filled McMaster Carr \#3813K7 \\
\hline & & $\mathrm{PI}$ & RW04 & N/A & Recycle Wash Pressure & Pressure Gage & Local & $0-60$ psig & & & & 0 & $\mathrm{JC}$ & Glycerin-Filled McMaster Carr \#3813K7 \\
\hline & & $\mathrm{PI}$ & SL11 & N/A & Draw Off Line Pressure & Pressure Gage & Local & vac-30 psig & & & & $1.5 \% \mathrm{FS}$ & $\mathrm{ZQ}$ & hok $25-40030 " \mathrm{Hg} / 30$ psig + McMaster isolator 433 \\
\hline & & $\mathrm{PI}$ & ST03 & TR-03886 & Steam Header Pressure & Pressure Gage & Local & $0-160 \mathrm{psig}$ & & & & 0 & $\mathrm{JC}$ & Glycerin-Filled McMaster Carr \#4088K511 \\
\hline & & $\mathrm{PI}$ & ST07 & N/A & Jet Pump Steam Pressure for 2nd. Stage & Pressure Gage & Local & $0-160$ psig & & & & 0 & $\mathrm{JC}$ & Glycerin-Filled McMaster Carr \#4088K511 \\
\hline & & $\mathrm{PI}$ & ST08 & N/A & Jet Pump Steam Pressure for 1st. Stage & Pressure Gage & Local & $0-160$ psig & & & & 0 & $\mathrm{JC}$ & Glycerin-Filled McMaster Carr \#4088K511 \\
\hline & & $\mathrm{Pl}$ & sw04 & N/A & Spent Wash Pressure & Pressure Gage & Local & $0-60$ psig & & & & 0 & $\mathrm{JC}$ & Glycerin-Filled McMaster Carr \#3813k7 \\
\hline & & sc & FR05 & N/A & Feed/Receipt Pump 1 VFD & VFD & Local & 0 & & & & 0 & JC & \\
\hline
\end{tabular}


RPP-39091, Rev. 0

RPT-3000755 Rev. 000

APPENDIX 8.8

PILOT EQUIPMENT LIST

(Consisting of 4 pages

Including coversheet) 


\begin{tabular}{|c|c|c|c|c|c|c|c|c|c|c|c|c|}
\hline \multicolumn{13}{|c|}{ Equipment List for Fractional Crystallization Test Facility } \\
\hline Sys & No. & Item Description & Specifications & Vendor, Model No., and Other Information & $\begin{array}{c}\text { Date } \\
\text { Walkdown }\end{array}$ & $\begin{array}{l}\text { Date Oper. } \\
\text { Verification }\end{array}$ & Cost & $\begin{array}{c}\text { Cost } \\
\text { Avoided }\end{array}$ & $\begin{array}{c}\text { Date Order } \\
\text { Placed }\end{array}$ & $\begin{array}{l}\text { Delivery } \\
\text { Date }\end{array}$ & $\operatorname{Resp}^{*}$ & Status \\
\hline $\mathrm{co}$ & 0 & Condensate System & & & & & & & & & & \\
\hline $\mathrm{co}$ & 1 & Primary Condenser & $1,000,000 \mathrm{Btu} / \mathrm{hr}$ & PO\# is AC60362 & & & & & & $08 / 31 / 07$ & $\mathrm{ZQ}$ & installed \\
\hline $\mathrm{co}$ & 2 & Steam Jet Vacuum Pump & $0.8 \mathrm{psia}$ & & & & & & & & & existing \\
\hline $\mathrm{CO}$ & 3 & Condensate Tank & 360 gal LDPE & National Tank OP0360 & & & $\$ 235$ & & & $08 / 20 / 07$ & SS & received \\
\hline $\mathrm{co}$ & 4 & Condensate Pump 1 & & Dynaflow Engineering MT5003-P3T6 Regenerative turbine pump, polypropylene & & & $\$ 1,948$ & & & & TS & received \\
\hline $\mathrm{co}$ & 5 & Condensate Pump 2 & & ITT B\&G, Type B, Series B, 616B, $2.5 \mathrm{gpm}$ & & & $\$ 1,595$ & & $06 / 18 / 07$ & & JG & installed \\
\hline $\mathrm{Co}$ & 6 & Condensate Tank F & 1500 Gallon LDPE & & & & & & & & $\mathrm{JC}$ & on hand \\
\hline $\mathrm{co}$ & 7 & Condensate Tank $G$ & 1000 Gallon LDPE & & & & & & & & $\mathrm{JC}$ & on hand \\
\hline $\mathrm{Co}$ & 8 & Steam Generators Feed Water Filte & & & & & & & & & $\mathrm{JC}$ & on hand \\
\hline $\mathrm{co}$ & 9 & Backpressure Regulator & $0-50 \mathrm{psig}$ & Fisher Model 98H-33 (1" castiron body, NPT conn, metal diaph, 25-75 psig spring) & & & $\$ 450$ & & $07 / 30 / 07$ & & TS & received \\
\hline $\mathrm{Co}$ & 10 & Desuperheater Spray Nozzle & & Spraying Systerns, 1/4AX-SS1-5W & & & $\$ 55$ & & $06 / 18 / 07$ & $06 / 21 / 07$ & JG & received \\
\hline $\mathrm{co}$ & 11 & Condensate Receiver & & 749-A shop modified inlets \& outlets & & & & & & & $\mathrm{JC}$ & installed \\
\hline $\mathrm{co}$ & 12 & Bag Filter 200 & 200 microns & & & & & & & & & \\
\hline CW & 0 & Cooling Water & & & & & & & & & & \\
\hline CW & 1 & CW Pump 1 (Seal water Pump) & & Teel 2P372 & & & & & & & & on hand \\
\hline CW & 2 & Seal Water tank & & & & & & & & & & on hand \\
\hline cW & 3 & Seal Water Filter & 25 then 1 micron & Pentek Cartridge DGD-2501-20 in Cole-Pharmer C-01507-77 "Big Blue" housing & & & & & & & TS & on hand \\
\hline FR & 0 & Feed/Receipt System & & & & & & & & & & \\
\hline FR & 1 & Feed Tank A & 1500 gal LDPE & & & & & & & & $\mathrm{JC}$ & on hand \\
\hline FR & 2 & Feed/LAW Tank B & 2500 gal LDPE & National Tank DCB2500-90 LHDPE Cone Bottom & & & $\$ 1,573$ & & & $08 / 20 / 07$ & SS & received \\
\hline FR & 3 & Feed/LAW Tank C & 2500 gal LDPE & National Tank DCB2500-90 LHDPE Cone Bottom & & & $\$ 1,573$ & & & $08 / 20 / 07$ & SS & received \\
\hline FR & 4 & Feed/LAW Tank D & 2500 gal LDPE & National Tank DCB2500-90 LHDPE Cone Bottom & & & $\$ 1,573$ & & & $08 / 20 / 07$ & SS & received \\
\hline FR & 5 & HLWT TankE & 1500 gal LDPE & & & & & & & & $\mathrm{JC}$ & on hand \\
\hline FR & 6 & Feed/Receipt Pump 1 & $2 \mathrm{gpm}$ & Teel, 1P8018 centrifugal, 3/4 hp, 208 v 3P,6 gpm @60' hd & & & & & & & $\mathrm{JC}$ & on hand \\
\hline FR & 7 & Feed/Receipt Pump 2 & $50 \mathrm{gpm}$ & 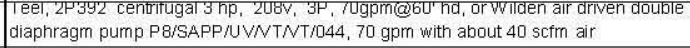 & & & & & & & $\mathrm{JC}$ & on hand \\
\hline FR & 8 & Mixer for HLW TankE & & Lightnin Mod. $1620-50120 \vee 8 \mathrm{a}$ & & & & & & & $\mathrm{JC}$ & on hand \\
\hline FR & 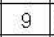 & Blade for HLW Tank Mixer & & Lightnin, A-310 & & & & & & & $\mathrm{JC}$ & on hand \\
\hline $\mathrm{MC}$ & 0 & Miscellaneous & & & & & & & & & & \\
\hline $\mathrm{MC}$ & 1 & Crystalizer to Cir. Pump Piping & 6" schd $10 \mathrm{~S} / \mathrm{S}$ & 749-A machine shop fabric ated & & & & & & & TS & received \\
\hline $\mathrm{MC}$ & 2 & Cir. Pump to Reboiler Piping & $6 "$ schd $10 \mathrm{~S} / \mathrm{S}$ & 749-A machine shop fabric ated & & & & & & & TS & installed \\
\hline MC & 3 & Reboiler to Crystallizer Piping & $6 "$ schd $10 \mathrm{~S} / \mathrm{S}$ & 749-A machine shop fabric ated & & & & & & & TS & installed \\
\hline$M C$ & 4 & Crystallizer to Condenser Piping & $8 "$ schd $10 \mathrm{~S} / \mathrm{s}$ & 749-A machine shop fabric ated & & & & & & & TS & installed \\
\hline MC & 5 & 6" Reboiler Steam Supply Piping & 6" schd $10 \mathrm{~s} / \mathrm{S}$ & 749-A machine shop fabric ated & & & & & & & $J C$ & received \\
\hline $\mathrm{MC}$ & 6 & Sec. Cont for Crystallizer & 1500 gallons & & & & $\$ 3,420$ & & & & SS & installed \\
\hline $\mathrm{MC}$ & 7 & Sec. Cont. for Outside Cond Area & 1800 gallons & & & & & & & & SS & on hand \\
\hline MC & 8 & Sec. Cont. for Feed Tank Area & 3000 gallons & Existing Secondary Cont. $25^{\prime} \times 15^{\prime} \times 1^{\prime} 2800$ Gal. & & & & $\$ 6,000$ & & & $\mathrm{JC}$ & on hand \\
\hline
\end{tabular}




\begin{tabular}{|c|c|c|c|c|c|c|c|c|c|c|c|c|}
\hline \multicolumn{13}{|c|}{ Equipment List for Fractional Crystallization Test Facility } \\
\hline Sys & No. & Item Description & Specifications & Vendor, Model No., and Other Information & $\begin{array}{c}\text { Date } \\
\text { Walkdown }\end{array}$ & $\begin{array}{l}\text { Date Oper. } \\
\text { Verification }\end{array}$ & Cost & $\begin{array}{c}\text { Cost } \\
\text { Avoided }\end{array}$ & $\begin{array}{c}\text { Date Order } \\
\text { Placed }\end{array}$ & $\begin{array}{c}\text { Delivery } \\
\text { Date }\end{array}$ & $\operatorname{Resp}^{*}$ & Status \\
\hline MC & 9 & Sec. Cont for Process Tanks \& $\mathrm{Ce}$ & 750 gallons & & & & $\$ 2,870$ & & & & SS & received \\
\hline $\mathrm{MC}$ & 10 & Thermocouple Extension Wire & Type E & & & & & & $06 / 27 / 07$ & & $\mathrm{JC}$ & received \\
\hline $\mathrm{MC}$ & 11 & Early Feed Simulant (no Cs \& Cr) & $10,000 \mathrm{gal}$ & & & & & & & & MW & ordered \\
\hline $\mathrm{MC}$ & 12 & Sodium dichromate Solution & 500 gal PP & & & & & & & & MW & ordered \\
\hline MC & 13 & Cesium nitrate & $25 \mathrm{~kg}$ & & & & & & & & MW & ordered \\
\hline $\mathrm{MC}$ & 14 & Microscope Parts for PLM & & Mccrome Associates, McCrome will be on site in August to train SRNL & & & & & $06 / 15 / 07$ & & MW & received \\
\hline MC & 15 & Condenser Support Frame & PerDWG & 749-A machine shop will fabric ate & & & & & $07 / 12 / 07$ & & DF & frabricated \\
\hline $\mathrm{MC}$ & 16 & Platform Supports & PerDWG & 749-A machine shop will fabric ate & & & & & $07 / 12 / 07$ & & $\mathrm{DF}$ & installed \\
\hline MC & 17 & Springs for Axial Pump support & $\mathrm{K}=544 \mathrm{Ib} / \mathrm{in}$ & McMaster-Car 9624K33 & & & $\$ 44$ & & & & TS & received \\
\hline $\mathrm{MC}$ & 18 & Flange and Seal for Press Relief & DWG & 749-A machine shop will fabric ate & & & & & & & TS & received \\
\hline $\mathrm{MC}$ & 19 & CPVC sweeps for drawoff line & $5 \mathrm{D}$ Bends & & & & $\$ 1,000$ & & & & TS & received \\
\hline $\mathrm{MC}$ & 20 & Gaskets for piping connections & Various sizes & & & & & & & & TS & received \\
\hline $\mathrm{MC}$ & 21 & Spare gasket for crystallizer & 24" Flexatalic & & & & & & $09 / 10 / 07$ & & $\mathrm{JC}$ & received \\
\hline $\mathrm{MC}$ & 22 & \multicolumn{2}{|c|}{ Instrument air dryer for centrifuge seals } & & & & & & & & MR & on hand \\
\hline $\mathrm{PA}$ & 0 & Plant Air System & & & & & & & & & & \\
\hline $\mathrm{PA}$ & 1 & Pressure Regulator for Centrifuge & 35 SCFH@5 psig & & & & & & & & $\mathrm{JC}$ & on hand \\
\hline $\mathrm{PA}$ & 2 & Air Dryer & & & & & & & & & MR & on hand \\
\hline $\mathrm{PD}$ & 0 & Product Dissolver System & & & & & & & & & & \\
\hline $\mathrm{PD}$ & 1 & Product Dissolver Tank & 500 gal PP & Chemtainer, TC5264CB / National Tank DOP T0500 & & & $\$ 1,060$ & & & $09 / 07 / 07$ & SS & received \\
\hline $\mathrm{PD}$ & 2 & PD Tank Stand & & Chemtainer, CK-CM5264CB Stand & & & & & & & $\mathrm{JC}$ & on hand \\
\hline $\mathrm{PD}$ & 3 & PD Tank Baffles & & & & & & & & & $\mathrm{JC}$ & on hand \\
\hline $\mathrm{PD}$ & 4 & Mixer for PD Tank & & & & & & & & & $\mathrm{JC}$ & on hand \\
\hline PD & 5 & Blade for PD Tank Mixer & & Lightnin, A-310 & & & & & & & $\mathrm{JC}$ & on hand \\
\hline $\mathrm{PD}$ & 6 & Product Dissolver Pump & & Teel, 2 2P92 centrifugal, 3 hp, 208 v 3P, 28 gpm @ 70' hd \& 70 gpm @ 60' hd & & & & & & & $\mathrm{JC}$ & on hand \\
\hline PD & 7 & PD Electrical Heater & & SRNLFabricated ST-MDX5-9878 & & & & & & & DF & on hand \\
\hline $\mathrm{PD}$ & 8 & PD Crossflow Filter Tubes Only & & & & & & & & $10 / 05 / 07$ & TS & received \\
\hline $\mathrm{PD}$ & 9 & PD Crossflow Filter Housing & & Custom design, fabrication in 749-A complete, assembly in EDL & & & & & & & TS & installed \\
\hline $\mathrm{RW}$ & 0 & Recycle Wash System & & & & & & & & & & \\
\hline RW & 1 & Recycle Wash Tank & 500 gal PP & $\begin{array}{l}\text { Chermtainer, TC 5264CB (received cracked, can use on-hand polyethylene tank for fitup and } \\
\text { shakedown. Can also use for operation at current planned temperatures) }\end{array}$ & & & $\$ 1,060$ & & & $09 / 07 / 07$ & SS & received \\
\hline RW & 2 & RWTank Stand & & Chemtainer, CK-CM5264CB Stand & & & & & & & $\mathrm{JC}$ & on hand \\
\hline RW & 3 & Mixer for RW Tank & & Lightnin Mod. $1620-50120 \vee 8 \mathrm{a}$ & & & & & & & $\mathrm{JC}$ & on hand \\
\hline RW & 4 & Blade for RW Tank Mixer & & Lightnin, A-310 & & & & & & & $\mathrm{JC}$ & on hand \\
\hline RW & 5 & Recycle Wash Pump & & Teel, 1P7018 centrifugal, 3/4 hp, 115v1P, $18 \mathrm{gpm} @$ @ 50' hd \& 30 gpm @ 40' hd & & & & & & & $\mathrm{JC}$ & on hand \\
\hline RW & 6 & RW Electrical Heater & & SRNL Fabricated ST-MDX5-9878 & & & & & & & DF & on hand \\
\hline
\end{tabular}




\begin{tabular}{|c|c|c|c|c|c|c|c|c|c|c|c|c|}
\hline \multicolumn{13}{|c|}{ Equipment List for Fractional Crystallization Test Facility } \\
\hline Sys & No. & Item Description & Specifications & Vendor, Model No., and Other Information & $\begin{array}{c}\text { Date } \\
\text { Walkdown }\end{array}$ & $\begin{array}{l}\text { Date Oper. } \\
\text { Verification }\end{array}$ & Cost & $\begin{array}{c}\text { Cost } \\
\text { Avoided }\end{array}$ & $\begin{array}{c}\text { Date Order } \\
\text { Placed }\end{array}$ & $\begin{array}{l}\text { Delivery } \\
\text { Date }\end{array}$ & $\operatorname{Resp}^{*}$ & Status \\
\hline SL & 0 & Slurry System & & & & & & & & & & \\
\hline $\mathrm{SL}$ & 1 & Crystallizer Vessel & & & & & & & & & Areva & installed \\
\hline $\mathrm{SL}$ & 2 & Circulation Pump & 6" Axial flow pump & & & & & & & 10/03/07 & Areva & received \\
\hline $\mathrm{SL}$ & 3 & Reboiler & & & & & & & & & Areva & received \\
\hline $\mathrm{SL}$ & 4 & Draw Off Pump & & & & & & & $09 / 05 / 07$ & $10 / 31 / 07$ & $\mathrm{RL}$ & received \\
\hline $\mathrm{SL}$ & 5 & Centrifuge & & & & & & & & $10 / 10 / 07$ & Areva & received \\
\hline $\mathrm{SL}$ & 6 & Motor Starter for Centrifuge & & McM aster-Carr $6559 \mathrm{~K} 66$ motor starter $+6559 \mathrm{~K} 52$ enclos ure $+9543 \mathrm{~K} 13$ conduit adapters & & & & & & & TS & received \\
\hline SL & 7 & Plug for 480 volt weld receptacle ? & $2 \mathrm{rq} d \mathrm{~d})$ & Crouse-Hinds APJ10487 or equal (McMaster-Car 7316K38) & & & $\$ 750$ & & & & TS & received \\
\hline $\mathrm{SL}$ & 8 & Motor Starter for Drawoff Pump & & McMaster-Carr $6559 \mathrm{KK} 67$ motor starter $+6559 \mathrm{~K} 52$ enclos ure + $9543 \mathrm{~K} 13$ conduit adapters & & & $\$ 141$ & & & & TS & received \\
\hline ST & 0 & Steam System & & & & & & & & & & \\
\hline ST & 1 & Steam Generator $1(150 \mathrm{~kW})$ & Electrical Heaters & Electro-Steam, LB-150 & & & & & & & & installed \\
\hline ST & 2 & Steam Generator $2(240 \mathrm{~kW})$ & Electrical Heaters & Electro-Steam, LB-240 & & & & & & & MR & received \\
\hline ST & 3 & Pressure Relief Valve for SG1 & & & & & & & & & & installed \\
\hline ST & 4 & Pressure Relief Valve for SG2 & & Ready to be installed & & & & & & & MR & received \\
\hline ST & 5 & Piping for steam supply & schd 40 pipe, 2000 t & Purchase request issued to buyer & & & & & $09 / 10 / 07$ & & $\mathrm{JC}$ & received \\
\hline SW & 0 & Spent Wash System & & & & & & & & & & \\
\hline SW & 1 & Spent Wash Tank & 500 gal PP & Chemtainer, TC5264CB / National Tank DOPT0500 & & & $\$ 1,060$ & & & $09 / 07 / 07$ & SS & received \\
\hline SW & 2 & SW Tank Stand & & Chemtainer, CK-CM5264CB Stand & & & & & & & $\mathrm{JC}$ & on hand \\
\hline SW & 3 & Mixer for SWTank & & Lightning Mod. EV5P25120V & & & & & & & $\mathrm{JC}$ & on hand \\
\hline SW & 4 & Blade for SW Tank Mixer & & Lightnin, A-310 & & & & & & & $\mathrm{JC}$ & on hand \\
\hline SW & 5 & Spent Wash Pump & & Teel, 1P7018 centrifugal, 3/4 hp, 115v 1P, $18 \mathrm{gpm} @$ @ 50' hd \& 30 gpm @ 40' hd & & & & & & & $\mathrm{JC}$ & on hand \\
\hline \multirow[t]{6}{*}{ SW } & 6 & SW Electrical Heater & & SRNLFabricated ST-MDX5-9878 & & & & & & & $\mathrm{DF}$ & on hand \\
\hline & & & & & & & & & & & & \\
\hline & & *Organization or initials of respons & sible person in SRNL & L. Note that the initials will be updated as activity changes, e.g. design, specific & ons, p & nent, insper & & & & & & \\
\hline & & ${ }^{*}$ Initials: DF-Don Fisher, JC-Jerry & Corbett, JG-John G & Sordon, MR-Mike Restivo, MW-Mike Williams, SS-Susan Shouse, TS-Tim Stee & $\mathrm{r}, \mathrm{ZC}$ & ureshi & & & & & & \\
\hline & & Note: This list matches P\&ID Revi & $\operatorname{sion} B$ & & & & & & & & & \\
\hline & & & & & & & & & & & & \\
\hline
\end{tabular}


RPP-39091, Rev. 0

RPT-3000755 Rev. 000

APPENDIX 8.9

\section{READINESS CERTIFICATION DOCUMENT}

(Consisting of 11 pages

Including coversheet) 


\section{Fractional Crystallization Pilot Plant Readiness Certification}

April 2008
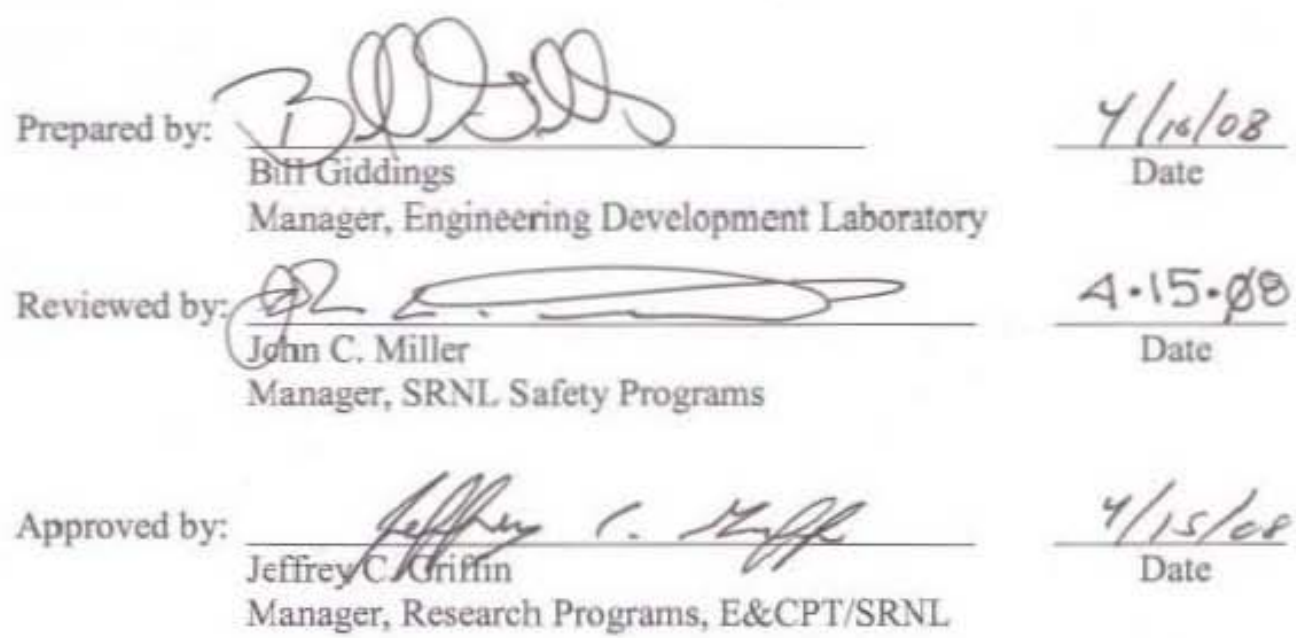


\author{
WASHINGTON SAVANNAH RIVER COMPANY \\ Savannah River National Laboratory \\ Engineering Development Laboratory
}

SRNL-PSE-2008-00075, Rev. 0

Page 2 of 10

\section{Introduction}

Fractional crystallization has been studied as a potential Hanford tank waste pretreatment process since January 2005. An extensive program of laboratory glassware (bench-scale) testing was performed on simulated and actual wastes to quantify the characteristics of the crystallized products and determine their correlation to thermodynamic model predictions (see reference 1)

The Engineering Development Laboratory (EDL) of SRNL assembled a Test Facility to achieve test conditions specified in the Process Flow Diagram (PFD) developed by AREVA. Major components such as Crystallizer Vessel, Reboiler, Circulation Pump and Centrifuge were provided by Swenson Technology Inc. EDL designed and fabricated balance of the system based on these documents and fundamental knowledge and experiences established in previous related experimentation.

The final design was documented by EDL researchers and is shown in the established P\&ID (see reference 2). This document was used to fabricate and install the components that will be utilized during the testing. The fabrication and installation was completed by the Engineering Development Laboratory Technicians and work was supplemented utilizing Bechtel Construction Pipefitters and Laborers as obtained through the existing site Memorandum of Understanding (MOU) process. Construction was started in August 2007 and completed in February 2008. The acceptance of construction was completed as specified in the Construction Acceptance Plan for the Facility (see reference 3 ).

Following construction activities, the facility initiated a series of system checks and functional tests commensurate with the design of the facility and with regards for the safety inspection requirements for the facility and equipment. All primary functional testing has been completed and the system is ready for chemical operations

\section{Purpose}

The purpose of this report is to establish a documentation record for the readiness of the facility for chemical operations based on the following criteria:

Work Construction

Safety Compliance Documentation and Controls

Compliance with Conduct of Research and Development

Work Documentation Completion and Readiness

Training Status for Personnel

Compliance with Expectations from Customer

Satisfying Internal Management Requirements

Satisfying DOE Oversight 


\author{
WASHINGTON SAVANNAH RIVER COMPANY \\ Savannah River National Laboratory \\ Engineering Development Laboratory
}

SRNL-PSE-2008-00075, Rev. 0

Page 3 of 10

\section{Scope}

The Fractional Crystallization Pilot Test Facility is Research and Development process that was conceived, built and tested per established procedures. Operations of the facility are planned within the constraints of the established Conduct of Research and Development Manual requirements. The readiness assessment for the operations of the facility was performed commensurate with the hazard category of the facility and a graded approach was taken to ensure the proper level of oversight and review was performed prior to each phase of installation and testing.

This document establishes the compliance with established procedures as defined above and provides a summary report of readiness to proceed with prescribed chemical operations as defined by established test documentation.

\section{Methodology}

The process used to establish the readiness for operations included the review of supporting documentation, facility walk-downs, witnessing testing and training activities and interviews with key personnel.

\section{Analysis}

The project testing program detailed in RPP-PLAN-34134, Hanford Medium/Low Curie Waste Pretreatment Alternatives Project Integrated Test and Demonstration Plan (ITDP) defines the approach for testing of proposed alternatives to address waste treatment needs at the River Protection Project (RPP) at the Hanford Site facilities. The end result of the testing program will provide the information that will be used to confirm the process model, validate design assumptions, resolve uncertainties and provide sufficient information to support initiation of a conceptual design following a CD-0 approval (DOE Order 413.3A). See the ITDP for details.

An extensive program of laboratory glassware (bench-scale) testing was performed on simulated and actual wastes to quantify the characteristics of the crystallized products and determine their correlation to thermodynamic model predictions. Reports on this testing program (RPP-RPT-27239, Hanford Medium/Low Curie Waste Pretreatment Project - Phase I Laboratory Report, RPP-RPT-30905, Fractional Ciystallization Simulant Test Comparisons, and RPP-RPT-31352, Fractional Crystallization Flowsheet Tests with Actual Tank Waste) contain descriptions of the waste historical background, crystallization process theory, agreement with model predictions, and effectiveness of the FC process in meeting project performance requirements.

With the conceptual process established, the Fractional Crystallization Pilot Test Facility process was developed. Base component/equipment and conceptual pilot plant design documents were provided to SRNL Task Technical Process and included Process Flow Diagrams, system Block Flow Diagrams, Crystallizer design documentation and operating instructions, Centrifuge design documentation and functional design specifications for control systems and proposed pilot plant test plans for the sequential testing of the facility. All of these documents can be obtained from the EDL Principal Investigator (PI) assigned to the task. 


\author{
WASHINGTON SAVANNAH RIVER COMPANY \\ Savannah River National Laboratory \\ Engineering Development Laboratory
}

SRNL-PSE-2008-00075, Rev. 0

Page 4 of 10

The supplied design and plan documentation were utilized by EDL personnel to establish a foundation for how testing would be accomplished at the EDL facility at SRNL. The analysis of readiness is shown below as previously defined in the purpose section of this report.

\section{Work Construction}

A baseline P\&ID was developed based on documentation provided by the customer. This P\&ID was utilized as the guiding document for the installation of equipment to be utilized in the pilot test facility. Personnel (Technician and Researcher) skills, previously established within the facility, were utilized to construct the test facility based on the design document. Construction personnel were added to the workforce to supplement the existing technicians used for the installation of equipment as designed. A facility construction schedule was developed and status was provided twice weekly to ensure facility construction and inspection testing were accomplished within defined parameters and prescribed timeframes. A weekly status report was provided to the Hanford customer and this was used as a means of refining plant design needs and developing action items to resolve technical and programmatic challenges encountered in progress. A detailed schedule can be obtained from the SRNL Program Controls group, as desired, to show the level of effort that went into the construction of the facility. A construction acceptance plan was written to ensure construction was accomplished as defined and tested in accordance with plans (see reference 3 ).

\section{Safety Compliance Documentation and Controls}

Various levels of safety documentation were established in conjunction with the construction and testing of the facility.

A preconstruction Process Hazard Review (PHR) (see reference 4) was completed to define the technical "What-If' scenarios for the facility. This information was used to refine design documents and facility equipment installation. Twenty one (21) items were identified in this initial PHR. Many of these items were corrected during the construction of the facility.

A follow-up Pre-operations Process Hazard Review (PHR) was conducted following construction. This resulted in an expansion of the original "What-If' list (from preconstruction) to a total of thirty four (34) items. All items have been addressed/resolved from the two PHR assessments.

Several Job Hazard Analysis (JHA) documents were developed in support of the Fractional Crystallization Process as follows:

- SRNL-PSE-2008-00007, Installation of Fiberglass Insulation on Piping and Instruments

- SRNL-PSE-2008-00035, Use of Frothpak Foam Process for Tank Bottom Support

- SRNL-PSE-2008-00041, Fractional Crystallization Acetone Washing of Crystals in 786-A

- SRNL-PSE-2008-00044, Fractional Crystallization Sampling and Sample Preparations

- SRNL-PSE-2008-00057, Fractional Crystallization Operations 


\author{
WASHINGTON SAVANNAH RIVER COMPANY \\ Savannah River National Laboratory \\ Engineering Development Laboratory
}

SRNL-PSE-2008-00075, Rev. 0

Page 5 of 10

The Safety Compliance process involved several layers of safety inspections per Manual $8 \mathrm{Q}$, procedure 51 Final Inspection Acceptance (FAI-51) requirements. These inspections involved:

- Steam Generator Installation [Seven (7) items identified and correct]

- Fractional Crystallization Operations [Eight (8) items identified and 7 items corrected, one item remaining dealing with specific Spill Kit materials, which have been ordered to supplement existing spill control materials in the facility]

- Fractional Crystallization Circulation and Draw-off Pump Equipment Installation [Three (3) items identified and corrected]

- Installation of Centrifuge Equipment [Four (4) items identified and corrected]

\section{Compliance with Conduct of Research and Development}

Per the requirements of the Conduct of R\&D manual, a Hazards Assessment Package (HAP) was developed and documented as SRNL-PSE-2007-0022 for the Fractional Crystallization process. From this review, specific precautions and documentation were addressed as follows:

- Chemical usage, including a caustic corrosive simulant; acetone used for sampling to lock in crystals, Sodium Chromate as an additive to match Hanford Waste tanks

- Steam hazards and controls

- Environmental Evaluation Checklist \#TC-A-2007-007

- Confined Space issues inside Crystallizer

- JHA/PHR requirements

- Hazardous Energy (steam)

- Management of Safety Basis (MSB) review

In addition, two sampling HAPs were developed for the process:

- SRNL-PSE-2007-0265, Fractional Crystallization Sampling at 786-A

- SRNL-PSE-2007-0274, Fractional Crystallization Pre-Run Sampling

As previously described, the PHR process was followed to review the additional safety requirements for operation.

Also, as previously described, Job Hazards Analysis documents were developed per the requirements of the HAPs.

\section{Work Documentation Completion and Readiness}

The requirements of SRNL Manual L1, procedure 1.01, Administration of SRNL Procedures and $R \& D$ Work Control Documents, were reviewed and it was determined that the operations will be performed through the use of work instructions. Equipment installation and testing was performed using $\mathrm{R} \& \mathrm{D}$ directions and technician/researcher training and education. 
WASHINGTON SAVANNAH RIVER COMPANY

Savannah River National Laboratory

Engineering Development Laboratory
SRNL-PSE-2008-00075, Rev. 0

Page 6 of 10

The Work Instructions developed in support of Fractional Crystallization Pilot Test Facility are as follows:

- ITS-WI-0028, Fractional Crystallization Test Facility. This is the main operations and abnormal operations procedure. This procedure also references the Test Run Plan for performance of testing of the facility and required expected results.

- ITS-WI-0023, Fractional Crystallization - Apparent Settling Volume

- ITS-WI-0024, Fractional Crystallization - Turbidity Measurements

- ITS-WI-0025, Fractional Crystallization - Crystal Size Distribution by Dry Sieving

- ITS-WI-0026, Fractional Crystallization - Sampling and Sample Preparation

- ITS-WI-0029, Fractional Crystallization - Weight Percent Solids and Density Measurement

The sampling documents have been developed, reviewed and approved for use. The main operating instruction has recently been revised, per the Validation and Verification process and approved.

\section{Training Status for Personnel}

The training of personnel associated with Fractional Crystallization has been performed using a variety of techniques as discussed below. Three of the four assigned shift technicians were involved in the construction of the facility and the subsequent testing (hydrostatic, pressure, circulation) as defined by work instructions or researchers directions. One technician had been partially involved with construction and has been involved with testing.

All technicians and test engineers have been trained on the following:

- Centrifuge Training LSEDL001

- System Overview LSEDL003

- ConOps for R\&D LSEDL002

- Sample Management, based on researchers demonstration on sampling and techniques. This was done as a Read-and-Sign process.

- Two Sessions were held with the Test Engineers and Technicians to demonstrate the sample processing and analysis required during shift operations.

In addition, the technicians had Practical Factor demonstrated skills documented for the following items:

- Operations PracFac LSED0004

- Abnormal Operations PracFac LSED005

Each of the test engineers and technicians have been paired up to become familiar with the operating instructions, walked down the procedure and all teams provided comments to the Principal Investigator for revision. These walk downs were used as the Verification and Validation of the existing procedure for operations. 


\section{WASHINGTON SAVANNAH RIVER COMPANY Savannah River National Laboratory Engineering Development Laboratory}

SRNL-PSE-2008-00075, Rev. 0

Page 7 of 10

At various phases of system boilout, the technicians and test engineers were involved with the operations of the key components, including the operations of the steam control valve, which is used as the shutdown mechanism in most of the abnormal operations expected to be encountered in the performance of testing.

\section{Compliance with Expectations from Customer}

The Hanford (CH2MHill) and AREVA customers have been involved in all aspects of the installation/construction and program reviews. Input has been sought and received for the following items associated with the Fractional Crystallization System:

- Preconstruction Process Hazard Review

- Preoperational Process Hazards Review

- Preparedness Assessment Review

- Sample/Analytical Management Plan

- Task Technical and Quality Assurance Plan

- Operations Work Instruction

- Test Run Plan

In addition, the customers provided feedback on the Process and Instrumentation Drawing (P\&ID), the Instrument listing, the Valve listing and the Material listing.

Weekly teleconference meetings where held between SRNL and the customers to cover the construction and pre-operational testing schedule and to address various technical issues that required resolution by SRNL or by the customer. Over 90 action items were developed and received a disposition on the action item list.

The SRNL DOE Facility Representatives have been involved in the Fractional Crystallization process at various levels. Information has been provided to the representatives concerning schedule progress, facility operations documentation and training. The Facility Representatives have attended the initial classroom training for Centrifuge Operations, Fractional Crystallization Operations and Conduct of Operations for Research and Development Training. Feedback was obtained from the DOE customer on the operating Procedure, Conduct of Operations and System Status controls.

\section{Shift Operations and Facility Control:}

The operation of the Fractional Crystallization system is under the control of the Test Engineers who will act as the shift managers for the facility. Shift activities include the following:

- A detailed shift turnover using the established turnover checklist

- A daily pre-job briefing each shift, to include the Shift Test Engineer and Technician.

- A review of the Status Board for the facility

- Assurance that minimum staffing is met (1-STE and 1-Technician)

- Daily round sheet completion

- Logbook maintenance

- Test Run Plan review and compliance 


\section{WASHINGTON SAVANNAH RIVER COMPANY Savannah River National Laboratory Engineering Development Laboratory}

SRNL-PSE-2008-00075, Rev. 0

Page 8 of 10

\section{Span of Command and Control:}

The Test Engineers are responsible for the operations of the facility. An expectation meeting was held with the four Shift Test Engineers and it was clarified that they were the sole control for the testing performed in the facility. All test issues, plant configuration and any other concerns are to be processed and controlled by the Shift Test Engineers. This includes interfaces with EDL researchers and Hanford Customer interfacing. Technician directions are given via the Shift Test Engineer and the approved work instruction/test plan.

\section{Abnormal Operations:}

The existing work instruction is written with twelve (12) sections of abnormal operations controls. Any activities or incidents that are not directly covered by these sections will require a level of analysis by the Shift Test Engineer to ensure any response is appropriate. During the expectation meeting with the Shift Test Engineers, it was clarified that we will not troubleshoot significant activities on the spot. In some cases a written plan will need to be developed to ensure we respond appropriately. No changes to the existing procedure and test run plan will be made without review and approval by the PI, Manager of EDL and other members of the established Joint Test Group as defined in the Task Technical and Quality Assurance Plan (TT\&QAP).

A protocol was established with the SRNL Research Operations Department (ROD) defining the expected interfaces with the facility during emergency and abnormal conditions. Facility support for SIRIM/ORPS issues remains with ROD. All facility issues will be communicated to ROD for information and response as necessary. The ROD control room will be contacted for assistance to emergency conditions, including personnel injuries and assistance with abnormal conditions related to chemical management.

\section{Equipment Maintenance:}

Because of the short duration of the pilot test (4-6 weeks) there is no established preventative maintenance planned during testing. Equipment repairs will be made in accordance with established facility hazard assessment and controls documentation or additional hazards assessment and work controls documentation will be provided. Critical Spare Parts were reviewed by the facility and key components are on hand and this was agreed upon by the customer. High dollar items, such as the main recirculation pumps, do not have replacements on hand and will cause the suspension of operations if problems occur and cannot be readily resolved. 
WASHINGTON SAVANNAH RIVER COMPANY

Savannah River National Laboratory

Engineering Development Laboratory

\section{References}

1. RPP-PLAN-34135, Hanford Medium/Low Curie Waste Pretreatment Alternatives Project Fractional Crystallization Pilot Plant Test Plan, August 2007, Rev. 0

2. SRNL Drawing: EES-23164-M6-001, Fractional Crystallization Pilot Scale Facility, P\&ID, March 2008, Rev M44

3. WSRC-TR-2007-00485, Hanford Medium/Low Curie Waste Pretreatment Alternatives Project Fractional Crystallization Pilot Scale Testing, Construction Acceptance Plan, January 2008, Rev 0

4. X-PHR-A-00003, Pre Construction Process Hazards Review for the Fractional Crystallization Process Test Facility, November 2007, Rev 0.

5. X-PHR-A-00003, Pre Operations Process Hazards Review for the Fractional Crystallization Process Test Facility, March 2008, Rev 1.

6. ITS-WI-0028, Fractional Crystallization Test Facility-Work Instructions, April 2008, Rev. 0

7. WSRC-TDP-2008-A-00001, Task Technical and Quality Assurance Plan for Fractional Crystallization Pilot Scale Testing, March 2008, Rev. 0 .

8. SRNL-PSE-2008-00041, Job Hazards Analysis for Fractional Crystallization Acetone Washing of Crystals in 786-A. February, 2008, Rev. 0

9. SRNL-PSE-2007-00265, Conduct of R\&D-ISM Hazards Assessment Package (HAP) for Fractional Crystallization Sampling in 786-A

10. EEC TC-A-2007-071, Environmental Evaluation Checklist-Fractional Crystallization (FC) Pilot Scale Test, Rev. 0

11. SRNL-PSE-2007-00242, JHA Troubleshooting Equipment for Fractional Crystallization, March 2008, Rev. 0.

12. SRNL-PSE-2008-0046, Analytical Plan for Fractional Crystallization Pilot Plant, April 2008, Rev. 0 
WASHINGTON SAVANNAH RIVER COMPANY

SRNL-PSE-2008-00075, Rev. 0

Savannah River National Laboratory

Page 10 of 10

Engineering Development Laboratory

Fractional Crystallization Readiness Checklist for Operations

\begin{tabular}{|c|c|c|}
\hline Checklist Action Item & $\begin{array}{c}\text { Status } \\
\text { Complete } \\
(\mathbf{Y} / \mathrm{N}) \\
\end{array}$ & Comments \\
\hline 1) Statement of Work & $\mathrm{Y}$ & On file with the PI \\
\hline 2) Design Documentation & $\mathrm{Y}$ & $\begin{array}{l}\text { Areva,Swenson and KMPF } \\
\text { designed documents were } \\
\text { obtained and utilized in the } \\
\text { development of the P\&ID }\end{array}$ \\
\hline $\begin{array}{l}\text { 3) Pre-Construction Process Hazards } \\
\text { Review (PHR) }\end{array}$ & $\mathrm{Y}$ & All issues were addressed \\
\hline 4) Hazards Assessment Package (HAP) & $\mathrm{Y}$ & On file with the PI \\
\hline 5) Construction Schedule Developed & $\mathrm{Y}$ & On file with the PI \\
\hline 6) Job Hazards Assessment (JHA) & $\mathrm{Y}$ & $\begin{array}{l}\text { Completed and on file with } \\
\text { FLM in } 786-A\end{array}$ \\
\hline $\begin{array}{l}\text { 7) Environmental Evaluation Checklist } \\
\text { (EEC) }\end{array}$ & $\mathrm{Y}$ & On file with PI \\
\hline $\begin{array}{l}\text { 8) Final Acceptance Inspection (FAI-51) } \\
\text { per Manual 8Q, procedure 51 }\end{array}$ & Y & $\begin{array}{l}\text { Completed and all issues } \\
\text { addressed, awaiting one spill kit }\end{array}$ \\
\hline $\begin{array}{l}\text { 9) Pre-operational Process Hazards Review } \\
\text { (PHR) }\end{array}$ & $\mathrm{Y}$ & $\begin{array}{l}\text { Completed and all issues have } \\
\text { been addressed }\end{array}$ \\
\hline 10) Preparedness Assessment Review & $\mathrm{Y}$ & $\begin{array}{l}\text { Completed and no operational } \\
\text { issues identified }\end{array}$ \\
\hline $\begin{array}{l}\text { 11) Task Technical and Quality Assurance } \\
\text { Plan (TT\&QAP) }\end{array}$ & $\mathrm{Y}$ & On file with PI \\
\hline 12) Work Instructions/Procedures & $\mathrm{Y}$ & Issued following V\&V \\
\hline 13) Sample/Analytical Plan & $\mathrm{Y}$ & On file with PI \\
\hline 14) Instrumentation Checkout & $\mathrm{Y}$ & On file with PI \\
\hline 15) Equipment Checkout & $\mathrm{Y}$ & On file with PI \\
\hline 16) Water-Run Testing & $\mathrm{Y}$ & $\begin{array}{l}\text { Initial runs completed, } \\
\text { additional run plan for } 4 / 10 / 08\end{array}$ \\
\hline $\begin{array}{l}\text { 17) Chemicals Ordered, Received and } \\
\text { Inventoried }\end{array}$ & $\mathrm{Y}$ & $\begin{array}{l}\text { All base simulant received, } \\
\text { modification simulant on order }\end{array}$ \\
\hline 18) Operations Training & $\mathrm{Y}$ & $\begin{array}{l}\text { All training completed with } \\
\text { exception to the Pracfacs }\end{array}$ \\
\hline 19) Abnormal Operations Training & $\mathrm{Y}$ & $\begin{array}{l}\text { All training completed with } \\
\text { exception to the Pracfacs }\end{array}$ \\
\hline 20) Sample Management Training & $\mathrm{Y}$ & Completed as of $4 / 9 / 08$ \\
\hline
\end{tabular}


RPP-39091, Rev. 0

RPT-3000755 Rev. 000

APPENDIX 8.10

FINAL BENCHMARK TEST RUN PLAN

(Consisting of 3 pages

Including coversheet) 


\section{Test Run Plan}

Test Run Plan No. FC-TRP-2008-01A

Date: $\underline{4 / 27 / 2008}$

1. Title. Test 1A. Benchmark Testing (Repeat)

2. Test Objectives: A. Startup and fill the pilot system

B. Achieve steady state operations

C. Produce acceptable crystals

D. Establish normal operating parameters

E. Check the correlation between the PFD and the pilot operations

3. Test Conditions/Parameters: Note the values given below are under steady state operations. During the initial start up, the will vary.

1. Feed Chemistry: SST Early Feed Phase 2 simulant (without cesium and chromium)

2. Crystallizer Vessel Liquid Operating Level $\underline{50 \%}$ ( $50 \%$ default value $=15$ " above draft tube top, $0 \%=9 ", 100 \%=21 ")$

3. Reboiler Steam Flow Rate, lbm/min.

$\underline{11.0}$

4. Crystallizer feed flow rate, gpm (under manual mode):

$1.5 \mathrm{gpm}$

5. Number of Draft Tube Extensions:

None

6. Crystallizer Pressure in the vapor space (psia):

$0.8-1$ psia (adjust this

pressure to achieve 131F Crystallizer temperature)

7. Crystallizer Temperature:

$\underline{131 \mathrm{~F}}$

8. Circulation Pump Flow Rate (gpm):

$600 \mathrm{gpm}$

9. Process Tanks Desired Temperature, $\mathrm{F}$

$\underline{131 \mathrm{~F}}$

10. PD Tank contents:

Initial: 250 gal DI H2O Steady State: $\underline{300 \text { gal, salt solution Sp. Gr. } 1.46}$

11. RW Tank contents:

Initial: $\underline{0 \text { gal }}$

Steady State: $\underline{300 \text { gal, recycled wash Sp Gr } 1.45}$

12. SW Tank contents:

Initial: $\underline{0 \text { gal }} \quad$ Steady State: 300 gal, recycled wash Sp Gr 1.43

13. Condensate Tank

Initial: $\underline{250 \text { gal DI H2O }} \quad$ Steady State: $\underline{250 \text { gal condensate }}$ 
RPP-39091, Rev. 0

RPT-3000755 Rev. 000

14. Initial Feed Tank $\underline{B}$ (Note: for the Benchmark Tests, the initial feed sequence is $B-A-C$ $D$, then the feed sequence is always $B-C-D-B-C-D$ with reconstituted feed)

15. Centrifuge Settings:

As recommended by the Customer CH2MHILL. (Note: The Centrifuge settings will be varied based on cake properties to achieve optimum performance)

4. Analytical Samples

Draw samples per sample plan. The actual samples schedule will be controlled by the sampling computer next to the fume hood.

5. System alignment modifications from Work Instructions:

1. Condensate flow rate to Spent Wash Purge, gpm (FT CO18) $0.29 \mathrm{gpm}$

2. Condensate flow rate to PD product, gpm (FT CO24) $0.56 \mathrm{gpm}$

3. Spent wash recycle flow rate to Crystallizer, gpm (FT SW09) $1.32 \mathrm{gpm}$

4. Spent wash Purge flow rate to Tank E, gpm (FT SW06) $0.29 \mathrm{gpm}$

5. Product dissolver flow to FR Tanks (B, C or D), gpm (FT PD09) $0.53 \mathrm{gpm}$

6. Special equipment or instruments: N/A

7. Precautions

- Centrifuge - Do not exceed 3000 rpm during operation

- Reboiler - Do not exceed a slurry temperature rise of greater than $3 F$ across the reboiler during heat up or operation

- Crystallizer - Do not allow the liquid level in the crystallizer to go outside the range of $20 \%$ $-80 \%$.

8. References:

- FC Pilot Test Plan - RPP-PLAN-34135, Rev 0

- SRNL P\&ID - EES-23164-M6-001, Rev 61

- SRNL FC Work Instructions - ITS-WI-0028

- SRNL Pilot Plant Analytical Plan - SRNL-PSE-2008-00046

- Equipment Vendor Manuals

- AREVA Drawing C-0110-008 Rev 1, Process Flow Diagram

9. Acceptance Criteria

- The filter cake dewaters, dislodges and dissolves easily.

- A feed rate of $1.5 \mathrm{gpm}$ is achieved without overloading the centrifuge.

- The system's controls are stable in full automatic operation. 
RPP-39091, Rev. 0

RPT-3000755 Rev. 000

APPENDIX 8.11

\section{FINAL BASELINE TEST RUN PLAN}

(Consisting of 3 pages

Including coversheet) 
RPP-39091, Rev. 0

RPT-3000755 Rev. 000

\section{Test Run Plan}

Test Run Plan No. FC-TRP-2008-02

Date: $\underline{5 / 20 / 2008}$

1. Title. Test 2 Baseline Testing

2. Test Objectives: A. To determine DF for cesium

B. Achieve steady state operations

C. Produce acceptable crystals

D. Establish normal operating parameters

E. Check the correlation between the PFD and the pilot operations

3. Test Conditions/Parameters: Note the values given below are under steady state operations. During the initial start up, the will vary.

16. Feed Chemistry: SST Early Feed Phase 2 simulant with cesium

17. Crystallizer Vessel Liquid Operating Level $\underline{50 \%}$ ( $50 \%$ default value $=15$ " above draft tube top, $0 \%=9 ", 100 \%=21 ")$

18. Reboiler Steam Flow Rate, $\mathrm{lbm} / \mathrm{min}$.

$\underline{11.0}$

19. Crystallizer feed flow rate, gpm (under manual mode):

$1.5 \mathrm{gpm}$

20. Number of Draft Tube Extensions:

None

21. Crystallizer Pressure in the vapor space (psia):

$0.8-1$ psia (adjust this

pressure to achieve 131F Crystallizer temperature)

22. Crystallizer Temperature:

$\underline{131 \mathrm{~F}}$

23. Circulation Pump Flow Rate (gpm):

$600 \mathrm{gpm}$

24. Process Tanks Desired Temperature, $\mathrm{F}$

$\underline{131 \mathrm{~F}}$

25. PD Tank contents:

Initial: From Benchmark Test Steady State: 300 gal, salt solution Sp. Gr. 1.46

26. RW Tank contents:

Initial: From Benchmark Test Steady State: 300 gal, recycled wash Sp Gr 1.45

27. SW Tank contents:

Initial: From Benchmark Test $\quad$ Steady State: $\underline{300 \text { gal, recycled wash } \mathrm{Sp} \mathrm{Gr} 1.43}$

28. Condensate Tank

Initial: $\underline{250 \text { gal DI H2O }}$ Steady State: $\underline{250 \text { gal condensate }}$ 
RPP-39091, Rev. 0

RPT-3000755 Rev. 000

29. Initial Feed Tank $\underline{B}$ (Note: for the Baseline Tests, the initial feed sequence is B-A - C - D, then the feed sequence is always $B-C-D-B-C-D$ with reconstituted feed)

30. Centrifuge Settings:

As recommended by the Customer CH2MHILL. (Note: The Centrifuge settings will be varied based on cake properties to achieve optimum performance)

4. Analytical Samples

Draw samples per sample plan. The actual samples schedule will be controlled by the sampling computer next to the fume hood.

5. System alignment modifications from Work Instructions:

6. Condensate flow rate to Spent Wash Purge, gpm (FT CO18) $0.29 \mathrm{gpm}$

7. Condensate flow rate to PD product, gpm (FT CO24) $0.56 \mathrm{gpm}$

8. Spent wash recycle flow rate to Crystallizer, gpm (FT SW09) $1.32 \mathrm{gpm}$

9. Spent wash Purge flow rate to Tank E, gpm (FT Sw06) $0.29 \mathrm{gpm}$

10. Product dissolver flow to FR Tanks (B, C or D), gpm (FT PD09) $0.53 \mathrm{gpm}$

6. Special equipment or instruments: N/A

7. Precautions

- Centrifuge - Do not exceed 3000 rpm during operation

- Reboiler - Do not exceed a slurry temperature rise of greater than $3 F$ across the reboiler during heat up or operation

- Crystallizer - Do not allow the liquid level in the crystallizer to go outside the range of $20 \%$ $-80 \%$.

8. References:

- FC Pilot Test Plan - RPP-PLAN-34135, Rev 0

- SRNL P\&ID - EES-23164-M6-001, Rev 61

- SRNL FC Work Instructions - ITS-WI-0028

- SRNL Pilot Plant Analytical Plan - SRNL-PSE-2008-00046

- Equipment Vendor Manuals

- AREVA Drawing C-0110-008 Rev 1, Process Flow Diagram

9. Acceptance Criteria

- The filter cake dewaters, dislodges and dissolves easily.

- A feed rate of $1.5 \mathrm{gpm}$ is achieved without overloading the centrifuge.

- The system's controls are stable in full automatic operation. 
RPP-39091, Rev. 0

RPT-3000755 Rev. 000

APPENDIX 8.12

\section{PILOT TESTING TIME LINE} (Consisting of 3 pages

Including coversheet) 
Date

Day

$2 / 11 / 2008$

$3 / 19 / 2008$

$3 / 27 / 2008$

$4 / 4 / 2008$

4/15/2008 Tue

4/16/2008 Wed

4/17/2008 Thu

4/18/2008 Fri

4/19/2008 Sat

4/20/2008 Sun $4 / 21 / 2008$ Mon 4/22/2008 Tue $4 / 23 / 2008$ Wed 4/24/2008 Thu

\section{Time Event}

Crystallizer vacuum test with mechanical pump was completed successfully

Crystallizer vacuum test with steam jet pump was completed successfully

Water boilout test was started

Centrifuge knife was photographed and characterized dimensionally

\section{2:00 Water boilout test was completed}

\section{6:41 Benchmark Tests started.}

20:01 Initial fill of Crystallizer from Tank B completed (910 gallons transferred)

9:54 Started steam supply to reboiler

20:38 Steam Generator \#2 shut down for burning odor (one of the 6 heating elements failed)

6:43 Feed Pump FR PUMP1 discharge fitting leaked $\sim 260$ gallons in to secondary contaiment

14:00 System restarted after pump repairs

16:57 Switched feed from Tank B to Tank A

22:44 Slurry density $1.67 \mathrm{~g} / \mathrm{ml}$ (from pulled sample)

7:30 Centrifuge started

10:12 First batch of crystals harvested, centrifuge operated at $1360 \mathrm{rpm}$.

11:00 Centrifuge basket full of crystals. Centrifuge bogged down. Cleared chute and performed 2 heel removals

11:54 Centrifuge speed increased to $1825 \mathrm{rpm}$ and throttled down the feed valve (too much feed to the centrifuge)

14:30 Centrifuge speed increased to $2500 \mathrm{rpm}$, ran 4 cycles and then increased to $2700 \mathrm{rpm}$

15:32 Centrifuge speed increased to $2800 \mathrm{rpm}$, ran 4 cycles and 2 heel removals

16:37 Centrifuge speed decreased to $2700 \mathrm{rpm}$, ran 7 cycles

17:31 Centrifuge speed decreased to $2600 \mathrm{rpm}$, added heel removal step after every 5 cycles

18:30 Installed a double plate type pinch to the feed line to the centrifuge. A similar pinch was applied to the centrifuge discharge port 5 to divert discharge to clear out p-trap connected to port 8

19:05 Flexible hose to port 5 bursted due to high pressure as the pinch was increased. Centrifuge emergency stop.

19:10 System shutdown started. Diluted crystallizer contents and transferred $997 \mathrm{gal}$ to B and $990 \mathrm{gal}$ to $\mathrm{A}$.

System shutdown due to hose burst

System shutdown due to hose burst

System modifications comleted. New SL18B valve added.

System vacuum tested

Contents of Tank A mixed
Feed Tank

Feed stopped

Feed stopped

Feed stopped

Feed stopped

Feed stopped

Feed stopped 
Date Day

4/25/2008 Fri

$4 / 26 / 2008$ Sat

4/27/2008 Sun 4/28/2008 Mon

4/29/2008 Tue

4/30/2008 Wed

5/1/2008 Thu

$5 / 2 / 2008$

\section{Time Event}

0:35 Transferred 835 gallons of feed from Tank $A$ to Tank $E$.

3:30 Transferred 880 gallons of feed from Tank $B$ to Tank $A$

4:27 Transferred 850 gallons of feed from Tank $E$ to Tank $B$

5:00 Mixing of Tanks A \& B complete

8:00 Preparations to fill the crystallizer started (to be filled under vacuum)

9:43 Crystallizer filled to the operating level by transferring 970 gallons from Tank $B$.

13:34 Started steam supply to reboiler

15:15 Crystallizer operating under normal conditions.

15:23 Started feeding crystallizer from Tank B

19:01 Centrifuge heel removal and cleanup complete.

21:04 Started filling PD Tank with condensate

6:30 PD Tank temperature not increasing, started work on PD Tank heater control

8:29 Switched feed from Tank B to Tank A

Work on PD Tank heater control continued

15:00 Started centrifuge operation at $2600 \mathrm{rpm}$

$18: 15$ Centrifuge shut down to install a flow restriction ( $3 / 8^{\prime \prime}$ dia hole) in the feed hose.

9:05 Centrifuge started at $2600 \mathrm{rpm}$.

12:04 Centrifuge speed increased to $2800 \mathrm{rpm}$

Centrifuge tripped several times due to high vibrations

$19: 40$ Centrifuge rpm increase to 2700 , vibrations acceptable $(<4)$

20:20 Started Spent Wash Tank.

22:15 Started centrifuge operation under auto mode

8:15 Recycle Wash Tank heater fuses replaced

8:30 DAS was inadvertently unplugged. DAS was restarted.

16:17 Started spent wash flow to Tank $E$ at $0.5 \mathrm{gpm}$

19:47 Started Spent Wash recycle to the crystallizer at $0.4 \mathrm{gpm}$. No flow, line was plugged.

The centrifuge was operated off and on due to pluggage after peel steps. Started heel removal after 5 cycles.

Continued centrifuge operations off and on due to high vibrations during peel steps

17:19 Crystallizer density was found to be too high $(1.75 \mathrm{~g} / \mathrm{ml})$. Added condensate to bring it below 1.7

Continued centrifuge operations off and on due to high vibrations during peel steps

19:21 Transferred 620 gallons from Tank $E$ to Tank $A$.

21:50 Started Wash 2 step for centrifuge. No wash 2 flow due to pluggage

23:35 Wash 2 flow observed ( 0.6 gpm)
Feed Tank

Feed stopped

Feed stopped

Feed stopped

Feed stopped

Feed stopped

Feed stopped

Feed stopped

Feed stopped

$\mathrm{B}$ 